\title{
Criticalidade auto-organizada no modelo Olami-Feder-Christensen de terremotos: dinâmica dos epicentros
}

\author{
Tiago de Paula Peixoto
}

Orientadora: Profa. Dra. Carmen Pimentel Cintra do Prado

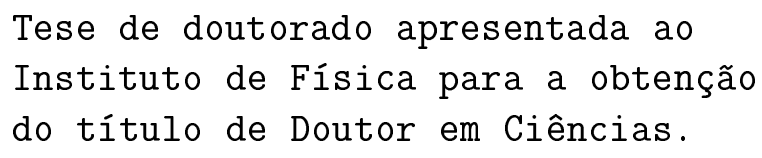

\section{Banca examinadora}

Profa. Carmen Pimentel Cintra do Prado (IFUSP)

Prof. Nestor Felipe Caticha Alfonso (IFUSP)

Prof. José Fernando Fontanari (IFSC/USP)

Prof. Jorge Simões de Sá Martins (UFF)

Prof. Giovani Lopes Vasconcelos (UFPE) 


\section{FICHA CATALOGRÁFICA}

Preparada pelo Serviço de Biblioteca e Informação do Instituto de Física da Universidade de São Paulo

Peixoto, Tiago de Paula

Criticalidade auto-organizada no modelo Olami-FederChristensen de terremotos: dinâmica dos epicentros. São Paulo, 2007.

Tese (Doutorado) - Universidade de São Paulo. Instituto de Física. Depto. Física Geral

Orientador: Profa. Dra. Carmen Pimentel Cintra do Prado

Área de Concentração: Física

Unitermos: 1. Redes Complexas; 2. Mecânica estatística; 3. Terremotos.

USP/IF/SBI-001/2008 
Wenn ist das Nunstück git und Slotermeyer? Ja! ... Beiherhund das Oder die Flipperwaldt gersput.

- Monty Python 


\section{Resumo}

Nesse trabalho será estudada a dinâmica de epicentros do modelo Olami-FederChristensen (OFC). Para isso, serão usados conceitos e ferramentas de redes complexas. Será analisado, em particular, o grafo de epicentros consecutivos do modelo, onde dois eventos subseqüentes são representados por uma aresta direcionada, cuja origem e vértice incidido representam os respectivos sítios no reticulado. A topologia desse grafo, que possui invariância de escala e correlação entre os graus, revela uma dinâmica característica, com atratores temporários, e quase-periodicidade. Essa dinâmica é comparada com a de terremotos reais, e as limitações do modelo são avaliadas. Em particular, foi constatado que a dinâmica governada por atratores temporários se encontra presente em terremotos reais, porém difere em pontos centrais da observada no modelo OFC. Além da análise da dinâmica dos epicentros, será feito um estudo sistemático de dois comportamentos não-triviais do modelo, o que foi necessário para a análise da dinâmica de epicentros: A identificação e caracterização de um "efeito de borda" no modelo, e uma separação de escalas de eventos de diferentes tamanhos, que considera também as suas distribuições espaciais. Esses resultados têm uma relevância importante o estudo do modelo de modo geral. Em particular, será retomada a análise da criticalidade do modelo, à luz desses critérios. 


\begin{abstract}
We study the dynamics of the epicenters of the Olami-Feder-Christensen model of earthquakes (OFC), using the concepts and tools of complex networks. In particular, we study the graph of consecutive epicenters, where two subsequent events represent a directed edge, and the source and target vertices represent the respective sites on the lattice. The topology of this graph, which exhibits scale-invariance and strong degree correlation, reveals a characteristic dynamics of temporary attractors and quasi-periodicity. This dynamics is compared to that of real seismicity, and the limitations of the model are assessed. The temporary attractor dynamics is also found in real earthquakes, however it differs from the one observed in the model in key points, which will be described in detail. Besides the analysis of the dynamics of the dynamics of epicenters, we systematically study two non-trivial behaviours of the OFC model, which was necessary for the study of the epicenters: The identification and characterization of a "border effect" in the model, and the separation of scales in the size of events, which takes into account their spatial distribution. These results have an important relevance to the study of the OFC model in general. In particular, we will revisit the analysis of the criticality of the model, which takes into account these criteria.
\end{abstract}




\section{Dedicatória}

Apesar de ser de praxe, não poderia deixar de dedicar esse trabalho à minha família. Gostaria de agradecer à minha mãe, ao meu pai, e aos meus irmãos, Caio e André. Por mais chatas que possam ser as eventuais desavenças, é fácil para mim afirmar que eu não os trocaria por ninguém.

Eu gostaria de agradecer à minha orientadora, a Profa. Carmen P. C. Prado, por ter me orientado, e por ter proporcionado tanto a liberdade necessária para que houvesse motivação e criatividade, quanto pela cobrança que todo bom orientador deve fazer.

Gostaria de agradecer aos meus amigos Alexandre Abdo e Laerte Andrade por existirem. Em especial, gostaria de agradecer à Ksenia Guseva, não só por existir, mas por todas as interrupções, que, sem a menor sombra de dúvida, foram cruciais.

Por último, gostaria de expressar a minha admiração pelas leis da física, que permitem a formação estável das formas moleculares indicadas abaixo, sem as quais a vida no universo (pelo menos em forma de pós-graduandos) não seria possível.<smiles>Cn1c(=O)c2c(ncn2C)n(C)c1=O</smiles><smiles>CCO</smiles>

Tiago de Paula Peixoto 


\section{Sumário}

1 Introdução 4

2 O modelo OFC $\quad 8$

2.1 Definição do modelo e principais características . . . . . . . . . . 8

2.1.1 Determinismo . . . . . . . . . . . . . . 9

2.1.2 Caracterização dos eventos . . . . . . . . . . . . . . . . . 10

2.1.3 Condições de contorno . . . . . . . . . . . . . . . . . . . 11

2.1.4 Regime transiente . . . . . . . . . . . . . . . . . 12

2.1 .5 Regime estacionário . . . . . . . . . . . . . . 13

Distribuição de tamanhos de eventos . . . . . . . . . . . . . . . 15

Taxa de ramificação . . . . . . . . . . . . . . . . 17

Distribuição de tensão no reticulado . . . . . . . . . . . . . . . 18

Considerações sobre a existência de criticalidade do modelo . . 19

2.1.6 Campo médio: Vizinhos aleatórios . . . . . . . . . . . . . 20

2.1.7 Semelhança com terremotos reais: Lei de Omori . . . . . . . . . 20

3 Eventos do modelo OFC 22

3.1 Distribuição espacial de epicentros . . . . . . . . . . . . . . . . . . 23

3.2 Propriedades espaciais dos eventos . . . . . . . . . . . . . . . . . . . . 29

3.2.1 Avalanches aleatórias . . . . . . . . . . . . 30

3.2 .2 Eventos do modelo OFC . . . . . . . . . . . . . . . . 31

Variação com o tamanho do reticulado . . . . . . . . . . . . . 34

Variação com a proximidade da borda . . . . . . . . . . . . 34

3.3 Variação da taxa de ramificação . . . . . . . . . . . . . . . . . . . . 42

4 Redes Complexas $\quad 47$

4.1 Definição e principais propriedades . . . . . . . . . . . . . . 47

4.1 .1 Redes complexas . . . . . . . . . . . . . . . . . . . 48

4.1.2 Grafos aleatórios e distribuição de graus . . . . . . . . . . . . . . . 49

4.1 .3 Correlação de graus . . . . . . . . . . . . . . . . . . . . . 49

4.1 .4 Aglomeração . . . . . . . . . . . . . . . . . . . 50

4.1 .5 Diâmetro . . . . . . . . . . . . . . . . . 51

4.2 Características emergentes . . . . . . . . . . . . . . . . . 52

4.2 .1 Redes livre de escala . . . . . . . . . . . . . . . . . . . 52

Grafo de Barabási e Albert . . . . . . . . . . . . . . . . . . . . . 52

4.2.2 Fenômeno de "mundo pequeno" (small-world) . . . . . . . . . . 54

O modelo de Watts e Strogatz . . . . . . . . . . . . . . . . 54 
5 Rede de epicentros consecutivos 56

5.1 Definição do grafo . . . . . . . . . . . . . . . . 57

5.1 .1 Crescimento do Grafo . . . . . . . . . . . . . . . 58

5.1 .2 Distribuição de Graus . . . . . . . . . . . . . . . . . . . . . 58

Ergodicidade ...................... 61

5.1 .3 Correlação de graus . . . . . . . . . . . . . . . 65

Dinâmica de atração: Correlação com tamanhos de eventos . . 65

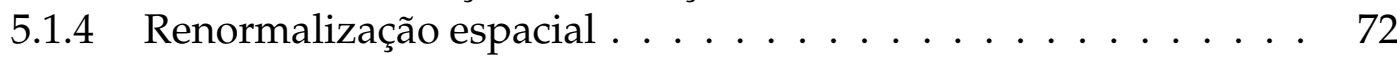

5.2 Comparação com terremotos reais . . . . . . . . . . . . . . . . 72

5.3 Redes de Markov com variáveis escondidas . . . . . . . . . . . . . . . . 80

5.3.1 Distribuição de graus de entrada . . . . . . . . . . . . . . . . 80

5.3.2 Correlação de graus de entrada . . . . . . . . . . . . . . . . 81

5.3.3 Dinâmica de atração e "aprisionamento" . . . . . . . . . . . 82

5.3.4 Comparação com a rede de epicentros consecutivos do modelo $\mathrm{OFC} \ldots \ldots \ldots . \ldots \ldots 3$

6 Conclusões $\quad 85$

$\begin{array}{lll}\text { A Rede de recorrências de epicentros } & \mathbf{8 8}\end{array}$

A.1 Definição da rede de recorrências . . . . . . . . . . . . . . . . . . 88

A.2 Principais resultados para o modelo OFC . . . . . . . . . . . . . 89

A.3 Versão preliminar do manuscrito . . . . . . . . . . . . . . . 90

B O programa graph-tool $\quad 102$

B.1 Filosofia de implementação . . . . . . . . . . . . . . . . . . . . . 102

B.2 Descrição geral do programa . . . . . . . . . . . . . . . . . . . . 103

B.3 Disponibilidade . . . . . . . . . . . . . . . . . 104

C Artigos publicados $\quad 106$

C.1 Artigo "Distribution of epicenters in the Olami-Feder-Christensen model" [1] 107

C.2 Artigo "Statistics of epicenters in the Olami-Feder-Christensen model in two and three dimensions " $[2]$. . . . . . . . . . . . . . . . . . 111

C.3 Artigo "Network of epicenters of the Olami-Feder-Christensen model of earthquakes" $[3] \ldots \ldots \ldots \ldots$. . . . . . . . . . . . . . . . 118 


\section{Capítulo 1}

\section{Introdução}

Cada vez mais se tem presenciado a incursão da física no estudo do que se chama de sistemas complexos. Como esse é um tópico altamente interdisciplinar, que abrange áreas do conhecimento com paradigmas distintos, como ciências sociais, biologia, e física, não há consenso na definição precisa do que seria complexidade. Mesmo na física falta tal definição, e muito mais um formalismo teórico. Porém, independentemente de qual definição se usa, em geral os sistemas ditos complexos compartilham uma característica central: Esses sistemas apresentam um comportamento global elaborado, que não pode ser facilmente deduzido a partir de componentes fundamentais. ${ }^{1}$ Dos sistemas que possuem essa característica, existe uma classe que é de especial interesse para a física, pois se adequa bem a sua tradição reducionista, que é a de sistemas que possuem comportamento emergente. Esses sistemas são caracterizados por regras fundamentais simples, fácil de serem descritas, mas cujo comportamento global não pode ser facilmente inferido. ${ }^{2}$ Alguns dos principais exemplos desse tipo de fenômeno na física são o caos determinístico [4,5], sincronização [6], a comportamento de redes neurais [7], e criticalidade auto-organizada [8-10]. Uma marca freqüente do comportamento desses sistemas é a dificuldade de previsão, apesar da característica determinística de suas regras fundamentais.

Em particular, a criticalidade auto-organizada (Self-Organized Criticality, ou SOC) é um tipo de comportamento emergente que tem recebido bastante atenção de pesquisadores, devido a sua potencial abrangência. O conceito de $\mathrm{SOC}$ foi originalmente proposto por Bak, Tang e Wiesenfeld [11,12] como uma tentativa de explicar de maneira única a ocorrência de invariância de escala na natureza. Invariância de escala é a propriedade de um determinado sistema físico de exibir as mesmas características independentemente da escala de observação. Essas invariâncias são normalmente caracterizadas espacialmente por distribuições fractais, que tem, em geral, uma forma auto-similar, observável em qualquer escala. Além disso, podem também ser carac-

\footnotetext{
${ }^{1}$ As definições divergem na que se quer dizer por "complexo". Por exemplo, pode-se dizer que a dinâmica global é difícil de ser caracterizada e estudada, logo "complicada", ou que os componentes fundamentais não são facilmente identificáveis, ou até que existem diversos tipos de componentes e a própria iteração entre eles é definida através de inúmeras regras, em potencial desconhecidas, que dificultam o modelamento do problema. De maneira geral, é possível encontrar qualquer interpretação da palavra "complexo" nesse contexto.

${ }^{2}$ Pode-se dizer, inclusive, despretensiosamente, que essa é a proposta central da física, que tenta descobrir as regras fundamentais, que, da maneira mais simples possível, regem unicamente o comportamento emergente e, nesse sentido, complexo, do universo.
} 
terizadas por distribuições que seguem uma lei de potência $\mathrm{P}(\mathrm{x}) \propto x^{-\gamma}$, que mantém as mesmas propriedades estatísticas sob qualquer transformação linear de escala do tipo bx, onde b é uma constante [13]. No caso de séries temporais, muitas vezes as flutuações também são independentes da escala temporal usada na observação, e os espectros de potência se comportam, portanto, como $1 / f^{\beta}$, o que é chamado de "ruído $1 / f$ ". Todas essas características são encontradas freqüentemente na natureza, como em terremotos [14,15], incêndios florestais [16], evolução de espécies [17], e tempestades solares [18]. O que foi proposto por Bak et al., com o conceito de SOC, é a identificação de uma dinâmica única responsável por tais características nesses diversos sistemas.

Diz-se que um sistema possui SOC se ele apresentar um estado estatisticamente estacionário, independente das condições iniciais, onde as grandezas as serem medidas são livres de escala, e se distribuem de acordo com lei de potências, como descrito acima. O sistema deve atingir esse estado de maneira autônoma, i.e. autoorganizada, sem que haja o ajuste externo de algum parâmetro. Deste modo, o sistema atingiria repetidamente um estado comparável ao de um sistema termodinâmico em equilíbrio, no ponto crítico de uma transição de fase de segunda ordem. Freqüentemente o conceito de SOC é confinado somente a sistemas que tem como dinâmica um acúmulo lento e progressivo de alguma grandeza, e eventos dissipativos rápidos, do tipo reação em cadeia. Existem, portanto, em geral, duas escalas de tempo distintas. A existência de uma escala de tempo mais lenta (que muitas vezes é definida como sendo arbitrariamente lenta, com uma velocidade de acúmulo no sistema tendendo a zero), pode então ser interpretada como uma maneira de ajustar um determinado parâmetro do sistema a um valor específico [19]. Porém, a proposta inicial de Bak et al. de que a grande maioria das invariâncias de escala observadas na natureza fossem explicadas unicamente por dinâmicas desse tipo não é considerada factível atualmente, devido a grande discrepância entre muito dos modelos propostos para modelar SOC e os fenômenos que eles deveriam modelar [20]. Além disso, ninguém ainda foi capaz de formular uma definição mais precisa da dinâmica de SOC, e de definir um formalismo matemático adequado.

O exemplo mais paradigmático de SOC é o modelo de pilha de areia de Bak, Tang, e Wiesenfeld (BTW) [11,12]. Esse modelo, que tenta, de forma qualitativa, simular o comportamento de uma pilha de areia, é composto, em sua forma bidimensional, por um autômato celular definido num reticulado quadrado, onde cada sítio possui uma variável inteira (número de grãos). Um novo grão é depositado, a cada iteração, aleatoriamente no reticulado. Se o valor de um sítio exceder um certo limiar, é subtraído 4 do valor desse sítio, e cada um dos 4 vizinhos recebe 1 grão. Se cada um dos vizinhos exceder o mesmo limiar, o mesmo volta a acontecer, e assim por diante. É possível mostrar analiticamente que a distribuição de tamanho de eventos (número de vezes que algum sítio excedeu o limiar, por evento) segue uma lei de potência, e é portanto invariante de escala. Esse modelo, porém, possui conservação local de partículas (nenhum grão de areia é perdido num evento). É possível mostrar que quando dissipação é incluída no sistema, por meio de uma probabilidade de um grão não ser transferido para cada uma das direções, a criticalidade do modelo é destruída, por menor que seja a dissipação [21]. Isso limita severamente a aplicação do modelo para explicar sistemas macroscópicos reais, que invariavelmente possuem 
algum tipo de dissipação. Os mecanismos, porém, que levariam a SOC em sistemas não-conservativos ainda não são bem conhecidos.

No contexto de SOC em sistemas dissipativos, um modelo que merece destaque é o Olami-Feder-Christensen (OFC) [15], que foi proposto parar modelar qualitativamente a dinâmica de placas tectônicas e terremotos. Esse modelo, bastante parecido com o BTW, se diferencia do mesmo em alguns aspectos importantes. O modelo OFC possui variáveis de estado contínuas, ao invés de discretas, possui uma dinâmica inteiramente determinística ${ }^{3}$, e admite dissipação. Ao contrário do modelo BTW, o modelo OFC não é facilmente tratável analiticamente, e a maioria dos resultados tem que ser obtidos numericamente. Outra diferença importante é que o modelo OFC apresenta evidencias numéricas de criticalidade, mesmo quando existe dissipação. A questão de criticalidade desse modelo tem sido motivo de polêmica, e gerado um número considerável de publicações, que apresentam conclusões contraditórias, mas que, devido à natureza numérica das argumentações, e a inacessibilidade analítica do modelo, não possibilitam uma afirmação categórica a respeito da existência de SOC. Em paralelo à questão da criticalidade - que permanece indefinida - o modelo OFC, que, como o modelo BTW, é um simples toy model, construído para capturar a dinâmica mais básica possível de terremotos, mostra uma dinâmica supreendentemente rica, capaz de reproduzir uma variedade de características não-triviais e ainda não bem entendidas de terremotos reais, como a existência de foreshocks e aftershocks [22,23]. Esses dois aspectos tornaram o modelo OFC talvez o modelo de SOC mais estudado na literatura.

No contexto mais geral de sistemas complexos, uma outra sub-área que tem se popularizando incrivelmente é a de redes complexas $[24,25]$. Ela representa o resgate do que vinha sido estudado por cientistas sociais desde o meio do século passado, sob o título de redes sociais [26], que representam as estruturas das relações arbitrárias entre indivíduos ou organizações, num contexto social. Recentemente, após o significativo aumento computacional, a disponibilidade maior de dados experimentais, e também o interesse maior da comunidade científica em sistemas complexos em geral, houve tanto uma contextualização mais abrangente como uma extensão desses conceitos, que passaram a representar não somente relações sociais, mas também relações pertinentes a qualquer outro tipo de sistema, como os biológicos e tecnológicos. Grande parte desse desenvolvimento foi devido ao interesse de físicos e matemáticos aplicados no assunto, que foram motivados pela existência nessas redes de propriedades "complexas", como o fenômeno de "mundo pequeno" (small world), onde dois indivíduos quaisquer na rede estão conectados em média por um caminho pequeno (embora a rede possa ser gigantesca), invariância de escala e auto-similaridade. O significado de complexidade em redes complexas sofre o mesmo problema de definição que no contexto mais geral de sistemas complexos (ver nota de rodapé 1, página 4). Porém, muito do estudo de redes complexas tem se concentrado em tentar identificar comportamentos emergentes, onde mecanismos simples de construção de redes resultariam em alguma das propriedades não-óbvias descritas acima. Alguns dos mecanismos importantes descobertos foi o de conexão preferencial [27,28], que gera redes livre de escala, e o modelo de small world de Watts e Strogatz [29], que mostra como poucas conexões aleatórias de longo alcance podem ser responsáveis

\footnotetext{
${ }^{3}$ Esse ponto do modelo é questionável. Ver seção 2.1.1, página 9.
} 
por esse fenômeno.

O objetivo desse projeto é estudar a dinâmica do modelo OFC, usando para isso conceitos e ferramentas de redes complexas, o que é uma maneira inteiramente nova de analisar o modelo. O principal resultado do projeto foi, além de providenciar uma conexão entre redes complexas e dinâmica de criticalidade auto-organizada, uma caracterização mais detalhada de diversas características dinâmicas não-triviais do modelo OFC, que possibilitaram a identificação de diferenças e semelhanças fundamentais do modelo com terremotos reais. Além disso, foi feito um estudo sistemático de dois comportamentos não-triviais do modelo, que foram necessários par a análise da dinâmica de epicentros: A identificação e caracterização de um "efeito de borda" no modelo, e uma separação de escalas de eventos de diferentes tamanhos.

Essa tese está organizada da seguinte maneira: No capítulo 2 será definido o modelo OFC, e apresentado um resumo dos resultados já conhecidos sobre ele na literatura. Antes do estudo das redes do modelo OFC, será apresentado no capítulo 3 uma análise dos diferentes tipos de eventos existentes no modelo, o que é importante para os outros estudos, pois possibilita a identificação do "efeito de bordo", mencionada acima, e da separação de escalas de tamanhos de eventos. No capítulo 4 será apresentada um introdução breve de redes complexas, com as descrições dos conceitos fundamentais. Finalmente, no capítulo 5, será detalhado o estudo da rede de epicentros consecutivos do modelo OFC, e a comparação da mesma rede obtida com terremotos reais. Por fim, no capítulo 6, serão apresentadas as discussões finais e conclusões.

Nos apêndices A e B serão apresentados dois outros trabalhos realizados no decorrer dessa tese: A rede de recorrências de epicentros (em andamento) e o programa graph-tool de análise estatística de grafos. 


\section{Capítulo 2}

\section{O modelo Olami-Feder-Christensen}

Neste capítulo será apresentado o modelo Olami-Feder-Christensen (OFC) de terremotos. Além da definição, será feito um resumo dos principais resultados já obtidos sobre o modelo.

\subsection{Definição do modelo e principais características}

O modelo OFC [15] foi inspirado em um modelo conhecido como "massa-mola", proposto por Burridge e Knopoff [30]. Ele consiste em uma discretização desse modelo, tanto espacialmente quanto temporalmente, que gera um autômato celular [31], definido num reticulado bidimensional. ${ }^{1} \mathrm{O}$ objetivo é modelar, de maneira simplificada, a dinâmica de fricção entre duas placas tectônicas, onde a tensão é acumulada na interface de maneira não-homogênea, e liberada em eventos do tipo avalanche. O modelo se assemelha ao modelo BTW de pilhas de areia [11, 12], porém tem como principais diferenças o uso de variáveis de estado contínuas, regras de evolução determinísticas, e um mecanismo de perturbação global. Essa semelhança do modelo OFC com esse modelo simplificado de pilhas de areia, que é um arquétipo do conceito de Criticalidade Auto-Organizada (SOC), vem justamente da tentativa de enquadrar a dinâmica de terremotos a essa classe de fenômenos.

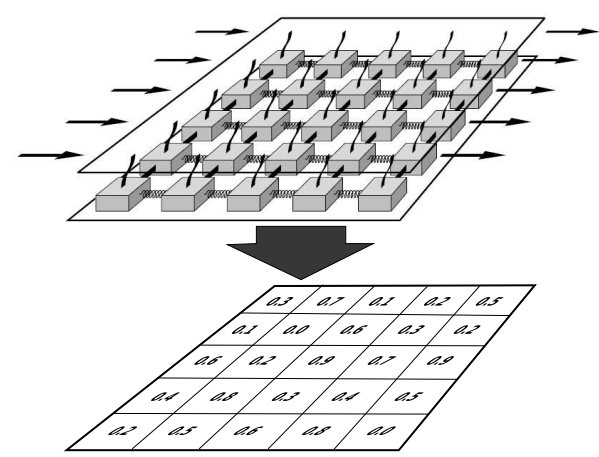

Figura 2.1.1: Discretização do modelo BK [30] em um reticulado.

O modelo é definido em um reticulado quadrado de tamanho $\mathrm{L}^{2}$. Para cada sítio $(i, j)$ é atribuída uma "tensão" $z_{i j}$, que é escolhida inicialmente de maneira aleatória ${ }^{2}$ dentro do intervalo $\left[0, z_{c}\left[\right.\right.$. A tensão de cada sítio $z_{i j}$ é então aumentada uniforme-

\footnotetext{
${ }^{1}$ Como será definido a seguir, a regra de relaxamento $z_{i j} \rightarrow 0$ do modelo OFC implicaria no bloco retornar sempre a sua posição de equilíbrio. O modelo OFC implicaria, nesse sentido, além da discretização, num sistema massa-mola imerso em um meio viscoso.

${ }^{2} \mathrm{~A}$ princípio, essa é a única aleatoriedade presente no modelo. Ver seção 2.1.1 adiante.
} 
mente, com uma velocidade $v$ constante qualquer ${ }^{3}$,

$$
\frac{\partial z_{i j}}{\partial t}=v
$$

Quando um sítio alcança o valor crítico $z_{i j}=z_{c}$, instantâneamente um evento de relaxamento - o "terremoto" - se inicia, e o aumento uniforme é interrompido. $\mathrm{O}$ sítio $(i, j)$ que inicia o evento é chamado de epicentro. O evento segue, a partir daí, as seguintes regras: Uma fração $\alpha$ da tensão do epicentro é distribuída igualmente entre os seus vizinhos, e posteriormente sua tensão é levada a zero,

$$
z_{i j} \geqslant z_{c} \Rightarrow\left\{\begin{array}{l}
z_{i \pm 1, j \pm 1} \rightarrow z_{i \pm 1, j \pm 1}+\alpha z_{i j} \\
z_{i j} \rightarrow 0 .
\end{array}\right.
$$

Esse processo é chamado de "relaxamento" de um sítio. Os relaxamentos continuam, dando origem a gerações posteriores de sítios que relaxam: Se a tensão de algum dos vizinhos do sítio que relaxou ultrapassar o valor crítico, $z_{i \pm 1, j \pm 1} \geqslant z_{c}$, as mesmas regras de relaxamento são aplicadas para esse sítio. Essas regras são aplicadas para cada geração, até que não reste nenhum sítio com tensão $z_{i j} \geqslant z_{\mathfrak{c}}$. Sem perda de generalidade, pode-se considerar $z_{c}=1$, já que qualquer outro valor de $z_{c}$ se reduz a um mero fator multiplicativo, que não influi na dinâmica. $O$ parâmetro $\alpha$ determina a quantidade de dissipação local do sistema. Para $\alpha=1 / 4$ o sistema é localmente conservativo e para $\alpha<1 / 4$ é localmente não-conservativo. $\mathrm{O}$ tempo do modelo pode ser medido pelo número de eventos (iterações), ou pela quantidade de tensão que se acumula entre os eventos.

Apesar da aparente simplicidade do modelo, ele tem se mostrado muito difícil de ser tratado analiticamente, o que impossibilitou, pelo menos até agora, a obtenção de resultados exatos sobre sua dinâmica. Logo, a ferramenta mais empregada tem sido o estudo numérico ${ }^{4}$.

\subsubsection{Determinismo}

As regras dinâmicas definidas acima são, a princípio, inteiramente determinísticas. Fora o estado inicial aleatório, o sistema progride de maneira não-ambígua, e o modelo é freqüentemente citado como sendo um modelo determinístico de terremotos, como o modelo Burridge-Knopoff [30], que apresenta SOC. Isso, porém, não é inteiramente verdadeiro, pois existe uma situação onde a evolução do sistema é ambígua: Se dois ou mais sítios atingirem, ao mesmo tempo, a tensão crítica $z_{c}$, não fica definido qual deveria iniciar a avalanche. No limite de precisão numérica infinita, logo após o estado inicial aleatório, isso não deveria ser possível, já que a probabilidade de existirem dois valores de tensão exatamente iguais é zero. Porém, mesmo no limite de precisão infinita, numa mesma avalanche, um número arbitrário de sítios pode

${ }^{3} \mathrm{O}$ valor de $v$ determina somente a escala de tempo do sistema, e não tem nenhuma outra influência na dinâmica. Como o modelo é definido de maneira adimensional, vinculado a nenhuma grandeza física específica, o valor de $v$ não é, portanto, um parâmetro importante.

${ }^{4}$ Algumas variantes do modelo foram introduzidas. A principal delas, o modelo de "vizinhos aleatórios", é uma abordagem de campo médio, e a maior parte dos resultados analíticos foram obtidos somente nesse contexto. Ver seção 2.1.6. 
terminar com o mesmo valor de tensão, já que a tensão de qualquer sítio vai a zero quando esse relaxa (perde-se, localmente, a memória da aleatoriedade inicial). Deste modo, existe uma tendência à sincronização no sistema, onde um grupo de sítios pode assintoticamente tender ao mesmo valor de tensão. Esse fato é agravado pela imprecisão inerente em qualquer análise numérica do modelo. Logo, torna-se necessário definir como progredir caso dois ou mais sítios forem candidatos a epicentro. $\mathrm{O}$ que se faz normalmente, quando se estuda o modelo (e o que será feito nesse trabalho), é escolher aleatoriamente entre os candidatos e continuar com as regras de evolução. Isso, porém, representa claramente a introdução de um ruído no modelo. Muitas vezes se argumenta que esse ruído tem um efeito negligível, pois não ocorre com freqüência, quando se usa precisão numérica suficiente. Além disso, no limite termodinâmico (reticulados muito grandes), epicentros simultâneos poderiam estar infinitamente distantes entre si, e a ordem das avalanches seria irrelevante. Uma análise cursória, que não será levada mais a fundo nesse trabalho, mostra, porém, que a ocorrência de epicentros simultâneos tende a aumentar conforme o sistema alcança o estado estacionário da dinâmica, devido a auto-organização do sistema.

No limite termodinâmico, com precisão infinita, permanece válido, portanto, considerar o sistema como sendo completamente determinístico. Porém, o modelo necessita de uma inclusão de ruído quando ele é realizado numericamente, conforme explicado acima. Os efeitos desse ruído aleatório, que vão além dos efeitos de imprecisão numérica, não são normalmente levados em conta quando se estuda o modelo, e esse aspecto tem sido negligenciado na literatura. Não será diferente nesse trabalho, pois a remoção dessa fonte de ruído implicaria numa mudança drástica do modelo, e uma análise detalhada dos seus efeitos fugiriam dos objetivos do trabalho. É necessário, porém, mencionar essa questão, pois ela pode vir a ser relevante na interpretação dos resultados do modelo OFC.

\subsubsection{Caracterização dos eventos}

Existem duas grandezas fundamentais associadas com os eventos ("terremotos"): $\mathrm{O}$ tamanho e a área. O tamanho de um evento é o número de relaxamentos que ocorrem até que o evento termine. A área do evento é o número de sítios que participam do processo. Essas duas grandezas não são idênticas em geral, pois é possível que um mesmo sítio relaxe um número indeterminado de vezes, durante o mesmo evento. Relaxamentos múltiplos, porém, não são possíveis para qualquer valor de $\alpha$. Considere o caso extremo (ver figura 2.1.2), onde um sítio $(i, j)$ está prestes a relaxar e todos os seus vizinhos tem tensão $z=1$. Pelas regras do modelo, o sítio doaria uma tensão $\alpha$ para cada um dos vizinhos, que adquiririam uma tensão $z_{i \pm 1, j \pm 1}=1+\alpha$. Cada um dos vizinhos iria então relaxar, e doar uma tensão $\alpha(1+\alpha)$ para o sítio original, que ficaria então com uma tensão final $z_{i j}=4 \alpha(1+\alpha)$. O sítio original relaxaria uma segunda vez somente se $4 \alpha(1+\alpha) \geqslant 1$. É fá-

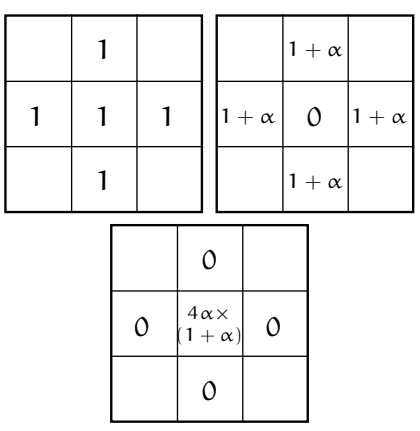

Figura 2.1.2: Caso extremo, onde o sítio que relaxa recebe de volta o máximo possível de tensão. 
cil ver que se o sítio não relaxar uma segunda vez nessa situação, fica impossível para qualquer sítio relaxar mais que uma vez em qualquer outra situação, para o mesmo valor de $\alpha$, já que nessa situação extrema o sítio que relaxou recebe de volta o maior valor possível de tensão de seus vizinhos. Logo existe um valor de transição $\alpha_{c}=(\sqrt{2}-1) / 2 \approx 0.207$, abaixo do qual é impossível a ocorrência de relaxamentos múltiplos, e a área de um evento é necessariamente igual ao tamanho.

\subsubsection{Condições de contorno}

Uma característica importante do modelo são as condições de contorno, que descrevem como a dinâmica deve se comportar para os sítios na borda do reticulado. Como será descrito adiante, as condições de contorno tem um papel decisivo na dinâmica do modelo. Em geral pode se escolher três tipos de condições de contorno (ver figura 2.1.3): Condições abertas, fechadas, ou periódicas. Com condições abertas os sítios da borda se comportam como se eles doassem tensão para sítios inexistentes, como se o sistema fizesse parte de um reticulado maior que não influi no sistema. Isso significa que os sítios da borda, quando relaxam, dissipam uma fração $\alpha$ (ou $2 \alpha$ para os 4 sítios com somente 2 vizinhos) para o exterior, fazendo que o modelo seja globalmente não-conservativo, independente do valor de $\alpha$. Porém, no caso $\alpha=1 / 4$, o modelo tenderia à conservação global para $\mathrm{L} \rightarrow \infty$. Com condições fechadas, o valor de $\alpha$ dos sítios da borda é alterado para $\alpha^{\prime}=4 \alpha / k$, onde $k$ é o número de vizinhos do sítio, e eles doariam toda sua tensão somente para os seus 3 ou 2 vizinhos. Dessa maneira, o sistema permaneceria globalmente conservativo para $\alpha=1 / 4$. Por último, o sistema pode ser definido com condi-

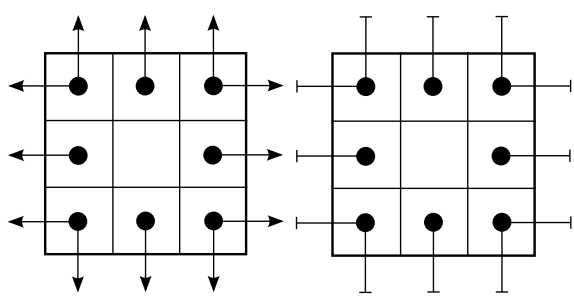

(a) Abertas

(b) Fechadas

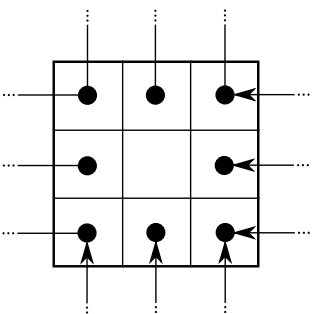

(c) Periódicas

Figura 2.1.3: Diferentes condições de contorno possíveis. ções periódicas de contorno, onde seria como se o reticulado estivesse sobre a superfície de um toro, e os sítios da borda estariam ligados com os sítios da borda oposta. Nesse caso, o sistema também seria globalmente conservativo para $\alpha=1 / 4$.

A escolha das condições de contorno é crucial para a dinâmica do modelo. Quando condições periódicas de contorno são usadas, o atrator da dinâmica é periódico, com um período de $\mathrm{L}^{2}$ eventos, onde todos os eventos tem tamanho $1[32,33]$. Todos os sítios relaxam, nesse caso, somente quando todos os seus vizinhos já relaxaram. O período da dinâmica, quando medido na escala de tensão, é então simplesmente $\mathrm{L}^{2}(1-4 \alpha)$, onde $(1-4 \alpha)$ é a dissipação por evento. Esse comportamento regular, porém, desaparece completamente quando condições de contorno abertas ou fechadas são usadas. Com condições de contorno abertas, os sítios da borda relaxam em média mais vezes que os do interior do reticulado, pois o número de vizinhos doadores de tensão é menor, e o sítio consegue acumular mais continuamente a tensão proveni- 
ente da perturbação global. A existência dessa assimetria causa, a partir do estado inicial aleatório, uma progressiva auto-organização do sistema, que se propaga da borda em direção ao centro (ver seção 2.1.4, para uma caracterização do estado transiente). Somente com essa auto-organização o modelo apresenta um comportamento aparentemente crítico, e são essas, portanto, as condições de contorno mais usadas quando se estuda o modelo OFC. Alguns autores alegam que as condições fechadas de contorno levam a resultados qualitativamente semelhantes [22], mas o modelo não é freqüente estudado com detalhe sob essas condições. ${ }^{5}$ Nessa tese serão apresentados somente resultados com condições de contorno abertas.

\subsubsection{Regime transiente}

A partir da configuração inicial aleatória, o sistema passa por um regime transiente, caracterizado pelo avanço para o interior do reticulado da auto-organização que se inicia na borda. De acordo com Middleton et al [34], essa auto-organização se propaga com uma lei de potência no tempo, $y(t) \sim t^{-\beta(\alpha)}$, com o expoente dependente de $\alpha$. Lise [35] relata, porém, observando o tamanho médio dos eventos, um expoente universal $\beta \approx 1.3$, independente de $\alpha$. Essa não é necessariamente uma contradição, já que os diferentes resultados foram obtidos para dois intervalos disjuntos do parâmetro $\alpha(\alpha \geqslant 0.18$ em [35] e $\alpha \leqslant 0.15$ em [34]). De Carvalho et al também estudaram a evolução do regime transiente [36], e constataram que o comportamento do mesmo é bastante diferente entre o caso conservativo $\alpha=1 / 4$ e o não-conservativo $\alpha<1 / 4$. No caso conservativo, o tempo do transiente $\mathrm{T}(\alpha=1 / 4, \mathrm{~L})$ depende de maneira simples do tamanho do reticulado, $\mathrm{T}(\alpha=1 / 4, \mathrm{~L}) \sim 0.15 \mathrm{~L}^{2}$. No caso não-conservativo, a evolução é mais complicada, e possui um termo dependente em $\mathrm{L}^{2}$, e outro que varia mais rapidamente, de uma maneira que depende de $\alpha$. Recentemente, uma análise mais detalhada realizada por Wissel et al [37], que considerou o avanço da distribuição de tensão no reticulado e alguns argumentos de campo médio, sugere que de fato o expoente $\beta$ acima depende de $\alpha$, e eles propõem uma expressão para o tempo transiente total necessário para o interior do reticulado ser alcançado por completo, $\mathrm{T}(\alpha, \mathrm{L}) \sim \mathrm{f}(\alpha) \mathrm{L}^{\mu(\alpha)}$, onde $\mathrm{f}(\alpha) \sim \exp \left(m \alpha-l-C \alpha^{c}\right)$, e $\mu(\alpha) \sim E \exp (D \alpha)$, onde todos os valores fora $L$ e $\alpha$ são constantes positivas maiores que 1 . Isso significa que o tempo transiente cresceria rapidamente com $\alpha \rightarrow 0$. Além disso, o tempo transiente tem que crescer pelo menos com $\sim \mathrm{L}^{2}$, que é o número de sítios no reticulado, o que acaba tornando proibitivo o estudo numérico do estado estacionário de redes grandes com $\alpha$ pequeno. Devido a isso é, em geral, difícil encontrar na literatura estudos do modelo com reticulados $L>1000$ e valores de $\alpha \lesssim 0.1$.

A auto-organização iniciada pela borda leva a uma formação de regiões no reticulado com tensões muito próximas, que se assemelham a manchas [33,37]. Quando o reticulado inteiro é tomado por esse processo, o interior permanece composto por essas manchas que permanecem quase "estáticas" por um tempo grande. Na figura 2.1.4, pode-se ver a progressão dessas manchas para o caso $\alpha=0.12$. O tamanho

\footnotetext{
${ }^{5}$ Sabe-se, porém, de algumas diferenças importantes, como, por exemplo, o fato do tempo transiente ser menor quando se usa condições fechadas, devido a falta de dissipação na borda [22]. Isso pode indicar, em potencial, um diferente mecanismo de auto-organização que pode levar a outras diferenças na dinâmica estacionária. Devido a importância das condições de contorno, talvez os detalhes das diferenças entre as condições abertas e fechadas merecessem mais atenção.
} 
dessas manchas aparenta ser distribuído de acordo com uma lei de potência do tipo $\mathrm{P}(\mathrm{m}) \sim \mathrm{m}^{-\eta}$, com $\eta$ independente de $\alpha$ [37], onde as menores se localizam mais perto da borda e as maiores no interior do reticulado ${ }^{6}$.

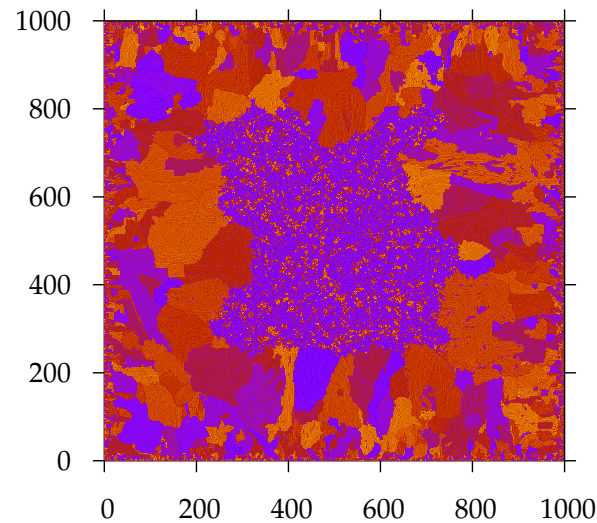

(a) $\alpha=0.12, \mathrm{~L}=1000$, regime transiente

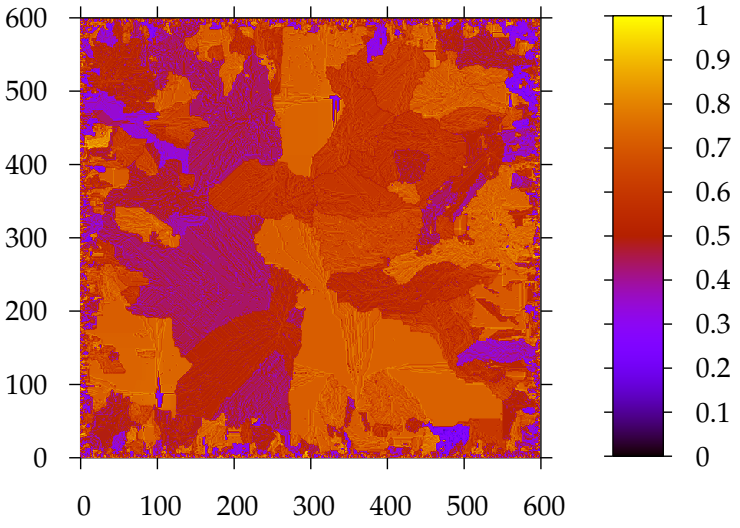

(b) $\alpha=0.12, \mathrm{~L}=600$, regime estacionário

Figura 2.1.4: Regime transiente e estacionário do modelo OFC, para $\alpha=0.12$, e dois tamanhos do reticulado. A legenda mostra os valores da tensão de cada sítio em escala de cores.

A maneira mais tradicional de identificar e separar o regime transiente do estacionário da dinâmica é a análise da estatística de tensões no reticulado ao longo do tempo. Em particular, mede-se a evolução da tensão média, e do desvio padrão em torno da mesma. Quando ambas grandezas se tornam estáveis, o sistema se encontra no regime estacionário. Na figura 2.1.5 pode ser vista tal evolução para $\alpha=0.22$.

\subsubsection{Regime estacionário}

Após o regime transiente, o sistema se encontra no regime estacionário, onde suas propriedades estatísticas não variam com o tempo. A principal característica do modelo nesse regime é a distribuição de tamanho de eventos, que exibe uma lei de potência aparente para vários valores de $\alpha$ (ver figura 2.1.6). Esse resultado é tido como principal sucesso do modelo, pois reproduz a lei empírica de Gutenberg-Richter [38] de tamanhos de terremotos (ver seção 2.1.7). Além disso, a presença de invariância de escala, representada pelas leis de potência não impostas pela construção do modelo, o classificaria como exibindo SOC. Os dois objetivos principais do modelo modelar terremotos e fazê-lo pela ótica de SOC - teriam sido, portanto, alcançados.

A maior parte do esforço feito no estudo desse modelo tem girado em torno dessa conclusão, que permanece controversa. Em geral, os pontos abordados são os seguintes:

${ }^{6}$ Como as manchas maiores estão no interior do reticulado, se o tamanho $\mathrm{m}$ das manchas no interior tender a $m \rightarrow \infty$, para $L \rightarrow \infty$, isso implicaria que o sistema e encontraria completamente sincronizado no limite termodinâmico. Porém, não foi feita uma análise detalhada em [37] da distribuição de tamanhos das manchas em função do tamanho $L$ do reticulado. 


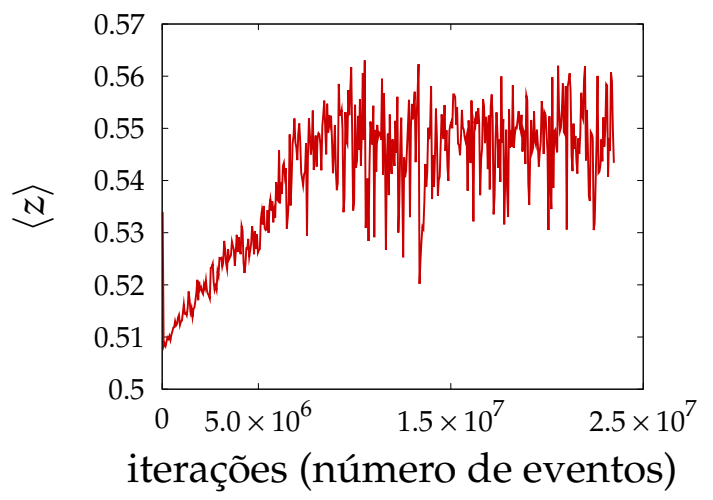

(a) Tensão média $\langle z\rangle$.

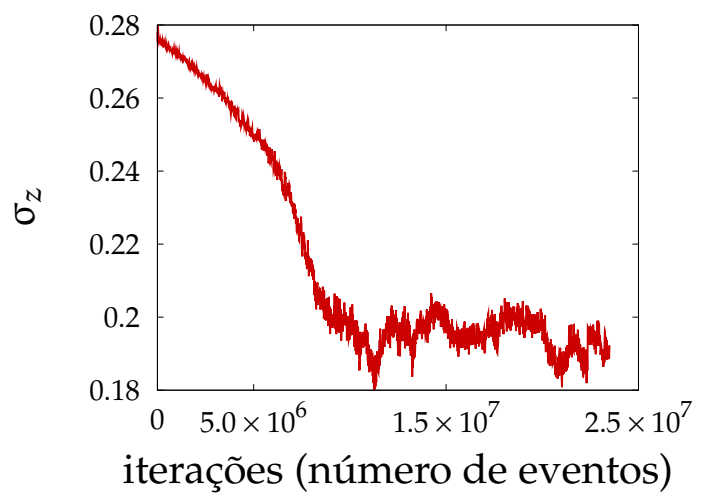

(b) Desvio padrão da tensão $\sigma_{z}$.

Figura 2.1.5: Evolução da estatística de tensões do modelo OFC, para $\mathrm{L}=300$ e $\alpha=0.22$, ao longo do tempo. A mudança mostra a transição do regime transiente para o estacionário.

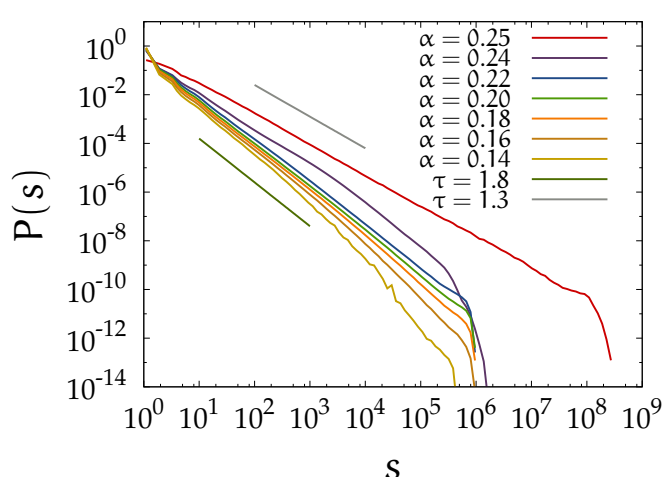

(a) Reticulado inteiro

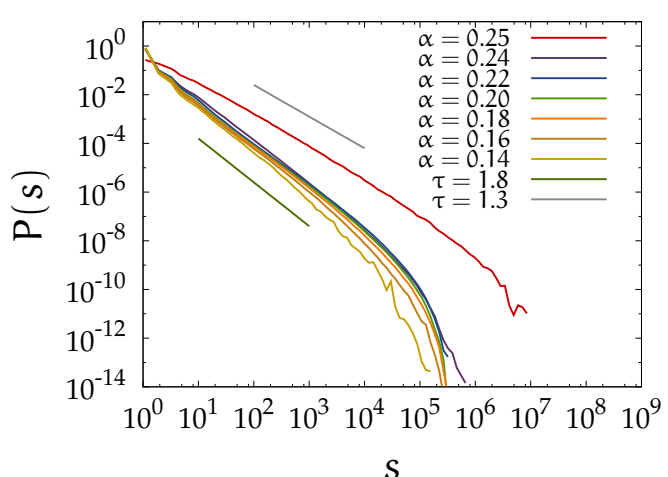

(b) Região interna $800 \times 800$

Figura 2.1.6: Distribuição de tamanho de eventos para diversos valores de $\alpha$ e $L=1000$. Os segmentos de reta representam leis de potência do tipo $\mathrm{P}(\mathrm{s}) \sim \mathrm{s}^{-\tau}$, com expoente indicado na legenda.

1. Há dúvidas se, de fato, o modelo OFC é crítico. No caso conservativo, $\alpha=1 / 4$, há evidencias suficientes de criticalidade. Porém, no caso dissipativo $\alpha<1 / 4$, existem resultados contraditórios, e a questão permanece em aberto.

2. A distribuição de tamanho de eventos não pode ser a única usada para descrever a dinâmica de terremotos. Existe uma série de outras características robustas presentes na estatística de terremotos, como a distribuição espaço-temporal de epicentros, que deveriam pertencer ao comportamento emergente de modelos auto-organizados, para que esses possam ser considerados bem-sucedidos. O modelo OFC reproduz, inclusive de maneira surpreendente, vários desses comportamentos, porém não todos.

Esses pontos serão mais detalhados a seguir, através de um resumo das propriedades já conhecidas do comportamento do modelo no regime estacionário. 


\section{Distribuição de tamanhos de eventos}

A característica mais central do modelo é a distribuição de tamanhos de eventos, que o relaciona de maneira mais direta com a fenomenologia de terremotos reais, mais especificamente com a lei de Gutenberg-Richter para a distribuição de magnitudes de terremotos [38]:

$$
P(m)=\beta \ln (10) 10^{-\beta\left(m-m_{d}\right)},
$$

onde $\mathrm{P}(\mathrm{m})$ é densidade de probabilidade de um terremoto ocorrer com magnitude $m$, e $\beta$ é um valor em geral em torno de 1. O limite inferior $m_{d}$ é escolhido para que $\mathrm{P}(\mathrm{m})$ seja normalizada em 1 , somando-se para todas as magnitudes acima de $m_{d}$.

A magnitude $m$ de um terremoto real é uma medida da energia liberada pelo evento, e é definida como o logaritmo da maior amplitude das ondas obtidas por um sismógrafo [38]. Logo, no modelo OFC, o análogo da magnitude é definido como

$$
m \propto \log _{10}(s),
$$

onde s é o tamanho do evento, definido como o número total de relaxamentos. Desta forma, a lei de Gutenberg-Richter é representada no modelo OFC por uma distribuição de tamanhos s que segue uma lei de potência da forma

$$
\mathrm{P}(\mathrm{s})=\mathrm{C} \mathrm{s}^{-\beta},
$$

onde C é uma constante de normalização. Como pode ser visto na figura 2.1.6, uma primeira análise do modelo revela que uma lei de potência é observável para essa distribuição, para vários valores de $\alpha$. O expoente $\beta \approx 1.8$ dessa distribuição não parece variar significativamente $\operatorname{com} \alpha<1 / 4$, sendo diferente somente para o caso conservativo $\alpha=1 / 4$, tendo o valor $\beta \approx 1.3$. Naturalmente, é observado um cut-off para tamanhos grandes, o que é devido, a princípio, ao tamanho finito do sistema.

A análise da robustez dessa lei de potência deve levar em consideração a variação dessa distribuição não somente com o valor de $\alpha$, mas também com o tamanho do sistema L. Em particular, espera-se que o comportamento do sistema exiba finite size scaling (FSS):

$$
\mathrm{P}_{\mathrm{L}}(\mathrm{s}) \sim \mathrm{L}^{-\beta} \mathrm{G}\left(\frac{\mathrm{s}}{\mathrm{L}^{\mathrm{D}}}\right),
$$

onde $\mathrm{G}$ é uma função de escala adequada, e $\beta$ e D são expoentes críticos que governam a variação de escala da distribuição. O sistema deve obedecer esse ansatz para que no limite termodinâmico $\mathrm{L} \rightarrow \infty$ exista uma lei de potência sem cut-off, e que esse seja identificado como causado somente pelo tamanho finito de L.

Um ansatz alternativo ao FSS, que pode ser mais adequado a fenômenos exibindo SOC, é um ansatz de "multi-escala" (multiscaling) [39], onde a distribuição de tamanhos deve possuir a seguinte variação de escala:

$$
\frac{\log P_{\mathrm{L}}\left(\mathrm{s} / \mathrm{s}_{0}\right)}{\log \left(\mathrm{L} / \mathrm{l}_{0}\right)}=\mathrm{F}\left(\frac{\log \mathrm{s} / \mathrm{s}_{0}}{\log \mathrm{L} / \mathrm{l}_{0}}\right)
$$

onde $s_{0}$ e $l_{0}$ são parâmetros que tipicamente refletem fenômenos de pequena escala, associados ao reticulado (ver figura 7 em [39]), e F é uma função de escala adequada. Para o modelo OFC, normalmente toma-se $s_{0}=l_{0}=1$, e assume-se $P_{L}(s) \sim s^{-\tau(\alpha)}$, de 
modo que $\log \mathrm{P}_{\mathrm{L}} / \log \mathrm{L} \sim-\tau(\alpha) \log \mathrm{s} / \log \mathrm{L}$. Se, de fato, $\mathrm{P}_{\mathrm{L}}(\mathrm{s})$ é uma lei de potência, e a equação 2.1.7 vale, então a curva

$$
\frac{\log P_{L}}{\log L}+\tau(\alpha) D_{a v}
$$

onde $\mathrm{D}_{\mathrm{av}}=\log \mathrm{s} / \log \mathrm{L}$ é a "dimensão da avalanche", deve convergir para uma linha reta, com inclinação 0 se $\tau(\alpha)$ for escolhido corretamente.

Uma análise de ambos os ansatz foi feita por Lise e Paczuski [40], para o modelo OFC com $L \in[32,512]$ e $\alpha \in[0.15,0.21]$. Os resultados apresentados para essa faixa de parâmetros mostram que o modelo não exibe FSS, pois não existe uma função universal G que colapse as distribuições conforme a equação 2.1.6. Esse comportamento é devido à ocorrência de avalanches grandes, da ordem do tamanho do sistema, com freqüência maior, para maiores valores de L, do que o esperado com FSS. Essa ocorrência maior de avalanches grandes, porém, quando analisada pelo ansatz da equação 2.1.7 em [40], leva a conclusão que o modelo OFC exibe SOC, com uma distribuição de lei de potência universal $\mathrm{P}(\mathrm{s}) \sim \mathrm{s}^{-1.8}$. Para a faixa de parâmetros estudada em [40], a curva (2.1.8) se aproxima de um linha reta conforme o valor de $L$ aumenta, com inclinação 0 para $\tau(\alpha)=1.8$, e o valor máximo de $D_{a v}$ se aproximando de 2. Posteriormente, os mesmos autores analisaram mais a fundo a violação de FSS neste modelo [41]. Dessa vez, foi feita uma distinção entre três tipos de eventos, de acordo com onde eles ocorrem no reticulado: Foi considerada uma sub-região interna, de tamanho linear $\Lambda<L$, centrada no centro do reticulado; os eventos foram categorizados como: (a) inteiramente confinados na região $\Lambda,(b)$ iniciados na região $\Lambda$, mas que, possivelmente, ultrapassem para o resto do reticulado, (c) iniciados em qualquer posição do reticulado. Os resultados apresentados em [41], também para $L \in[32,512] \mathrm{e}$ $\alpha \in[0.15,0.21]$, mostram que, quando somente

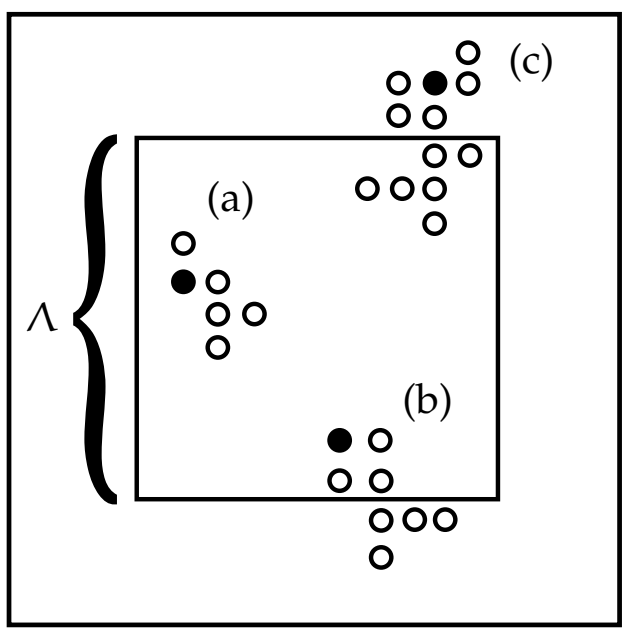

Figura 2.1.7: Diferentes tipos de eventos considerados em [41]. eventos do tipo (a) ou (b) são considerados, o sistema exibe FSS, para $\Lambda \in[32,512]$, com expoentes críticos $\beta=3.6$ e $D=2$, independentes de $\alpha$, e uma lei de potência universal, com expoente -1.8 (ver figura 2.1.6b, página 14). Isso indica que os eventos grandes, da ordem do tamanho do reticulado, responsáveis por destruir o FSS, se iniciam numa região próxima à borda do sistema. ${ }^{7}$ Portanto, o cenário de SOC também é confirmado por FSS, quando eventos próximos a borda são desconsiderados. ${ }^{8}$

\footnotetext{
${ }^{7}$ Essa assimetria aparenta estar relacionada com a maneira com a qual o sistema se auto-organiza no regime transiente, começando pela borda e progredindo para o interior do sistema (ver seção 2.1.4).

${ }^{8} \mathrm{Em}[41]$ não é feita uma análise do valor máximo de $\Lambda$, para cada valor de $L$, com o qual FSS não é violado. Dessa maneira não é possível concluir se o sistema exibe FSS assintoticamente, e conseqüentemente SOC, para $\mathrm{L} \rightarrow \infty$. Essa análise é feita na seção 3.1, página 23, onde é mostrado que esse "efeito de borda" é independente do tamanho L do sistema.
} 
Boulter e Miller [42] retomaram a análise de multi-escala feita em [40], dessa vez com uma faixa de parâmetros mais abrangente: $L \in[128,1000]$ e $\alpha \in[0.13,0.25]$. Eles chegaram a conclusões que contradizem o que foi apresentado em [40], pois, para a nova faixa de valores de $L$, a curva (2.1.8) não se aproxima de uma linha reta para nenhum valor de $\alpha<1 / 4$. Somente no limite conservativo, $\alpha=1 / 4$, o sistema exibe o comportamento previsto pela equação 2.1.7, compatível com uma distribuição de tamanhos seguindo uma lei de potência com expoente $\approx 1.25$. Os autores de [42] atribuem as diferenças entre os resultados ao pequeno tamanho $\mathrm{L} \leqslant 512$ dos reticulados estudados em [40], pois o desvio de um linha reta da curva (2.1.8) se acentua conforme L aumenta. Os mesmos autores, porém, não fazem a distinção de eventos feita em [41], de acordo com onde eles ocorrem no reticulado (ver figura 2.1.7), o que poderia afetar os resultados.

\section{Taxa de ramificação}

A criticalidade do modelo OFC pode ainda ser analisada de uma maneira diferente, que não envolve a variação de escala da distribuição de tamanhos de eventos. Essa maneira consiste em mapear o modelo OFC em um processo ramificado, como já foi feito para alguns modelos exibindo SOC, sem correlações espaciais e no limite termodinâmico [43]. Um processo ramificado é um processo Markoviano, definido como uma seqüência de variáveis aleatórias $\left\{X_{j}\right\}_{j=0}^{\infty}$, onde $X_{j}$ representa o número de indivíduos na j-ésima geração. A cada geração, cada indivíduo gerado na geração anterior tem uma probabilidade $p_{i}$ de gerar $i$ descendentes, que independe de geração atual. A taxa de ramificação, $\sigma=\sum_{i=0}^{\infty} i p_{i}$, é o número médio de descendentes por indivíduo. Essa taxa define se um processo ramificado pode ser sub-crítico $(\sigma<0)$ crítico $(\sigma=1)$, ou super-crítico $(\sigma>1)$. O número final médio $S$ de indivíduos num ensemble de processos ramificados, iniciados com $X_{0}=1$, é relacionado com $\sigma$ por (ver, por exemplo, [44])

$$
S= \begin{cases}\frac{1}{1-\sigma} & \text { se } \sigma<1 \\ \infty & \text { se } \sigma \geqslant 1\end{cases}
$$

O modelo OFC pode ser mapeado em um processo ramificado, considerando cada sítio que relaxa como um indivíduo, que pode gerar descendentes, se alguns de seus vizinhos também relaxarem. Como existem correlações espaciais no modelo OFC, e cada sítio tem probabilidades diferentes de gerarem descendentes ${ }^{9}$, é considerada somente a taxa de ramificação média, definida como sendo a média do número de descendentes por relaxamento, para todos os sítios do reticulado, por um tempo suficientemente grande para que o valor se estabilize. Cada avalanche $n$ no modelo OFC tem uma taxa de ramificação média

$$
\sigma_{n}=\sum_{b} b \frac{N_{n}(b)}{\sum_{b} N_{n}(b)}=\frac{s_{n}-1}{s_{n}},
$$

onde $\mathrm{N}_{\mathfrak{n}}(\mathrm{b})$ é o número relaxamentos que criaram $b \in[0,4]$ descendentes, e $s_{\mathfrak{n}}$ é o tamanho final da avalanche. A taxa de ramificação final do sistema é obtida somando-

\footnotetext{
${ }^{9}$ Além disso, no modelo OFC, é possível que um sítio relaxe depois de receber tensão de mais de um sítio, o que tornaria esse sítio descendente de mais de um individuo.
} 
se em todas as avalanches, cada uma com peso igual a seu tamanho,

$$
\sigma(\alpha, \mathrm{L})=\frac{\sum_{n} \sigma_{n} s_{n}}{\sum_{n} s_{n}}=1-\frac{1}{\langle s(\alpha, L)\rangle}
$$

onde $\langle s(\alpha, \mathrm{L})\rangle$ é o tamanho médio das avalanches.

Logo, para que o modelo OFC seja crítico, de acordo com a equação 2.1.11, o tamanho médio de avalanches $\langle s(\alpha, L)\rangle$ deve crescer continuamente com $L$, para que no limite termodinâmico $L \rightarrow \infty$, o valor da taxa de ramificação média $\sigma(\alpha, L)$ tenda a 1.

A variação da taxa de ramificação média $\sigma(\alpha, \mathrm{L})$ do modelo OFC com L e $\alpha$ foi analisada por de Carvalho e Prado [45], para $L \in[100,1000]$ e $\alpha \in[0.15,0.25]$, que constataram que, para $\alpha<1 / 4$, o valor de $\sigma(\alpha, \mathrm{L})$ tende a um valor menor do que 1 para $\mathrm{L} \rightarrow \infty$. O sistema seria crítico $\left(\lim _{\mathrm{L} \rightarrow \infty} \sigma(\alpha, \mathrm{L})=1\right)$ somente no caso conservativo, $\alpha=1 / 4$. Como, porém, os valores assintóticos de $\sigma(\alpha, \mathrm{L})$ para $\mathrm{L} \rightarrow \infty$ se aproximariam razoavelmente de 1, para vários valores de $\alpha<1 / 4$, os autores de [45] classificaram o modelo como "quase crítico", pois as propriedades numéricas são, para fins práticos, indistinguíveis de um sistema verdadeiramente crítico. Dessa maneira, o modelo OFC poderia ainda servir para modelar fenômenos livre de escala, observados experimentalmente. As conclusões de [45] geraram uma certa controvérsia, e Christensen et al alegaram em [46] que os resultados apresentados por de Carvalho et al não invalidariam a criticalidade do sistema, se fosse usado um ansatz apropriado para a forma com a qual a taxa de ramificação varia $\operatorname{com} \operatorname{Le} \alpha$,

$$
\sigma(\alpha, \mathrm{L})=1-\frac{\mathrm{a}}{\mathrm{A}(\alpha) \mathrm{L}^{\eta(\alpha)}}
$$

onde $A(\alpha)$ e $\eta(\alpha)$ são funções apropriadas, dependentes de $\alpha$, ao invés da extrapolação linear suposta em [45]. De Carvalho et al responderam em [47] que de fato a questão de criticalidade no modelo ainda está em aberto, mas salientaram que o uso do ansatz da equação 2.1.12 pode não ser conclusivo, pois uma mesma análise da taxa de ramificação do modelo OFC com vizinhos aleatórios (ver seção 2.1.6), que se sabe analiticamente ser crítico somente para $\alpha=1 / 4$, não exclui a possibilidade do sistema ser crítico para $\alpha<1 / 4$, o que se sabe que é falso.

Miller e Boulter [48] também analisaram a taxa de ramificação do modelo OFC, porém fizeram distinção entre os diferentes sítios do reticulado, calculando a taxa de ramificação das diferentes "camadas" do reticulado, começando pela borda mais externa e progredindo para o centro. Os autores constataram que a taxa de ramificação dos sítios aumenta conforme esses se encontram mais no interior do reticulado. Eles argumentaram que os sítios mais próximos do centro representariam melhor o comportamento do sistema no limite termodinâmico, onde todos os sítios estariam a um distância infinita da borda. Apesar desse aumento da taxa de ramificação, foi também concluído em [48] que o sistema exibe $\sigma(\alpha, \mathrm{L})<1$ para $\alpha<1 / 4$ no limite $\mathrm{L} \rightarrow \infty$. O modelo OFC cairia, portanto, somente na classe de "quase-criticalidade" proposta em [45].

\section{Distribuição de tensão no reticulado}

Diversas vezes foram estudadas propriedades da distribuição de tensões no reticulado do modelo OFC para tentar extrair conclusões relevantes sobre o modelo. 
De particular importância foi a análise feita por Drossel [33], para $\alpha \in[0.05,0.1] \mathrm{e}$ $\mathrm{L} \in[100,200]$, onde foi mostrado que a precisão numérica tem um papel importante na dinâmica do modelo, e conjecturou-se que, com precisão infinita, o sistema seria dominado por avalanches de tamanho 1 somente, pelo menos para valores de $\alpha \approx 0.1$. Um estudo mais detalhado foi feito posteriormente em [49], através da distribuição de diferenças de tensão de sítios vizinhos, e também a distribuição de valores super-críticos de tensão. Os autores alegaram, nesse trabalho, que existe um valor específico $\alpha_{X} \approx 0.14$ que separa dois comportamentos qualitativamente distintos dessas duas propriedades. De acordo com [49], sistemas com $\alpha<\alpha_{X}$ possuiriam somente eventos de tamanho 1 no limite termodinâmico. Porém, nesse caso, os vizinhos do sítio que relaxou poderiam ter tensão arbitrariamente perto de 1, que tornaria a avalanche maior, se a precisão numérica for limitada (o que é sempre o caso em simulações numéricas). Essa dependência em precisão infinita não desqualificaria o modelo em explicar invariância de escala em sistemas reais, pois nesse caso a presença garantida de ruído faria o mesmo papel da falta de precisão numérica.

A análise da distribuição de tensão do modelo foi levada mais adiante por Wissel e Drossel [37], que analisaram a distribuição espacial de tensões, tanto no regime estacionário quanto no transiente, para $L \in[64,512]$ e $\alpha \in[0.03,0.18]$. Baseando-se na distribuição de tamanhos de regiões com valor similar de tensões (ver figura 2.1.4b), e supondo que os eventos subseqüentes a um evento específico tendem a pertencer a mesma região, e que a distribuição de tamanhos de eventos dentro de uma região específica é uma lei de potência com um cut-off da ordem do tamanho da região, os autores de [37] chegaram na seguinte expressão para a distribuição de tamanhos de eventos do modelo OFC:

$$
P(s) \sim s^{-\tau(\alpha)-\sigma(\alpha) \log s,}
$$

onde $\tau(\alpha)$ e $\sigma(\alpha)$ são expoentes que dependem de $\alpha$. Deste modo, a distribuição de eventos não seria uma lei de potência, devido ao termo logaritmo na equação 2.1.13. Apesar dessa expressão ser capaz de ajustar alguns dados apresentados em [37], as várias suposições feitas para alcançá-las não foram verificadas explicitamente.

\section{Considerações sobre a existência de criticalidade do modelo}

Analises numéricas somente nunca determinarão, com exatidão, se o modelo OFC possui estatística de tamanho eventos que segue uma lei de potência, no limite termodinâmico. Além dessa limitação inerente, métodos usuais como identificação de finite size scaling e análise da taxa de ramificação, que é o melhor que se poderia obter nessas circunstâncias, esbarram em características peculiares do modelo. Em geral, uma análise sistemática do modelo que venha responder a questão da criticalidade, teria que levar em consideração, simultaneamente, os seguintes aspectos: 1) Dado um valor de $L$ e $\alpha$, tem que se ter certeza que o regime estacionário foi alcançado; 2) $\mathrm{O}$ tamanho de $\mathrm{L}$ tem que ser grande o suficiente, para que os efeitos da borda do sistema sejam desprezíveis, ou alternativamente, que esses sejam identificados e isolados da análise; 3) Os comportamentos para diferentes valores de L devem ser comparados, o suficiente para que seja possível inferir o comportamento de $\mathrm{L} \rightarrow \infty$; 4) Alcançado o regime estacionário, um número suficiente de eventos tem que ser considerado, até que a estatística obtida se estabilize. Desses critérios, o que é mais 
freqüentemente negligenciado na literatura é o segundo, que diz respeito a efeitos de superfície do modelo, que são bastante presentes. Esses efeitos, impossibilitam que conclusões úteis possam ser tomadas quando o tamanho do reticulado é muito pequeno. Uma análise detalhada desse efeito de superfície será feita no capítulo 3. Em particular estudos feitos com reticulados de tamanho $\mathrm{L} \lesssim 200$ muitas vezes não contém nada além desse efeito. Mesmo em reticulados maiores L 1000, muitas vezes os resultados obtidos são muito diferentes quando eventos próximos à borda são desconsiderados. Como foi mostrado em [48] e também será mostrado, de maneira diferente, no capítulo 3, eventos que não são afetados por esse efeito de superfície se aproximam mais do cenário de criticalidade. Porém, a conclusão mais provável, de acordo com [48] (onde os critérios acima foram obedecidos), é de que o sistema não é de fato crítico para $\alpha<1 / 4$, e se enquadra somente no cenário de "quasecriticalidade", proposto em [45].

\subsubsection{Campo médio: Vizinhos aleatórios}

O modelo OFC, como muitos modelos construídos para estudar SOC, é fácil de ser implementado. Porém, é extremamente custoso obter resultados exatos sobre o modelo, devido a predominância de correlações espaciais. Logo, o primeiro passo em tentar obter resultados analíticos é simplificar de alguma maneira essas correlações, para que elas sejam tratáveis. A maneira mais direta de se fazer isso é removê-las por inteiro, fazendo um tratamento de campo médio do sistema. Para isso a regra de evolução do sistema (equação 2.1.2, página 9) é modificada para

$$
z_{i} \geqslant z_{c} \Rightarrow\left\{\begin{array}{l}
z_{j_{k}} \rightarrow z_{j_{k}}+\alpha z_{i}, \quad k=1, \ldots, n \\
z_{i} \rightarrow 0,
\end{array}\right.
$$

onde $n$ é um número inteiro arbitrário, e cada um dos $n$ sítios é escolhido aleatoriamente, cada vez que a regra deve ser aplicada. Dessa maneira o reticulado efetivamente desaparece, e o modelo deixa de ser definido espacialmente. Esse modelo ficou conhecido na literatura como modelo com "vizinhos aleatórios".

Um tratamento analítico desse modelo foi feito por Bröker e Grassberger [50], que obtiveram resultados exatos para a estatística de tamanhos de eventos. O modelo OFC com vizinhos aleatórios possui criticalidade, com distribuição de tamanhos seguindo uma lei de potência com expoente $3 / 2$, somente no caso conservativo $\alpha=1 / n$. Para qualquer valor de $\alpha<1 / n$, a distribuição de tamanhos decai muito mais rápido que uma lei de potência.

A existência, portanto, de leis de potência aparentes, para o caso não-conservativo do modelo OFC no reticulado, mostra que as correlações espaciais fortalecem a criticalidade do modelo, independentemente se o modelo nesse caso é de fato crítico.

\subsubsection{Semelhança com terremotos reais: Lei de Omori}

Além da lei de Gutenberg-Richter [38], terremotos são governados por outra lei empírica chamada de lei de Omori [51], que foi identificada pela primeira vez há mais de 100 anos. Essa lei diz que, após um terremoto suficientemente grande, a freqüência 
de terremotos subseqüentes $N(t)$ decai com o tempo $t$ de acordo com

$$
N(t)=\frac{K}{(c+t)^{\theta}}
$$

onde $\mathrm{K}$ e $\mathrm{c}$ são constantes, e $\theta \approx 1$ para terremotos em diversas partes do mundo. Os terremotos que decaem dessa maneira são chamados de aftershocks, e o terremoto originário, de mainshock. Existe também o que é chamado de lei de Omori inversa [52-54],

$$
N^{\prime}(t)=\frac{K^{\prime}}{(c-t)^{\theta}}
$$

onde $\theta^{\prime} \lesssim \theta$, que governa a ocorrência de foreshocks, i.e., terremotos que precedem outros terremotos, com freqüência dada pela equação 2.1.16. Essa propriedade, porém, é mais difícil de ser detectada, sendo necessário que seja feita a média da atividade imediatamente antes de muitos mainshocks, ao contrário dos aftershocks, que são facilmente identificáveis para somente um evento. Além disso, o número $\mathrm{N}_{\mathrm{a}} \mathrm{de}$ aftershocks está vinculado com a magnitude $m$ do mainshock por

$$
\mathrm{N}_{\mathrm{a}}(\mathrm{m}) \sim 10^{\beta \mathrm{m}}
$$

onde $\beta \in[1 / 2,1]$ (ver [55]).

As propriedades de terremotos descritas acima são unicamente temporais. Muitos estudos, porém, relataram a existência de difusão de aftershocks [56,57], e de migração de foreshocks [52,58,59], que representam, respectivamente, a expansão da área afetada por aftershocks em torno do mainshock, e a aproximação da ocorrência de foreshocks em torno do mesmo. Porém, a maneira exata de como isso acontece ainda não é bem conhecida.

Hergarten e Neugebauer descobriram [22] que o modelo OFC exibe a lei de Omori e lei de Omori reversa, para foreshocks e aftershocks, respectivamente. Esse resultado é surpreendente, por ser esse um modelo tão simples. Algumas das explicações para a lei de Omori incluem a transferência de estresse [60,61], migração de fluidos [62] e processos físico-químicos [63], nenhum dos quais existem no modelo OFC. Os expoentes das equações 2.1.15 e 2.1.16 relatados em [22] variam com o parâmetro $\alpha$, sendo maiores quanto maior for a dissipação. Quando não há dissipação, $\alpha=1 / 4$, e o modelo é comprovadamente crítico, ele não exibe ocorrência de foreshocks ou aftershocks. Posteriormente, Helmstetter et al fizeram uma análise mais detalhada do modelo OFC [23], e constataram que todas as propriedades da lei de Omori são presentes, ao menos de forma qualitativa. Essas propriedades incluem a variação da taxa de ocorrência com o tamanho do evento (equação 2.1.17), e a difusão de aftershocks descrita acima, representada pelo crescimento da zona de aftershocks, em função do tamanho do evento, de acordo com uma lei de potência. 


\section{Capítulo 3}

\section{Caracterização de eventos do modelo OFC}

Neste capítulo serão analisadas algumas características dos eventos (avalanches ou "terremotos") do modelo OFC, que serão usadas para classificá-los em tipos qualitativamente distintos. O objetivo é mostrar que existe uma escala característica de eventos no modelo. Eventos abaixo dessa escala exibem uma série de propriedades que os separam dos da escala acima. Os eventos maiores, acima dessa escala, são indistinguíveis, independentemente da escala de observação. Além disso, pretende-se mostrar que existem eventos que estão vinculados a um "efeito de borda" do reticulado, que também possuem características distintas, e que desapareceriam no limite termodinâmico. Essa análise remete, em alguns pontos, a alguns resultados já conhecidos, mas é, no todo, um estudo completamente original e sistemático, sem paralelo na literatura.

Como apresentado no capítulo 2, a proposta central de SOC é que eventos de diferentes tipos, onde os tipos são, em geral, caracterizados por diferentes tamanhos ou intensidades, são gerados por uma dinâmica única, livre de escala, que resulta numa distribuição de tamanhos ou intensidades que segue uma lei de potência. Essa dinâmica única significaria que eventos de diferentes tamanhos seriam qualitativamente iguais, já que não haveria regras diferentes para determinar um tamanho específico de evento. Porém, outras características relacionadas aos tamanhos dos eventos podem, a principio, variar de maneira arbitrária, o que possibilitaria a identificação de escalas e tipos distintos de eventos, apesar das regras serem as mesmas para todos eles. Além disso, a dinâmica auto-organizada poderia se aplicar somente para parte dos eventos, que poderiam ser, então, divididos entre os que representam SOC e os que não representam.

O modelo OFC, que possivelmente exibe SOC (ver capítulo 2), é definido num reticulado bidimensional, e possui uma dinâmica que é fortemente dependente de correlações espaciais. A maneira que os eventos se dispõem espacialmente pode ser usada, então, para caracterizar melhor eventos de diferentes tamanhos. A seguir será detalhado o estudo de dois tipos de características espaciais, que serão de particular relevância para os estudos que virão em seqüência, e também para a análise do modelo em geral: A distribuição espacial de epicentros (seção 3.1) e a extensão espacial dos eventos (seção 3.2). Por último será avaliada a relevância dessa diferenciação na análise da taxa de ramificação média dos eventos (seção 3.3). 


\subsection{Distribuição espacial de epicentros}

As condições de contorno na dinâmica do modelo OFC são cruciais para o resultado obtido (ver seção 2.1.3, página 11). Quando a simetria espacial é preservada, usandose condições periódicas de contorno, o sistema exibe comportamento sincronizado, onde cada sítio do reticulado relaxa em seqüência, e todos os eventos são de tamanho $s=1$. Somente quando uma assimetria espacial é incluída no sistema, através de condições de contorno abertas ou fechadas, o sistema exibe um comportamento rico, com as características que já foram discutidas. Sabe-se, inclusive, que a auto-organização do sistema se inicia pela borda do reticulado (ver seção 2.1.4), e que eventos próximos à borda são qualitativamente distintos (ver seção 2.1.5).

A maneira, que é proposta neste trabalho, de determinar a dependência dos eventos da assimetria espacial introduzida pela borda é medir a freqüência de epicentros no reticulado, no regime estacionário. Como foi explicado na seção 2.1.3, essa análise será restrita a condições de contorno abertas. A contagem de epicentros num reticulado de tamanho $L=1000$, para diversos valores de $\alpha$ pode ser vista na figura 3.1.2. O que se observa, imediatamente, é que, para qualquer taxa de dissipação, a maior parte dos eventos se inicia próximo à borda. Esse efeito (essa "atração" para a borda), que será denominado "efeito de borda", muda abruptamente quando uma pequena quantidade de dissipação é incluída no sistema (comparar figuras 3.1.2a e 3.1.2b). No caso conservativo $\alpha=1 / 4$, a distribuição é mais uniforme e completamente diferente dos demais. Mesmo para uma dissipação muito pequena, como $\alpha=0.249$, o comportamento se torna completamente diferente, com um forte efeito de borda (ver figura 3.1.2b). A partir daí, para $\alpha<1 / 4$ o efeito de borda diminui gradativamente conforme a dissipação aumenta.

Esse efeito de borda pronunciado leva à questão de como deve se comportar o modelo no limite termodinâmico. Para $L \rightarrow \infty$, qualquer efeito vinculado com a borda do reticulado, $\mathrm{O}(\mathrm{L})$, deve ser desprezível em comparação com o interior do reticulado, $\mathrm{O}\left(\mathrm{L}^{2}\right)$. Resta saber, portanto, como o efeito de borda varia com o tamanho $L$ do reticulado. Essa dependência pode ser determinada pela taxa média de ocorrência de epicentros, em função da distância à borda. Para evitar efeitos de quina, foram considerados todos os eventos contidos na área do reticulado mostrada na figura 3.1.1, onde a região interna considerada representa uma fração de 1/3 do comprimento total, e 5/9 da área total. A taxa média de ocorrência foi obtida calculando-se a taxa de ocorrência em cada sítio da área especificada, e posteriormente a media da taxa para todos os sítios a uma mesma distância $x$ da borda mais próxima. Os resultados para diversos valores de $\alpha$ e tamanho do reticulado L podem ser vistos na figura 3.1.4. Pode-se ver, claramente, que para todos os valores de $\mathrm{L}$ a

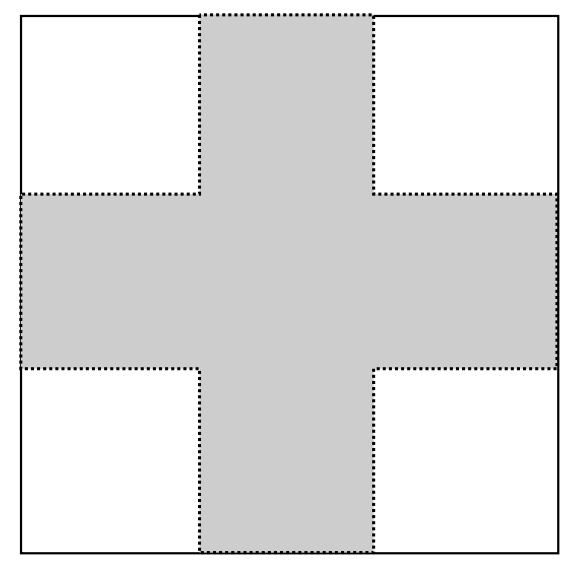

Figura 3.1.1: Região do reticulado considerada para análise do efeito de borda. 
dependência com a borda é a mesma. Além disso, para $\alpha \leqslant 0.24$, pode-se identificar uma distância, a partir da qual o efeito de borda se torna desprezível, e a ocorrência de epicentros é aproximadamente constante em função da distância da borda. $\mathrm{Na}$ figura 3.1.4 está marcado, para todos os valores de $\alpha$, a distancia $L_{B}=100$, que foi julgada suficiente para desconsiderar a maior parte dos eventos relacionados ao efeito de borda, para $\alpha \leqslant 0.24$. Uma comparação direta entre os diferentes valores de $\alpha$ pode ser feita pela figura 3.1.3.

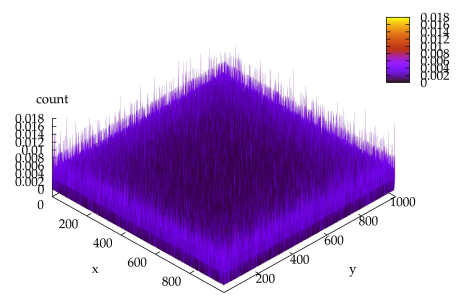

(a) $\alpha=0.25$

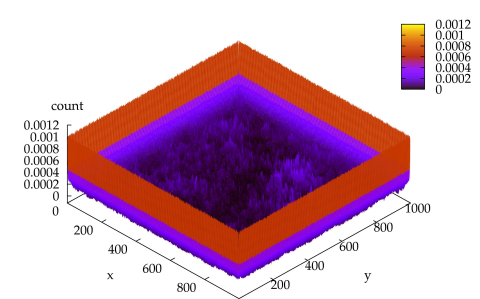

(d) $\alpha=0.22$

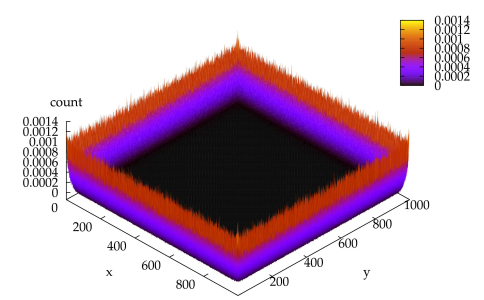

(b) $\alpha=0.249$

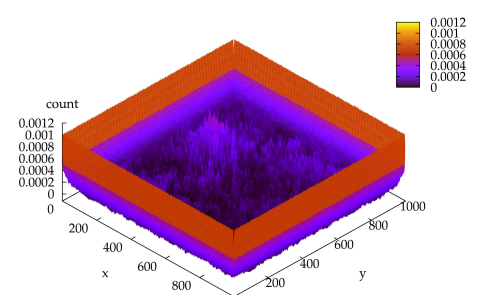

(e) $\alpha=0.20$

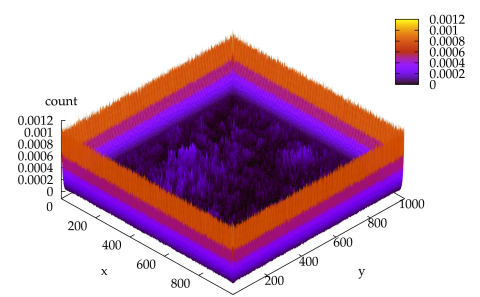

(c) $\alpha=0.24$

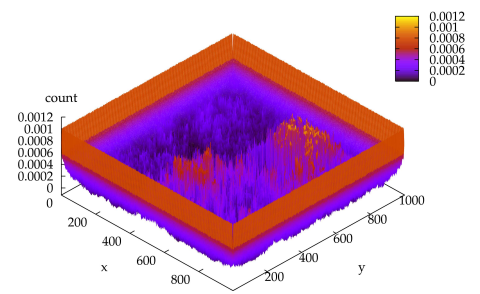

(f) $\alpha=0.18$

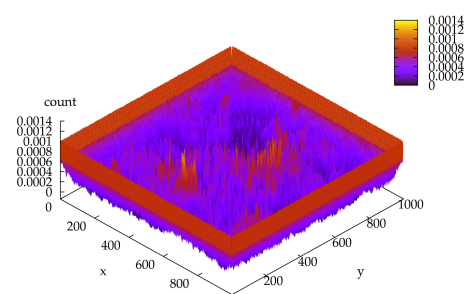

(g) $\alpha=0.16$

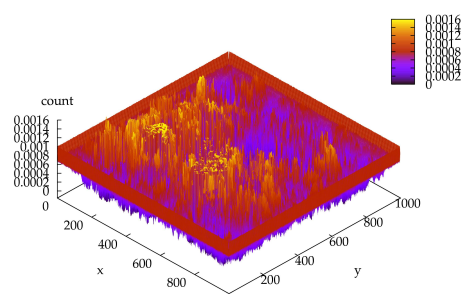

(h) $\alpha=0.14$

Figura 3.1.2: Contagem (normalizada) de epicentros no reticulado para $\mathrm{L}=$ 1000, e diversos valores do parâmetro de dissipação $\alpha$.

Como tinha sido já observado por Lise e Paczuski [41], os eventos mais próximos da borda são responsáveis pela quebra de Finite-Size Scaling (FSS), conforme discutido na seção 2.1.5. A violação de FSS é devida a um excesso de eventos de tamanho maior, da ordem do tamanho do sistema. Logo, é relevante avaliar a dependência do efeito de borda discutido até agora com o tamanho dos eventos. Na figura 3.1.5 estão, então, mostrados os mesmos resultados da figura 3.1.4, porém, somente para eventos de tamanho $s>100$. Como pode-se ver, o efeito de borda é de fato diferente para eventos maiores. As mesmas conclusões, porém, permanecem: $\mathrm{O}$ efeito independe de L e se torna desprezível no interior do reticulado. Na figura 3.1.6 estão apresentadas as taxas de ocorrências de eventos de diversos tamanhos, para $L=1000$. 


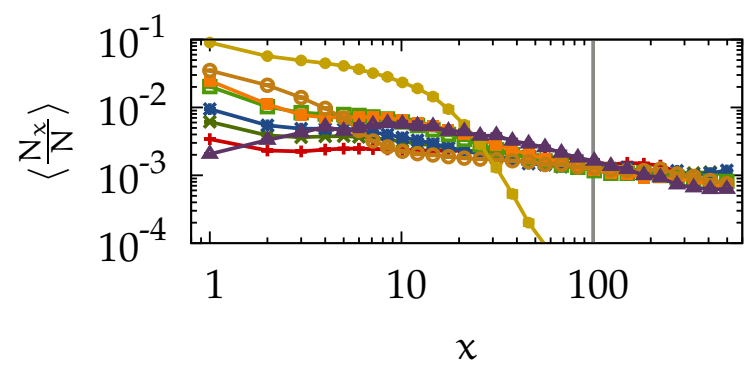

(a) $s>0$

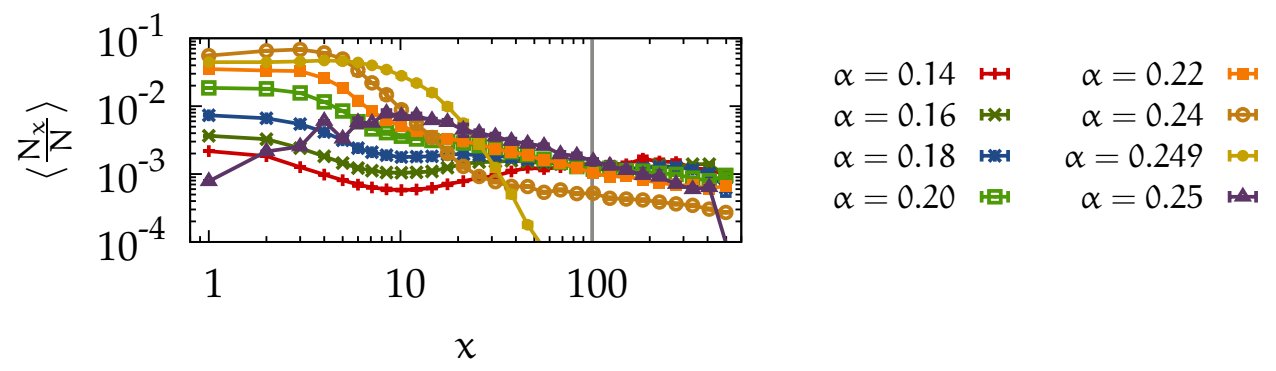

(b) $s>100$

Figura 3.1.3: Taxa média de ocorrência de epicentros $\left\langle N_{x} / N\right\rangle$, em função da distância $x$ da borda mais próxima, para $\mathrm{L}=1000$ e diversos valores de $\alpha$. A curva para $\alpha=0.249$ varia de maneira mais acentuada do que as demais, $\mathrm{e}$ pode ser vista separadamente na figura 3.1.4b.

Observa-se que a diferença entre os eventos de diferentes tamanhos é tão mais acentuada quanto maior for a dissipação. Uma análise mais detalhada do comportamento de eventos de diferentes tamanhos será apresentada na seção 3.2.

Uma conclusão importante da caracterização detalhada que foi feita desse efeito de borda, que não depende do tamanho do sistema, é que a distância necessária para ignorá-lo por completo, $\mathrm{L}_{\mathrm{b}} \sim 100$, invalida o estudo do modelo com redes pequenas, $\mathrm{L} \lesssim 300$. Redes desse tamanho seriam dominadas por eventos pertencentes ao efeito de borda. Como esse efeito independe do tamanho do sistema, ele deve ser desprezível no limite termodinâmico, onde dominaria a ocorrência de epicentros no interior do reticulado. Uma parte significativa da literatura sobre o modelo OFC se baseia em resultados obtidos com reticulados onde o efeito de borda é dominante. Mesmo quando o reticulado é grande o suficiente para que a ocorrência de epicentros no interior seja significativa, para os valores de L acessíveis computacionalmente atualmente, muitas vezes a maior parte dos eventos ainda acorre bem próximo à borda (conforme a figura 3.1.2, obtida para $L=1000$ ). Esses eventos são raramente excluídos ou analisados à parte na maioria dos estudos já publicados sobre o modelo. 


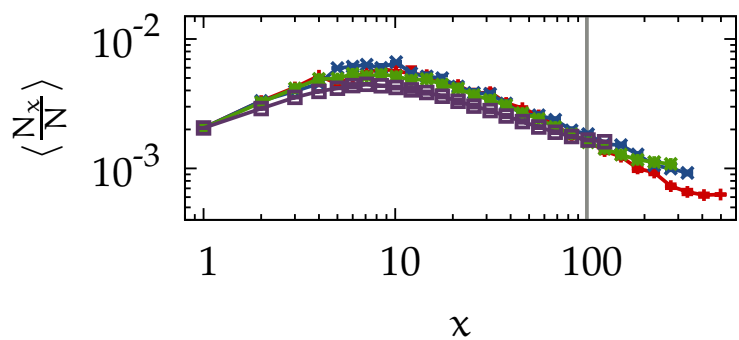

(a) $\alpha=0.25$

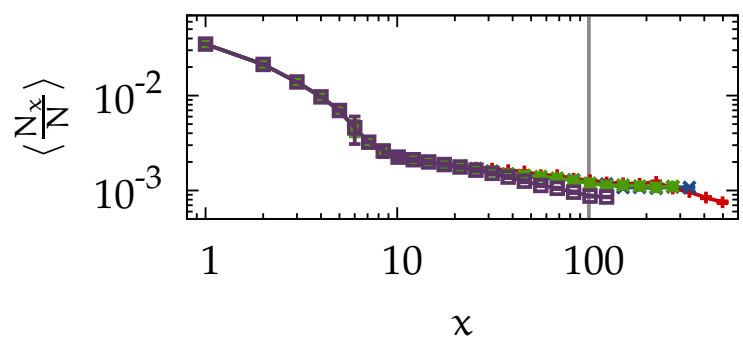

(c) $\alpha=0.24$

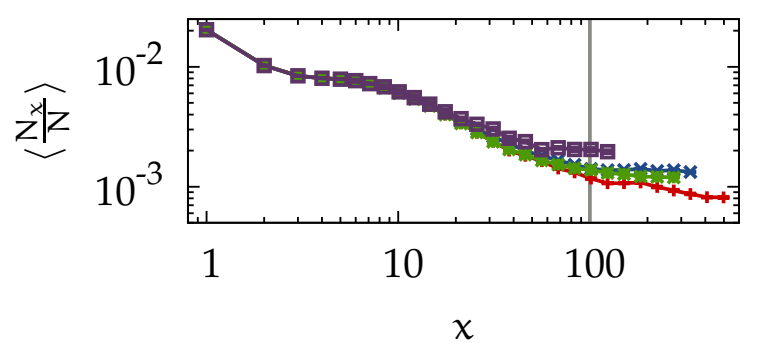

(e) $\alpha=0.20$

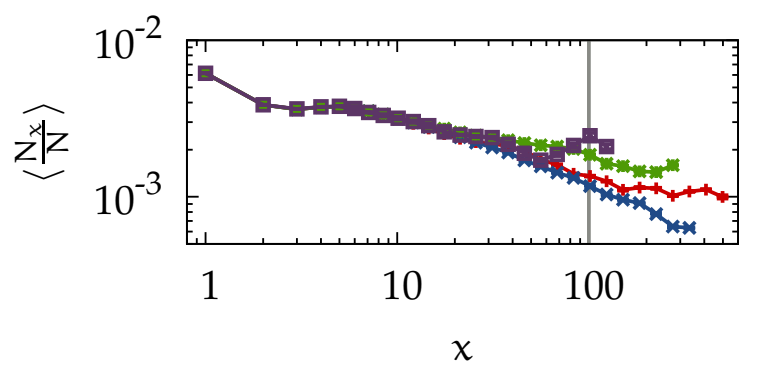

(g) $\alpha=0.16$

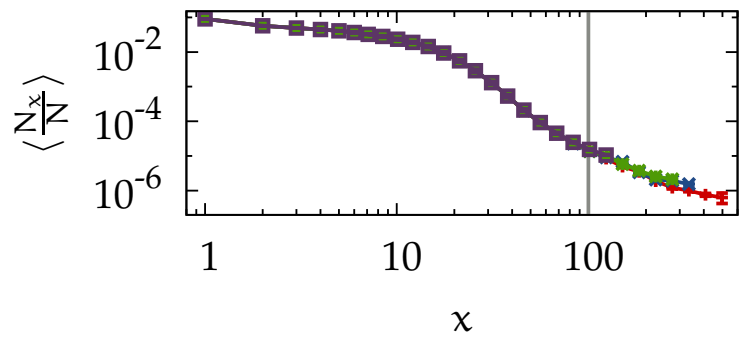

(b) $\alpha=0.249$

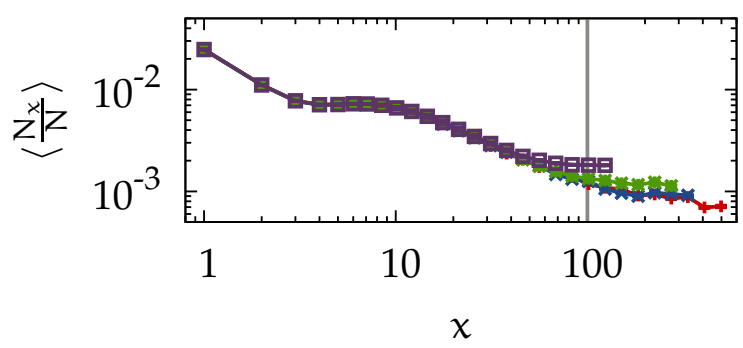

(d) $\alpha=0.22$

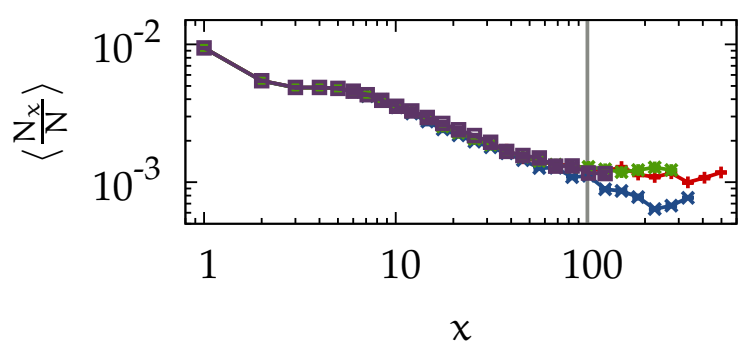

(f) $\alpha=0.18$

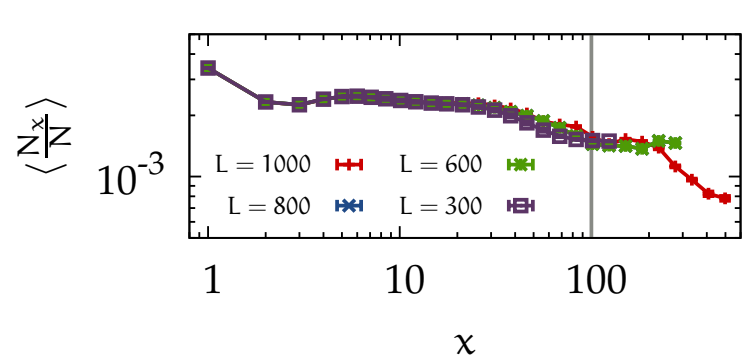

(h) $\alpha=0.14$

Figura 3.1.4: Taxa média de ocorrência de epicentros $\left\langle N_{x} / N\right\rangle$, em função da distância $x$ da borda mais próxima, para diversos tamanhos $L$ e valores de $\alpha$. 


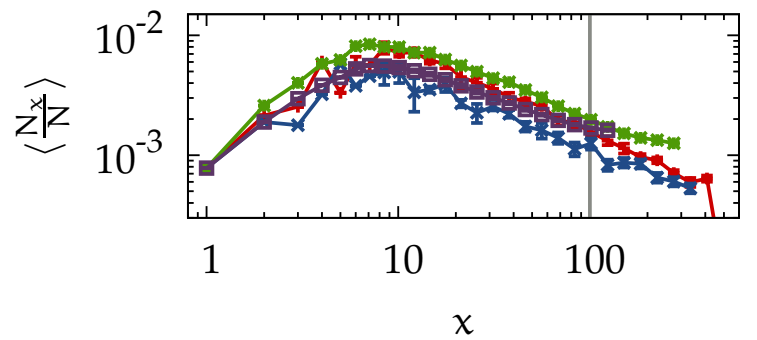

(a) $\alpha=0.25$

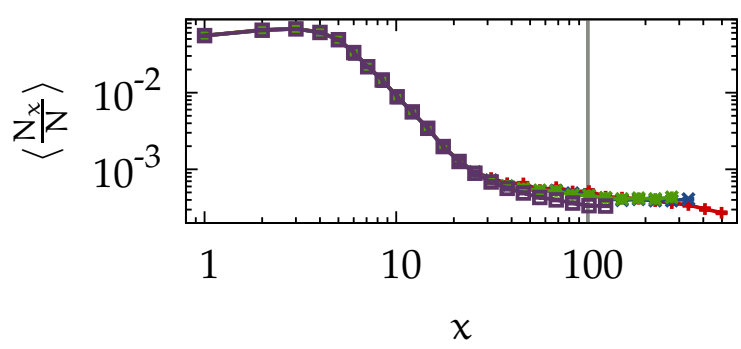

(c) $\alpha=0.24$

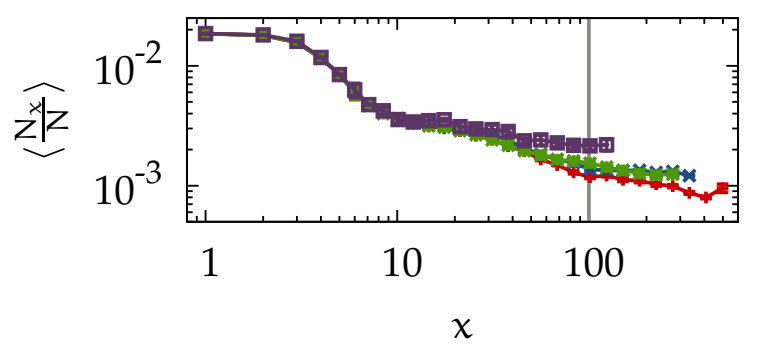

(e) $\alpha=0.20$

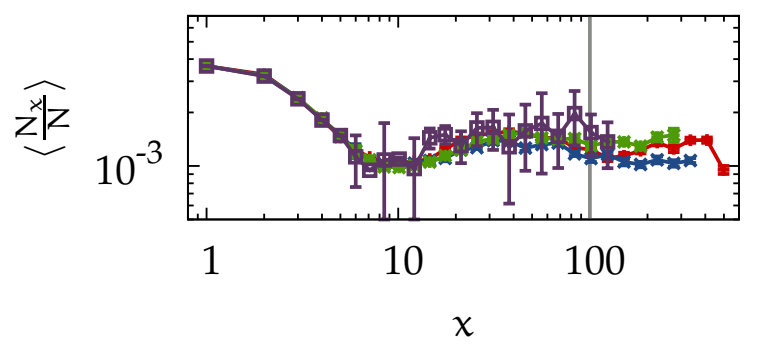

(g) $\alpha=0.16$

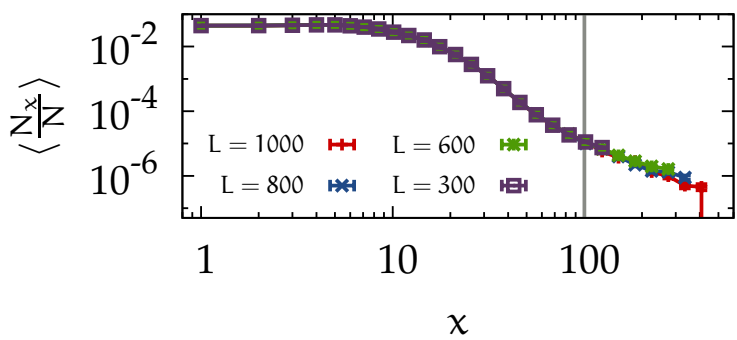

(b) $\alpha=0.249$

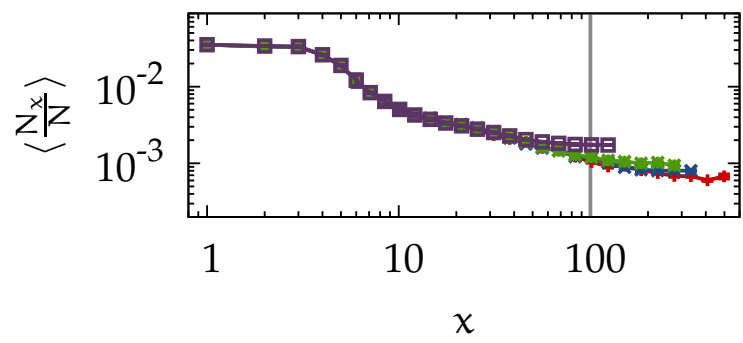

(d) $\alpha=0.22$

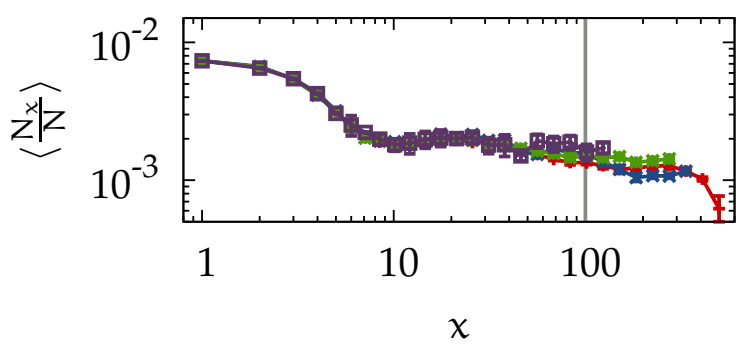

(f) $\alpha=0.18$

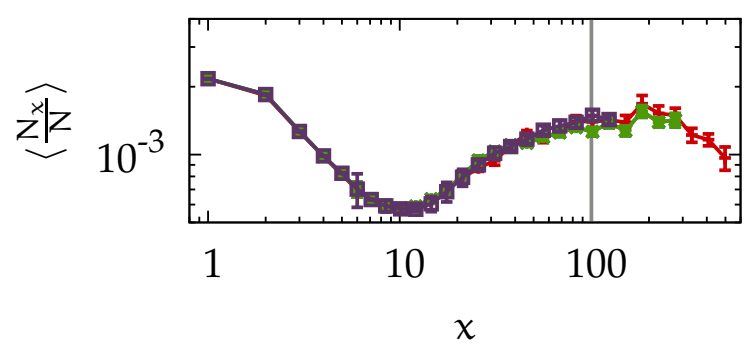

(h) $\alpha=0.14$

Figura 3.1.5: Taxa média de ocorrência de epicentros $\left\langle N_{x} / N\right\rangle$, em função da distância $x$ da borda mais próxima, para diversos tamanhos $L$ e valores de $\alpha$, somente para eventos de tamanho $s>100$. 


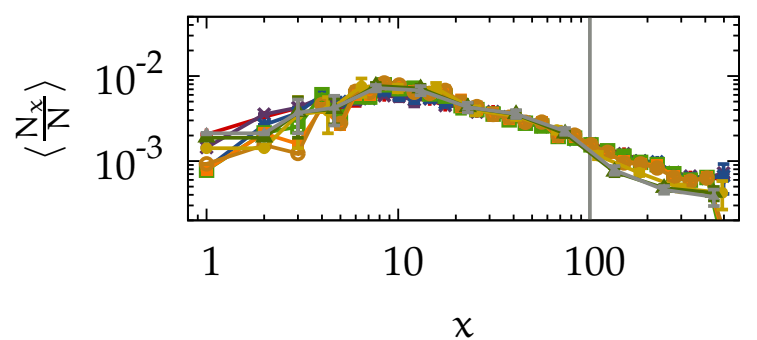

(a) $\alpha=0.25$

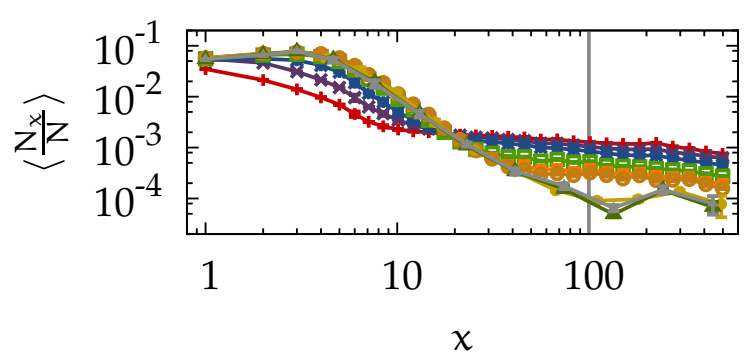

(c) $\alpha=0.24$

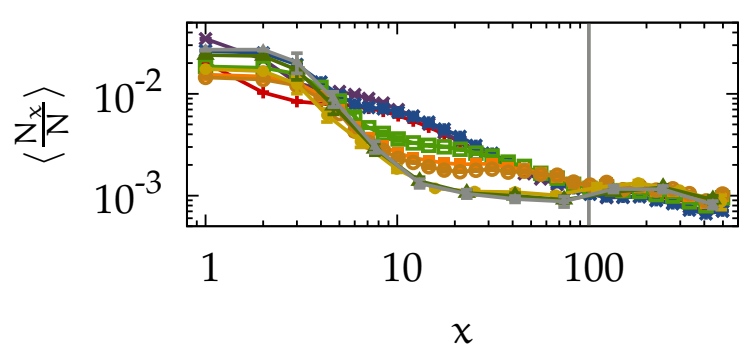

(e) $\alpha=0.20$

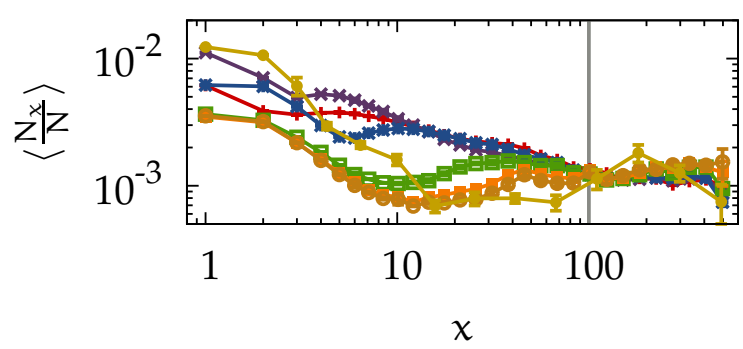

(g) $\alpha=0.16$

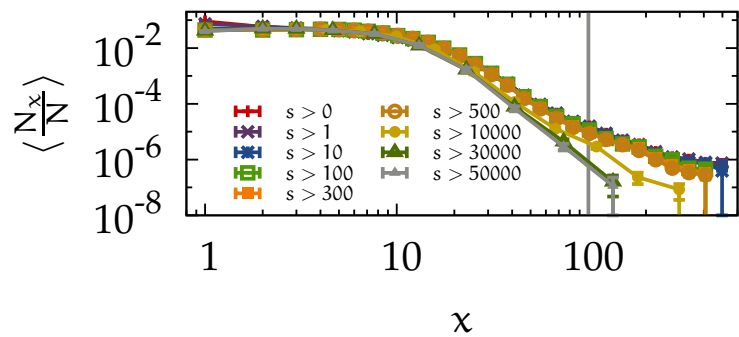

(b) $\alpha=0.249$

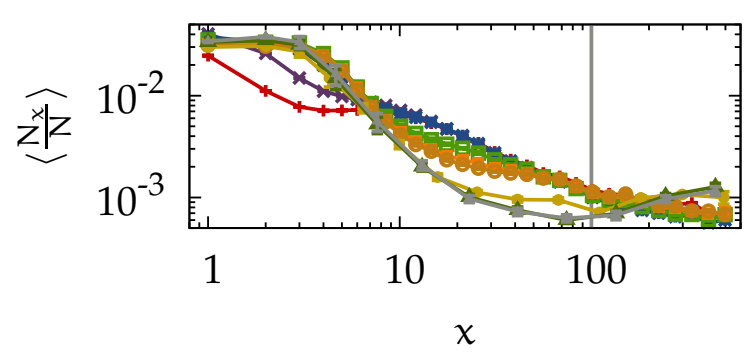

(d) $\alpha=0.22$

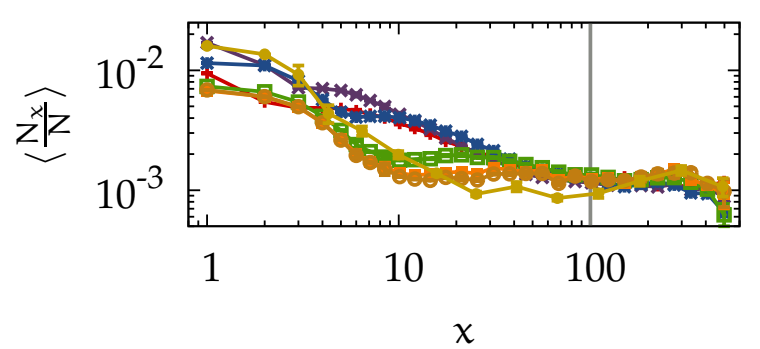

(f) $\alpha=0.18$

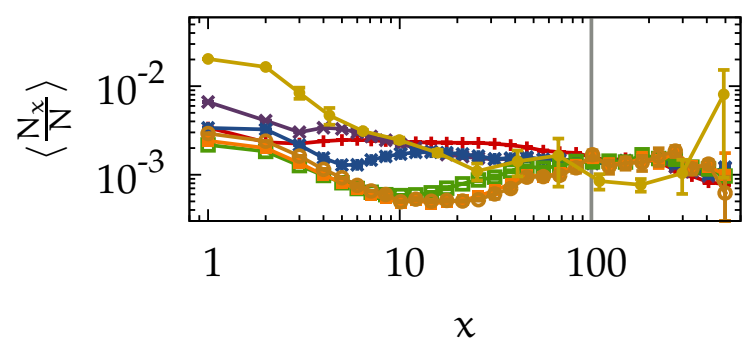

(h) $\alpha=0.14$

Figura 3.1.6: Taxa média de ocorrência de epicentros $\left\langle N_{x} / N\right\rangle$, em função da distância $x$ da borda mais próxima, para tamanho $L=1000$, diversos valores de $\alpha$, e de tamanho de eventos s. 


\subsection{Propriedades espaciais dos eventos}

Eventos de diferentes tamanhos se distribuem espacialmente no reticulado de acordo com a disposição de tensões num dado instante, que possui uma estrutura autoorganizada não-óbvia (ver figura 2.1.4). Eventos bem pequenos, $s \sim 1$, possuem um número limitado de configurações espaciais possíveis, e, por isso, não são fortemente dependentes das correlações espaciais existentes no reticulado. Sabe-se, por exemplo, que eventos de tamanho $s=1$ não necessitam de nenhuma auto-organização, já que ocorrem de maneira trivial quando $\alpha=0$. Eventos de tamanho $s=2$, por exemplo, não devem ser muito diferentes. Eventos grandes, porém, podem se distribuir espacialmente de maneira quase arbitrária, e possuem uma disposição no reticulado que reflete diretamente as correlações espaciais de tensão. Deve existir, portanto, uma transição no comportamento dos eventos, conforme maior for o tamanho destes. Nesse sentido, não se pode dizer que o comportamento do sistema é completamente livre de escala. Resta somente tentar identificar uma escala específica, acima da qual o comportamento dos eventos não varie mais com o tamanho. Eventos abaixo desse limite inferior seriam qualitativamente distintos dos que estão acima, e somente esses, portanto, teriam comportamento que poderia ser considerado livre de escala.

As propriedades espaciais que serão consideradas para tentar identificar essa transição se baseiam em considerar o menor retângulo necessário para conter todos os sítios que participaram do evento, e são as seguintes (ver figura 3.2.1): 1) Distância $|\vec{R}|$ do epicentro ao centro do retângulo ("distância de difusão"1), 2) A razão $\Delta x / \Delta y$ do retângulo envolvente (a deformação do evento) ${ }^{2}$, e 3) A razão entre a área do retângulo e área do evento, $\Delta x \Delta y / a$ (a esparcidade do evento).

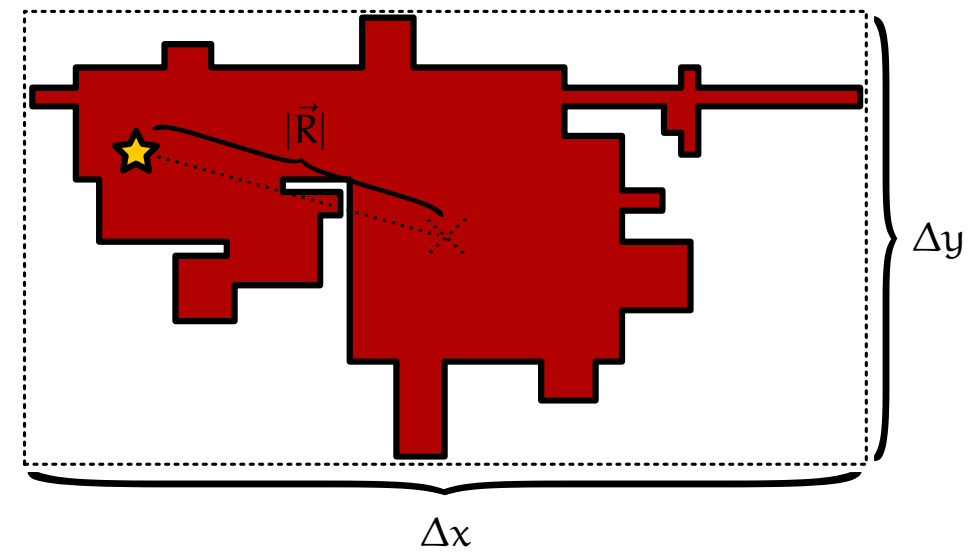

Figura 3.2.1: Propriedades geométricas dos eventos: A distância de difusão, $|\vec{R}|$, a deformação do evento, $\Delta x / \Delta y$, e a esparcidade do evento, $\Delta x \Delta y / a$, onde a é a área do evento.

\footnotetext{
${ }^{1}$ Essa distância é comparável ao "raio de giro" [64], se fosse considerado o centro de massa do evento, ao invés do centro do retângulo. Essa distância é estudada usualmente em problemas de caminhantes aleatórios [64] e animais de reticulado [65].

${ }^{2}$ É importante notar que a orientação nesse caso não é importante, e $\Delta x$ representa sempre o maior lado do retângulo.
} 


\subsubsection{Avalanches aleatórias}

Antes de analisar a distribuição espacial dos eventos do modelo OFC, é útil saber o que seria esperado para um evento aleatório ocorrendo no reticulado, que não dependesse de correlações espaciais. Como o número de configurações possíveis também aumenta com o tamanho dos eventos nesse caso, simplesmente pelo fato do evento ocorrer num reticulado, também deverá existir uma transição no comportamento dos eventos. Obtendo essa transição, seria possível verificar quanto os eventos do modelo OFC diferem espacialmente de eventos aleatórios.

A evento aleatório a ser considerado aqui é uma variação do problema conhecido como caminho aleatório discreto sem retorno (self-avoiding random walk [64]), onde um andarilho começa numa posição específica de um reticulado, e a cada passo, se move em qualquer direção, com igual probabilidade, mas sem voltar para uma posição pela qual ele já passou anteriormente ${ }^{3}$. Essa limitação muda fundamentalmente o processo, que deixa de ser Markoviano, i.e., um determinado passo do caminho depende de todos os passos anteriores. Essa diferença faz com que nesse caso, ao contrário do problema do caminhante aleatório usual, seja muito mais difícil a obtenção de resultados analíticos, e a maioria dos resultados existentes na literatura foram obtidos somente numericamente [64].

Existem algumas diferenças importantes entre caminhos aleatórios usuais e sem retorno. Como o andarilho não pode retornar a uma posição anterior (o que é chamado de "exclusão de volume"), o movimento desse tende a se expandir mais para longe da origem, com alguma direção que é privilegiada na fase inicial do caminhada, o que torna a difusão não-esférica [64]. A distância quadrática média do andarilho à origem cresce com

$$
\left\langle R^{2}\right\rangle \sim n^{1.5},
$$

para $n \gg 1$, onde $n$ é o número de passos. Isso difere de caminhos aleatórios com retorno, onde a dependência em $n$ é linear. Além disso, o caminho aleatório sem retorno pode simplesmente terminar, se o andarilho ficar "preso", sem nenhuma direção possível para prosseguir. De fato, o número médio de passos até que isso aconteça é 71, para o caso bidimensional [64].

A modificação feita aqui para a comparação com o modelo OFC é a possibilidade de ramificação, onde um determinado andarilho pode dar origem a outros andarilhos em todas as direções possíveis, cada um com probabilidade $p$. Para $p=0$ recuperase o problema do caminhante aleatório sem retorno usual. Na figura 3.2.2 podem ser vistos alguns caminhos (avalanches) aleatórios para alguns valores de $p$. Conforme maior o valor de $p$, maiores e mais densos são, em média, os eventos.

As propriedades espaciais de interesse podem então ser medidas numericamente para os diversos valores de $p$, conforme mostra a figura 3.2.3. Observa-se que a inclusão de ramificação, quando $p>0$, modifica fundamentalmente o comportamento do processo. A distância de difusão, para $p=0$, varia com o mesmo expoente que a distancia média do andarilho (equação 3.2.1). Esse expoente diminui, porém, conforme $p$ aumenta. A esparcidade dos eventos muda continuamente conforme se aumenta

\footnotetext{
${ }^{3}$ A proibição de retornos é necessária, já que para $\alpha<(\sqrt{2}-1) / 2 \approx 0.207$ um sítio não pode relaxar mais que uma vez no mesmo evento no modelo OFC (ver seção 2.1.2, página 10), e mesmo para valores de $\alpha$ ligeiramente acima desse limite a ocorrência de repetições é muito rara.
} 


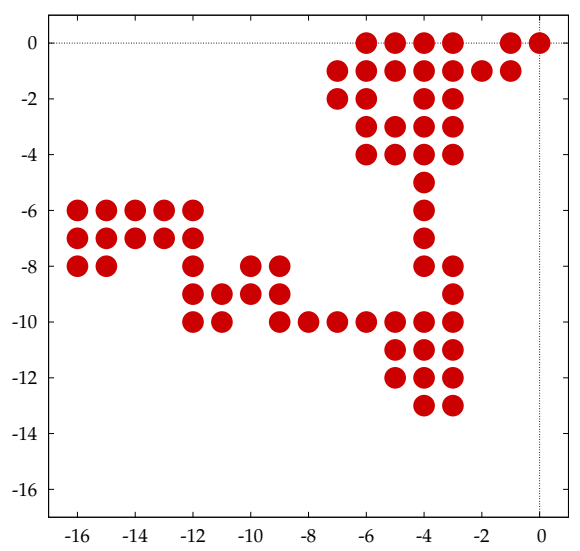

(a) $p=0$

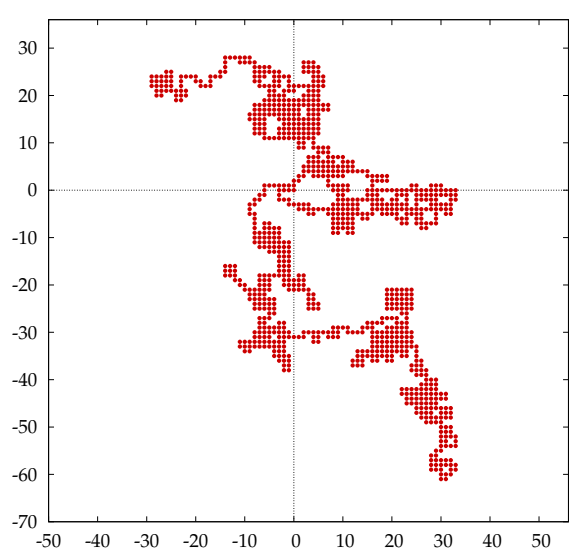

(c) $p=0.02$

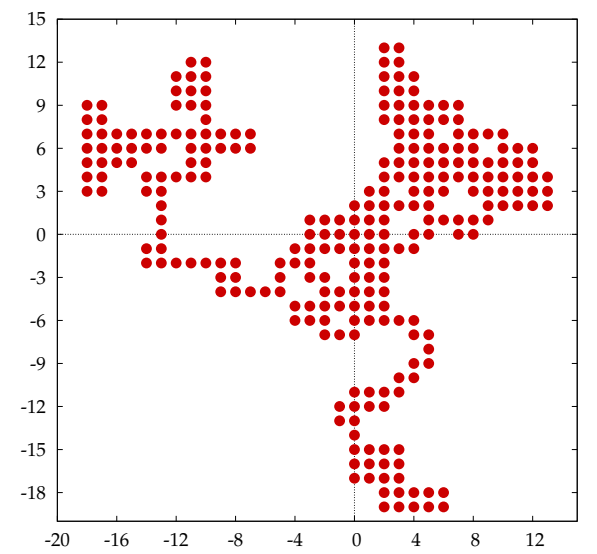

(b) $p=0.01$

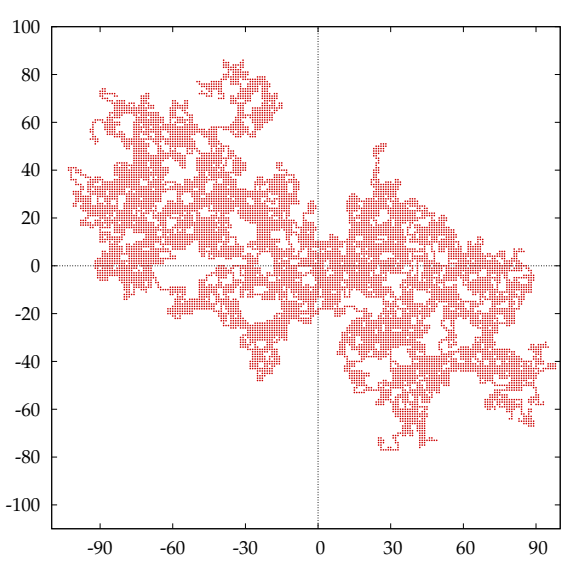

(d) $p=0.04$

Figura 3.2.2: Algumas avalanches aleatórias, para alguns valores de $p$.

a ramificação, e a partir de um determinado $p \approx 0.4$, decresce com o tamanho do evento. A deformação do evento também muda com a ramificação, e é progressivamente menor quanto maior for o valor de $p$, e o tamanho do evento. Interessantemente, para $p=0$, a deformação aumenta com o tamanho do evento, devido a exclusão de volume já mencionada. Para qualquer $p$, porém, é observado $\langle\Delta x / \Delta y\rangle>1$ para os eventos maiores, i.e., o evento é sempre, em média, não-esférico.

\subsubsection{Eventos do modelo OFC}

Sabendo como avalanches aleatórias se comportam, é possível voltar para o estudo das propriedades espaciais dos eventos do modelo OFC. Na figura 3.2.4 estão as três propriedades analisadas ${ }^{4}$, para uma rede de tamanho $\mathrm{L}=1000$ e diferentes valores de $\alpha$. Conforme o que foi discutido na seção 3.1, foram ignorados eventos perten-

\footnotetext{
${ }^{4}$ Tanto na figura 3.2.4, quanto nas demais a seguir, estão marcados os tamanhos $s=300$ e $s=$ 30000. Somente eventos dentro dessa faixa foram considerados para estudo em partes posteriores do trabalho, pois estão, para a maioria dos valores de $\alpha$, acima da escala de eventos "pequenos" e abaixo dos efeitos de tamanho finito.
} 


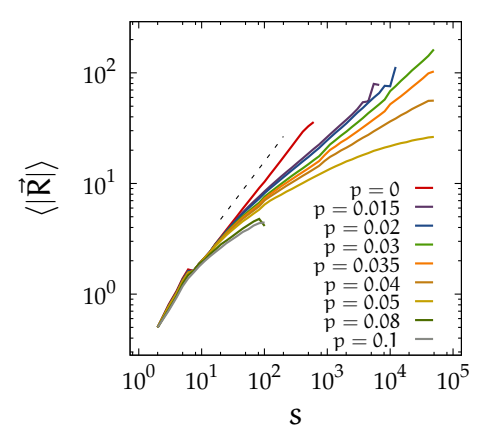

(a) Distância de difusão $|\vec{R}|$

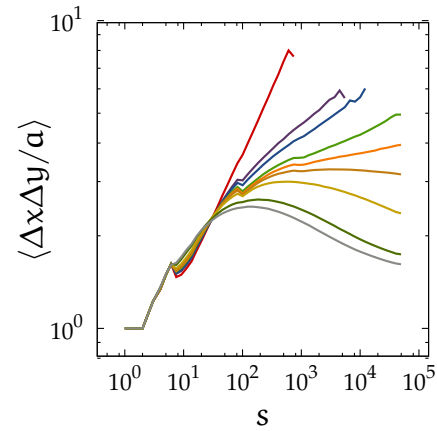

(b) esparcidade, $\Delta x \Delta y / a$

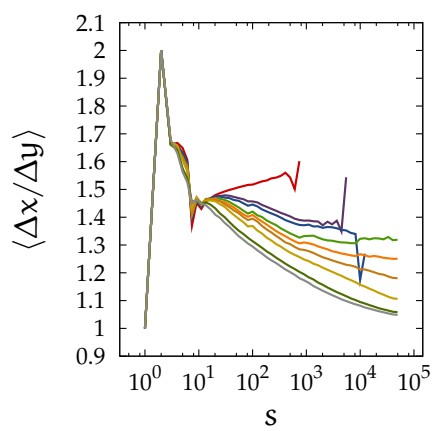

(c) Deformação, $\Delta x / \Delta y$

Figura 3.2.3: Características espaciais médias para avalanches aleatórias de diferentes tamanhos $s$, com diferentes valores de $p$. A linha tracejada na figura (a) representa um crescimento do tipo $s^{0.75}$.

centes à camada exterior do reticulado, de espessura $L_{B}=100$, para evitar o efeito de borda. Na figura 3.2.4 pode-se, também, comparar com o comportamento de uma avalanche aleatória, com $p=0.035$ (considerado o valor mais adequado para comparação).

Novamente se observa uma diferença qualitativa drástica entre o regime conservativo e não-conservativo do modelo. Para $\alpha=1 / 4$, a esparcidade é somente um pouco menor do que as dos outros valores, porém as outras grandezas diferem bastante: A difusão é dada por um expoente completamente diferente, e a deformação das avalanches é bem menor. Adicionalmente, os eventos do modelo OFC (mesmo para $\alpha=1 / 4$ ) se comportam de maneira bem distinta de eventos aleatórios, como descritos na sessão anterior. Em primeiro lugar, a distância de difusão $|\vec{R}|$ parece crescer de acordo com

$$
\langle|\vec{R}|\rangle \sim s^{v},
$$

com expoente $v \approx 0.48$, que não depende fortemente em $\alpha$ (exceto para $\alpha=1 / 4$ ). O expoente $v$ da avalanche aleatória depende de $p$, logo seria possível encontrar um valor desse parâmetro que reproduza o mesmo expoente do modelo OFC. Porém, isso implicaria em um outro expoente para a esparcidade (ver a seguir), e os dois expoentes não seriam simultaneamente iguais aos do modelo OFC, para um mesmo valor de p. Além disso, a difusão dada pela equação 3.2.2 só é observada no modelo OFC para eventos maiores, da ordem de $10^{2}$, e para avalanches aleatórias essa difusão começa a ser observada pare eventos menores, da ordem de $10^{1}$. A esparcidade é bem mais parecida entre os dois tipos de eventos, e evolui de maneira semelhante (para esse valor de $p$ ), e permanece constante para eventos a partir de um certo tamanho $10^{2}$. O valor absoluto, porém, da esparcidade de eventos grandes parece depender de $\alpha$. O que mais difere de eventos aleatórios é a deformação dos eventos, que é bastante acentuada para eventos menores, $\sim 10^{1}$, e decresce a partir de um certo tamanho, e permanece aproximadamente constante para eventos maiores, além de ser acima do esperado para avalanches aleatórias. A deformação dos eventos não parece também depender fortemente do parâmetro $\alpha$ (exceto, novamente, para $\alpha=1 / 4$ ). 


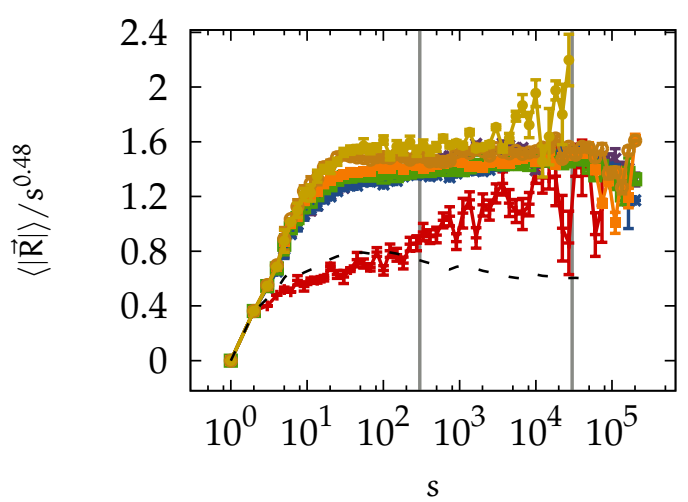

(a) Distância de difusão $|\vec{R}|$

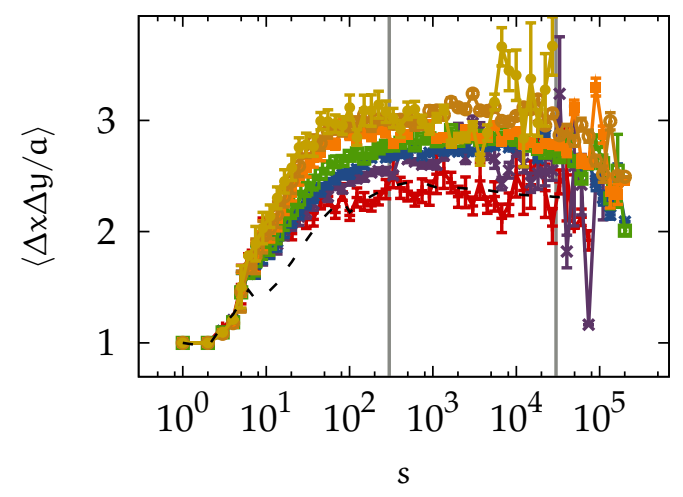

(b) Esparcidade, $\Delta x \Delta y / a$

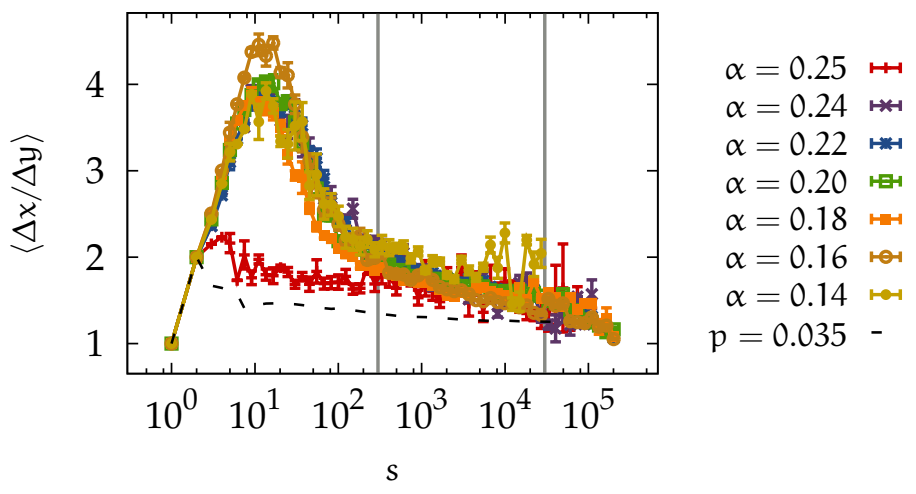

(c) Deformação, $\Delta x / \Delta y$

Figura 3.2.4: Características espaciais médias para eventos do modelo OFC de diferentes tamanhos $s$, com diferentes valores de $\alpha$. A linha tracejada corresponde a uma avalanche aleatória $\operatorname{com} p=0.035$.

A alta deformação média dos eventos do modelo OFC, que pode chegar na ordem de 4 para eventos de tamanho $s \sim 10$, indica que grande parte desses pequenos eventos estão dispostos de maneira próxima a uma linha reta no reticulado. Isso pode ser verificado pela distribuição de deformações $\mathrm{P}(\Delta x / \Delta y)$, na figura 3.2.5. A distribuição $\mathrm{P}(\Delta \mathrm{x} / \Delta \mathrm{y})$ é bastante larga para $\alpha<1 / 4$, e na faixa de tamanhos $s \in[10,150]$. Para $\mathrm{s} \in[100,150]$ e $\alpha=0.24$, a figura 3.2.5b mostra que algumas avalanches tiveram deformação próxima a $10^{2}$, i.e., quase linhas retas perfeitas. Para valores menores de $\alpha$ a distribuição não é tão larga, mas é mais abrangente do que o esperado para o caso aleatório (figura 3.2.6). Para avalanches maiores $s \gtrsim 1000$, a distribuição se afina, e eventos mais deformados se tornam mais raros. De acordo com essa diferença na deformação espacial, os eventos menores parecem possuir de fato uma dinâmica distinta dos maiores. As regras de evolução são sempre as mesmas, independentemente do tamanho do evento. Porém, eventos de diferentes tamanhos possuem, a que tudo indica, evolução espaço-temporal distintas, que dependem das correlações de tensões. Eventos que se distribuem em linhas retas, por exemplo, teriam uma taxa de ramificação $0^{5}$ constante $\sigma=1$, durante a avalanche (desconsiderando o último rela-

\footnotetext{
${ }^{5}$ Ver página 17.
} 
xamento, que tem $\sigma=0$ ). Eventos maiores, distribuídos bidimensionalmente, teriam taxas de ramificação dinâmicas que dependeria de cada sítio específico.

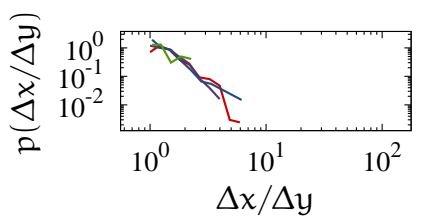

(a) $\alpha=0.25$

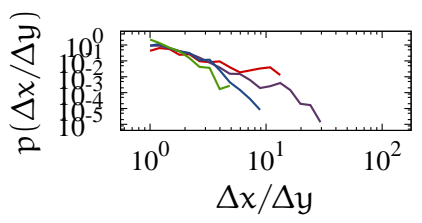

(d) $\alpha=0.20$

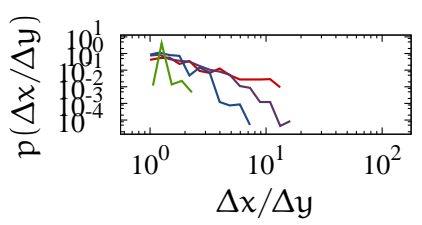

(g) $\alpha=0.14$

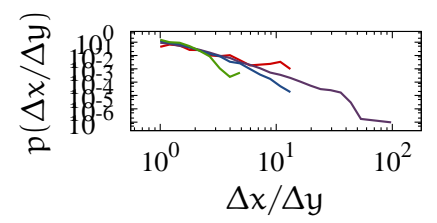

(b) $\alpha=0.24$

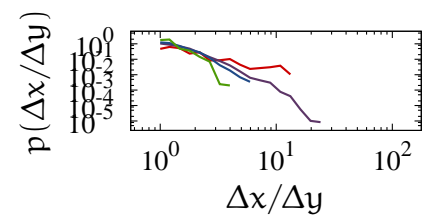

(e) $\alpha=0.18$

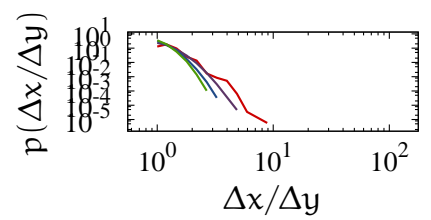

(h) $p=0.035$

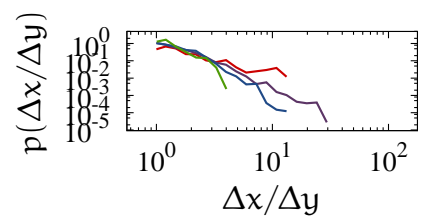

(c) $\alpha=0.22$

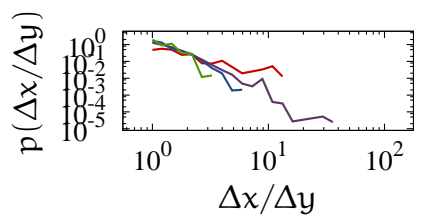

(f) $\alpha=0.16$

$s \in[10,15]-\quad s \in[1000,1500]-$ $s \in[100,150]-\quad s \in[10000,15000]-$

Figura 3.2.5: Distribuição de deformações $P(\Delta x / \Delta y)$, para $L=1000$ diversos valores de $\alpha$, e para avalanches aleatórias $\operatorname{com} p=0.035$.

\section{Variação com o tamanho do reticulado}

Em potencial, as propriedades espaciais dos eventos apresentadas acima podem depender do tamanho do reticulado, e serem, portanto, afetadas por efeitos de tamanho finito, como o cut-off observado para eventos grandes em todas as figuras correspondentes. Vale, portanto, verificar como as propriedades mudam com o tamanho do reticulado. Nas figuras 3.2.7, 3.2.8 e 3.2.9 estão as variações com tamanho do reticulado da distância de difusão, esparcidade e deformação, respectivamente, para os diversos valores de $\alpha$. Sem exceção, os resultados para os diferentes tamanhos diferem unicamente no cut-off existente para os eventos maiores. Dessa maneira, todas as propriedades espaciais observadas devem ser válidas para o limite termodinâmico $\mathrm{L} \rightarrow \infty$. Nesse caso todas os eventos acima de um certo valor $s \sim 10^{2}$ devem ser qualitativamente idênticos, de acordo com as características analisadas.

\section{Variação com a proximidade da borda}

Eventos que se iniciam perto da borda do reticulado são vinculadas ao efeito de borda já descrito, e se dispõem, potencialmente, de maneira específica no reticulado. Para checar essa dependência estrutural dos eventos com a proximidade da borda, nas figuras 3.2.10, 3.2.11 e 3.2.12 estão as variações com a proximidade da borda da distância de difusão, esparcidade e deformação, respectivamente, para os diversos va- 


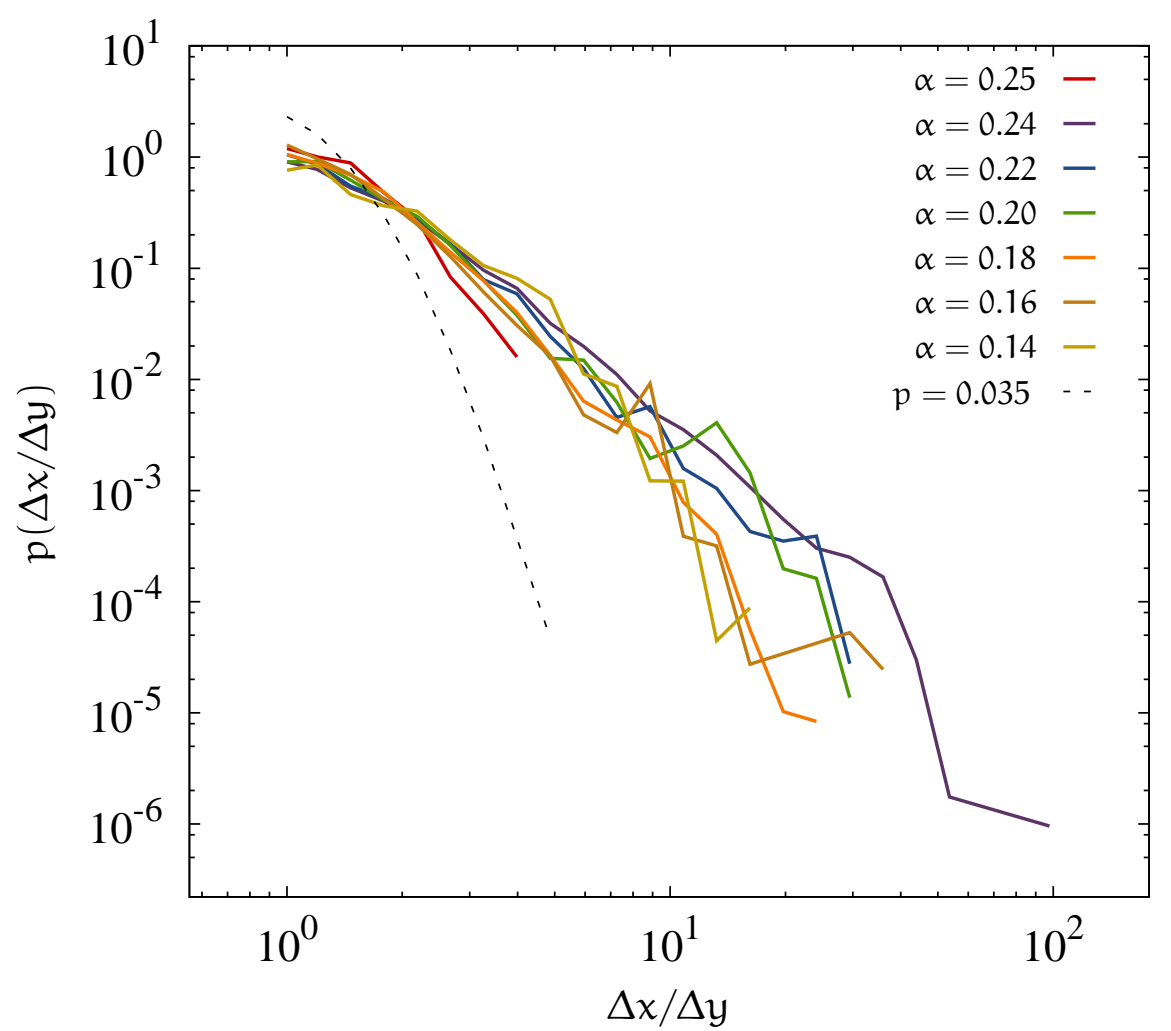

Figura 3.2.6: Distribuição de deformações $\mathrm{P}(\Delta x / \Delta y)$, com $s \in[100,150]$, para $\mathrm{L}=1000$ diversos valores de $\alpha$, e para avalanches aleatórias $\operatorname{com} p=0.035$.

lores de $\alpha$ e $L=1000$. Com exceção da esparcidade, são observadas diferenças nas propriedades espaciais dos eventos que se iniciam próximos a borda, até uma distância $L_{B} \approx 100$. Eventos iniciados nessa região externa do reticulado se difundem de maneira diferente, e são menos deformados, do que os que se iniciam e permanecem no interior de reticulado. Para valores de $L_{B} \gtrsim 100$, os eventos passam a exibir as mesmas propriedades. Essa estabilidade indica que o interior do reticulado, que não é afetado pelo efeito de borda, foi alcançado com $L_{B} \approx 100$, conforme discutido na seção 3.1. 


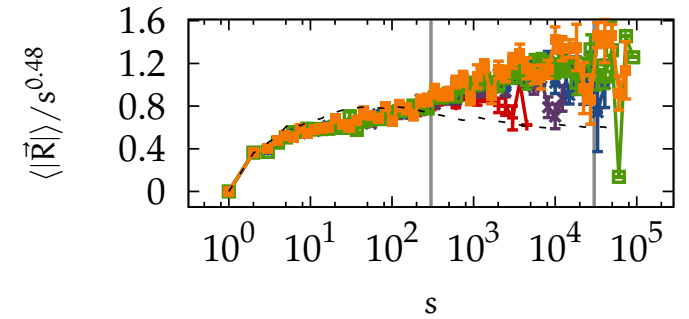

(a) $\alpha=0.25$

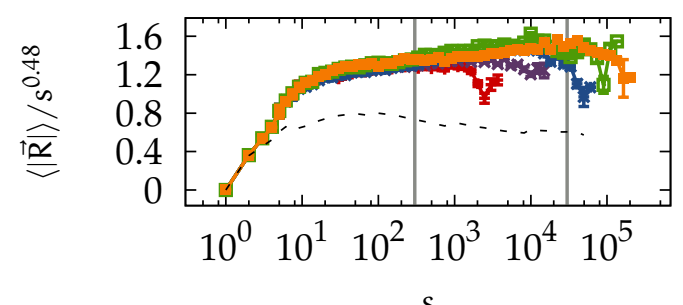

(c) $\alpha=0.22$

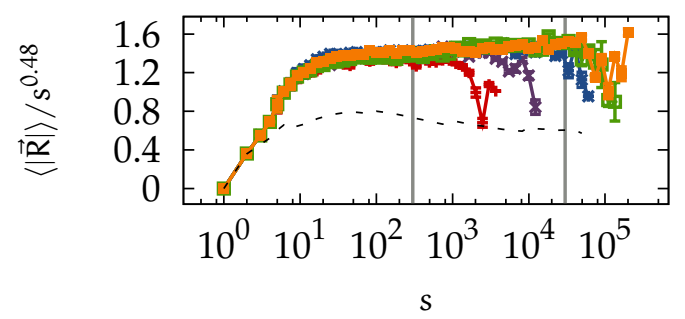

(e) $\alpha=0.18$

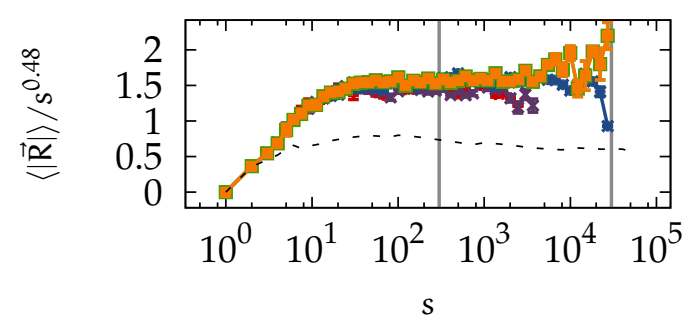

(g) $\alpha=0.14$

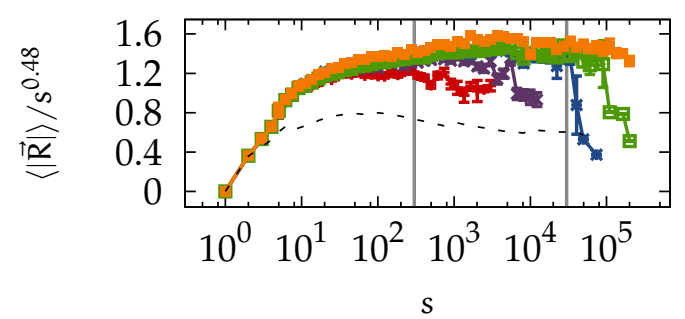

(b) $\alpha=0.24$

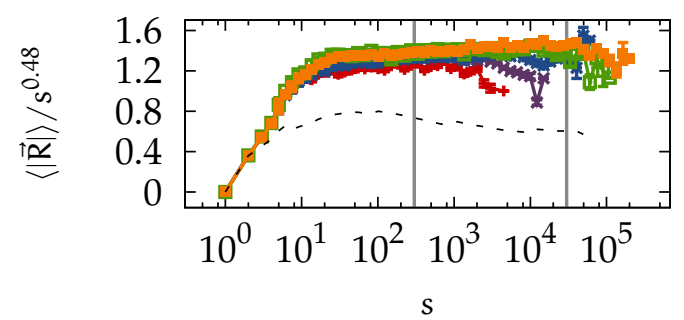

(d) $\alpha=0.20$

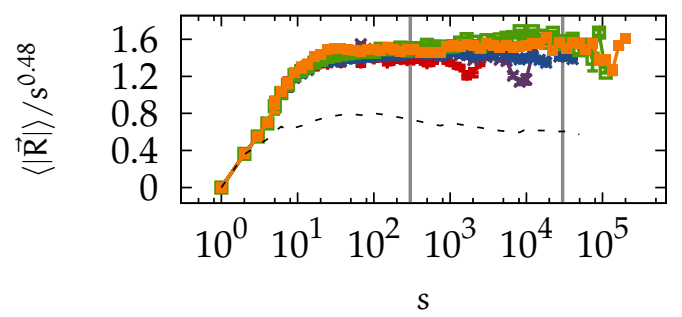

(f) $\alpha=0.16$

$$
\begin{aligned}
& \mathrm{L}=300 \\
& \mathrm{~L}=400 \\
& \mathrm{~L}=600
\end{aligned}
$$

Figura 3.2.7: Distância de difusão $|\vec{R}|$ em função do tamanho dos eventos, para diferentes tamanhos do reticulado L, e valores do parâmetro $\alpha$. A linha tracejada corresponde a uma avalanche aleatória $\operatorname{com} p=0.035$. 


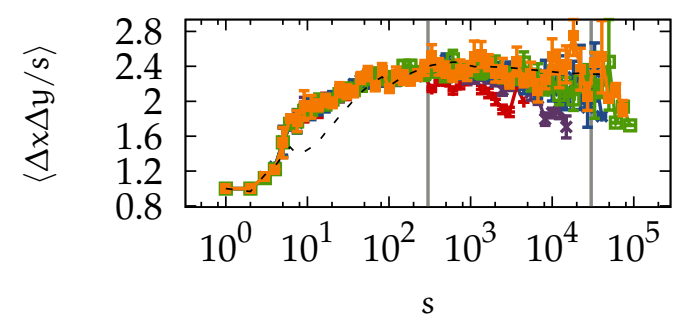

(a) $\alpha=0.25$

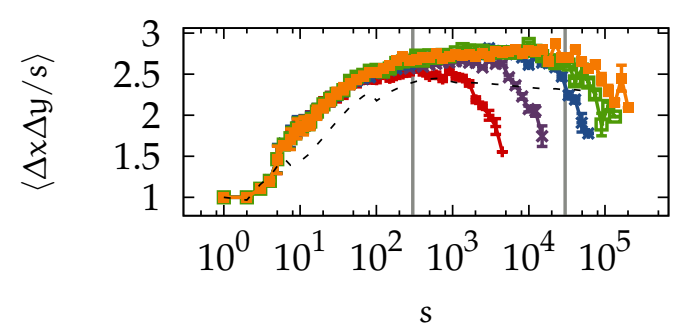

(c) $\alpha=0.22$

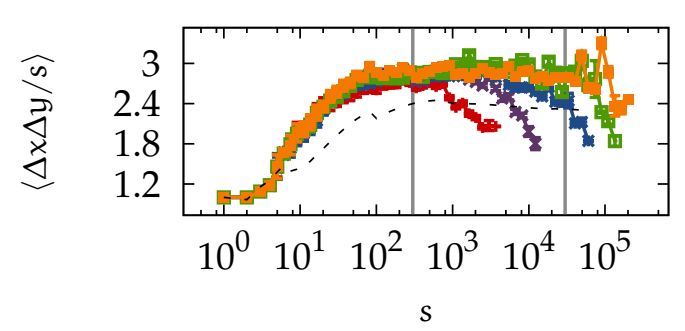

(e) $\alpha=0.18$

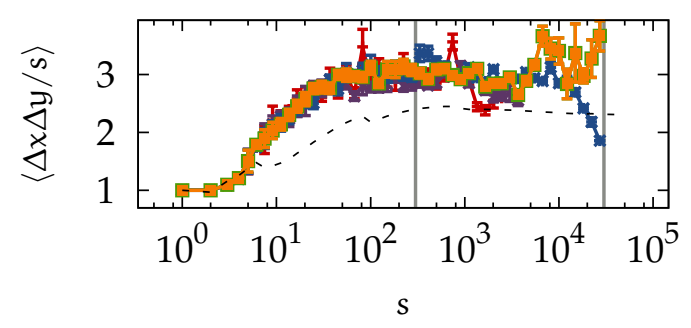

(g) $\alpha=0.14$

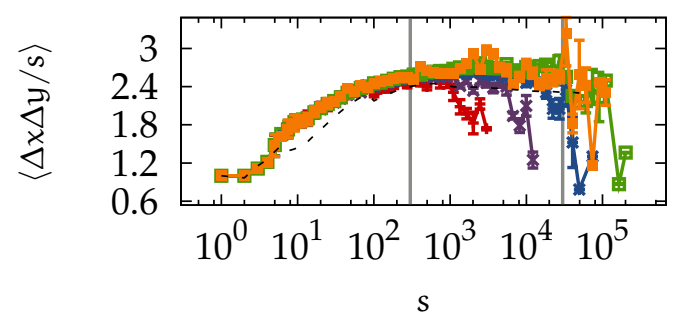

(b) $\alpha=0.24$

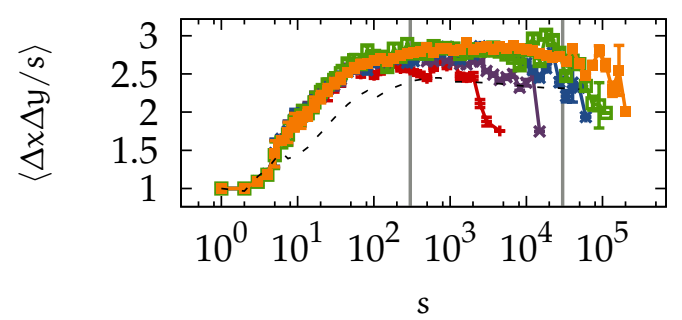

(d) $\alpha=0.20$

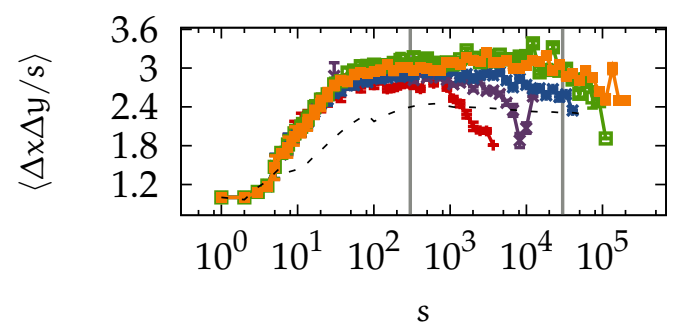

(f) $\alpha=0.16$

$$
\begin{aligned}
& \mathrm{L}=300 \mapsto \quad \mathrm{L}=800 \\
& \mathrm{~L}=400 \\
& \mathrm{~L}=600 \ldots+1000
\end{aligned}
$$

Figura 3.2.8: Esparcidade $\Delta x \Delta y / s$ em função do tamanho dos eventos, para diferentes tamanhos do reticulado $\mathrm{L}$, e valores do parâmetro $\alpha$. A linha tracejada corresponde a uma avalanche aleatória com $p=0.035$. 


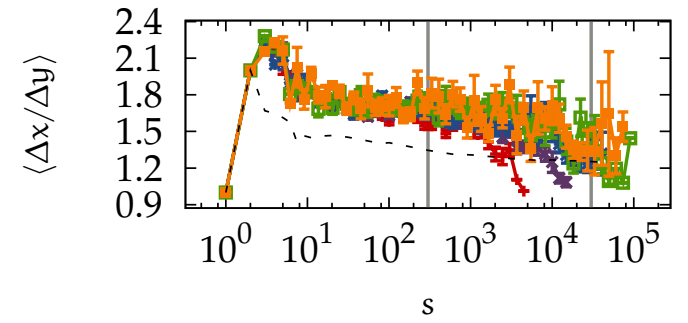

(a) $\alpha=0.25$

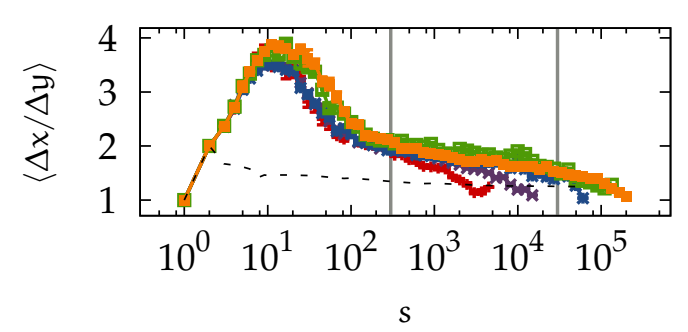

(c) $\alpha=0.22$

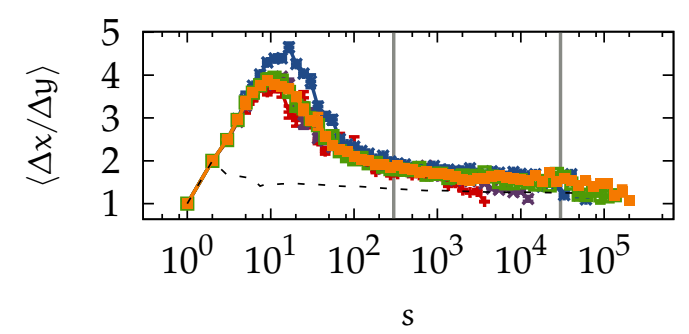

(e) $\alpha=0.18$

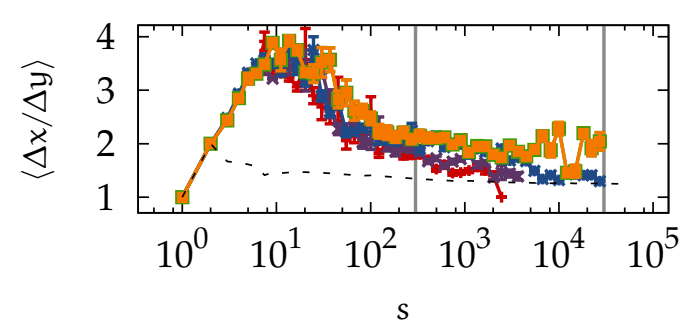

(g) $\alpha=0.14$

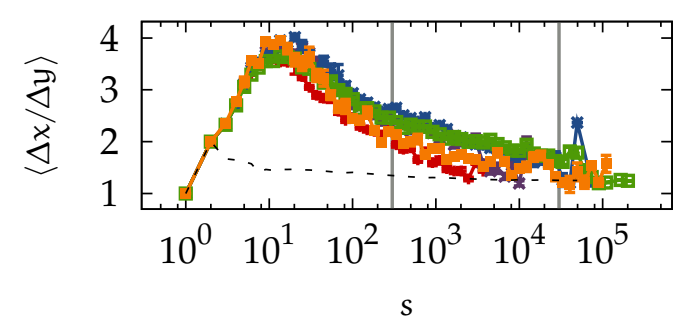

(b) $\alpha=0.24$

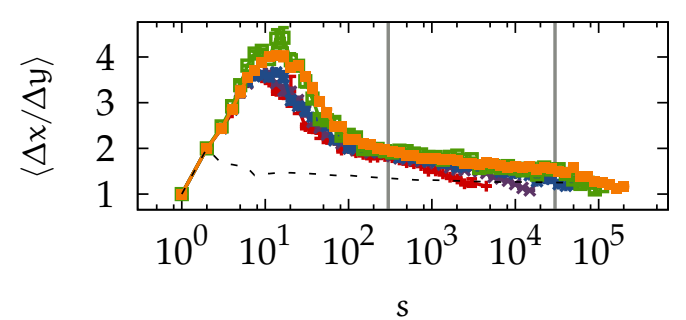

(d) $\alpha=0.20$

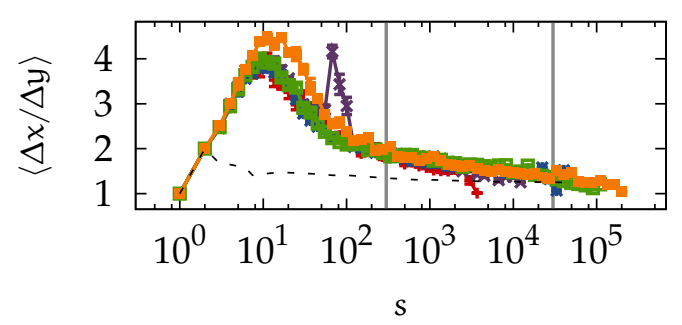

(f) $\alpha=0.16$

Figura 3.2.9: Deformação $\Delta x / \Delta y$ em função do tamanho dos eventos, para diferentes tamanhos do reticulado $\mathrm{L}$, e valores do parâmetro $\alpha$. A linha tracejada corresponde a uma avalanche aleatória com $p=0.035$. 


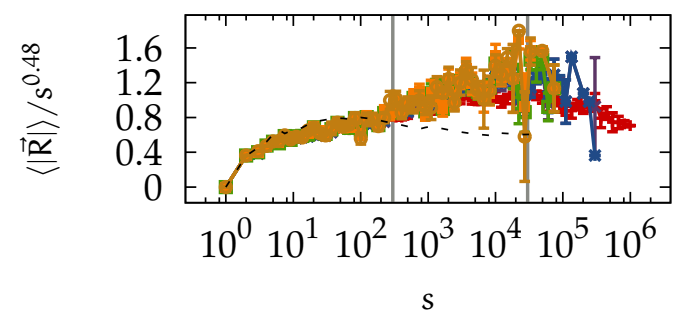

(a) $\alpha=0.25$

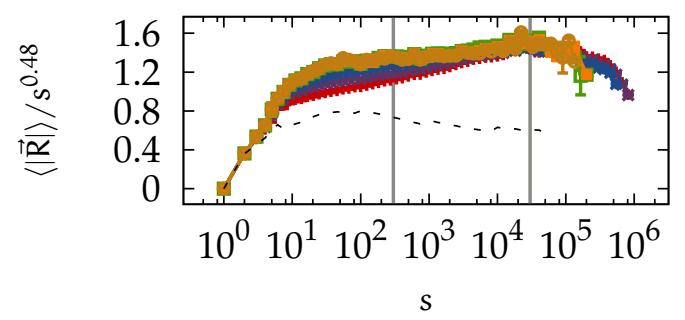

(c) $\alpha=0.22$

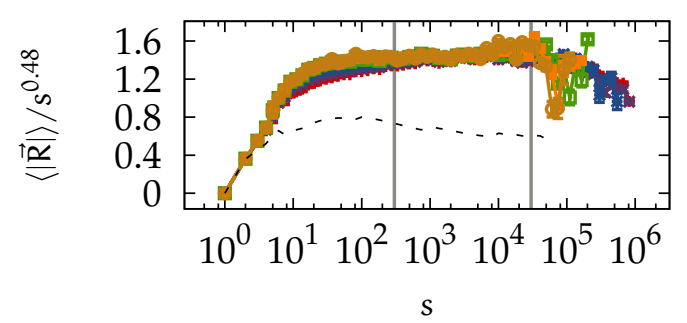

(e) $\alpha=0.18$

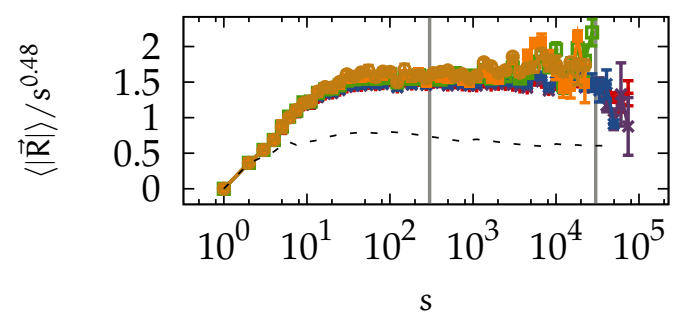

(g) $\alpha=0.14$

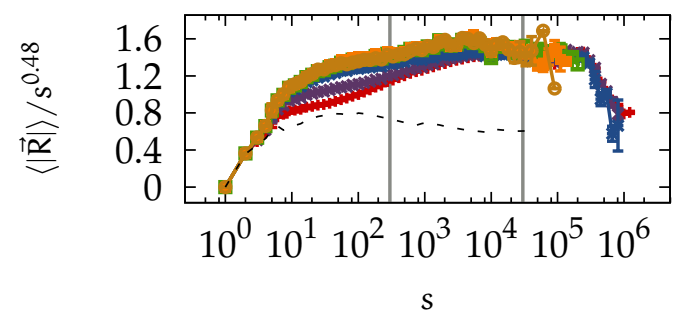

(b) $\alpha=0.24$

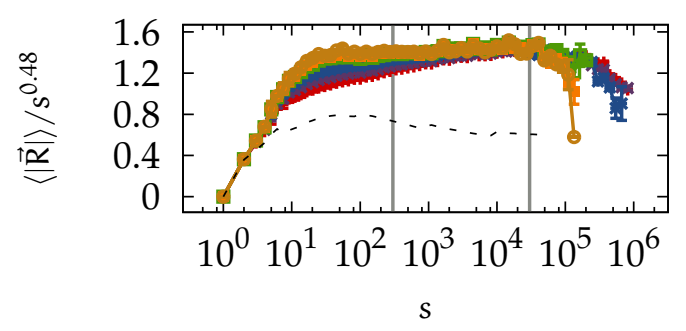

(d) $\alpha=0.20$

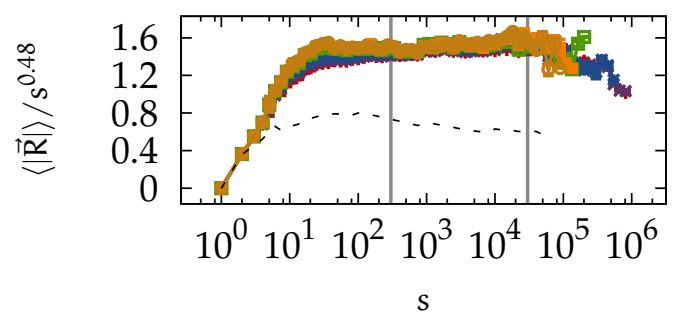

(f) $\alpha=0.16$

$$
\begin{array}{rll}
L_{B}=0 & L_{B}=100 \\
L_{B}=1 & L_{B}=150 \\
L_{B}=10 & L_{B}=200
\end{array}
$$

Figura 3.2.10: Distância de difusão $|\vec{R}|$ em função do tamanho dos eventos, para $L=100$ e diferentes tamanhos da borda excluída $L_{B}$, e valores do parâmetro $\alpha$. A linha tracejada corresponde a uma avalanche aleatória com $p=0.035$. 


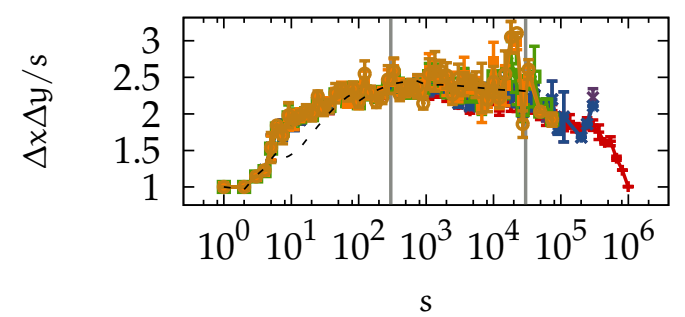

(a) $\alpha=0.25$

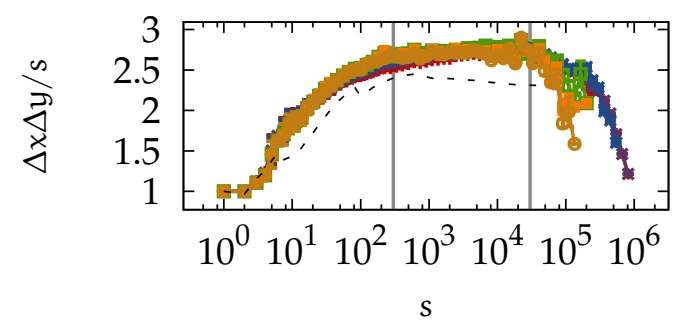

(c) $\alpha=0.22$

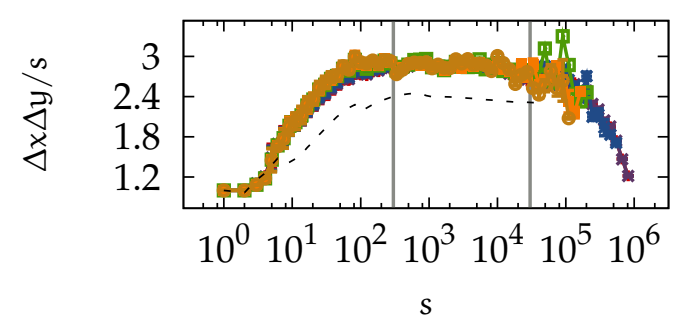

(e) $\alpha=0.18$

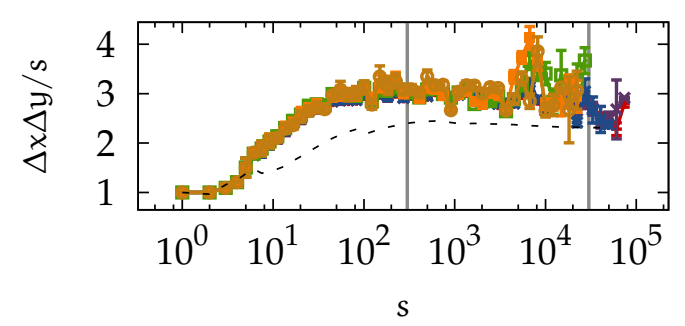

(g) $\alpha=0.14$

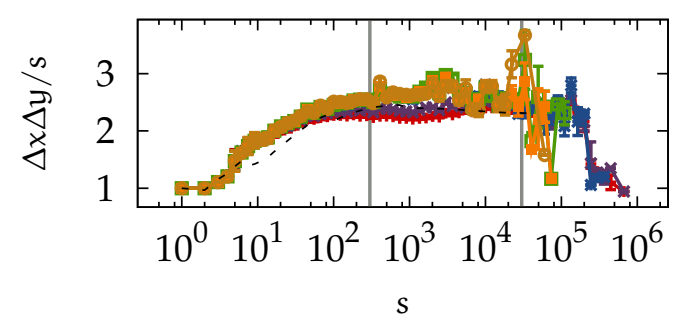

(b) $\alpha=0.24$

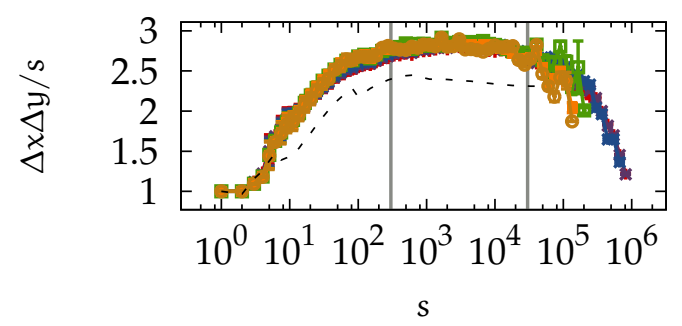

(d) $\alpha=0.20$

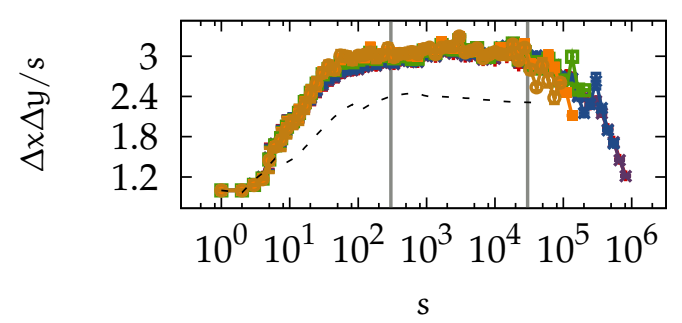

(f) $\alpha=0.16$

$$
\begin{aligned}
& L_{B}=0 L_{B}=100 \\
& L_{B}=1 L_{B}=150 \\
& L_{B}=10
\end{aligned}
$$

Figura 3.2.11: Esparcidade $\Delta x \Delta y / s$ em função do tamanho dos eventos, para $\mathrm{L}=100$ e diferentes tamanhos da borda excluída $\mathrm{L}_{\mathrm{B}}$, e valores do parâmetro $\alpha$. A linha tracejada corresponde a uma avalanche aleatória $\operatorname{com} p=0.035$. 


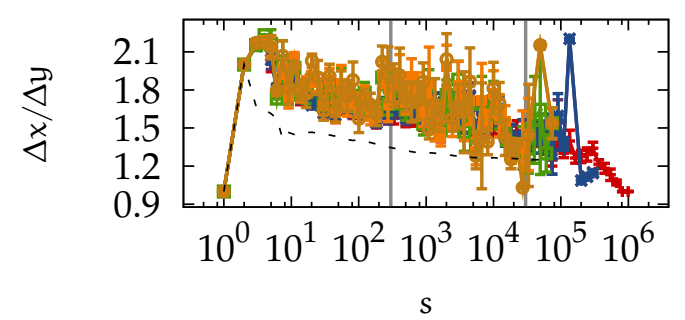

(a) $\alpha=0.25$

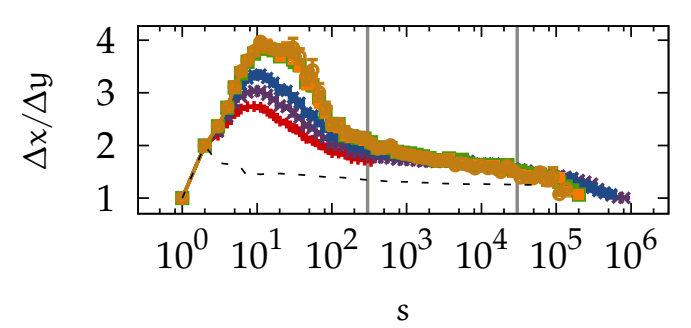

(c) $\alpha=0.22$

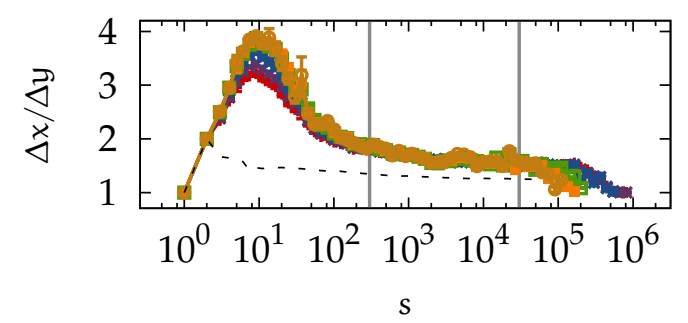

(e) $\alpha=0.18$

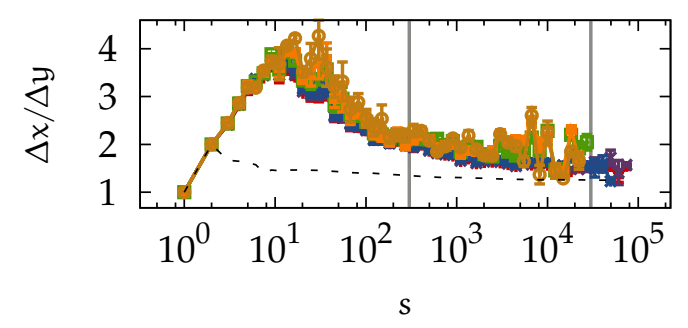

(g) $\alpha=0.14$

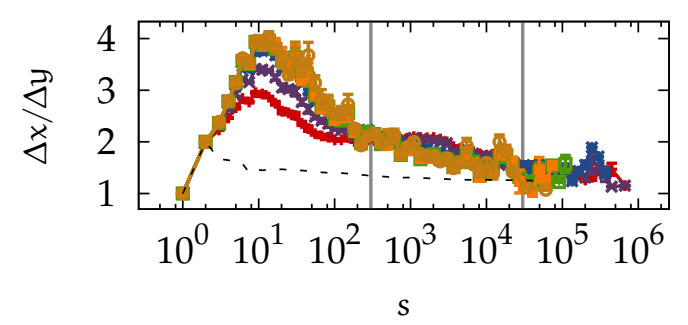

(b) $\alpha=0.24$

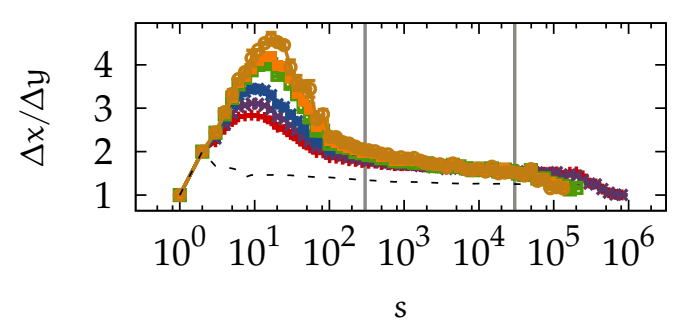

(d) $\alpha=0.20$

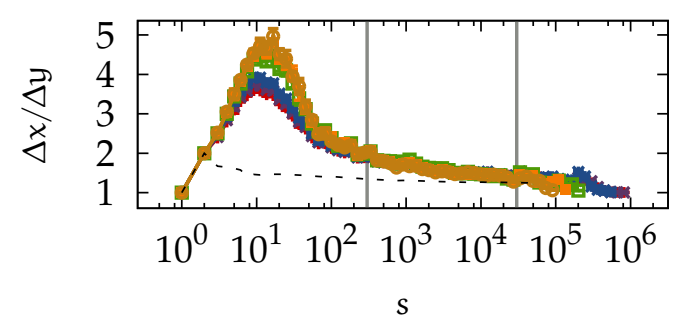

(f) $\alpha=0.16$

$$
\begin{aligned}
L_{B}=0 & L_{B}=100 \\
L_{B}=1 & L_{B}=150 \\
L_{B}=10 & L_{B}=200
\end{aligned}
$$

Figura 3.2.12: Deformação $\Delta x / \Delta y$ em função do tamanho dos eventos, para $\mathrm{L}=100$ e diferentes tamanhos da borda excluída $\mathrm{L}_{\mathrm{B}}$, e valores do parâmetro $\alpha$. A linha tracejada corresponde a uma avalanche aleatória com $p=0.035$. 


\subsection{Variação da taxa de ramificação}

As propriedades espaciais descritas nas seções anteriores permitem a diferenciação dos eventos, de maneira geral, em quatro tipos distintos: 1) Eventos afetados pelo efeito de borda do reticulado; 2) Eventos no interior do reticulado não afetados pela borda; 3) Eventos pequenos, próximos ao tamanho fundamental do reticulado; e 4) eventos grandes, cujas propriedades espaciais não dependem do seu tamanho. De particular interesse são os eventos do tipo 2, que representam melhor o modelo no limite termodinâmico, e os eventos do tipo 4, que representam uma dinâmica livre de escala. A seguir será apresentada uma análise da taxa de ramificação média do modelo, que tentará determinar como a criticalidade do modelo está relacionada com esses diferentes tipos de eventos. O objetivo é comparar os resultados obtidos para a taxa de ramificação média, isolando alguns dos tipos acima, com o esperado para um fenômeno critico, e com o que já foi obtido na literatura [45,48].

O ansatz principal utilizado é que a distribuição $\mathrm{P}(\mathrm{s})$ de tamanho de eventos $s$ segue uma lei de potência,

$$
P(s)= \begin{cases}A s^{-\gamma} & \text { para } s \in[S, C] \\ 0 & \text { para } s \notin[S, C]\end{cases}
$$

onde $S$ e $C$ são os limites inferior e superior do tamanho de eventos existentes, e $A$ é uma constante de normalização ${ }^{6}$. O tamanho médio de eventos é, então,

$$
\langle s\rangle=(\gamma-1) \frac{C^{2-\gamma}-S^{2-\gamma}}{S^{1-\gamma}-C^{1-\gamma}} \approx(\gamma-1) C^{2-\gamma} S^{\gamma-1}
$$

para $C \gg S$. A taxa média de ramificação $\sigma$ de um evento de tamanho $\langle s\rangle$ é simplesmente

$$
\sigma=1-\frac{1}{\langle s\rangle}
$$

Tomando o valor de $\mathrm{C}$ como sendo simplesmente o cut-off devido ao tamanho finito da rede, tem-se então $C \propto\left(L-2 L_{B}\right)^{2}$, onde $L$ é o tamanho linear da rede e $L_{B}$ é a largura da borda externa ignorada. A expressão da taxa média de ramificação fica, então,

$$
1-\sigma=\frac{S^{1-\gamma}}{(\gamma-1)\left(L-2 L_{B}\right)^{2(2-\gamma)}},
$$

onde obtém-se o resultado esperado $\sigma=1$ (processo crítico) somente para $\mathrm{L} \rightarrow \infty$, quando $\langle s\rangle \rightarrow \infty$.

A equação 3.3.4 pode ser usada para avaliar se a dependência de $\sigma$ com $L$ e $S$ é compatível com o ansatz da equação 3.3.1. Na figura 3.3.1 pode-se ver a variação de $\sigma$ por $1 / \mathrm{L}$, para diversos valores de $S$ e $\alpha$, considerando o reticulado inteiro, $L_{B}=$ 0 . As diversas curvas foram re-escaladas na direção $y$, em função de $S$, de acordo com a equação 3.3.4 e conforme indicado na legenda da figura. Pode-se ver que há um colapso das curvas somente para $S>2$, indicando que eventos de tamanhos

\footnotetext{
${ }^{6} \mathrm{~A}$ forma especifica dos cut-off inferiores e superioras não foi considerada importante, e variações descontínuas são usadas somente por simplicidade.
} 
1 e 2 não são distribuídos de acordo com a equação 3.3.1. As diferenças espaciais identificadas na sessão anterior, que separam eventos maiores e menores que $s \sim 100$, não são observadas aqui, já que somente a distribuição de tamanhos é importante, e apenas eventos $s \leqslant 2$ se distribuem de uma maneira significativamente diferente. Há, porém, um comportamento diferente entre esses pequenos eventos e os demais. Na figura 3.3.1 foram ajustadas funções do tipo

$$
\sigma(L)=\sigma^{\prime}-\frac{b}{L^{a}}
$$

onde $a, b$ e $\sigma^{\prime}$ são parâmetros do ajuste, tanto para $S=1$ quanto para $S=1000$. A equação 3.3.5 representa um ansatz simplista da variação de $\sigma$ com $\mathrm{L}$, que tem o limite $\lim _{\mathrm{L} \rightarrow \infty} \sigma(\mathrm{L})=\sigma^{\prime}$. Os valores do ajuste para $\sigma^{\prime}$ e a estão na tabela 3.1. Para diversos valores apresentados a imprecisão do ajuste não permite discernir com clareza se o valor de $\sigma^{\prime}$ é compatível com criticalidade ou não (esses casos estão assinalados com um asterisco na tabela 3.1). Essa incerteza é devida predominantemente ao número pequeno de tamanhos de reticulados usados. Uma análise mais definitiva deveria ser feita, portanto, usando um número maior de reticulados. É possível, porém, apesar das incertezas, usar os dados da tabela 3.1 para avaliar o impacto do efeito de borda e dos eventos "pequenos" na análise de criticalidade, como será feito a seguir.

Para $L_{B}=0$, quando a precisão do ajuste permite discernir, o cenário mais compatível é o de não-criticalidade, com $\sigma^{\prime}<1$ para $\alpha<1 / 4$, conforme argumentado por de Carvalho e Prado [45] (que ignoraram eventos de tamanho 1, como usual) ${ }^{7}$. Porém, a remoção dos eventos de tamanhos $s \leqslant 2$ resulta em um aumento de $\sigma^{\prime}$ (onde a precisão permite afirmar), o que mostra que a desproporção desses eventos menores causa, em maior parte, a diminuição da taxa de ramificação. Apesar disso, para $L_{B}=0$, o cenário mais provável permanece o de não-criticalidade.

Quando somente o interior do reticulado é considerado, de forma a ignorar o efeito de borda, com $L_{B}=100$, a taxa de ramificação $\sigma^{\prime}$ permanece inalterada para $S=1$, porém cresce sistematicamente para $S=1000$, como pode ser visto na figura 3.3.2 e na tabela 3.1 (conforme a precisão permite afirmar; ver nota de rodapé 7). Esse resultado está de acordo com o que foi obtido por Miller e Boulter [48], que calcularam a taxa de ramificação no interior do reticulado, e obtiveram valores maiores do que próximo da borda. Porém, ao contrário do obtido em [48], os resultados da tabela 3.1, dentro da precisão disponível, não permitem excluir a criticalidade para $\alpha>0.14$. Quando os eventos menores $s \leqslant 2$ são ignorados, os resultados obtidos não possibilitam a exclusão de criticalidade para nenhum valor de $\alpha$ estudado. A falta de precisão, devida ao número pequeno de valores de L analisados, como mencionado anteriormente, impossibilita uma afirmação mais categórica a respeito da criticalidade. O que se pode concluir, de maneira mais certa, é que tanto o efeito de borda, quanto os eventos pequenos, tem um papel importante na determinação da criticalidade do modelo, e eles não devem ser ignorados em uma análise definitiva.

\footnotetext{
${ }^{7}$ Os valores do ajuste para $\alpha \in[0.20,0.16]$ não permitem discernir se $\sigma^{\prime} \stackrel{?}{=} 1$, dentro da precisão obtida. Porém para valores maiores de $\alpha \in[0.22,0.24]$, o ajuste aponta para $\sigma^{\prime}<1$. É improvável, portanto, que se obtenha $\sigma^{\prime}=1$ para $\alpha \in[0.16,0.20]$, já que a tendência é que a taxa média de ramificação diminua conforme maior for a dissipação. O mesmo argumento vale para os valores de $\sigma^{\prime}$ para $\mathrm{L}_{\mathrm{B}}=100$ e $\mathrm{S}=1$.
} 


\begin{tabular}{l||l|l|l|l||l|l|l|l}
\multicolumn{1}{c||}{$\alpha$} & \multicolumn{9}{c||}{$\mathrm{L}_{\mathrm{B}}=0$} & \multicolumn{5}{c}{$\mathrm{L}_{\mathrm{B}}=100$} \\
\cline { 2 - 9 } & \multicolumn{1}{||}{$\sigma_{\mathrm{S}=1}^{\prime}$} & $\sigma_{\mathrm{S}=1000}^{\prime}$ & $\mathrm{a}_{\mathrm{S}=1}$ & $\mathrm{a}_{\mathrm{S}=1000}$ & $\sigma_{\mathrm{S}=1}^{\prime}$ & $\sigma_{\mathrm{S}=1000}$ & $\mathrm{a}_{\mathrm{S}=1}$ & $\mathrm{a}_{\mathrm{S}=1000}$ \\
\hline 0.25 & $1.0000000(7)$ & $1.0000000(15)$ & $2.418(15)$ & $2.39(3)$ & $0.999984(13)$ & $1.00027(3)$ & $1.801(18)$ & $1.13(2)$ \\
0.24 & $0.9969(2)$ & $1.00025(11)$ & $0.91(9)$ & $0.878(6)$ & $0.992(4)$ & $1.0159(3)$ & $0.55(3)$ & $0.4225(18)$ \\
0.22 & $0.9962(11)$ & $0.9967(3)$ & $0.063(3)$ & $0.918(18)$ & $0.994(7)^{*}$ & $1.007(8)^{*}$ & $0.64(4)$ & $0.52(8)$ \\
0.20 & $1.006(5)^{*}$ & $0.9963(5)$ & $0.49(4)$ & $0.72(2)$ & $1.000(4)^{*}$ & $1.008(4)^{*}$ & $0.58(2)$ & $0.47(4)$ \\
0.18 & $1.2(3)^{*}$ & $1.0057(19)^{*}$ & $0.14(12)$ & $0.399(18)$ & $1.04(2)^{*}$ & $1.0041(6)^{*}$ & $0.43(6)$ & $0.474(5)$ \\
0.16 & $1.2(4)^{*}$ & $0.9698(5)$ & $0.2(2)$ & $0.596(9)$ & $1.00(6)^{*}$ & $0.977(10)^{*}$ & $0.44(12)$ & $0.59(10)$ \\
0.14 & $0.883(6)$ & $0.94(4)^{*}$ & $0.346(9)$ & $0.4(5)$ & $0.842(16)$ & $0.97(2)^{*}$ & $0.52(5)$ & $0.44(9)$
\end{tabular}

Tabela 3.1: Resultados dos ajustes da função 3.3.5, para os dados das figuras 3.3.1 e 3.3.2. Os valores de $\sigma^{\prime}$ que não permitem discernir entre criticalidade e não-criticalidade, dentro da precisão obtida, estão assinalados com um asterisco. 


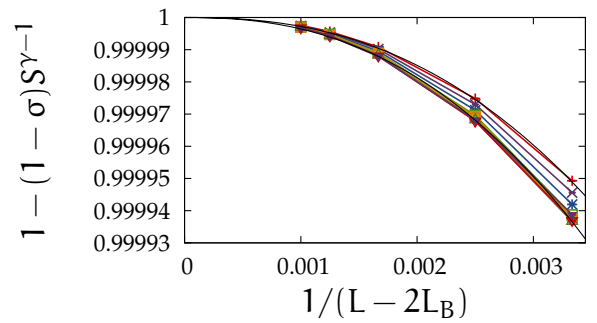

(a) $\alpha=0.25$

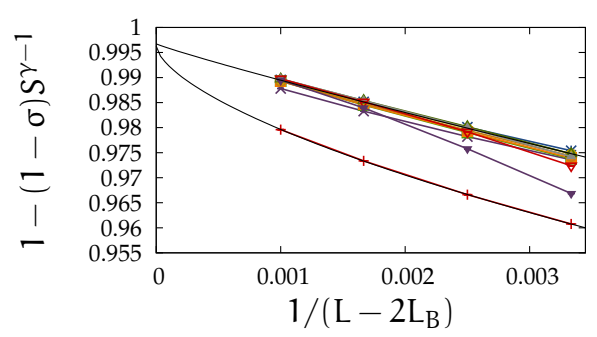

(c) $\alpha=0.22$

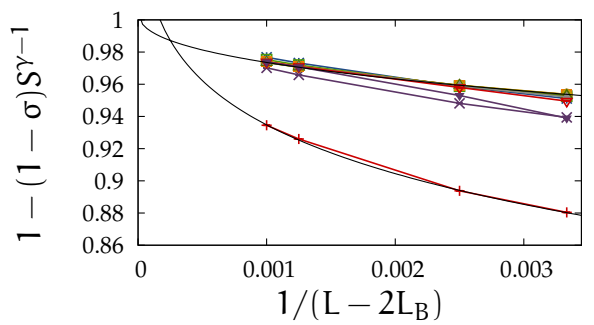

(e) $\alpha=0.18$

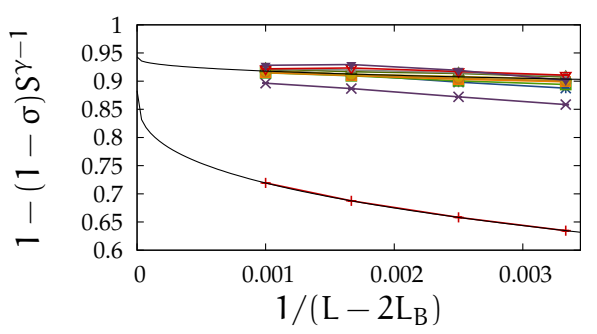

(g) $\alpha=0.14$

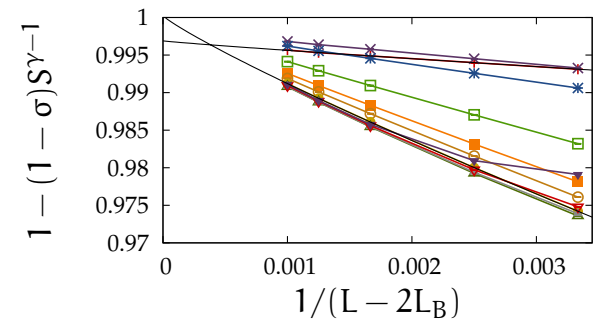

(b) $\alpha=0.24$

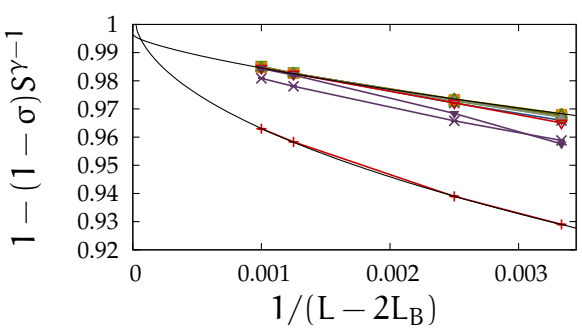

(d) $\alpha=0.20$

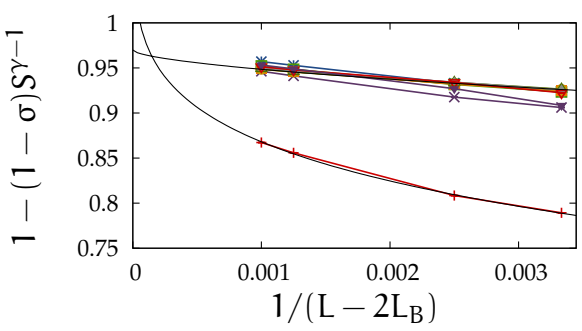

(f) $\alpha=0.16$

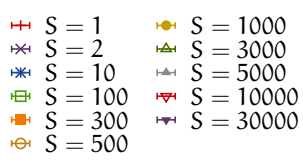

Figura 3.3.1: Taxa média de ramificação em função do tamanho do reticulado, para $\mathrm{L}_{\mathrm{B}}=0$ (reticulado inteiro). As curvas foram ajustadas na direção y conforme indicado na legenda, e de acordo com a equação 3.3.4. As linhas sólidas são ajustes da equação 3.3 .5 para $S=1$ e $S=1000$. Os valores dos ajustes estão na tabela 3.1 . 


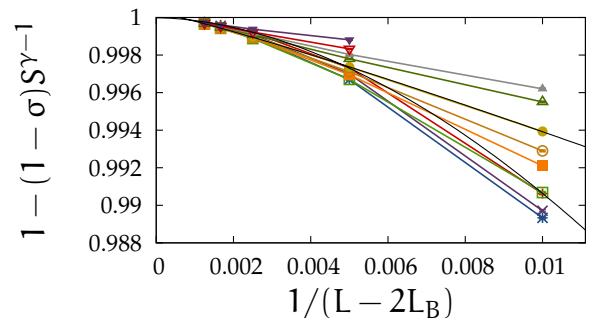

(a) $\alpha=0.25$

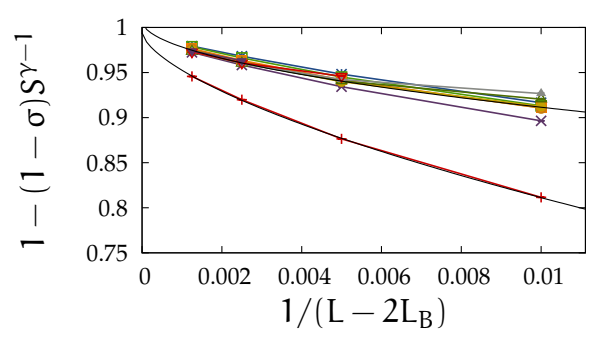

(c) $\alpha=0.22$

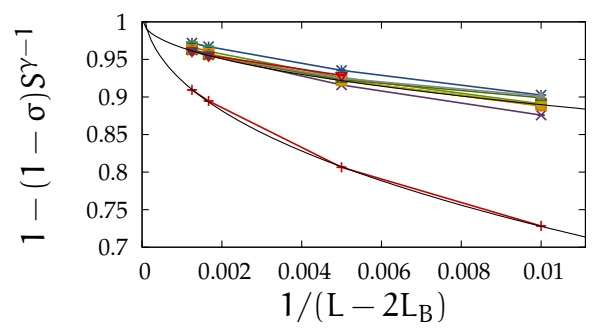

(e) $\alpha=0.18$

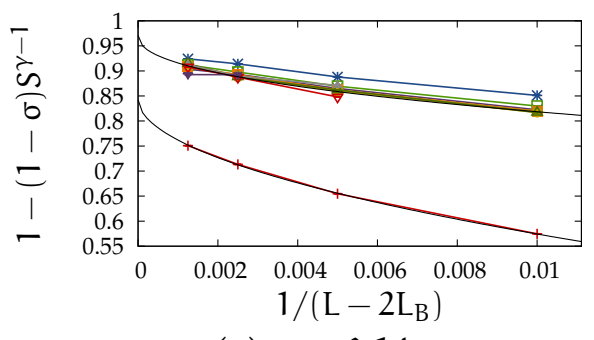

(g) $\alpha=0.14$

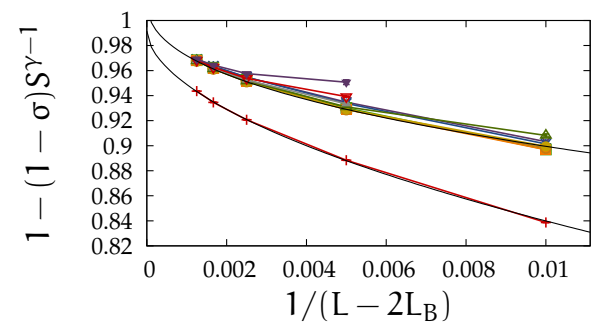

(b) $\alpha=0.24$

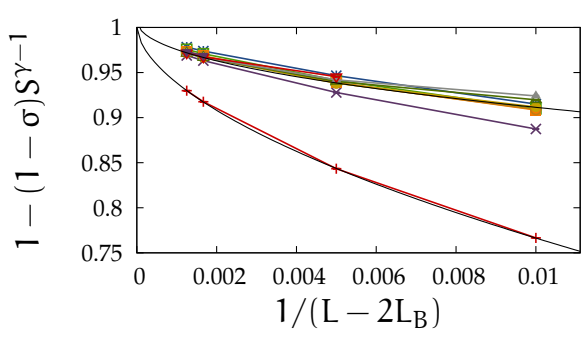

(d) $\alpha=0.20$

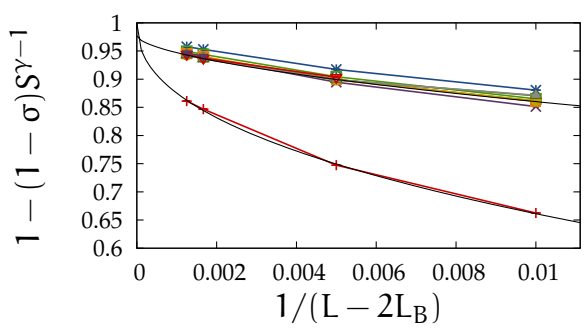

(f) $\alpha=0.16$

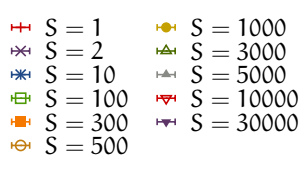

Figura 3.3.2: Taxa média de ramificação em função do tamanho do reticulado, para $\mathrm{L}_{\mathrm{B}}=100$ (interior do reticulado). As curvas foram ajustadas na direção y conforme indicado na legenda, e de acordo com a equação 3.3.4. As linhas sólidas são ajustes da equação 3.3 .5 para $S=1$ e $S=1000$. Os valores dos ajustes estão na tabela 3.1. 


\section{Capítulo 4}

\section{Redes Complexas}

Nesse capítulo será apresentada uma introdução breve de redes complexas, onde serão dadas as definições básicas e descritos apenas os conceitos mais fundamentais. Uma apresentação mais detalhada e abrangente pode ser obtida, por exemplo, em $[24,25]$.

\subsection{Definição e principais propriedades}

Uma rede (ou "grafo") G é definida por dois conjuntos $V$ e $E$, de vértices e arestas ${ }^{1}$, respectivamente, onde um vértice é uma entidade discreta qualquer, e uma aresta é um par de vértices do conjunto $V$. Quando usados para modelar algo real, de maneira geral, os vértices representam indivíduos, e as arestas representam uma relação qualquer entre dois indivíduos, dentro de algum contexto específico. Em redes sociais, por exemplo, os vértices podem representar pessoas, e as arestas podem representar algum tipo de relacionamento entre duas pessoas, como, por exemplo, amizade. Grafos podem ser "não-direcionados", quando não existir nenhum ordenamento dos vértices apontados por uma aresta, ou podem ser "direcionados", quando a relação representada por uma aresta não for simétrica, e a ordem dos vértices incididos for relevante. Além disso, grafos podem ser "simples" se existir no máximo uma aresta entre dois vértices (duas, se o grafo for direcionado), ou "multigrafos" se for possível arestas múltiplas. Algumas representações gráficas dos diferentes tipos de grafos podem ser vista na figura 4.1.1. Grafos são o principal objeto de estudo da Teoria de Grafos [66], e foram estudados pela primeira vez por Euler, quando solucionou o famoso problema das sete pontes de Königsberg [67].

O número de arestas que incidem num dado vértice é chamado de "grau" do vértice. No caso de grafos direcionados, é útil diferenciar entre o número de arestas que tem origem num dado vértice ("grau de saída") e que tem destino no mesmo vértice ("grau de entrada"). De maneira compacta, um grafo pode ser representado pela matriz de adjacência $\boldsymbol{A}$, cujos elementos são dados por,

$$
A_{u v}= \begin{cases}1 & \text { se o vértice } u \text { incide em } v \\ 0 & \text { caso contrário. }\end{cases}
$$

\footnotetext{
${ }^{1}$ Na literatura é freqüente o uso de variações de nomenclatura: Vértices são muitas vezes chamados de "nós", e arestas de "arcos" ou simplesmente "ligações" ou "conexões".
} 


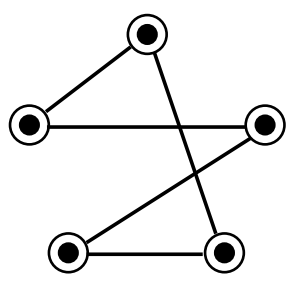

(a) Grafo simples

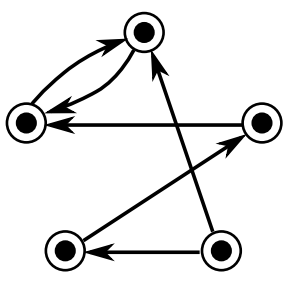

(b) Grafo direcionado simples

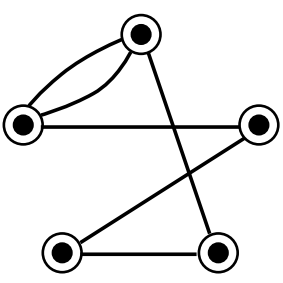

(c)

Multigrafo

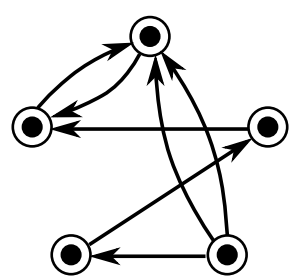

(d)

Multigrafo direcionado

Figura 4.1.1: Exemplos dos diferentes tipos de grafos, conforme descritos no texto.

No caso de um grafo não-direcionado, a matriz $\mathbf{A}$ é simétrica. Se arestas múltiplas são permitidas, os elementos $A_{u v}$ indicam o número de arestas de $u$ ate $v$. O grau $k_{u}$ de um vértice $u$ é dado, então, por $k_{u}=\sum_{v} A_{u v}$ (no caso de um grafo direcionado $k_{u}$ é o grau de saída, e grau de entrada é dado por $j_{\mathfrak{u}}=\sum_{v} A_{v \mathfrak{u}}$ ).

\subsubsection{Redes complexas}

Redes no mundo real têm as mais diversas origens. Em geral, as redes mais estudadas são divididas em três grupos: 1) Redes sociais [26,68], que modelam relações de natureza social entre pessoas; 2 ) Redes biológicas, que modelam, de alguma maneira, sistemas biológicos, como a rede de cadeia alimentar [69,70], rede de neurônios [71], e rede de regulação de genes [72,73]; e 3) Redes tecnológicas, como a Internet [74,75] e World Wide Web [76,77]. Essa classificação serve somente para dividir os tipos das redes mais estudadas, não para definir o que é uma "rede real". Grafos não estão vinculados com nenhum tipo de realidade física especifica (são somente objetos matemáticos), e logo podem ser usados para representar relações que são de natureza fundamentalmente diferentes. Apesar disso, muitas vezes são encontradas, nessas redes, propriedades estatísticas que são muito semelhantes, e indicam um tipo de comportamento emergente que não depende das características específicas de cada sistema que está sendo representado (daí o termo complexo). Além disso, essas redes são freqüentemente muito grandes, e métodos estatísticos, como empregados na mecânica estatística, são imprescindíveis para analisá-las e modelá-las.

Em geral, redes complexas são estudadas sob dois aspectos: Topologia e dinâmica. O estudo da topologia engloba a determinação de diversas medidas estatísticas do grafo, e de modelos de geração de redes que as reproduzam. Dinâmica nesse contexto significa dinâmica em redes, onde a estrutura topológica da rede serve como parâmetro para uma dinâmica qualquer, como propagação de doenças (ver [78], para um apanhado geral da área). Aqui serão apresentados somente os conceitos básicos da parte topológica, pois é o que é relevante para esse trabalho. A seguir, as medidas estatísticas mais básicas serão apresentadas juntamente com o modelo aleatório mais básico, o grafo de Erdős e Rényi. Posteriormente, os fenômenos emergentes de redes livre de escala e mundo pequeno serão apresentados, juntamente com modelos mais famosos que os reproduzem. 


\subsubsection{Grafos aleatórios e distribuição de graus}

O modelo mais simples de redes não regulares é o grafo aleatório de Erdős e Rényi [79]. Esse modelo consiste em um ensemble de grafos $\mathrm{G}_{\mathrm{N}, \mathrm{p}}$, no qual o número de vértices $\mathrm{N}$ é fixo, e cada par possível de vértices é conectado com uma aresta com probabilidade $p$ (e, conseqüentemente, permanece desconectado com probabilidade $1-p)^{2}$. A distribuição de graus $\mathrm{P}(\mathrm{k})$ desse grafo, definida como a fração de vértices que possuem um grau específico $k$, é dada pela distribuição binomial,

$$
P(k)=\frac{1}{N} \sum_{u}\left[k_{u}=k\right]=\left(\begin{array}{l}
N \\
k
\end{array}\right) p^{k}(1-p)^{N-k} \approx \frac{z^{k} e^{-z}}{k !},
$$

onde $\left[k_{\mathfrak{u}}=1\right]=1$ se $k_{\mathfrak{u}}=1$, ou 0 caso contrário, e $z=N p$ é o grau médio. No limite $\mathrm{N} \rightarrow \infty$ a distribuição se aproxima de uma Poisson, conforme o último termo da equação 4.1.2. Nesse ensemble de grafos existe, portanto, um grau característico $z=\mathrm{Np}$ dos vértices, e a topologia é inteiramente aleatória. Dificilmente redes reais se aproximam muito de redes de Erdős e Rényi, pois em geral se observa estruturas mais elaboradas. Apesar disso, esse grafo é bastante importante, pois é freqüentemente usado para comparação, e é possível obter uma série de resultados analíticos, que são mais difíceis, ou impossíveis, com grafos mais elaborados.

\subsubsection{Correlação de graus}

A distribuição de graus descreve as propriedades estatísticas da topologia de um grafo de maneira somente superficial, pois ela não contém nenhuma informação específica de como os vértices estão conectados entre si. Essa informação pode ser obtida, de maneira menos superficial, pela correlação de graus de vértices vizinhos, $P\left(k, k^{\prime}\right)$, definida como a fração de arestas entre vértices de grau $k$ e $k^{\prime}$,

$$
P\left(k, k^{\prime}\right)=\frac{1}{\langle k\rangle N} \sum_{u v} A_{u v}\left[k_{u}=k\right]\left[k_{v}=k^{\prime}\right]=\frac{k P(k) k^{\prime} P\left(k^{\prime}\right)}{\langle k\rangle^{2}} r\left(k, k^{\prime}\right),
$$

onde $\langle k\rangle=\sum_{k} k P(k)$ é o grau médio, e $r\left(k, k^{\prime}\right)$ é uma função simétrica em $k$ e $k^{\prime}$, que define a correlação: $\operatorname{Se} r\left(k, k^{\prime}\right)=1$, independente de $k$ e $k^{\prime}$, o grafo é descorrelacionado, e é, portanto, correlacionado se houver qualquer dependência de $r\left(k, k^{\prime}\right)$ em $k$ e $k^{\prime}$. Como os grafos estudados na maioria dos casos são esparsos, i.e., possuem grau médio $\langle k\rangle \ll N$, não existe estatística suficiente para analisar $\mathrm{P}\left(\mathrm{k}, \mathrm{k}^{\prime}\right)$ diretamente. $\mathrm{O}$ que se faz, normalmente, é reduzir essa função no grau médio $\bar{k}_{n n}(k)$ de vizinhos de um vértice de grau $k$,

$$
\bar{k}_{n n}(k)=\frac{\langle k\rangle}{k P(k)} \sum_{k^{\prime}} k^{\prime} P\left(k, k^{\prime}\right),
$$

que é mais fácil de ser analisada. É fácil ver que, para um grafo descorrelacionado, com $r\left(k, k^{\prime}\right)=1$, tem-se $\bar{k}_{n n}(k)=\left\langle k^{2}\right\rangle /\langle k\rangle$, independente de $k$. Se $\bar{k}_{n n}(k)$ for, porém, crescente em k, o grafo é dito ser "assortativo", e se for decrescente, "dissortativo".

\footnotetext{
${ }^{2}$ Uma variante do modelo consiste em definir outro ensemble, $\mathrm{G}_{\mathrm{N}} \mathrm{m}$, onde o número de vértices $\mathrm{N}$ e arestas m são fixos, e as arestas são conectadas aleatoriamente. Porém, ambos ensembles são equivalentes no limite $\mathrm{N} \rightarrow \infty$, da mesma forma que os ensembles canônico e microcanônico são equivalentes no limite termodinâmico, na mecânica estatística.
} 
É possível reduzir ainda mais a análise de correlação de graus, considerando o "coeficiente escalar de assortatividade" [80], definido por

$$
r=\frac{\sum_{k k^{\prime}} k k^{\prime}\left(e_{k k^{\prime}}-a_{k} b_{k^{\prime}}\right)}{\sigma_{a} \sigma_{b}}
$$

onde $e_{k k^{\prime}}$ é a fração de arcos entre vértices de grau $k$ e $k^{\prime}, a_{k}=\sum_{k^{\prime}} e_{k k^{\prime}}, b_{k^{\prime}}=$ $\sum_{k} e_{k k^{\prime}}$, e $\sigma_{a}$ e $\sigma_{b}$ são os desvios padrão de $a_{k}$ e $b_{k^{\prime}}$, respectivamente. Dessa forma, tem-se $r>1$ para grafos assortativos, $r=0$ para grafos não-correlacionados, e $r<1$ para grafos dissatortativos.

Para o grafo aleatório de Erdős e Rényi não existe conexão preferencial entre vértices de graus específicos (a probabilidade de conexão é $p$ para qualquer par de vértices), logo obtém-se facilmente que $r\left(k, k^{\prime}\right)=1$ e $r=0$.

\subsubsection{Aglomeração}

Um fenômeno muito estudado da topologia local de redes é o de "aglomeração": Se um vértice $u$ está conectado aos vértices $v$ e $w$, então pode existir uma probabilidade maior que $v$ e $w$ estejam conectados entre si. Caso isso aconteça, diz-se que o grafo possui clusters (ou "triângulos"), ou alta "transitividade". Isso pode ser quantificado pelo coeficiente de aglomeração local de um vértices u [29],

$$
\mathrm{C}_{\mathfrak{u}}^{(2)} \equiv \frac{\text { número de triângulos conectados ao vértice } u}{\text { número de triplas centradas no vértice } u},
$$

onde uma "tripla" significa três vértices conectados entre si por duas ou mais arestas, e aos vértices com nenhuma tripla é atribuído $C_{\mathfrak{u}}^{(2)}=0$. O coeficiente de aglomeração para o grafo inteiro é a média dos coeficientes locais,

$$
\mathrm{C}^{(2)}=\frac{1}{\mathrm{~N}} \sum_{\mathrm{u}} \mathrm{C}_{\mathrm{u}}^{(2)}
$$

Existe ainda uma definição mais tradicional do coeficiente de aglomeração, chamada de "coeficiente de aglomeração global" [24],

$$
C^{(1)} \equiv \frac{3 \times \text { número de triângulos no grafo }}{\text { número de triplas no grafo }},
$$

onde o fator três no numerador é devido ao fato que cada triângulo corresponde a três triplas, e garante que $0 \leqslant C^{(1)} \leqslant 1$. As duas definições medem a mesma densidade, porém não são equivalentes: Há uma inversão na ordem do cálculo da razão de triângulo por triplas, já que na equação 4.1 .8 é calculada a razão das médias, e na equação 4.1.7, a média das razões. Devido a isso, a definição de $C^{(2)}$ tende a dar um peso maior a vértices com grau baixo, pois eles contribuem com um denominador menor em 4.1.6. Ambas as definições são, porém, amplamente utilizadas na literatura. Independentemente do coeficiente de aglomeração escolhido, a existência de uma aglomeração não-nula é o que diferencia, muitas vezes, redes reais de redes aleatórias, como a de Erdős e Rényi, que possui $C^{(1)}=C^{(2)}=0$ no limite $\mathrm{N} \rightarrow \infty$. 
Como definido nas equações 4.1 .8 e 4.1.7, a aglomeração medida por esses dois coeficientes é somente de primeira ordem, pois só medem o quanto os vizinhos de um determinado vértice estão conectados diretamente entre si. Se os vizinhos estiverem a uma distância 2 uns dos outros, por exemplo, isso é completamente ignorado pelas definições dos coeficientes. Uma maneira de generalizar a coeficiente de aglomeração $C^{(2)}$ foi proposta por Abdo et al [81], e consiste em definir um índice de aglomeração local de um vértice $u$,

$$
\mathrm{C}^{\mathrm{d}}(\mathrm{u}) \equiv \frac{\left|\left\{\{v, w\} ; v, w \in \mathrm{N}(u) \mid \mathrm{d}_{\mathrm{G}\left(\bigvee\left\{u_{\}}\right)\right.}(v, w)=\mathrm{d}\right\}\right|}{\left(\begin{array}{c}
|\mathrm{N}(u)| \\
2
\end{array}\right)}
$$

onde dé a distância de aglomeração considerada, $\mathrm{N}(\mathrm{u})$ são os vizinhos de $u, G(\bigvee\{u\})$ é o grafo induzido, sem o vértice $u$, e $d_{G}(v, w)$ é a distância de $v$ até $w$ no grafo $G$. Definido dessa maneira, para $d=1$, obtém-se de volta $C^{1}(u)=C_{\mathfrak{u}}^{(2)}$. Além disso, a equação 4.1 .9 possui a propriedade interessante de normalização, $\sum_{d=1}^{\infty} C_{(\mathfrak{u})}^{d} \leqslant 1$. Dessa forma, a equação 4.1 .9 proporciona uma maneira natural de generalizar o coeficiente de aglomeração para ordens maiores.

\subsubsection{Diâmetro}

Outra característica básica de redes é o diâmetro l, que mede o quão distantes estão, em média, os vértices do grafo,

$$
l \equiv \frac{1}{\frac{1}{2} \mathrm{~N}(\mathrm{~N}-1)} \sum_{\mathrm{u} \geqslant v} \mathrm{~d}_{\mathrm{uv}}
$$

onde $d_{u v}$ é a distância mínima entre os vértices $u$ e $v$. Para um grafo direcionado o denominador da equação 4.1 .10 se torna $\mathrm{N}(\mathrm{N}-1)$, pois, de maneira geral, $\mathrm{d}_{\mathfrak{u} v} \neq \mathrm{d}_{v u}$.

Tanto para grafos direcionados quanto para grafos não-direcionados onde existam vários "componentes", i.e., conjuntos maximais de vértices que possuam todos um caminho entre si, é possível que não haja uma distância entre dois vértices específicos. Neste caso, omite-se a distancia em questão da soma da equação 4.1.10. Uma maneira alternativa, e possivelmente mais adequada a esse caso, é considerar a média harmônica das distâncias,

$$
l_{h} \equiv \frac{1}{\frac{1}{2} N(N-1)}\left[\sum_{u \geqslant v} \frac{1}{d_{u v}}\right]^{-1}
$$

que não desconsidera distâncias não-existentes, pois se considera $1 / d_{\mathfrak{u} v}=0$ se $d_{\mathfrak{u} v}$ não existe, i.e, $\mathrm{d}_{\mathfrak{u} v} \rightarrow \infty$.

O grafo de Erdős e Rényi possui uma propriedade interessante, sobre como o diâmetro cresce com o tamanho do grafo: O número médio de vizinhos a uma distância $\mathrm{d}$ de um vértice específico é, em média, $\langle k\rangle^{\mathrm{d}}$, e, logo, o valor de $\mathrm{d}=\mathrm{l}$ necessário para percorrer a rede inteira é $\langle k\rangle^{l} \approx N$, de modo que a distância típica para atravessar a rede é $l \approx \log N / \log \langle k\rangle$, onde $\langle k\rangle$ é o grau médio do grafo. Esse crescimento lento é conhecido como fenômeno de mundo pequeno, que será descrito melhor na seção 4.2.2. 


\subsection{Características emergentes}

Muitas vezes redes de natureza fundamentalmente diferentes apresentam propriedades estatísticas que são muito semelhantes, que são provenientes de mecanismos gerais, que não dependem de características específicas da rede em questão. É exatamente a identificação desses comportamentos gerais que motivou o estudo dessas redes por grande parte dos físicos. A seguir será apresentada duas dessas características: 1) Redes livre de escala (seção 4.2.1), e 2) O efeito de mundo pequeno (seção 4.2.2).

\subsubsection{Redes livre de escala}

Como foi visto na seção 4.1.2, grafos completamente aleatórios possuem uma distribuição de graus com um grau típico. Muitas redes reais, porém, como a rede de citação de artigos $[27,28]$ e a internet $[76,77]$, possuem uma distribuição de graus que não exibem uma escala característica, decaindo como uma lei de potência, $\mathrm{P}(\mathrm{k}) \sim k^{-\gamma}$. Essas redes são, portanto, chamadas de "redes livre de escala" ${ }^{3}$. A existência, portanto de alguns hubs, i.e., vértices com grau bastante elevado, coexistindo com muitos vértices de grau várias ordens de grandeza mais baixo, é uma característica importante de redes livre de escala.

Uma tentativa de identificar um mecanismo geral responsável por essa propriedade levou ao mecanismo de conexão preferencial, proposto pela primeira vez por Price [27], e mais recentemente por Barabási e Albert [28]. Tanto o modelo de Price quanto o de Barbási e Albert ilustram como um simples mecanismo de vantagem cumulativa é capaz de gerar redes livre de escala. Apesar desse mecanismo ser aceito como a dinâmica de criação de algumas redes livre de escala (como a rede de citação de artigos), existem várias redes livre de escala que não obedecem a mesma regra de criação, e exibem, portanto, várias características que diferem bastante de redes criadas por conexão preferencial, como diferentes correlações de graus: De maneira geral, grafos do tipo Price e Barabási-Albert são dissortativos. Qualquer rede livre de escala que for descorrelacionada ou assortativa não pode ter sido gerada unicamente por esse método.

O mecanismo de conexão preferencial será detalhado a seguir, com o grafo de Barabási e Albert.

\section{Grafo de Barabási e Albert}

O grafo de Barabási e Albert é um grafo simples e não-direcionado, definido pelo seguinte processo iterativo: A cada iteração, um vértice com grau m é adicionado ao grafo, e cada uma das $m$ arestas novas são conectadas a outros vértices do grafo. Um vértice do grafo recebe uma das arestas novas com probabilidade proporcional ao seu grau. Esse modelo pode ser resolvido analiticamente no limite de número grande de vértices [82,83].

\footnotetext{
${ }^{3}$ Vale notar que somente os graus não possuem uma escala característica, enquanto outras propriedades da rede possuem, como, por exemplo, o diâmetro.
} 
A probabilidade de uma nova aresta se conectar a um vértice de grau $k$ é dada por

$$
\frac{k p_{k}}{\sum_{k} k p_{k}}=\frac{k p_{k}}{2 m}
$$

onde $p_{k}$ é a distribuição de graus, e $\sum_{k} k p_{k}=2 m$ é o grau médio do grafo. O número médio de vértices de grau $k$ que ganham uma aresta, quando um vértice novo de grau $\mathrm{m}$ é adicionado, é $\mathrm{m} \times \mathrm{k} p_{\mathrm{k}} / 2 \mathrm{~m}=\frac{1}{2} \mathrm{k} p_{\mathrm{k}}$, que não depende de $\mathrm{m}$. O número médio de vértices com grau $k$ decresce por essa mesma quantia, já que vértices que recebem uma aresta obtém grau $k+1$. O número médio de vértices com grau $k$ também cresce, já que os vértices com grau $k-1$ também podem receber arestas, exceto para vértices com grau $m$, onde o fluxo de entrada é exatamente 1 , correspondendo somente ao novo vértice adicionado. Sendo $p_{k, n}$ o valor de $p_{k}$ quando o grafo tem $n$ vértices, então a variação total em $n p_{k}$ por vértice adicionado é

$$
(n+1) p_{k, n+1}-n p_{k, n}= \begin{cases}\frac{1}{2}(k-1) p_{k-1, n}-\frac{1}{2} k p_{k, n} & \text { se } k>m, \\ 1-\frac{1}{2} m p_{m, n} & \text { se } k=m,\end{cases}
$$

sendo que não existem vértices com $k<m$. Para as soluções estacionárias $p_{k, n+1}=$ $p_{k, n}=p_{k}$, as equações ficam

$$
p_{k}= \begin{cases}\frac{1}{2}(k-1) p_{k-1}-\frac{1}{2} k p_{k} & \text { se } k>m, \\ 1-\frac{1}{2} m p_{m} & \text { se } k=m .\end{cases}
$$

Rearranjando essa expressão, obtém-se, facilmente, $p_{m}=2 /(m+2)$ e $p_{k}=p_{k-1}(k-$ $1) /(k+2)$, ou então

$$
p_{k}=\frac{(k-1)(k-2) \ldots m}{(k+2)(k+1) \ldots(m+3)} p_{m}=\frac{2 m(m+1)}{(k+2)(k+1) k} .
$$

No limite de $k \gg 1$, essa expressão se torna uma lei de potência $p_{k} \approx k^{-3}$.

Uma série de outros resultados são conhecidos para esse modelo, como correlação entre o grau e a idade de um vértice [84], com vértices mais velhos tendo grau maior. Por exemplo, para $m=1$, é possível mostrar que a probabilidade de um vértice $i$ com idade a, definida como sendo o número de vértices adicionados depois de $i$, ter grau ké dada por

$$
p_{k}(a)=\sqrt{1-\frac{a}{n}}\left(1-\sqrt{1-\frac{a}{n}}\right)^{k} .
$$

Deste modo, para uma idade específica a, a distibuição é uma exponencial, com uma escala de graus característica que diverge com $(1-a / n)^{-1 / 2} \operatorname{com} a \rightarrow n$. É devido a esse fato, de que os vértices mais antigos tem grau substancialmente mais elevados que vértices novos, que o comportamento livre de escala da distribuição de graus emerge. Porém, essa correlação explícita entre a idade e os graus é o que impede a aplicação desse modelo como explicação de certas redes, como a World Wide Web, que não apresenta tal correlação [85].

Esse modelo pode ser estendido e generalizado de diversas maneiras [25, 82-84]. Uma delas é definir a probabilidade de conexão como sendo proporcional a $k+k_{0}$, 
sendo $k_{0}$ uma constante qualquer, que pode estar na faixa $-m<k_{0}<\infty$. Com essa modificação [82,84], o modelo gera uma lei de potência $p_{k} \approx k^{3+k_{0} / m}$, cujo expoente está na faixa $2<\alpha<\infty$, sendo essa uma possível explicação para expoentes $\alpha<3$ observados em redes reais.

\subsubsection{Fenômeno de "mundo pequeno" (small-world)}

Muitas redes possuem a propriedade de que a maioria dos pares de vértices podem ser alcançados percorrendo um caminho comparativamente curto na rede. Esse efeito, chamado de "mundo pequeno" (small-world), foi demonstrado no famoso experimento de Milgram [86,87], onde os participantes tinham a tarefa de entregar uma carta a um determinado destinatário, mas podiam passar a carta somente a um conhecido próximo. Foi determinado, nesse experimento, que as cartas passaram em média pelas mãos de em torno de seis pessoas, considerado um número supreendentemente baixo, dando origem ao conceito popular de "seis graus de separação". De uma maneira mais precisa, diz-se que uma rede exibe o efeito de mundo pequeno se o valor de $l$ crescer de acordo com

$$
l \propto \log N
$$

ou mais lentamente, sendo $\mathrm{N}$ o número de vértices da rede, para um valor fixo do grau médio.

Esse fenômeno pode ser atribuído ao efeito de poucas conexões aleatórias de longo alcance, que diminuem dramaticamente a distância média do grafo. O efeito de conexões de longo alcance foi explicado por Watts e Strogatz [29], que definiram um modelo que mostra esse efeito bem explicitamente, e que será detalhado a seguir.

\section{O modelo de Watts e Strogatz}

A idéia do modelo de Watts e Strogatz [29] é mostrar, de maneira explícita, como a introdução de conexões aleatórias, que conectam vértices distantes, é responsável pelo efeito de mundo pequeno. O modelo parte de um grafo regular circular, com $\mathrm{N}$ vértices, cada um conectado com $K$ de seus vizinhos ( $K / 2$ de cada lado), conforme a figura 4.2.1. A distância média desse grafo cresce com $l=N / 2 K$, e portanto não exibe efeito de mundo pequeno, como a maioria dos grafos regulares. Esse grafo também possui uma aglomeração que independe de $\mathrm{N}, \mathrm{C}^{(0)}=3 / 4$. O próximo passo é introduzir conexões aleatórias: Para cada vértice, reconecta-se cada um dos arcos que dele saem, com probabilidade $p$, com um outro vértice qualquer, escolhido aleatoriamente. Esse processo transforma, em média, $p N K / 2$ arcos em conexões aleatórias. Logo, para $p=1$, a rede se torna completamente aleatória (ver figura 4.2.1).

O principal resultado do modelo é que existe uma fase intermediária, com $0<p<$ 1 , na qual o modelo exibe propriedades de redes tanto regulares quanto aleatórias. Mesmo quando uma fração pequena $p \approx 0.01$ de conexões aleatórias é introduzida, o modelo já exibe o fenômeno de mundo pequeno, $\operatorname{com} l \sim \log (\mathrm{N}) / \log (\mathrm{K})$, porém mantém a aglomeração inicial $C^{(1)} \sim 3 / 4$, longe do esperado no caso aleatório, $C^{(1)}=$ $K / N$. De fato, é possível ver que $C^{(1)}(p) \sim(3 / 4)(1-p)^{3}$. A distribuição de graus desse modelo, em função de $p$, varia entre um delta de Dirac centrado em $k=K$, 
no caso regular, e uma Poisson, no caso completamente aleatório, e pode ser escrita como [88]

$$
P(k)=\sum_{n=0}^{\min \left(k-\frac{K}{2}, \frac{K}{2}\right)}\left(\begin{array}{c}
K / 2 \\
n
\end{array}\right)(1-p)^{n} p^{\frac{K}{2}-n} \frac{\left(\frac{p K}{2}\right)^{k-\frac{K}{2}-n}}{\left(k-\frac{K}{2}-n\right) !} e^{-\frac{p K}{2}}
$$

onde $k \geqslant K / 2$. Esses resultados mostram, de maneira bem clara, como muitas redes reais, que não são completamente aleatórias, exibem o efeito de mundo pequeno, simplesmente devido a poucas conexões de longa distância.

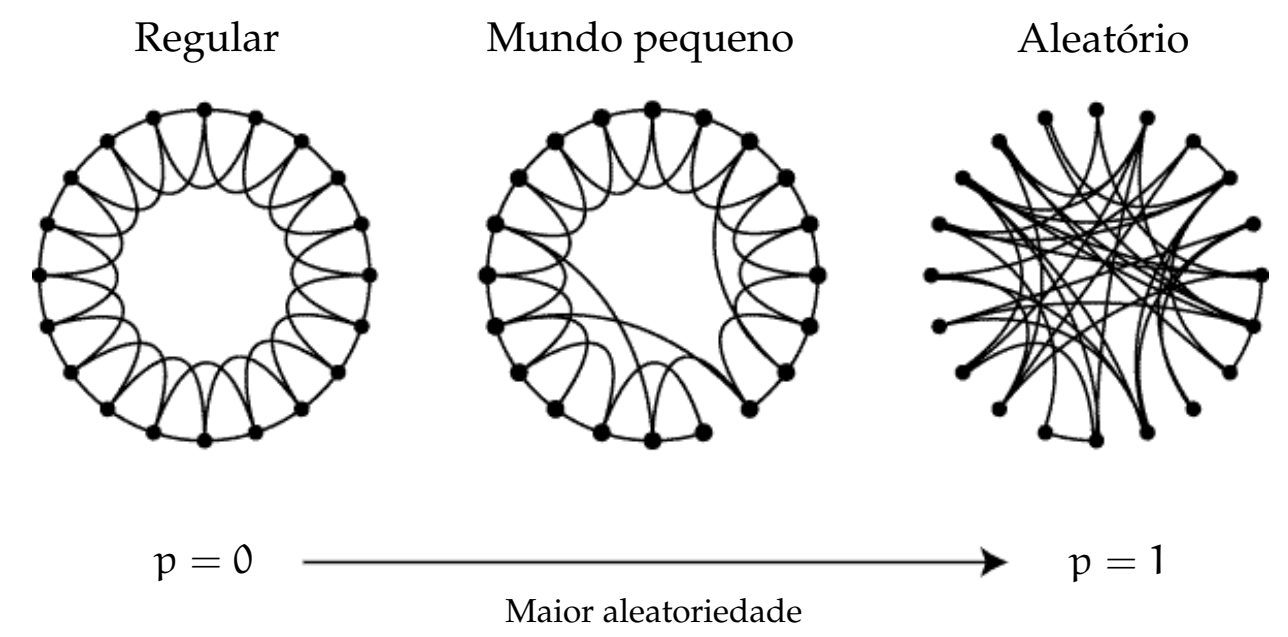

Figura 4.2.1: Variação do modelo Watts e Strogatz, entre uma rede regular $(p=0)$ e uma aleatória $(p=1)$. 


\section{Capítulo 5}

\section{Rede de epicentros consecutivos}

Nesse capítulo será apresentado o estudo da rede de epicentros consecutivos do modelo OFC. O objetivo do trabalho é analisar as correlações espaço-temporais do modelo, de uma maneira unificada, sem introduzir parâmetros, e para isso usando conceitos e ferramentas da teoria de redes complexas. Dessa forma, pretende-se relacionar, de uma maneira específica, a área de criticalidade auto-organizada com a de redes complexas ${ }^{1}$. Essa análise permite, também, uma comparação adicional entre o modelo e a estatística de sismicidade, que vai além da detecção das leis empíricas usuais (lei de Gutenberg-Richter, e lei de Omori, conforme seções 2.1.5 e 2.1.7, nas páginas 15 e 20, respectivamente), o que contribui, portanto, para a compreensão dos limites desse modelo, bem como as origens do comportamento crítico autoorganizado.

Esse trabalho foi motivado inicialmente por uma análise semelhante feita por Abe e Suzuki [91] para terremotos reais. Essa análise consistia na construção de um grafo de epicentros consecutivos de terremotos reais, que exibia uma distribuição de graus livre de escala. A análise apresentada aqui difere dessa em pontos importantes, que por si já a torna original, além de ser feita para estudar o modelo OFC: 1) Nenhuma informação é perdida na construção do grafo. Isso implica que o grafo definido aqui é um multigrafo direcionado (ver seção 5.1, abaixo), diferentemente de [91], onde a rede é um grafo simples, não direcionado; 2) Além da distribuição de graus, serão analisadas vários outros aspectos do grafo. Em particular, será dado atenção para as correlações de graus, que revela um tipo característico de dinâmica, e a correlação do crescimento do grafo com o tamanho dos eventos. Além disso será visto, inclusive para terremotos reais, a dependência das características da rede com a escala de observação. Por fim, será feito um tratamento analítico do crescimento desse grafo, considerando-o como um processo Markoviano.

A maioria dos resultados apresentados nesse capítulo foram publicados em [1-3].

\footnotetext{
${ }^{1}$ Vale notar que outras abordagens também foram propostas, como as feitas por Baiesi et al $[89,90]$ para terremotos reais, que envolve comparar a ocorrência espaço-temporal de epicentros com um modelo nulo, completamente aleatório. Dado um limiar pré-determinado, os eventos são conectados entre si, se a probabilidade deles ocorrerem, de acordo com o modelo nulo, forem menores que esse limiar. Essa abordagem difere da apresentada aqui, por não introduzir escalas de observação $a$ priori, porém ainda possui um parâmetro global. No apêndice A será apresentada uma abordagem alternativa, que é inteiramente não-paramétrica.
} 


\subsection{Definição do grafo}

A seqüencia de epicentros do modelo OFC pode ser usada para construir um grafo direcionado da seguinte maneira: Cada sítio que se torna um epicentro é representado por um vértice; Dois epicentros consecutivos são então conectados por um arco direcionado, do primeiro a ocorrer ao segundo (ver figura 5.1.1). A princípio, o mesmo sítio pode se tornar um epicentro duas vezes consecutivas, logo loops são permitidos (porém, não ocorrem com freqüência). Além disso, de maneira mais geral, uma determinada seqüência de epicentros também pode ocorrer repetidamente, logo arcos paralelos também são permitidos. Um grafo construído dessa maneira tem algumas regularidades: O grau de entrada de um vértice qualquer é sempre igual ao seu grau de saída (exceto para o primeiro e último vértices do grafo, se não coincidirem). Deste modo, o grau total de cada vértice é sempre par. Além disso, se a direção dos arcos for ignorada, o grafo possui somente um componente ${ }^{2}$.

De maneira geral, esse processo de construção de rede pode ser estendido para processos pontuais, ocorrendo em um espaço contínuo, N-dimensional. Para isso, porém, é necessário subdividir o espaço num reticulado, o que introduz uma escala de observação. Características abaixo dessa escala não seriam capturadas pelo método, e o tamanho da célula teria que ser variado, para que a análise seja completa. No caso específico do modelo OFC, e de eventos em geral, que ocorrem em espaços discretos, já existe uma escala espacial fundamental inerente, e o crescimento do grafo é, nesse caso, não-paramétrico.

A seguir serão descritos os grafos obtidos da maneira apresentada acima para o modelo OFC, considerando vários valores do parâmetro de dissipação $\alpha$. Como foi justificado no capítulo 3, serão considerados somente eventos pertencentes ao interior do reticulado, e os eventos que envolvem sítios pertencentes a uma borda externa, de espessura $L_{B}=100$, foram descartados na análise. Além disso, serão considerados somente eventos de tamanho $s \geqslant 300$, conforme também foi justificado no capítulo 3 .

\footnotetext{
${ }^{2}$ Um componente de um grafo é um conjunto maximal de vértices, que possuem todos pelo menos um caminho entre si.
}

\begin{tabular}{|c|c|c|c|c|}
\hline 1 & 2 & 3 & 4 & 5 \\
\hline 6 & 7 & 8 & 9 & 10 \\
\hline 11 & 12 & 13 & 14 & 15 \\
\hline 16 & 17 & 18 & 19 & 20 \\
\hline 21 & 22 & 23 & 24 & 25 \\
\hline
\end{tabular}

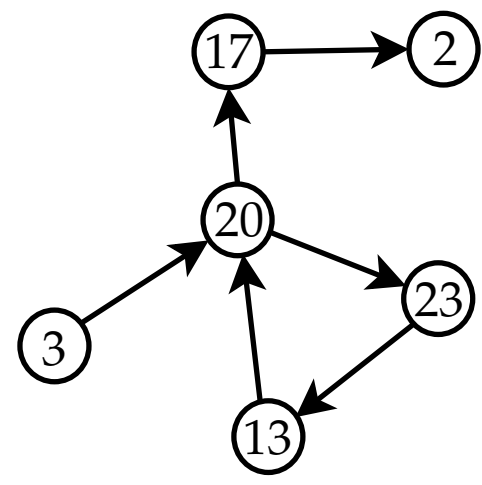

Figura 5.1.1: Um grafo de epicentros (direita) gerado por uma seqüência de epicentros (em vermelho) em um reticulado $5 \times 5$. Esse grafo corresponde à seqüencia: $3,20,23,13,20,17,2$. 
Na maioria dos casos, o tamanho do reticulado usado foi $L=1000$.

\subsubsection{Crescimento do Grafo}

A primeira característica a ser analisada desse grafo é a sua evolução temporal. Conforme mais eventos são considerados, o número de arcos $E$ aumenta linearmente, de maneira trivial, e o número de vértices pode se encontrar, de maneira arbitrária, dentro do intervalo $V \in[1, E]$. Para o modelo OFC se observa duas fases do crescimento do grafo (ver figura 5.1.2): $O$ número de vértices $V$ cresce linearmente, e depois alcança um patamar $V_{a}$ (dependente de $\alpha$ ), após um certo tempo, e volta, então, a crescer linearmente. Nota-se que essa mudança do crescimento ocorre quando o número de vértices ainda é bem menor do que o número máximo possível, $\left(\mathrm{L}-2 \mathrm{~L}_{\mathrm{B}}\right)^{2}=$ $6,4 \times 10^{5}$. É possível interpretar essa característica do crescimento da seguinte maneira: Num determinado instante, somente uma sub-região interna do reticulado corresponde a sítios que podem se tornar epicentros. No momento que o grafo já inclui todos esses "sítios ativos", o crescimento do número de vértices é menor, e o grau médio passa a crescer linearmente. O número de vértices volta a crescer linearmente, após certo tempo, pois a região de sítios ativos não é inteiramente estática, e muda com o tempo. O tamanho da fração de sítios ativos, por sua vez, aumenta quando somente eventos maiores são considerados. Essa mudança, porém, deve estar relacionada com a migração da área ativa mencionada acima, pois o tempo de observação para a obtenção desses eventos é maior, já que eles são mais raros. A variação temporal dessa área ativa será mais detalhada a seção 5.1.3, página 65. Deve-se observar que essas diferentes fases do crescimento do grafo só são observadas para $\alpha<1 / 4$. No caso conservativo, o grafo cresce constantemente de forma linear.

O crescimento do grafo também pode ser acompanhado pela variação do grau de entrada médio $\langle k\rangle=E / V$, como pode ser visto na figura 5.1.3. É possível ver as fases do crescimento na variação de $\langle k\rangle$ de maneira clara, onde o patamar descrito acima representa um crescimento linear em $\langle k\rangle$ e um crescimento linear do número de vértices leva a um $\langle k\rangle$ constante. $\mathrm{O}$ crescimento acentuado final do grau médio, observado para alguns valores de $\alpha$. é devido ao número máximo de vértices ter se aproximado do número máximo possível, $\left(\mathrm{L}-2 \mathrm{~L}_{\mathrm{B}}\right)^{2}=6,4 \times 10^{5}$, e é, portanto, um efeito de tamanho finito. Estipula-se, portanto, que se $L=\rightarrow \infty$, o grau médio deva tender para um valor específico ${ }^{3}$. Esse valor do grau médio é característica para cada valor de $\alpha$, e é maior conforme maior for a dissipação.

\subsubsection{Distribuição de Graus}

Como foi mostrado na seção anterior, a partir de um certo ponto do crescimento do grafo, o grau de entrada médio estabiliza, e volta a crescer somente devido ao tamanho finito do reticulado. A distribuição de graus deve variar de maneira correspondente, e deve, então, depender do número de eventos considerados, e também do pa-

\footnotetext{
${ }^{3}$ Diz-se que se o grau médio de uma rede em crescimento aumentar, essa rede possui então um crescimento acelerado, ao contrario de redes onde o grau médio permanece o mesmo. No caso da rede de epicentros consecutivos do modelo OFC, conforme mostra a figura 5.1.3, o crescimento é acelerado, mas tende a não-acelerado para $\mathrm{L} \rightarrow \infty$.
} 


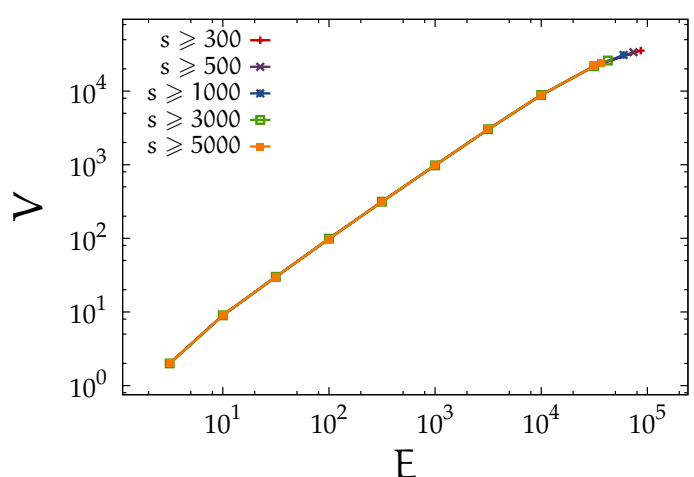

(a) $\alpha=0.25, L=400$

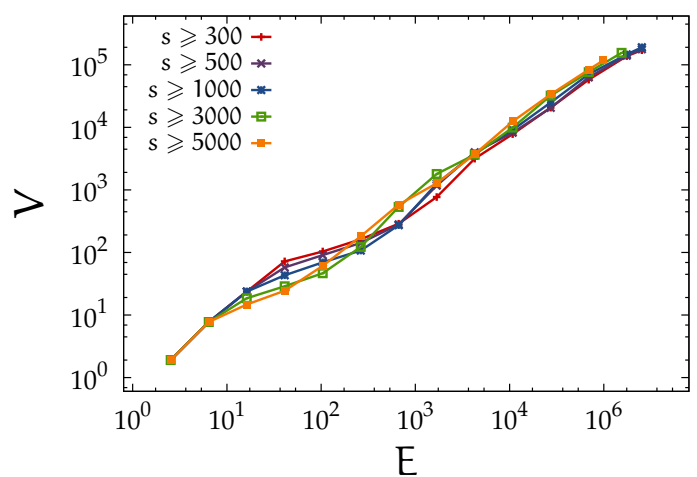

(c) $\alpha=0.20$

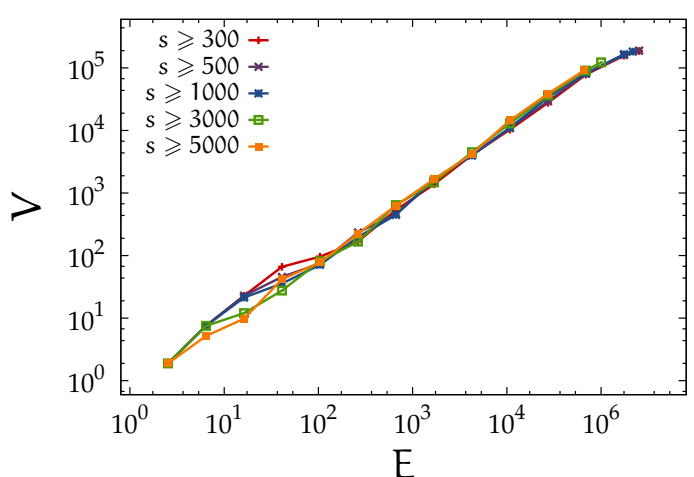

(b) $\alpha=0.22$

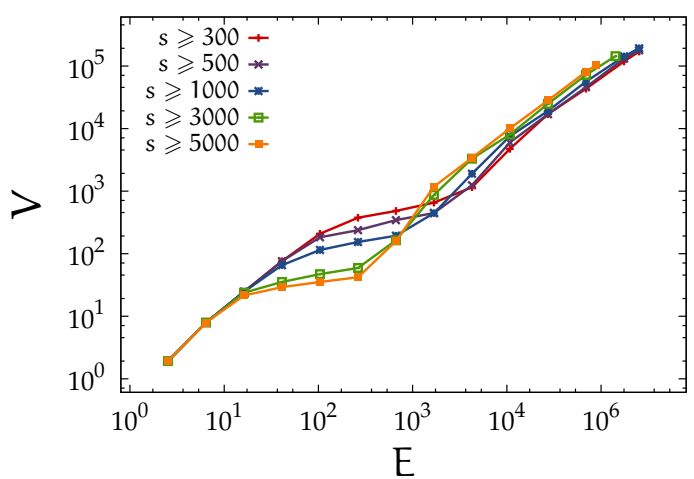

(d) $\alpha=0.18$

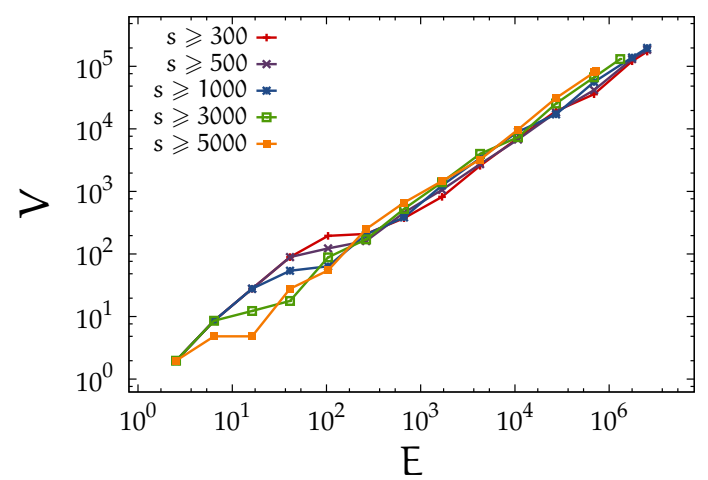

(e) $\alpha=0.16$

Figura 5.1.2: Número de vértices $V$ em função do número de eventos $E$, para $\mathrm{L}=1000$ (exceto $\alpha=0.25$ ), diversos valores de $\alpha$, e do tamanho de eventos S. 


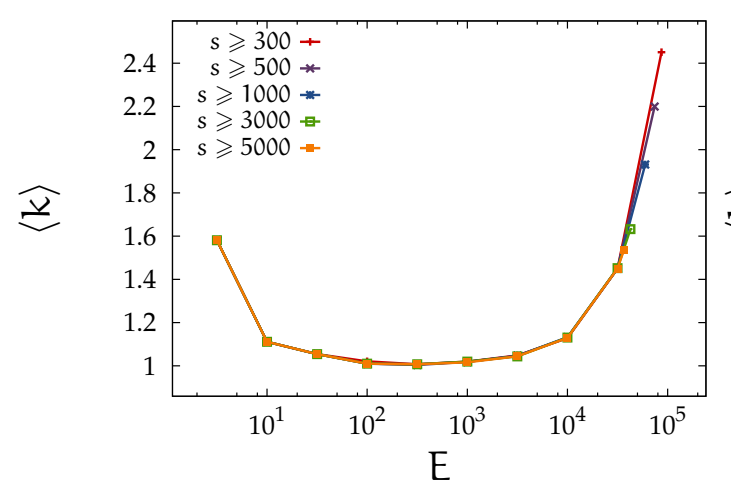

(a) $\alpha=0.25, L=400$

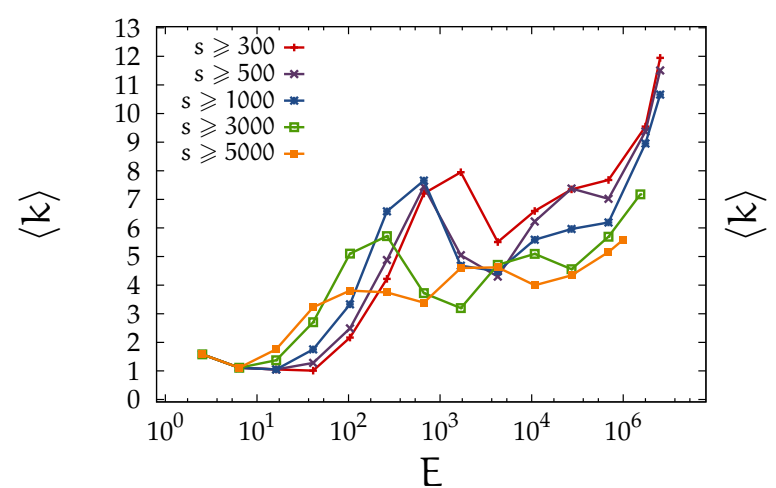

(c) $\alpha=0.20$

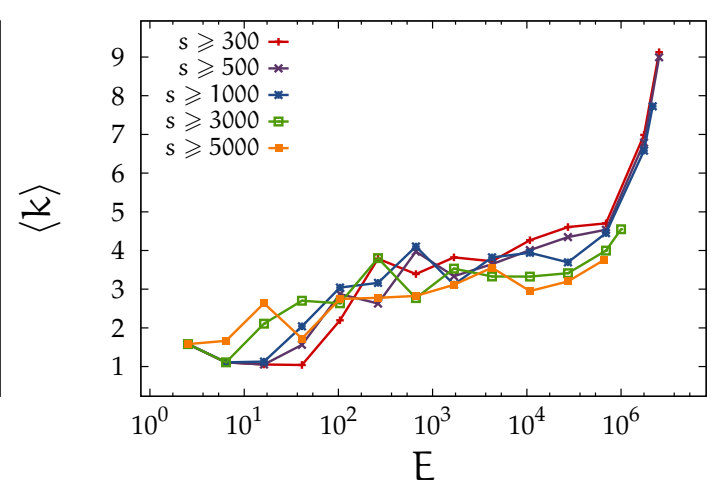

(b) $\alpha=0.22$

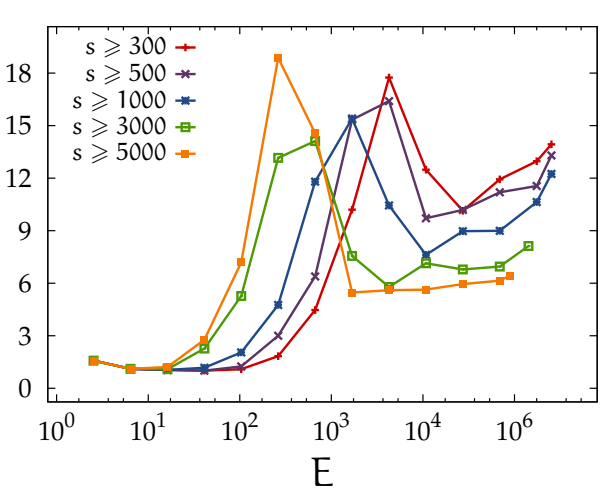

(d) $\alpha=0.18$

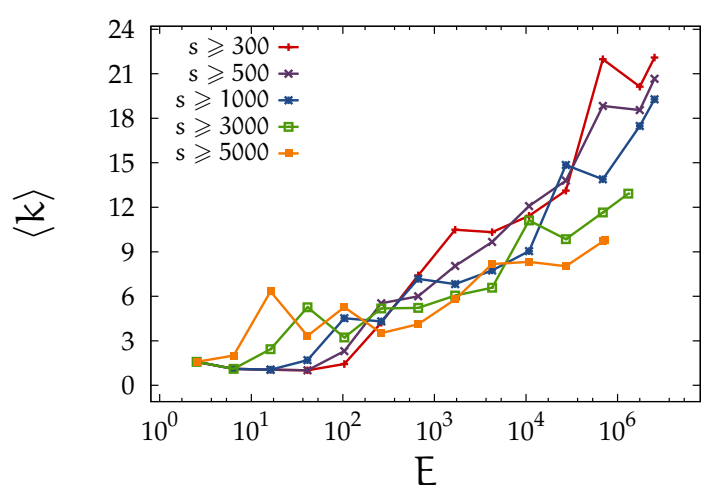

(e) $\alpha=0.16$

Figura 5.1.3: Grau de entrada médio $\langle k\rangle=E / V$ em função do número de eventos $E$, para $L=1000$ (exceto $\alpha=0.25$ ), diversos valores de $\alpha$, e do tamanho de eventos $s$. 
râmetro $\alpha$, que define o grau médio característico. Na figura 5.1.4 podem ser observadas as distribuições para diversos valores de $\alpha$, e maior número de eventos, conforme na figura 5.1.2. Novamente o caso conservativo $\alpha=1 / 4$ difere completamente dos demais, e aparenta possuir uma distribuição de graus que segue uma Poisson, como se os epicentros ocorressem aleatoriamente no reticulado. Já para $\alpha<1 / 4$, as distribuições são bastante largas, compatíveis com leis de potência $P(k) \sim k^{-\gamma}$, para $k \gg 1$. As inclinações parecem depender fracamente do tamanho dos eventos considerados, porém mais fortemente do parâmetro $\alpha$. Essa última diferença pode ser atribuída aos diferentes graus médios, que são característicos para cada valor de $\alpha$, conforme discutido acima. As distribuições da figura 5.1.4 foram obtidas considerando sempre o maior número de eventos disponíveis (na maioria dos casos $5 \times 10^{6}$ eventos, que corresponde ao máximo dos crescimentos das figuras 5.1.2 e 5.1.3). Apesar de que, nessa região, para alguns valores de $\alpha$ o grau médio tenha saído de sua região estável, e crescido devido ao efeito de tamanho finito, essa variação final do grau médio não tem um efeito muito grande na inclinação da distribuição (conforme pode ser visto mais adiante na figura 5.1.6). Essas inclinações estão, portanto, próximas do que se obtém quando o grafo se encontra com o grau médio estável. As distribuições foram obtidas para essa fase de crescimento, pois o grafo está bem maior nessa situação, e as distribuições são, então, bem mais largas e legíveis, devido à melhor estatística.

O grau de um vértice, de maneira isolada, indica simplesmente quantas vezes o sítio correspondente se tornou epicentro. As distribuições obtidas mostram que, para $\alpha<1 / 4$, a dinâmica do modelo OFC leva o estado aleatório inicial do reticulado de tensões a um estado onde a tensão está distribuída no reticulado de tal forma, que alguns sítios são epicentros muito mais vezes do que outros, e a distribuição do número de vezes que algum sítio é epicentro não apresenta nenhuma escala característica. Logo, é possível, a princípio, encontrar sítios que se tornam epicentros um número arbitrário de vezes. Além disso, essa característica não depende da faixa de tamanhos de eventos observada. Esse comportamento não trivial demonstra a robustez do comportamento livre de escala do modelo.

Como a ocorrência de epicentros no caso não-conservativo é distribuída espacialmente de maneira não igualitária, é interessante tentar identificar padrões espaciais dos sítios de acordo com o seu grau, e tentar relacioná-los com os padrões de tensões já conhecidos, como a formação de regiões sincronizadas no reticulado (ver [37] e figura 2.1.4, página 13). Quando todos os eventos são considerados, inclusive os de tamanho $s=1$, os epicentros ocorrem em regiões contínuas, cuja estrutura está relacionada com as regiões sincronizadas no reticulado (ver figura 5.1.5a). Já os eventos maiores, por serem mais raros, ocorrem mais longe temporalmente uns dos outros, o que permite uma maior reorganização das tensões, e a memória espacial passa a não ser tão evidente, e, como conseqüência, os epicentros se distribuem uniformemente pelo reticulado (ver figura $5.1 .5 \mathrm{~b}$ ).

\section{Ergodicidade}

A distribuição de graus do grafo de epicentros consecutivos permite uma análise da ergodicidade da dinâmica do modelo, como será visto a seguir. Apesar da existência de dissipação com $\alpha<1 / 4$ (e nas bordas, com L finito), existe sempre uma re-introdução de tensão no sistema após cada evento, o que faz com que tensão mé- 


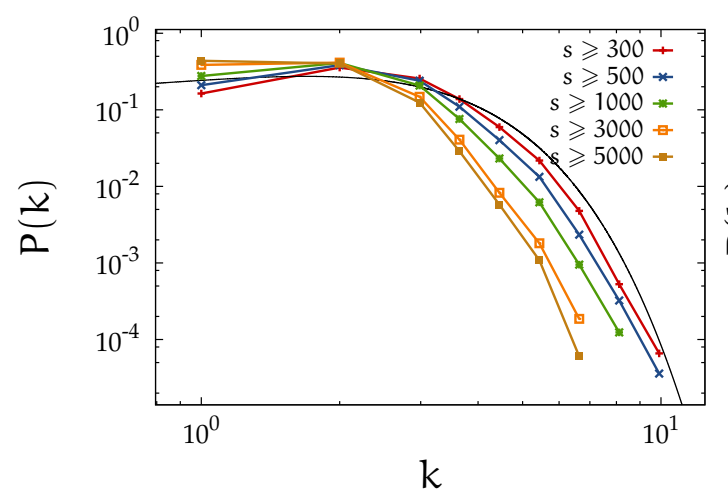

(a) $\alpha=0.25, \mathrm{~L}=400$

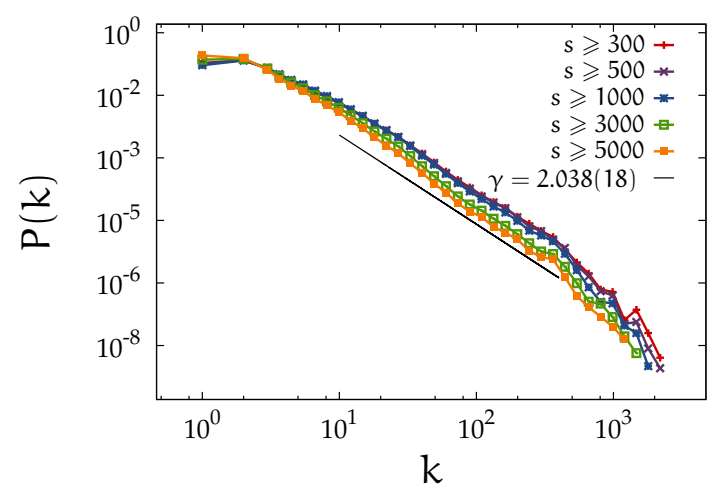

(c) $\alpha=0.20$

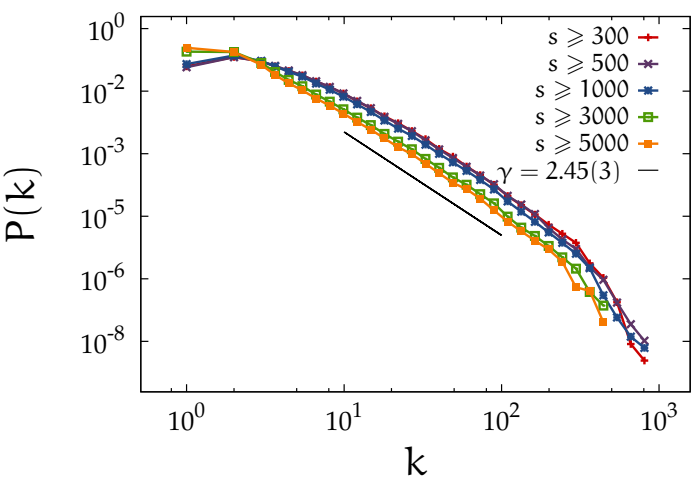

(b) $\alpha=0.22$

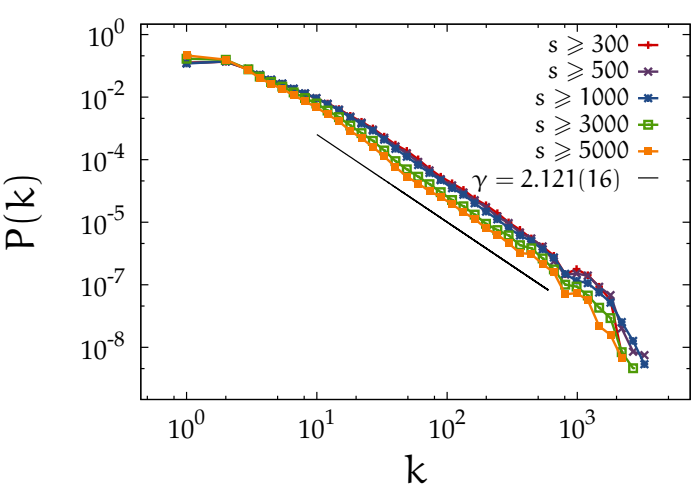

(d) $\alpha=0.18$

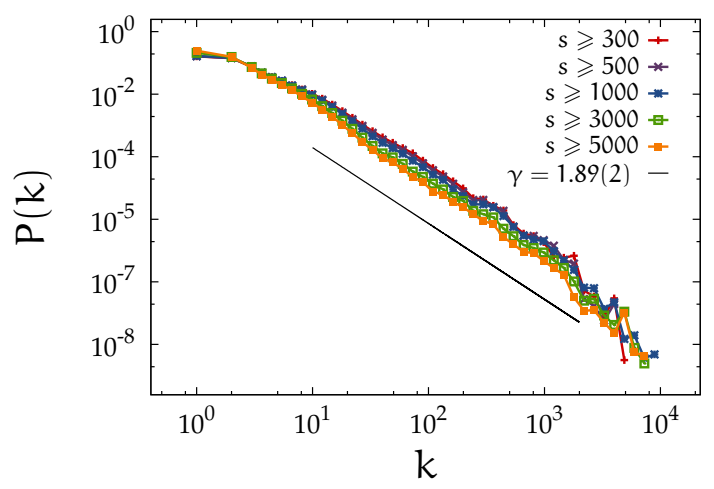

(e) $\alpha=0.16$

Figura 5.1.4: Distribuição de graus do grafo de epicentros consecutivos para $\mathrm{L}=1000, \mathrm{~L}_{\mathrm{B}}=100$, diversos valores de $\alpha$ e do tamanho de eventos s. A linha sólida em (a) corresponde a uma Poisson. As linhas sólidas restantes representam inclinações do tipo $k^{-\gamma}$, com valor de $\gamma$ indicado nas respectivas legendas. 


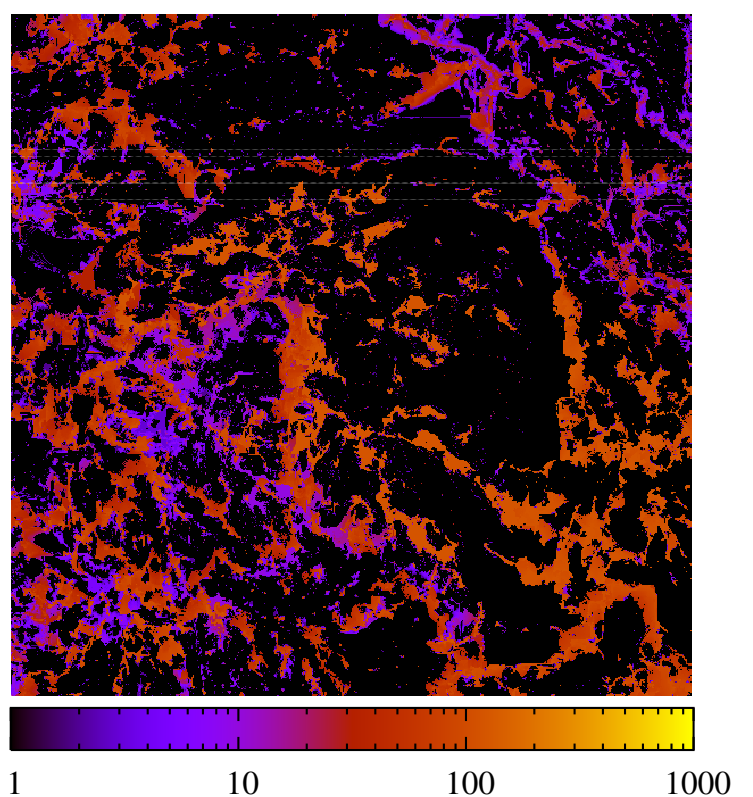

(a) $s>0$

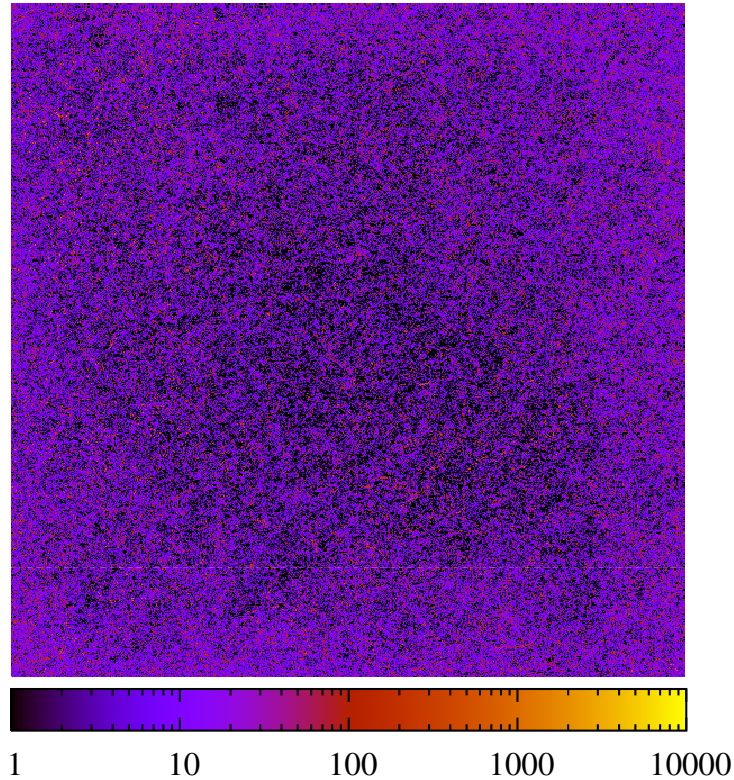

(b) $s>300$

Figura 5.1.5: Graus dos vértices distribuídos espacialmente no reticulado, para $\mathrm{L}=800, \mathrm{~L}_{\mathrm{B}}=100, \alpha=0.18, \mathrm{e}\langle\mathrm{k}\rangle \approx 17$.

dia flutue sempre em torno de um valor constante, que é, em geral, maior do que o valor médio do estado aleatório inicial $\langle z\rangle=1 / 2$. Espera-se, portanto, que o sistema obedeça a hipótese ergódica, i.e., que o espaço de fase do sistema seja sempre completamente acessível, e que num tempo infinitamente grande, ele seja visitado por completo. Como a única assimetria espacial existente no modelo é a distância de um determinado sítio à borda do reticulado, espera-se que no interior do sistema, para $L \rightarrow \infty$, onde todos os sítios estão infinitamente longe da borda, todos os sítios devam ser, em última instância, indistinguíveis. Isso significa que, esperado um tempo suficientemente grande, todos os sítios devem se tornar epicentro o mesmo número de vezes. Logo, para um número maior de eventos, as distribuições de graus de entrada mostradas da figura 5.1.4 deveriam progressivamente se aproximar mais de uma Poisson, e as distribuições observadas seriam somente um efeito transiente. O que ocorre na prática, porém, é que o tempo necessário para que isso aconteça é muito longo, e não pode ser facilmente observado computacionalmente. Dessa forma, qualquer realização numérica do modelo exibirá assimetrias, e comportamento que parece contradizer sua ergodicidade. Esse fenômeno é bastante conhecido de forma geral, e é chamado de quebra espontânea de simetria (ou ergodicidade), como é observado em sistemas desordenados em equilíbrio, como vidros de spin, onde as propriedades macroscópicas do estado de equilíbrio não correspondem às simetrias do sistema.

Para analisar como fica a distribuição de graus $\mathrm{P}(\mathrm{k} \mid \mathrm{E}, \mathrm{L})$ no limite termodinâmico, em geral, pode-se considerar dois limites específicos,

$$
P_{\infty}(k) \equiv \lim _{\substack{L \rightarrow \infty \\ \mathrm{L} \rightarrow \infty \\\langle k\rangle \gg 1}} P(k \mid E, L) \quad P_{\langle k\rangle}(k) \equiv \lim _{\substack{L \rightarrow \infty \\ E \rightarrow \infty \\\langle k\rangle=\text { cte. }}} P(k \mid E, L),
$$


que correspondem, respectivamente, a se deixar variar o grau de entrada médio $\langle k\rangle$ de maneira arbitrária, ou mantê-lo em um valor fixo, enquanto se tomam os limites $\mathrm{L} \rightarrow \infty$ e $E \rightarrow \infty$. A existência de ergodicidade, como discutida acima, implicaria na forma de $P_{\infty}(k)$ se aproximar de uma Poisson, enquanto a forma de $P_{\langle k\rangle}(k)$ permaneceria larga. $O$ tempo necessário para que $P_{\infty}(k)$ seja observado numericamente é muito alto, porém a progressão para uma distribuição Poisson pode ser detectada comparando-se as distribuições de graus de sistemas com diferentes tamanhos $\mathrm{L}$, e mesmo número de eventos E. Sistemas menores possuem um volume de espaço de fase correspondentemente menor, e, logo, também é menor o tempo necessário para percorre-lo. Como pode ser visto na figura 5.1.6, conforme menor é o tamanho do reticulado, mais encurvada é a distribuição. Estipula-se, porém, que a forma de $\mathrm{P}_{\langle k\rangle}(k)$, diferentemente de $\mathrm{P}_{\infty}(k)$, se distancie ao máximo de uma Poisson, e decaia mais lentamente, possivelmente se aproximando assintoticamente a uma lei de potência $P(k) \sim k^{-\gamma}$. Nesse limite, para qualquer grau médio finito, a distribuição de graus permaneceria larga, e isso não seria um efeito transiente.

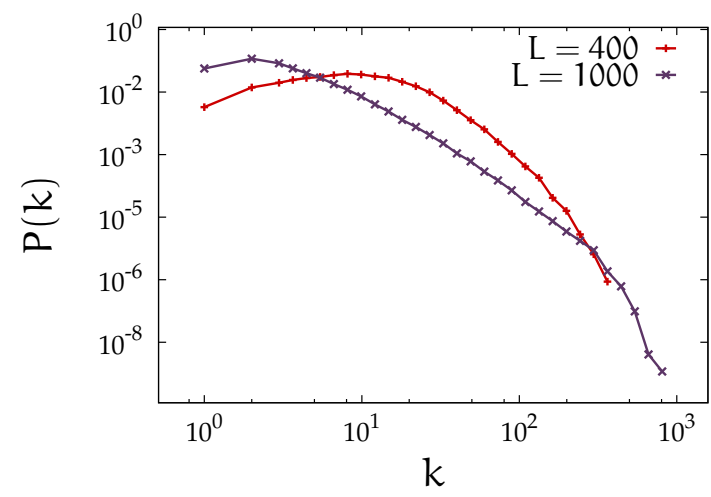

(a) $\alpha=0.22$

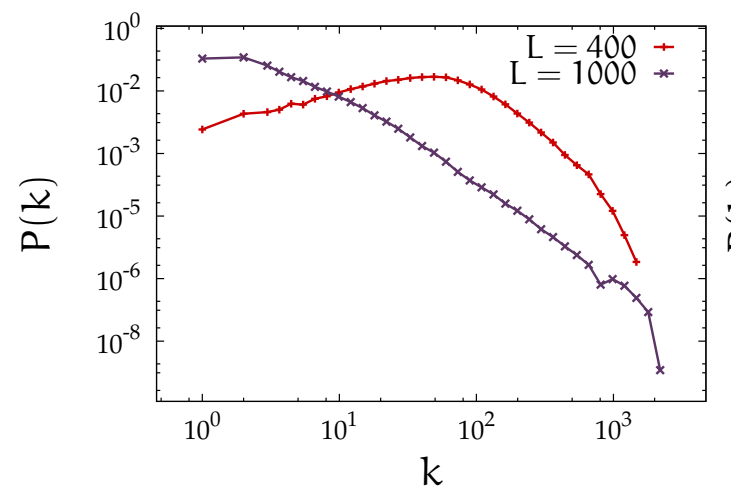

(c) $\alpha=0.18$

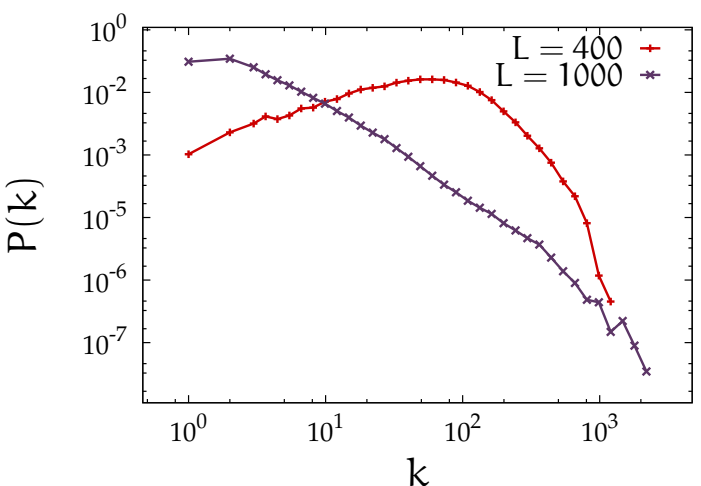

(b) $\alpha=0.20$

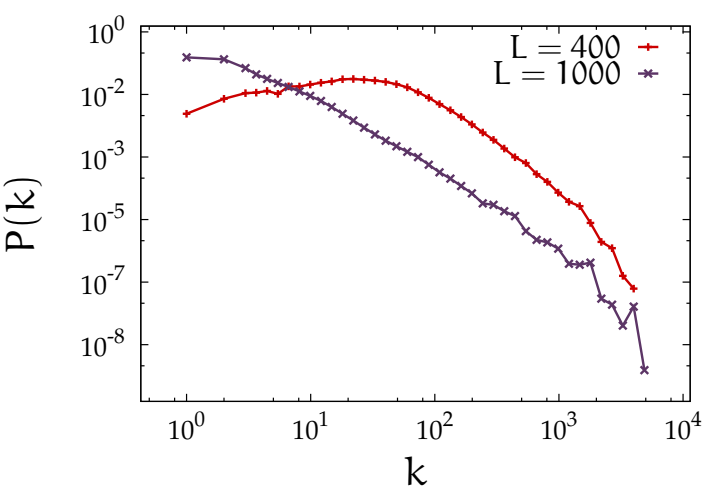

(d) $\alpha=0.16$

Figura 5.1.6: Distribuição de graus do grafo de epicentros consecutivos para $\mathrm{L}_{\mathrm{B}}=100, \mathrm{~s}>300$, diferentes valores de $\alpha$ e dois tamanhos do reticulado $\mathrm{L}$, indicados na legenda. Em todos os casos o número de eventos é $E=5 \times 10^{6}$. 


\subsubsection{Correlação de graus}

A distribuição de graus descreve a topologia do grafo de maneira limitada, pois ela contém somente uma informação global a respeito de quantos arcos incidem em cada vértice. Quase nenhuma característica da dinâmica dos epicentros pode ser inferida da distribuição de graus somente, pois nada se sabe, através dela, sobre a ordem temporal em que ocorreram os epicentros. Essa informação pode ser obtida pela correlação de graus do grafo, que descreve, em média, os graus dos vizinhos de um vértice de grau específico. Aqui será analisado simplesmente o grau de entrada médio dos vizinhos de um vértice de entrada $k, \bar{k}_{n n}(k)$. O que se observa para o modelo OFC, como pode ser visto na figura 5.1.7, é que a correlação é linear, da forma $\bar{k}_{n n}(k) \sim a+b k$, com $a$ e $b$ constantes, para todos os valores de $\alpha<1 / 4$ analisados. Para $\alpha=1 / 4$ o comportamento é novamente diferente dos demais, e o grafo é descorrelacionado, compatível novamente com uma ocorrência aleatória de epicentros. O coeficiente escalar de assortatividade (equação 4.1.5, página 50) reflete essa correlação linear, e bastante alto para $\alpha<1 / 4$, e próximo a zero para $\alpha=1 / 4$, como pode ser visto na tabela 5.1 .

\begin{tabular}{c|c|c|c|c|c} 
& $\alpha=0.25$ & $\alpha=0.22$ & $\alpha=0.20$ & $\alpha=0.18$ & $\alpha=0.18$ \\
\hline \hline$s \geqslant 300$ & $-0.001(3)$ & $0.6094(12)$ & $0.8184(15)$ & $0.7660(11)$ & $0.8363(12)$ \\
\hline$s \geqslant 500$ & $-0.005(4)$ & $0.5908(15)$ & $0.7702(16)$ & $0.7199(12)$ & $0.8036(13)$ \\
\hline$s \geqslant 1000$ & $0.007(4)$ & $0.5930(16)$ & $0.7414(16)$ & $0.7015(12)$ & $0.7672(14)$ \\
\hline$s \geqslant 3000$ & $-0.006(5)$ & $0.583(3)$ & $0.6822(19)$ & $0.6345(17)$ & $0.6238(14)$ \\
\hline$s \geqslant 5000$ & $-0.006(5)$ & $0.548(3)$ & $0.620(3)$ & $0.590(2)$ & $0.4839(18)$
\end{tabular}

Tabela 5.1: Coeficiente escalar de assortatividade (equação 4.1.5, página 50) para o grafo de epicentros consecutivos, diversos valores de $\alpha$ e do tamanho do tamanho de eventos $s$.

O mecanismo básico que pode ser inferido dessa correlação linear é o de atratores temporários na dinâmica: No momento que um certo sítio se torna epicentro, os sítios que se tornarão epicentros subseqüentes com mais probabilidade representam uma fração bem menor dos que podem se tornar epicentros eventualmente. A dinâmica fica "aprisionada" dessa maneira, até eventualmente "escapar" e os outros sítios, por sua vez, ficarem ativos. Esses atratores temporários podem ser relacionados com o ocorrência de eventos grandes, como será visto a seguir. Posteriormente, na seção 5.3, será apresentado um modelo de crescimento de grafos, baseado em variáveis escondidas, que tenta capturar esse mecanismo de atratores temporários e pode ser tratado analiticamente.

\section{Dinâmica de atração: Correlação com tamanhos de eventos}

Uma maneira de testar a hipótese levantada acima, da dinâmica de atratores temporários, é observar a evolução da topologia do grafo ao longo do tempo. Se a hipótese for válida, no momento que houver aprisionamento num atrator, o grau médio deve aumentar localmente, pois o número de vértices recebendo arestas será menor durante o período. Na figura 5.1.8 pode-se ver a variação do grau médio ao longo do 


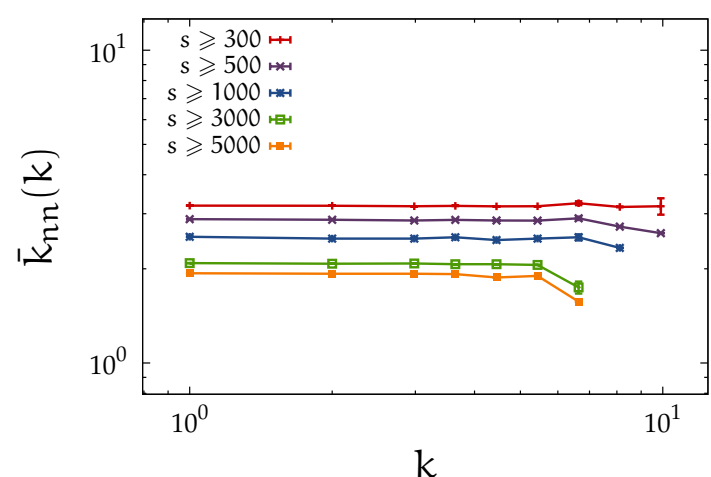

(a) $\alpha=0.25, L=400$

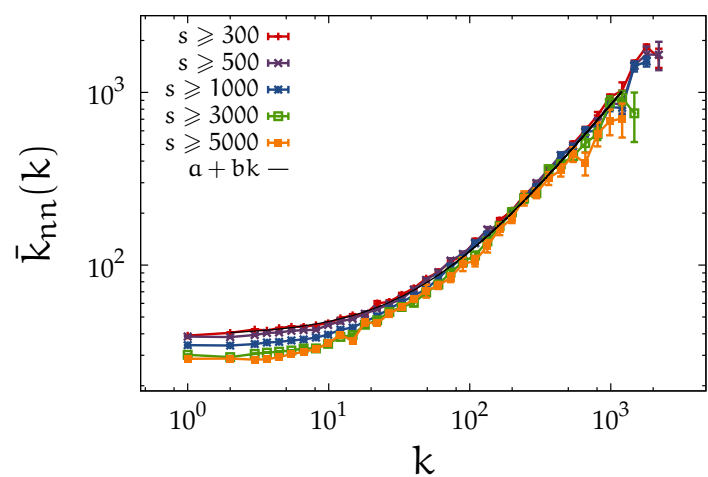

(c) $\alpha=0.20$

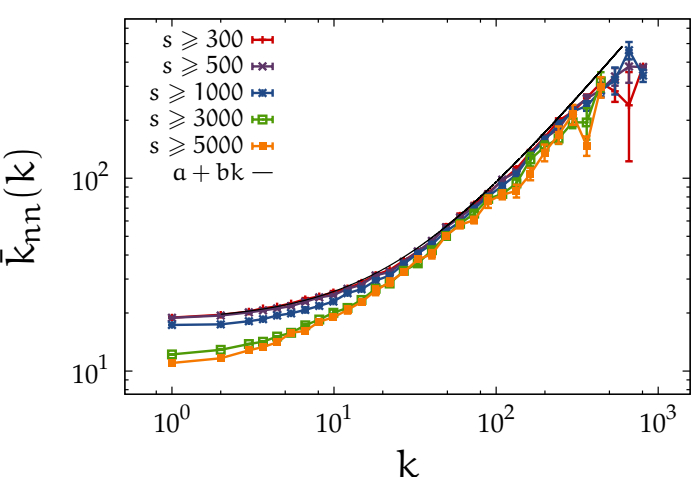

(b) $\alpha=0.22$

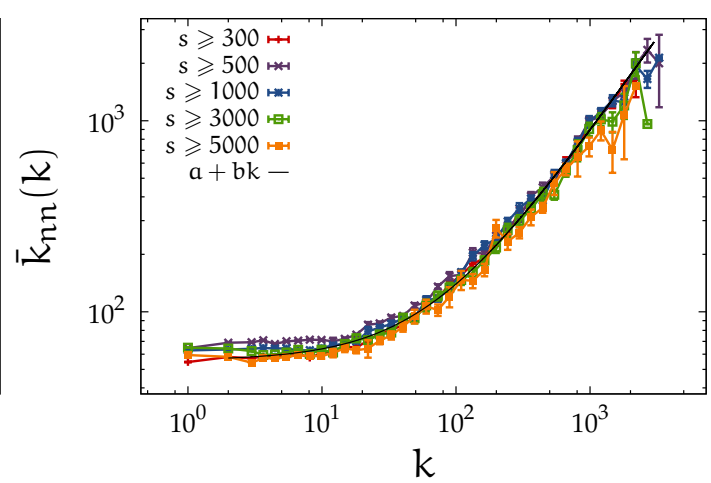

(d) $\alpha=0.18$

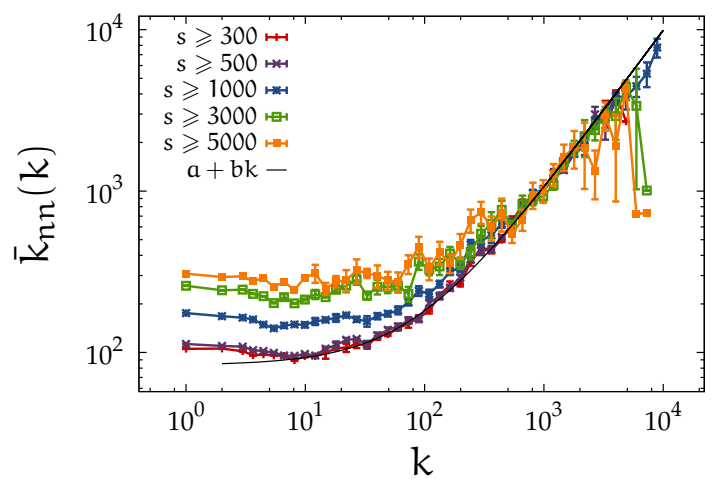

(e) $\alpha=0.16$

Figura 5.1.7: Correlação de graus do grafo de epicentros consecutivos para $\mathrm{L}_{\mathrm{B}}=1000$ (exceto $\alpha=0.25$ ), $\mathrm{L}_{\mathrm{B}}=100$, diversos valores de $\alpha$ e do tamanho do tamanho de eventos $\mathrm{s}$. 
tempo, considerando somente uma janela móvel composta dos últimos $10^{5}$ eventos, i.e., o subgrafo composto pelos últimos $10^{5}$ arcos, e seus respectivos vértices. Juntamente com a variação do grau médio, pode-se observar o tamanho dos eventos correspondentes. A variação significativa do grau médio local ao longo do tempo é compatível com a hipótese de que o tamanho da região ativa de epicentros varia com o tempo, formando atratores temporários. Além disso, essa variação aparenta estar fortemente ligada com a ocorrência de seqüência de eventos grandes, que aparentemente "destroem" os atratores e expandem a área ativa de epicentros, o que diminui o grau médio do subgrafo local.

Fora o grau médio, o grafo apresenta outras características topológicas que diferem quando a dinâmica se encontra aprisionada ou não pelos atratores. Na figura 5.1.9 pode-se ver o subgrafo correspondente aos últimos $10^{4}$ eventos na região apontada pela linha vertical à esquerda na figura 5.1.8, e fora, portanto, de um atrator temporário. Nota-se que existe uma certa repetição de seqüências de epicentros, mas a estrutura geral é razoavelmente irregular. Já a figura 5.1.10 mostra o mesmo subgrafo, porém na região apontada pela linha vertical à direita na figura 5.1.8, e, portanto, dentro do atrator temporário. Nota-se claramente que, nesse caso, a mesma seqüência de $\sim 10^{3}$ epicentros se repete diversas vezes, apenas com alguma perturbação, o que mostra a existência de sincronização marginal temporária da dinâmica.

A existência de quasi-periodicidade da dinâmica do modelo OFC, posteriormente à publicação dos resultados apresentados aqui [3], foi estudada mais a fundo por Ramos et al [92], que identificaram um período característico $t^{*}$ que varia com a dissi-

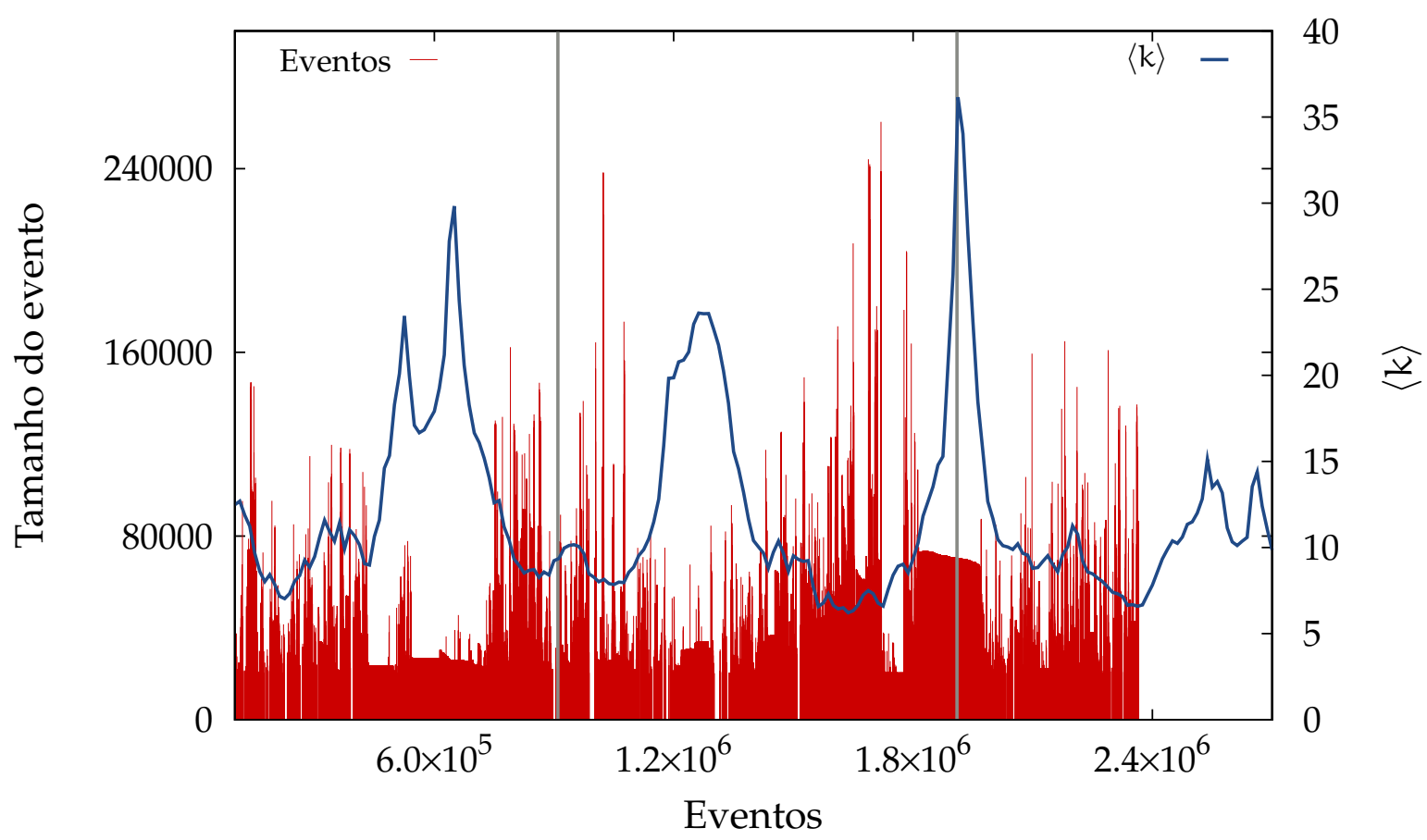

Figura 5.1.8: Variação do grau médio $\langle k\rangle$ do sub-grafo composto dos últimos $10^{5}$ eventos, sobreposto aos tamanhos dos eventos respectivos, para $\mathrm{L}=1000, \alpha=0.18$ e $s \geqslant 300$. As duas regiões marcadas com linhas verticais possuem uma topologia local representada nas figuras 5.1.9 e 5.1.9. 


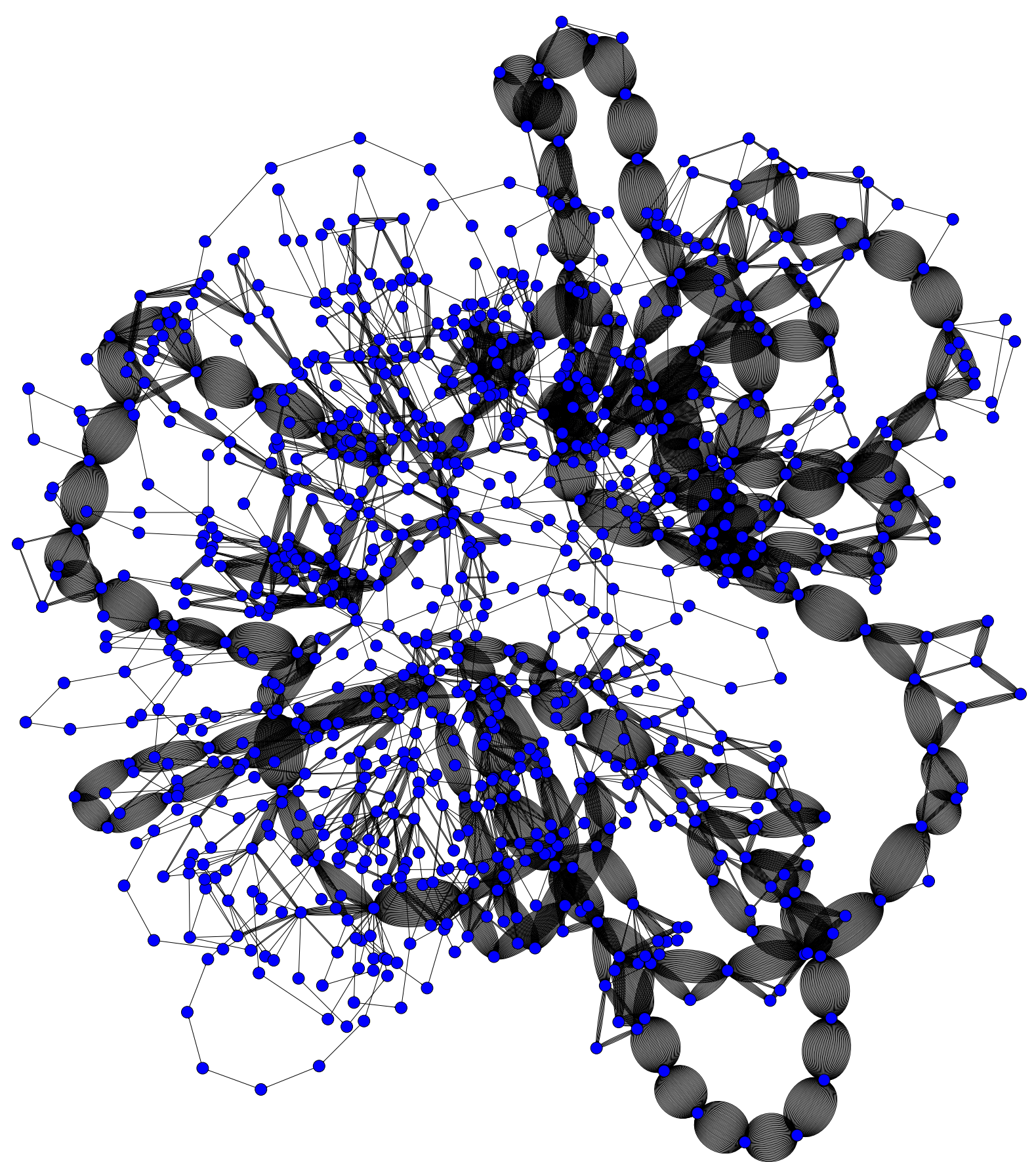

Figura 5.1.9: Subgrafo composto pelos últimos $10^{4}$ epicentros consecutivos, correspondentes à região à esquerda, indicada na figura 5.1.8. 


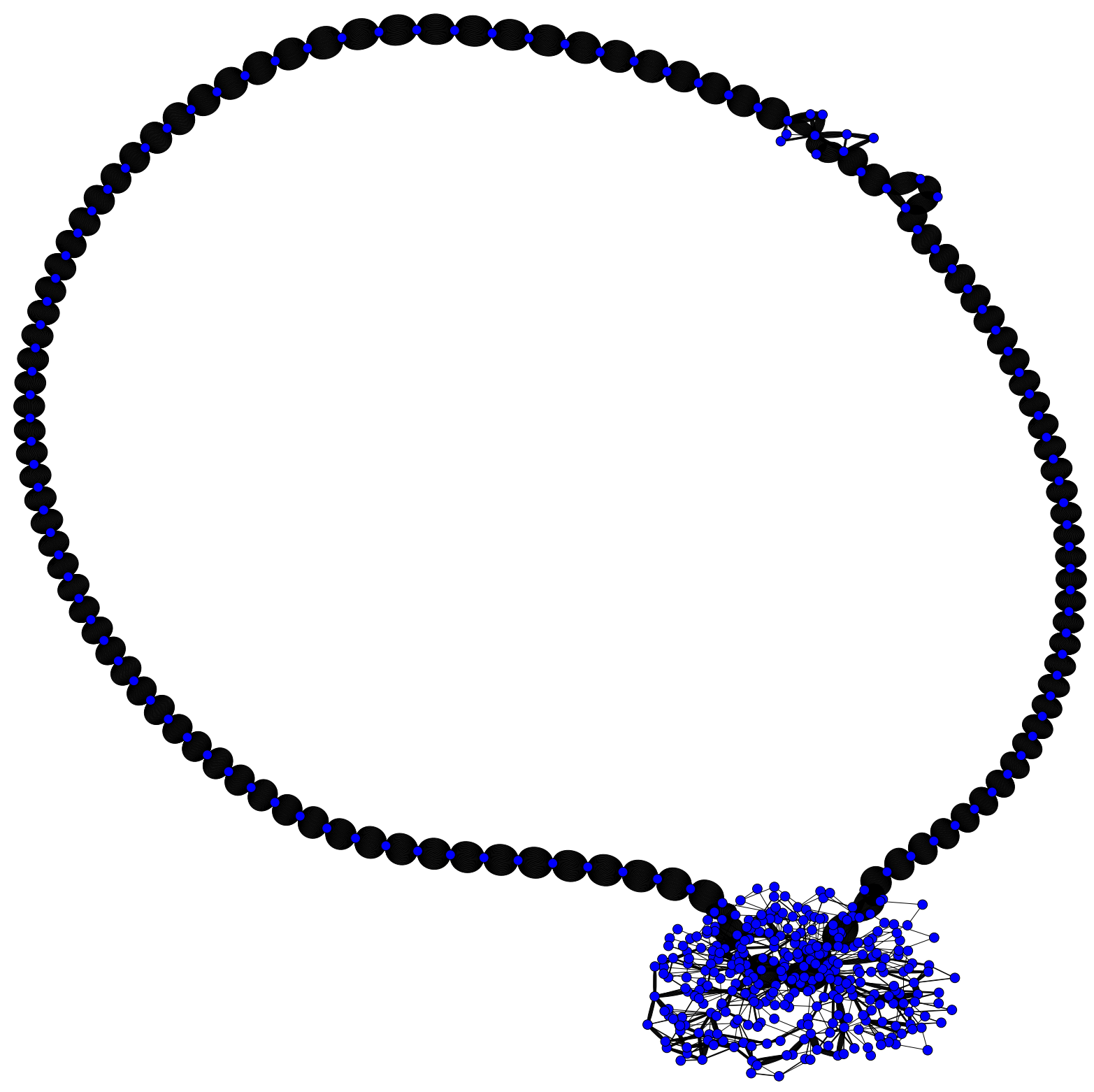

Figura 5.1.10: Subgrafo composto pelos últimos $10^{4}$ epicentros consecutivos, correspondentes à região à direita, indicada na figura 5.1.8. 
pação do sistema, $t^{*} \propto 1-4 \alpha$. Os autores de [92], porém, introduziram uma modificação importante do modelo OFC, que foi a inclusão de um aumento da tensão global em passos discretos entre eventos, ao contrario de um aumente contínuo, infinitesimalmente lento, definido no modelo original. Devido a essa modificação, não se sabe ao certo o quanto as conclusões obtidas em [92] valem para o modelo OFC inalterado.

As seqüências repetidas de epicentros levam a uma ocorrência elevada de arcos paralelos, como podem ser vistos nas figuras 5.1.10 e 5.1.9, e essa aparenta ser a causa principal da correlação de graus linear observada. De fato, se os arcos paralelos do grafo são removidos, a correlação desaparece quase por completo, como pode ser visto na figura 5.1.11. As distribuições de graus, porém, ainda permanecem compatíveis com leis de potência, quando arcos múltiplos são removidos, conforme pode ser visto na figura 5.1.12. A única diferença entre as distribuições é a inclinação da distribuição, que é maior quando se remove arcos duplos (o que é provavelmente devido ao menor grau médio do grafo nesse caso).

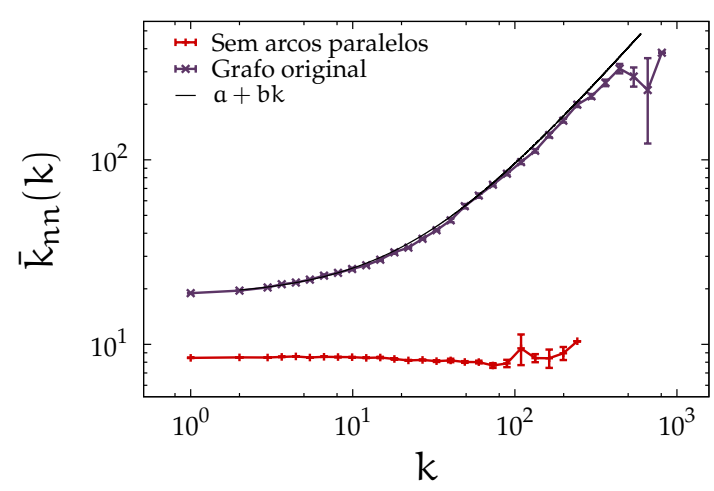

(a) $\alpha=0.22$

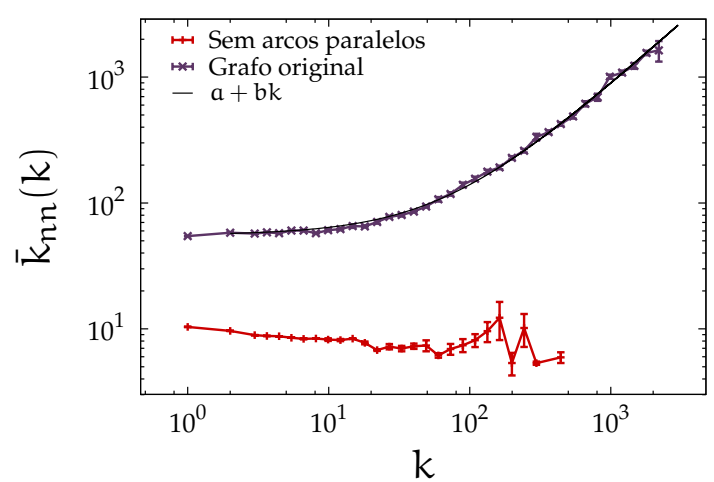

(c) $\alpha=0.18$

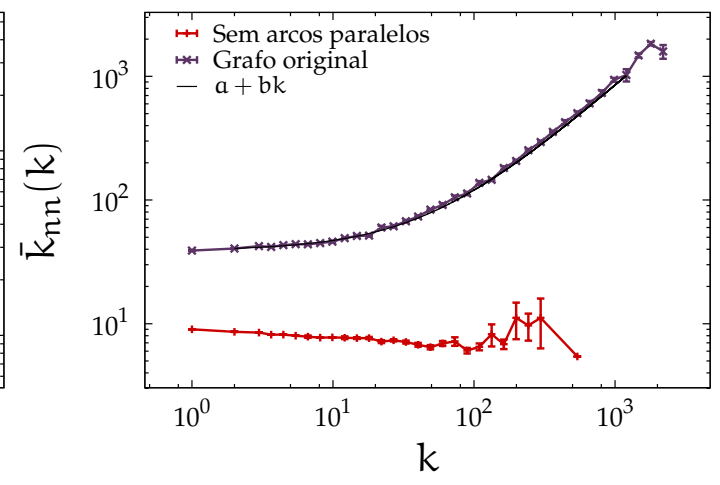

(b) $\alpha=0.20$

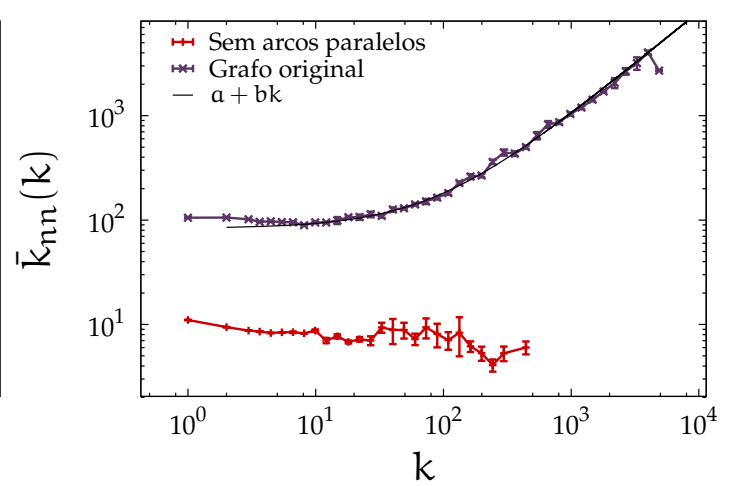

(d) $\alpha=0.16$

Figura 5.1.11: Correlação de graus do grafo de epicentros consecutivos para $\mathrm{L}_{\mathrm{B}}=1000, \mathrm{~L}_{\mathrm{B}}=100$, diversos valores de $\alpha$ e do tamanho do tamanho de eventos s. Uma das curvas representa a versão do grafo com arcos paralelos removidos. 


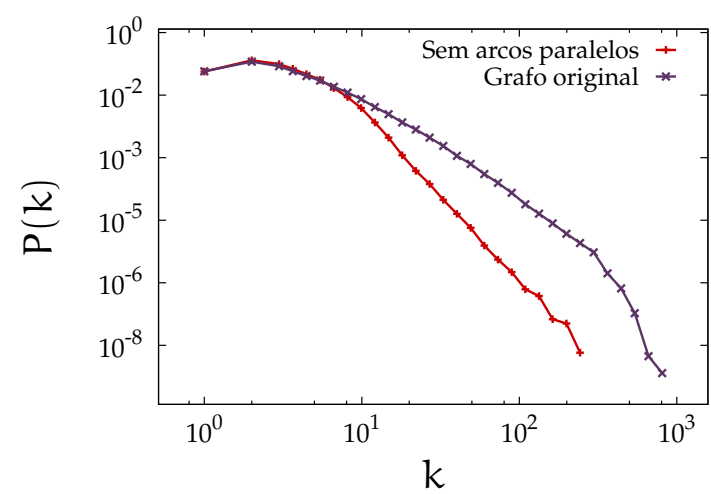

(a) $\alpha=0.22$

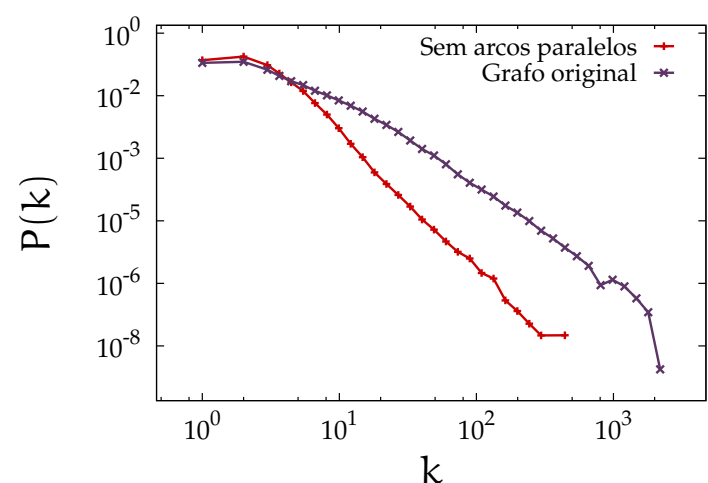

(c) $\alpha=0.18$

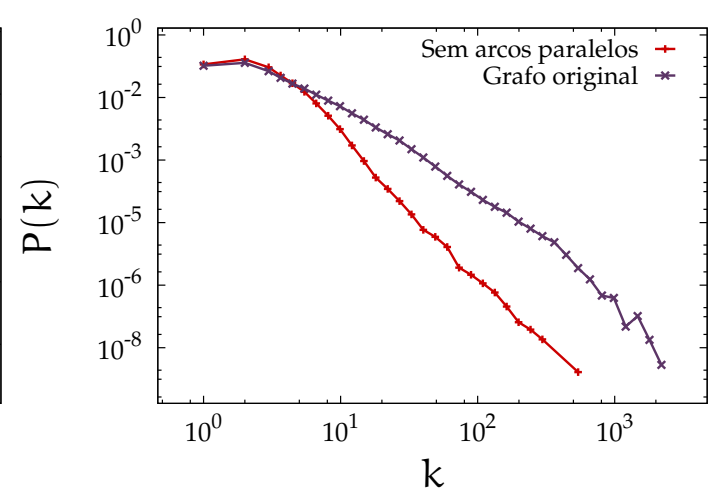

(b) $\alpha=0.20$

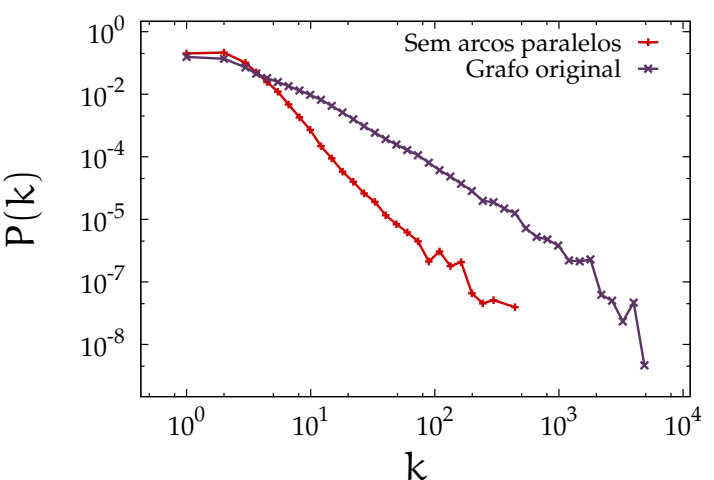

(d) $\alpha=0.16$

Figura 5.1.12: Distribuição de graus do grafo de epicentros consecutivos para $\mathrm{L}=1000, \mathrm{~L}_{\mathrm{B}}=100$, diversos valores de $\alpha$ e do tamanho de eventos s. Uma das curvas representa a versão do grafo com arcos paralelos removidos. 


\subsubsection{Renormalização espacial}

O objetivo do modelo OFC é capturar a dinâmica essencial de terremotos. Porém, epicentros verdadeiros ocorrem em um espaço contínuo, e portanto nunca retornam exatamente ao mesmo local (exceto quando há imprecisão experimental). Nesse caso, para que a rede de epicentro consecutivos tenha alguma topologia não-trivial, é necessário subdividir o espaço contínuo em células quadradas discretas, de tamanho c arbitrário, que introduz uma escala de observação. É importante determinar o quão robustas são as características da rede, quando se varia essa escala de observação. Esse análise, para terremotos reais, será feita na seção 5.2. Com o modelo OFC, uma introdução de escala de observação não é estritamente necessária, já que o reticulado no qual ele é definido já possui uma escala característica. Porém, ainda vale testar se as características da rede, nesse caso, são também invariantes sob transformações de escala espacial, o que pode ser, posteriormente, comparado com terremotos reais. Para isso, o reticulado deve ser subdivido em células quadradas, cujo tamanho pode ser variado, e as diferentes redes de epicentros devem ser comparadas. Tal comparação pode ser feita com as figuras 5.1 .13 e 5.1.14, que mostram as distribuições de graus e correlações, respectivamente, para redes obtidas com tamanhos de célula c diferentes. Observa-se que em todos os casos a distribuição obtida é a mesma. As diferenças observadas para a correlação de grau podem ser atribuídas simplesmente aos diferentes tamanhos de rede, que são menores (tanto em número de vértices, quanto de arestas, para o que grau médio seja o mesmo). Vale lembrar que, como apresentado na seção 4.1.3, página 49, para grafos aleatórios descorrelacionados, a correlação de graus esperada é $\bar{k}_{n n} \sim\left\langle k^{2}\right\rangle /\langle k\rangle$, que deve variar com o tamanho do grafo, ainda mais se $\mathrm{P}(\mathrm{k}) \sim \mathrm{k}^{-\gamma}$, já que $\left\langle\mathrm{k}^{2}\right\rangle \rightarrow \infty$ para $\gamma \leqslant 3$. Portanto, a variação observada para os diversos grafos, na região de $\bar{k}_{n n}$ que é aproximadamente constante em k, é esperada. Logo, pode-se concluir que as características gerais do grafo se mostram robustas quanto a variação da escala espacial de observação.

\subsection{Comparação com terremotos reais}

A rede de epicentros de terremotos reais foi estudada pela primeira vez por Abe e Suzuki [91], que construíram uma versão não direcionada e sem arcos múltiplos do grafo para terremotos do Japão e do sul da Califórnia. O resultado principal de [91] foi que as distribuições de graus decaiam como uma lei de potência, o que adicionou mais uma aspecto de invariância de escala ao fenômeno de terremotos. Em [91] foi analisado somente a distribuições de grau do grafo, e somente para um tamanho de célula específico ${ }^{4}$. Não foi dada a atenção à possível importância da escala de observação que é introduzida à mão com a subdivisão espacial. Essa análise será feita a seguir, não só para avaliar a robustez das características da rede de epicentros reais, mas também para que essas possam ser comparadas com a rede de epicentros do modelo OFC.

Os dados usados para a análise foram os disponibilizados pelo Southern Cali-

\footnotetext{
${ }^{4}$ Posteriormente, os mesmos autores analisaram as correlações de grau e clusterização do grafo [93], porém, novamente para somente um tamanho de célula, o que impossibilitou a detecção da correlação linear de graus de maneira clara, como está apresentada trabalho.
} 


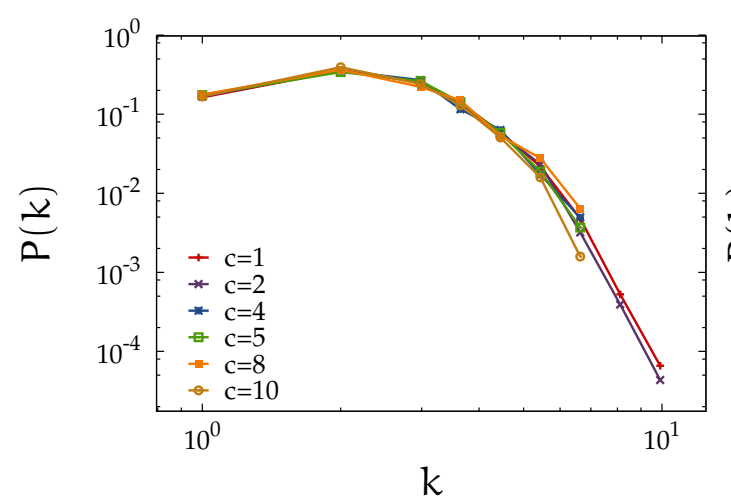

(a) $\alpha=0.25, \mathrm{~L}=400$

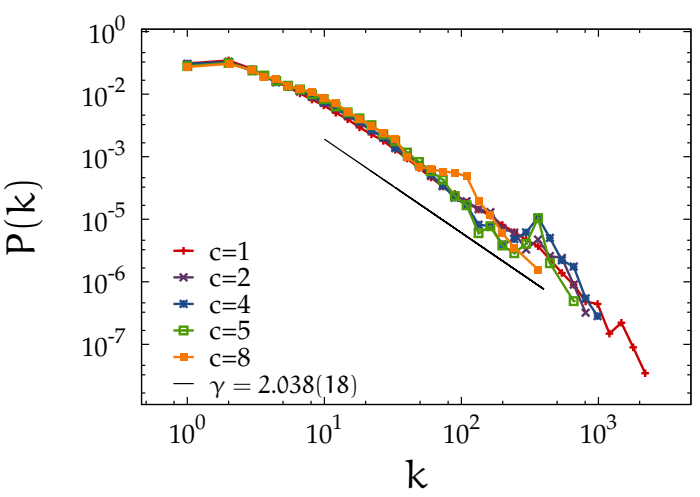

(c) $\alpha=0.20$

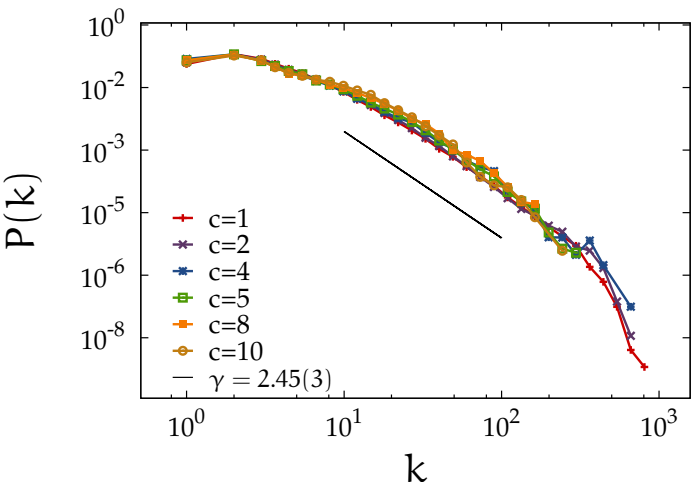

(b) $\alpha=0.22$

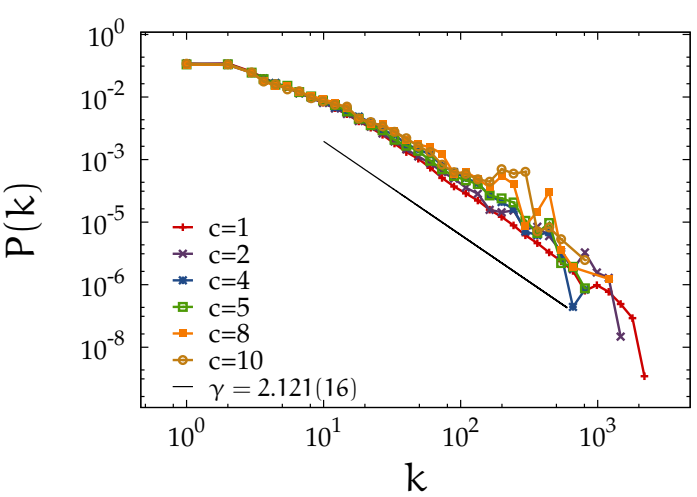

(d) $\alpha=0.18$

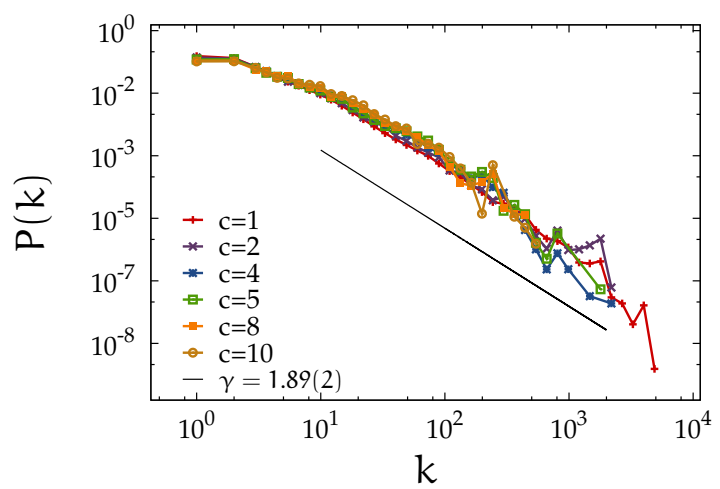

(e) $\alpha=0.16$

Figura 5.1.13: Distribuição de graus do grafo de epicentros consecutivos para $\mathrm{L}=1000$ (exceto $\alpha=0.25$ ), $\mathrm{L}_{\mathrm{B}}=100, \mathrm{~s}>300$, diversos valores $\mathrm{de} \alpha$ e do tamanho da célula c. Foram considerados eventos suficientes para que os graus médios das distribuições obtidas com diferentes valores de c fossem os mesmos. 


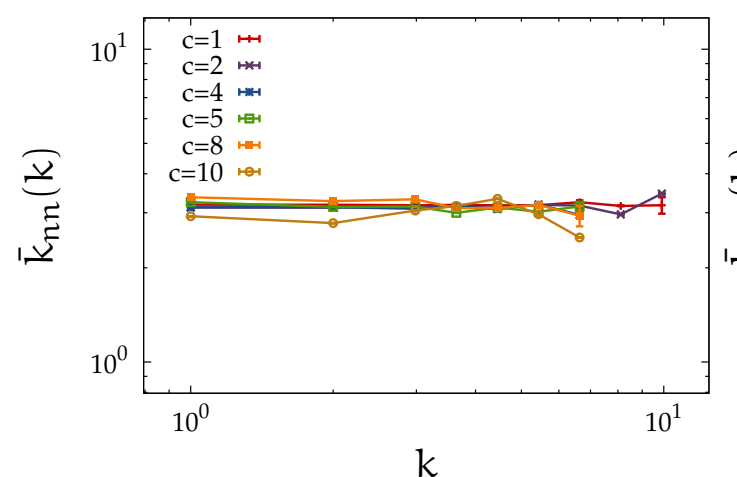

(a) $\alpha=0.25$

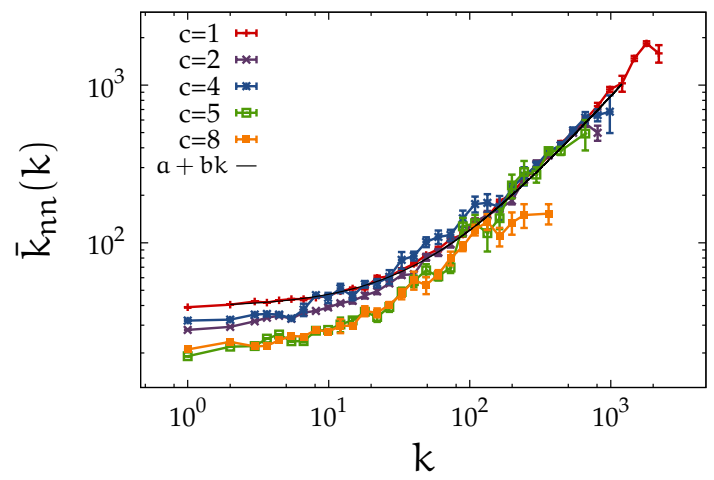

(c) $\alpha=0.20$

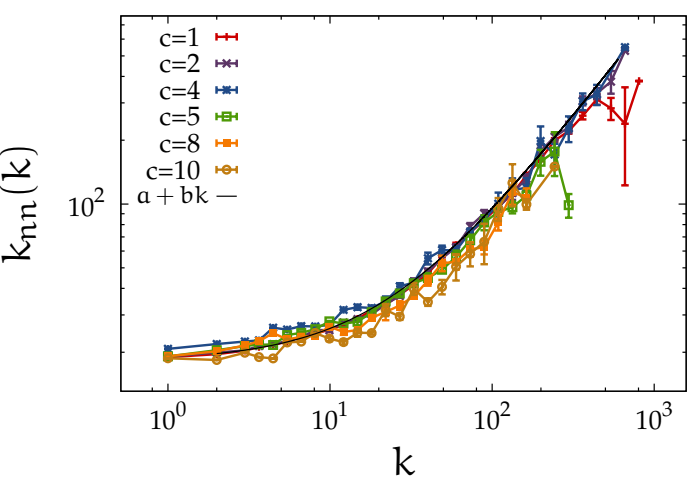

(b) $\alpha=0.22$

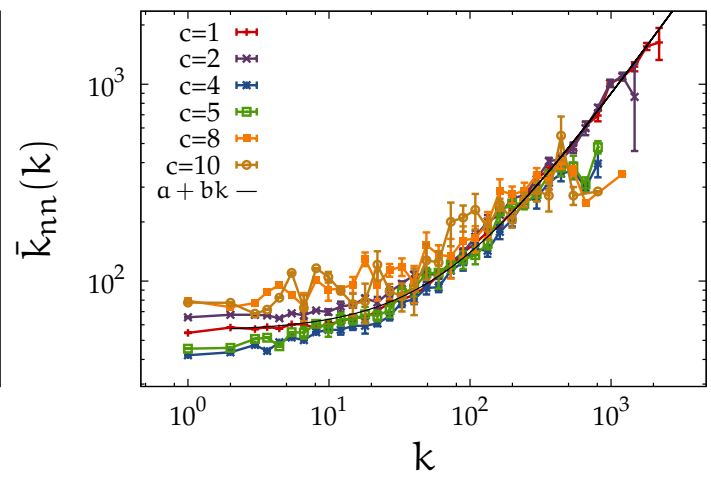

(d) $\alpha=0.18$

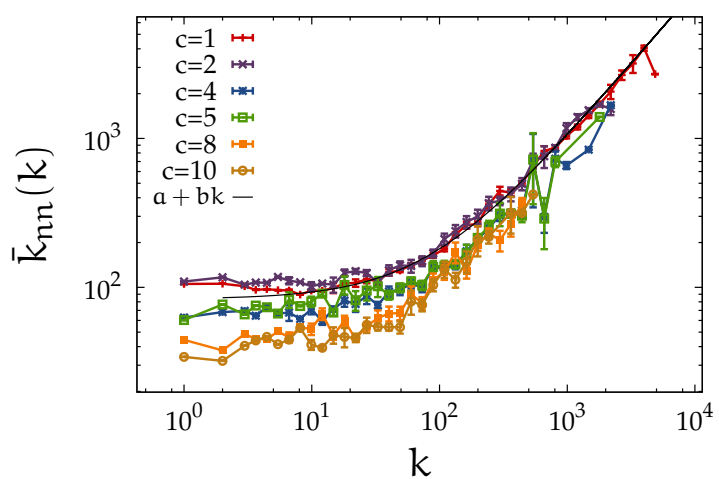

(e) $\alpha=0.16$

Figura 5.1.14: Correlação de graus do grafo de epicentros consecutivos para $\mathrm{L}=1000$ (exceto $\alpha=0.25$ ), $\mathrm{L}_{\mathrm{B}}=100, \mathrm{~s}>300$, diversos valores $\mathrm{de} \alpha$ e do tamanho da célula c. Foram considerados eventos suficientes para que os graus médios das distribuições obtidas com diferentes valores de c fossem os mesmos. 
fornia Earthquake Data Center ${ }^{5}$, e consistem no posicionamento temporal e espacial dos epicentros, e também as magnitudes, de todos os terremotos catalogados no sul da califórnia desde 1984. Os métodos de detecção e análise usados estão descritos com detalhes em [94]. Na análise aqui apresentada foram utilizados todos os eventos do catálogo $\left(\sim 3.4 \times 10^{5}\right)$, e suas posições tridimensionais ${ }^{6}$. A região espacial que o catálogo engloba $(\sim 690 \mathrm{~km} \times 620 \mathrm{~km}$, ver figura 5.2 .1$)$ foi então subdividida em células cúbicas de diferentes tamanhos lineares $c$, e a seqüência de epicentros do catálogo foi usada para construir grafos de epicentros consecutivos, como feito para o modelo OFC. As distribuições de grau para os diversos tamanhos de células podem ser vistas na figura 5.2.2. Observa-se que uma distribuição larga, compatível, a princípio, com uma lei de potência, é obtida para todos os valores de c analisados. Contudo, a inclinação da distribuição varia claramente com c, e não representa, portanto, um expoente universal como afirmado em [91]. Essa variação é, na verdade, esperada, pois o grau médio dos diferentes grafos não é o mesmo, já que foram considerados o mesmo número de eventos (arcos) e o número máximo de vértices menor conforme o tamanho da célula aumenta. Dessa forma, espera-se também que a inclinação da distribuição aumente com o tempo, se aproximando assintoticamente de $\mathrm{P}(\mathrm{k}) \sim \mathrm{k}^{-1}$, conforme mais eventos são considerados. A dependência da inclinação simplesmente com o grau médio pode ser verificada considerando grafos de diferentes tamanhos que tenham o mesmo grau médio. Como o número disponível de eventos é bem menor do que pode ser obtido numericamente com o modelo OFC, é necessário fazer uma média de diversos grafos com o mesmo grau médio, obtido em diferentes partes do catálogo, para que a estatística seja boa (ver figura 5.2.3). Dessa maneira, quanto todos os graus médios são os mesmos, as distribuições colapsam todas umas em cima das outras, com a mesma inclinação, como pode ser visto na figura 5.2.2b.

As correlações de grau também podem ser obtidas para os grafos com diferentes valores de $c$, conforme pode ser visto na figura 5.2.4. Observa-se que o grafos apresentam, de maneira semelhante ao obtido com o modelo OFC, uma correlação linear, da forma $\bar{k}_{n n}(k) \sim a+b k$, que fica mais evidente conforme $c$ aumenta, porém, somente se o grau médio é o mesmo. Novamente, grande parte das diferenças obtidas para valores diferentes de c podem ser atribuídas aos diferentes tamanhos dos grafos, como discutido para o modelo OFC.

A existência de uma correlação de graus linear leva à conclusão de que terremotos reais também apresentam a mesma dinâmica geral de atratores temporários, como no modelo OFC. É natural, portanto, que se tente verificar se esses atratores estão também relacionados com a ocorrência de eventos grandes, como observado no modelo OFC. Um resultado positivo teria, em potencial, uma relevância na elaboração de métodos de previsão de terremotos, cuja importância não é necessário enfatizar. Da mesma maneira que foi feito para o modelo OFC, na figura 5.2.5 pode ser visto a variação do grau médio do subgrafo composto somente dos últimos $10^{3}$ eventos, juntamente com as magnitudes dos eventos, para diversos valores de c. Nesse caso,

\footnotetext{
${ }^{5}$ Disponíveis em http://www.data.scec.org/ftp/catalogs/SHLK/.

${ }^{6} \mathrm{~A}$ profundidade dos epicentros (ou hipocentros, como são chamados quando se considera a profundidade) são, em geral, duas ordens de grandeza menores do que a extensão superficial onde eles ocorrem $\left(10^{1} \mathrm{~km}\right.$ e $10^{3} \mathrm{~km}$, respectivamente). Ignorar a profundidade não seria, portanto, algo muito grave, e é feito freqüentemente em análises sísmicas.
} 


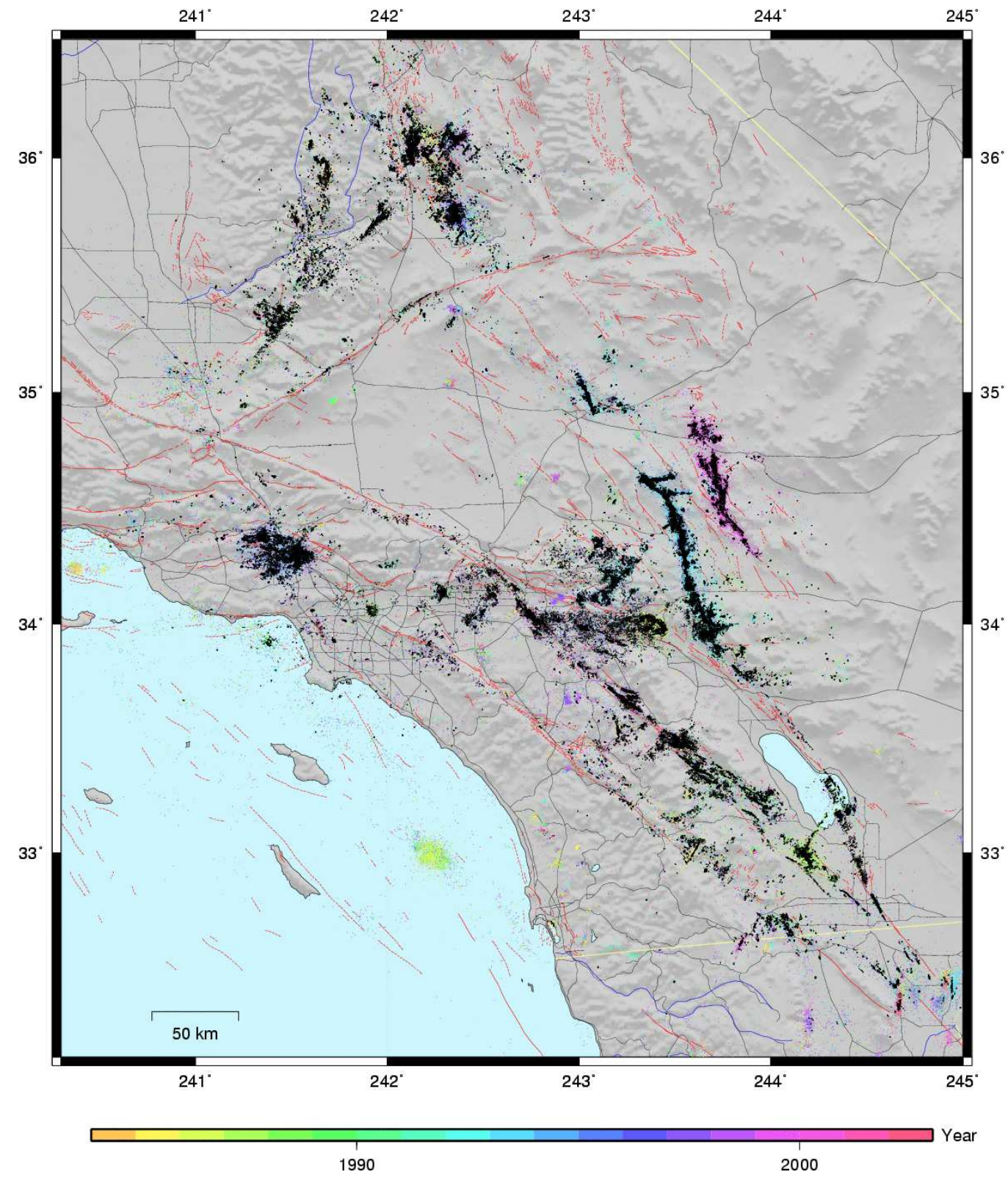

Figura 5.2.1: Epicentros do sul da Califórnia usados na análise, pertencentes ao catálogo disponível em http://www.data.scec.org/ftp/catalogs/SHLK/. 


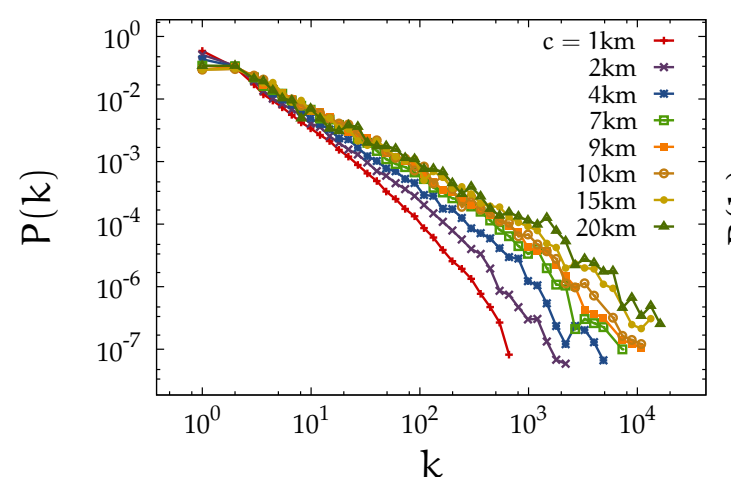

(a) $\mathrm{E} \sim 3.4 \times 10^{5}$

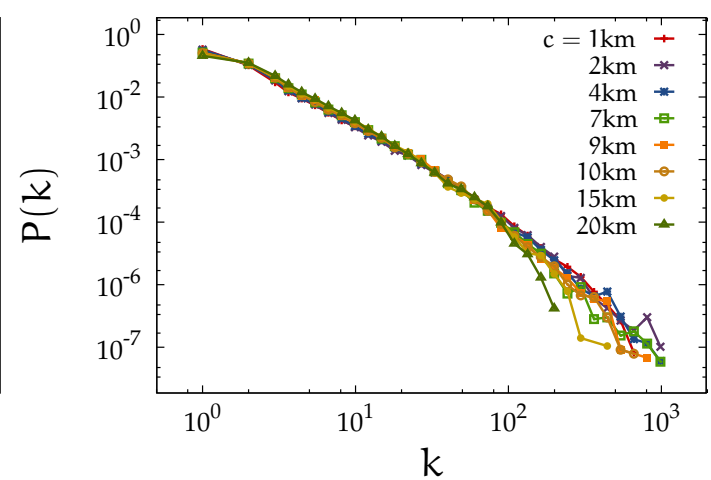

(b) $\langle k\rangle \approx 4.7$

Figura 5.2.2: Distribuição de graus do grafo de epicentros consecutivos para terremotos do sul da califórnia, para diversos valores do tamanho da célula c. Em (b) foram considerados eventos suficientes para que o grau médio $\langle k\rangle$ fosse o mesmo, conforme ilustrado na figura 5.2.3.

$\langle k\rangle$

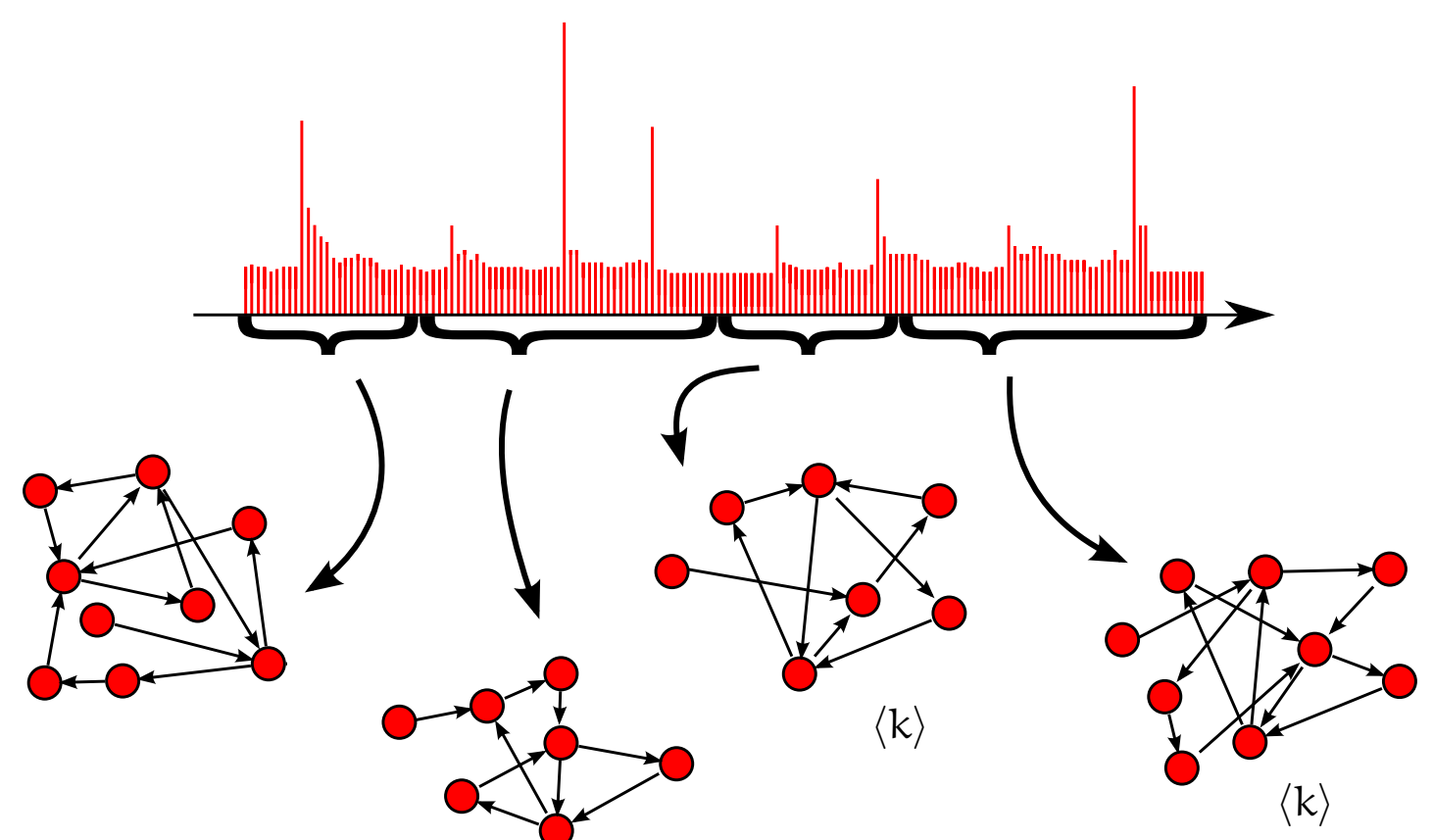

$\langle k\rangle$

Figura 5.2.3: Ilustração do método de construção de diversos grafos com o mesmo grau médio $\langle k\rangle$, que considera intervalos subseqüentes do catálogo de eventos, de tamanho variável. 


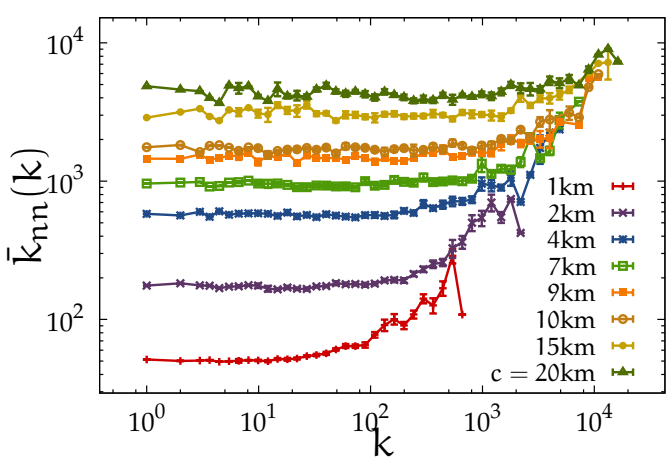

(a) $\mathrm{E} \sim 3.4 \times 10^{5}$

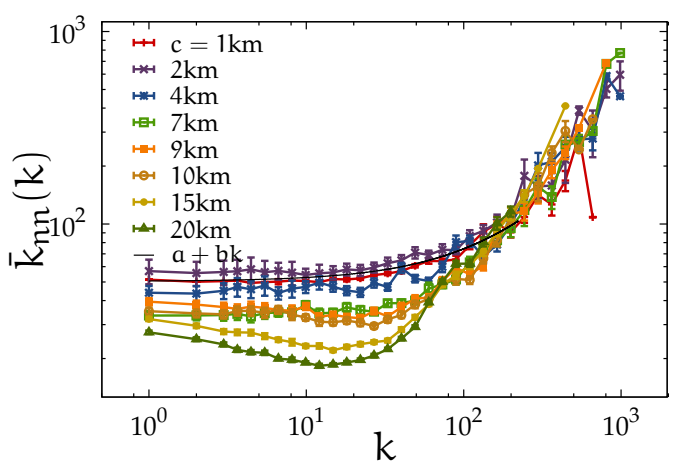

(b) $\langle k\rangle \approx 4.7$

Figura 5.2.4: Correlação de graus do grafo de epicentros consecutivos para terremotos do sul da califórnia, para diversos valores do tamanho da célula c. Em (b) foram considerados eventos suficientes para que o grau médio $\langle k\rangle$ fosse o mesmo, conforme ilustrado na figura 5.2.3.

porém, não pode ser detectada de maneira clara uma correspondência entre a variação do grau médio e a magnitude dos eventos, pelo menos não da mesma forma que é observada no modelo OFC. Em particular, nota-se que o grau médio permanece baixo na maior parte do tempo, e aumenta e diminui de uma maneira que às vezes acompanha um evento grande, e outras vezes não. Quando se aumenta o tamanho da célula, as correlações ficam mais evidentes, mas as características gerais são as mesmas. Porém, quando se considera o intervalo de tempo $\Delta \mathrm{t}$ entres eventos subseqüentes, a correlação com os aumentos do grau médio fica muito mais clara, como pode ser visto na figura 5.2.6. Nesse caso o aumento do grau médio acontece sempre logo após a queda abrupta do intervalo de tempo entre eventos. Essa alta atividade de eventos num intervalo curto de tempo é devido aos aftershocks de um evento grande, cuja taxa decai com o tempo de acordo com a lei de Omori (ver seção 2.1.7, página 20). Os tais atratores temporários, que levam a correlação linear de graus observada, são portanto, no caso de terremotos reais, a seqüencia de aftershocks de um evento, que são espacialmente correlacionados ${ }^{7}$. Isso mostra uma diferença grande entre o comportamento do modelo OFC e o de terremotos reais: Apesar do modelo OFC exibir seqüencias de aftershocks [22,23], o que rege o crescimento do grafo de epicentros é a existência de uma sincronização marginal temporária que é destruída por eventos grandes, conforme descrito acima. Tal sincronização não é observada em terremotos reais, o que marca uma diferença significativa entre a dinâmica do modelo OFC e os fenômenos sísmicos.

\footnotetext{
${ }^{7}$ É fácil, portanto, entender porque a variação do grau médio móvel (figuras 5.2.5 e 5.2.6) e a correlação de graus (figura 5.2.4) são mais claras conforme o valor de c aumenta: Os aftershocks se distribuem próximo ao evento original, e conforme maior for o tamanho da célula espacial, menor vai ser o número de células “ativas" durante o período, e maior será o grau dos vértices correspondentes.
} 


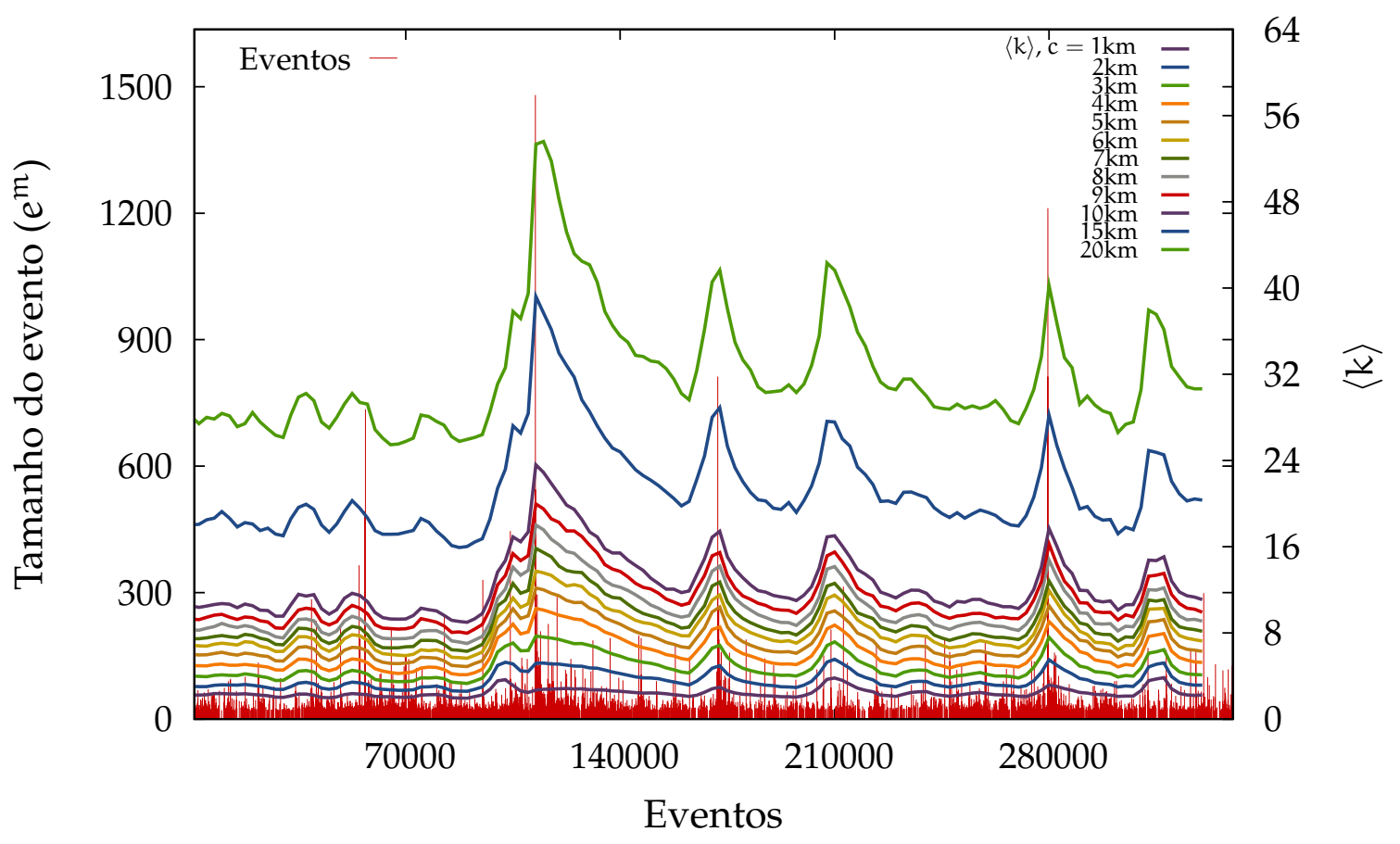

Figura 5.2.5: Variação do grau médio $\langle k\rangle$ do sub-grafo composto dos últimos $10^{4}$ eventos, para diversos tamanhos de células, sobreposto aos tamanhos dos eventos respectivos, para terremotos reais.

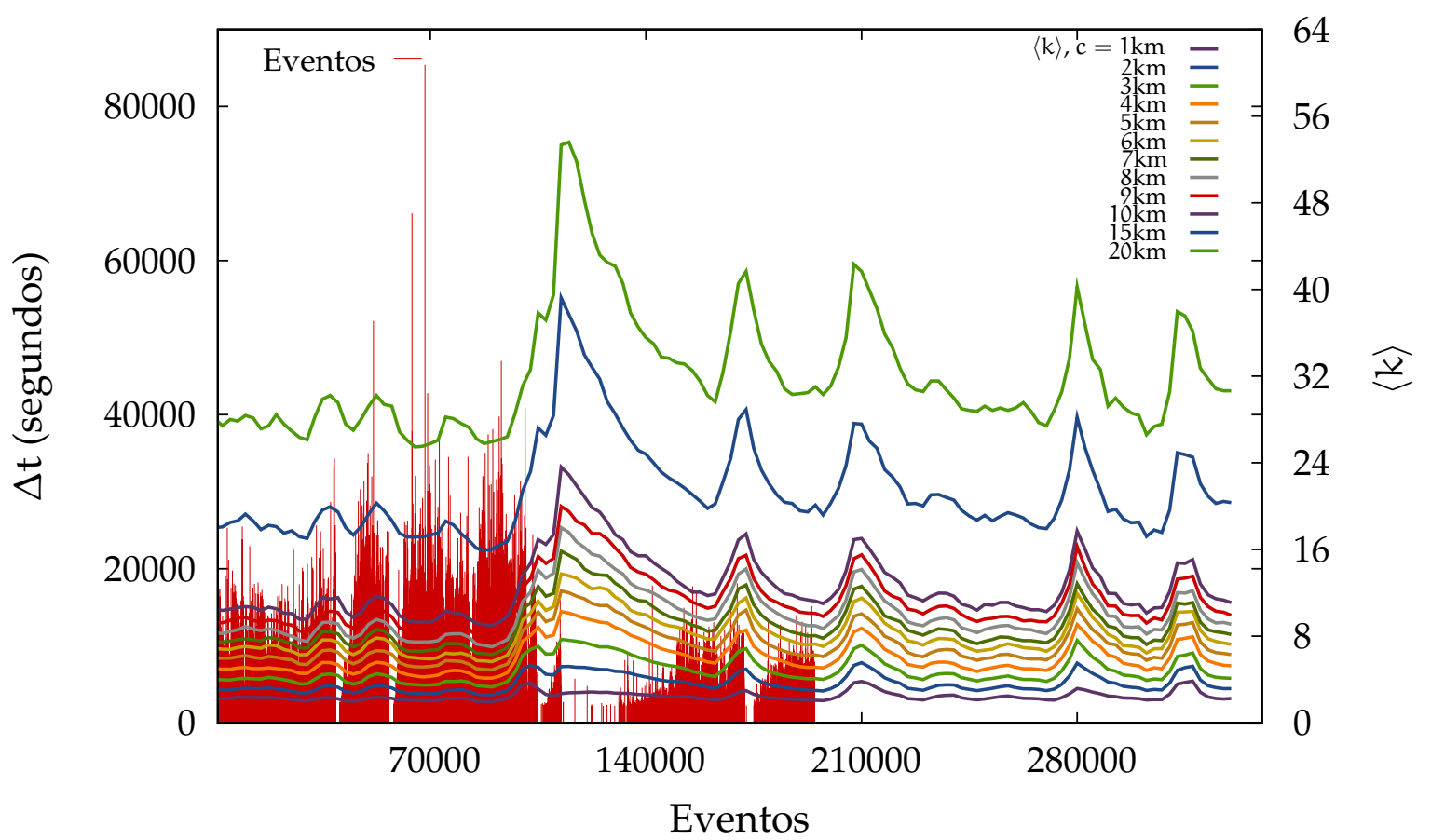

Figura 5.2.6: Variação do grau médio $\langle k\rangle$ do sub-grafo composto dos últimos $10^{4}$ eventos, para diversos tamanhos de células, sobreposto aos intervalos de tempo entre os eventos respectivos, para terremotos reais. 


\subsection{Redes de Markov com variáveis escondidas}

Nessa seção será descrito um modelo geral de grafos aleatórios, baseado em variáveis escondidas aleatórias e uma cadeia de Markov ${ }^{8}$. O objetivo desse modelo é entender com mais detalhe o tipo de dinâmica que gera grafos com algumas das propriedades que foram observadas com o modelo OFC, e também com terremotos reais. Esse modelo é baseado numa classe de grafos desenvolvida por Boguñá et al [95], mas modificado o suficiente para corresponder melhor ao grafo de epicentros analisado nesse capítulo: Ao invés de um grafo com uma topologia qualquer, aqui é considerado um grafo gerado a partir de uma seqüência de vértices, que correspondem a uma seqüência de Markov. A definição detalhada do modelo vem a seguir.

Considere um conjunto fixo de $V$ vértices, onde $V \gg 1$. Para cada vértice $v$ é atribuído uma variável escondida $h_{v}$, sorteada de uma distribuição $\rho(h)$. Um multigrafo direcionado pode ser construído por uma rede de Markov, da seguinte maneira: Iniciando-se de um vértice aleatório $\mu$, um arco direcionado $\mu \rightarrow v$ é adicionado com probabilidade $\mathrm{P}(\mu \rightarrow v) \equiv \mathrm{r}\left(\mathrm{h}_{\mu}, \mathrm{h}_{v}\right)$, e posteriormente um outro arco $v \rightarrow \omega$ com probabilidade $r\left(h_{v}, h_{\omega}\right)$, e assim por diante. Qualquer conexão é independe, portanto, da conexão feita anteriormente. Definido dessa forma, esse grafo é razoavelmente geral; De fato, qualquer processo Markoviano gera um grafo desse tipo, se os estados discretos forem considerados vértices e as transições entre eles como arcos direcionados. Dado esse procedimento básico, é possível calcular as propriedades estatísticas esperadas do grafo, como será mostrado a seguir.

\subsubsection{Distribuição de graus de entrada}

Como o grafo de epicentros consecutivos, cada vértices da rede tem o grau de entrada igual ao grau de saída. Logo, é suficiente descrever somente uma das duas grandezas. Para obter a distribuição de graus de entrada desse grafo, deve-se considerar o ensemble de grafos e a probabilidade no ensemble de um vértice $v$ receber uma conexão depois de um tempo $E$ (igual ao número de $\operatorname{arcos}), w_{v}(E)$, dada por

$$
w_{v}(E+1)=\sum_{\mu} P(\mu \rightarrow v) w_{\mu}(E)
$$

Depois de um tempo E suficientemente grande, o sistema alcança um estado estacionário, $w(\infty)$, definido como

$$
w(\infty)=\mathbf{P}^{\mathrm{n}} \mathcal{w}(\infty),
$$

onde $\mathbf{P}$ é a matriz de transição, cujos elementos são $P_{\mu v} \equiv P(\mu \rightarrow v), w(E)$ é o vetor de estados em um tempo $E$, e $n$ é o período da solução (aqui será considerado somente $n=1)$.

A probabilidade de um vértice $\mu$ ter grau de entrada $k$ após um tempo $E \gg 1$, $P(k \mid \mu, E)$, é dada simplesmente pela distribuição binomial,

$$
\mathrm{P}(\mathrm{k} \mid \mu, \mathrm{E})=\left(\begin{array}{l}
\mathrm{E} \\
k
\end{array}\right) w_{\mu}^{\mathrm{k}}\left(1-w_{\mu}\right)^{\mathrm{E}-\mathrm{k}} \approx \frac{\left(\mathrm{E} w_{\mu}\right)^{\mathrm{k}} e^{-\mathrm{E} w_{\mu}}}{\mathrm{k} !}
$$

\footnotetext{
${ }^{8}$ Os resultados foram publicados em [3].
} 
onde $w_{k} \equiv w_{k}(\infty)$, que pode ser aproximada por uma distribuição Poisson, conforme o último termo acima.

A distribuição total de graus de entrada após um tempo $E, P(k \mid E)$, é então dada por

$$
P(k \mid E)=\frac{1}{V} \sum_{\mu} P(k \mid \mu, E) .
$$

Como um vértice $\mu$ é identificado unicamente pela sua variável escondida $h_{\mu}$, devese ter que $w_{\mu} \equiv \mathcal{w}\left(h_{\mu}\right)$. Logo, $w(h)$ pode ser obtido reescrevendo-se a equação 5.3.1,

$$
w(h)=V \int_{h} r\left(h_{\mu}, h\right) w\left(h_{\mu}\right) \rho\left(h_{\mu}\right) d h_{\mu}
$$

supondo que h é uma variável contínua (a última expressão acima seria uma soma, ao invés de uma integral, se fosse discreta). Solucionando essa equação integral para $w(h)$, é possível então obter a distribuição de graus pela equação 5.3.4,

$$
P(k, E)=\int_{h} \frac{(E w(h))^{k} e^{-E w(h)}}{k !} \rho(h) d h .
$$

\subsubsection{Correlação de graus de entrada}

Uma expressão geral para a correlação de graus de entrada desse grafo também pode ser obtida, como será mostrado a seguir. A probabilidade de um vértice $\mu$, com grau de entrada $k$, se conectar a outro vértice de grau de entrada $k^{\prime}$ é dada por

$$
\mathrm{P}\left(k^{\prime} \mid k, \mu, E\right)=\frac{\mathrm{P}(k \mid \mu, E)}{\operatorname{VP}(k \mid E)} \sum_{v} \mathrm{P}(\mu \rightarrow v) \mathrm{P}\left(k^{\prime}-1 \mid v, E\right) .
$$

A probabilidade total de um vértice de grau de entrada $k$ se conectar a outro de grau de entrada $k^{\prime}$ é, então, simplesmente

$$
P\left(k^{\prime} \mid k, E\right)=\sum_{\mu} P\left(k^{\prime} \mid k, \mu, E\right),
$$

e o grau de entrada médio dos vizinhos de saída mais próximos é, então,

$$
\bar{k}_{n n}(k, E)=\sum_{k^{\prime}} k^{\prime} P\left(k^{\prime} \mid k, E\right) .
$$

Em termos das variáveis escondidas, substituindo a equações 5.3 .6 e 5.3 .3 na equação 5.3.8, e calculando a soma na equação 5.3.9, tem-se então

$$
\begin{aligned}
\bar{k}_{n n}(k, E)=1+\frac{V}{P(k, E)} \iint_{h} \frac{\left(E w\left(h_{\mu}\right)\right)^{k} e^{-E w\left(h_{\mu}\right)}}{k !} \\
\quad \times r\left(h_{\mu}, h_{v}\right) E w\left(h_{v}\right) \rho\left(h_{\mu}\right) \rho\left(h_{v}\right) d h_{\mu} d h_{v} .
\end{aligned}
$$

Sabendo-se $w(h)$, é possível, a principio, obter uma expressão para $\bar{k}_{n n}(k, E)$, conforme acima. 


\subsubsection{Dinâmica de atração e "aprisionamento"}

O objetivo agora é entender como correlações lineares e distribuições de grau tipo lei de potência podem aparecer em grafos gerados dessa maneira. Para isso, é necessário definir funções $r\left(h, h^{\prime}\right)$ e $\rho(h)$ adequadas. É evidente que o que define unicamente o grau de um vértice é a sua variável escondida. Logo, para que a correlação de graus seja da forma $\bar{k}_{n n}(k) \sim k$, para $k \gg 1$, é necessário que $\bar{h}^{\prime}(h) \sim h$, para $h \gg 1$, onde $\bar{h}^{\prime}(h)$ é variável escondida média dos vizinhos de saída de um vértice com variável escondida $h$. Com isso em mente, propõe-se a seguinte expressão geral para a probabilidade de conexão:

$$
r\left(h_{\mu}, h_{v}\right)=F\left(h_{\mu}\right)\left[\frac{G\left(h_{v}\right) h_{\mu}^{\gamma}}{\rho\left(h_{v}\right)}\left[h_{v}<h_{\mu}\right]+\frac{G\left(h_{\mu}\right) h_{v}^{\gamma}}{\rho\left(h_{\mu}\right)}\left[h_{v}>h_{\mu}\right]\right]
$$

onde $G(h)$ é a função que descreve o quão rapidamente decai a probabilidade de distribuição para $h_{v}<h_{\mu}$ (ver figura 5.3.1), e o expoente $\gamma$ define a preferência com a qual vértices com maior $h$ são escolhidos. A função $F\left(h_{\mu}\right)$ é dada simplesmente pela condição de normalização $\sum_{v} r\left(h_{\mu}, h_{v}\right)=1$. É possível ver que, usando a equação 5.3.11, existe a seguinte solução geral para a equação 5.3.5,

$$
w(h)=\frac{C}{V^{2}} F(h),
$$

onde C é uma constante qualquer. Logo, dado $G(h)$ e $\rho(h)$, é possível obter expressões para as formas assintóticas de $P(k)$ e $\bar{k}_{n n}(k)$, para $k \gg 1$.

Foram considerados algumas formas específicas de $G(h)$ e $\rho(h)$ e calculadas a distribuição e correlações de graus de entrada pelas equações 5.3.6 e 5.3.10, ambas para $k \gg 1$, para isso usando métodos analíticos de aproximação usuais. Os resultados estão resumidos na tabela 5.2.

O que se obtém é que o efeito da probabilidade de conexão dada pela equação 5.3.11 é gerar uma distribuição de graus de entrada correspondendo a uma forma

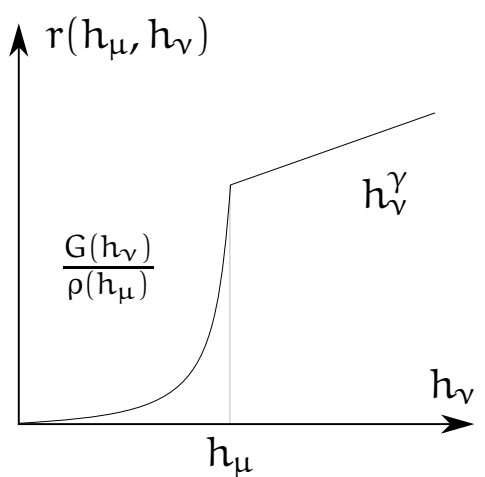

(a) Probabilidade de conexão de um vértice $\mu$ a um vértice $v$.

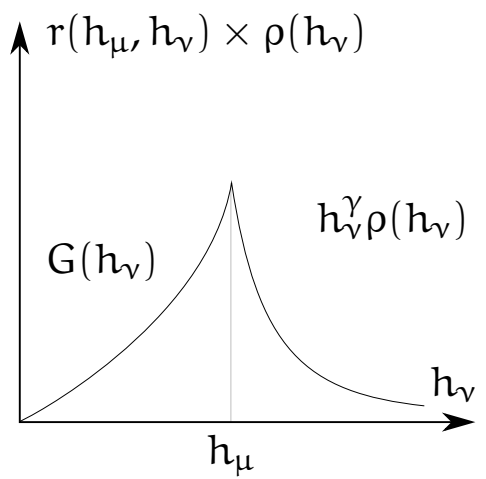

(b) Probabilidade de conexão de um vértice $\mu$ a qualquer vértice com variável escondida $h_{v}$.

Figura 5.3.1: Ilustração da probabilidade de conexão dada pela equação 5.3.11. 


\begin{tabular}{c|c|c|c}
$\rho(h)$ & $G(h)$ & $\bar{k}_{\mathrm{nn}}(\mathrm{k})$ & $\mathrm{P}(\mathrm{k})$ \\
\hline$\frac{\mathrm{h}^{-\beta}}{\beta-1}$ & 1 & $\sim \mathrm{k}$ & $\sim \mathrm{k}^{-\frac{\beta+\gamma}{\gamma+1}}$ \\
$\beta e^{-\beta h}$ & 1 & $\sim \mathrm{k}$ & $\sim \mathrm{k}^{-\frac{\gamma}{\gamma+1}} e^{-C k} \frac{1}{\gamma+1}$ \\
$\beta e^{-\beta h}$ & $e^{\xi h}$ & $\sim \mathrm{k}$ & $\sim \mathrm{k}^{-\frac{\beta+\xi}{\xi}}$
\end{tabular}

Tabela 5.2: Diferentes formas assintóticas de $\bar{k}_{n n}(k)$ e $P(k)$, para $k \gg 1$, e diferentes formas para $G(h)$ e $\rho(h)$.

"esticada" de $\rho(h)$. Se G(h) é independente de h, e logo o "aprisionamento" na região de valores de $h$ próximos é o mais fraco, tem-se o seguinte: Se $\rho(h)$ é uma lei de potência com expoente $\beta$, então $P(k)$ também é uma lei de potência com expoente no intervalo $[1, \beta]$, que se aproxima de 1 quando $\gamma$ for grande. Se $\rho(h)$ for uma distribuição exponencial, a distribuição de graus resultante é uma exponencial estendida, como indicada na tabela 5.2, que é indistinguível numericamente de uma lei de potência se $\gamma$ for relativamente alto, e o grafo for finito. Porém, se um efeito de "aprisionamento" mais forte for considerado, por exemplo com $G(h)$ que cresce exponencialmente, obtém-se que um $\rho(h)$ exponencial é suficiente para levar a uma distribuição de graus de entrada que decai como uma lei de potência. Isso significa que não é necessário supor uma invariância de escala intrínseca, representada por uma lei de potência em $\rho(h)$, para que $P(k)$ seja livre de escala. Além disso, a forma assintótica da distribuição de graus de entrada nesse caso não depende de $\gamma$, e é dominada inteiramente pelo efeito de "aprisionamento", e não pela preferência de conexão.

\subsubsection{Comparação com a rede de epicentros consecutivos do modelo OFC}

O modelo apresentado acima descreve uma maneira possível de gerar grafos com algumas das características observadas do grafo de epicentros consecutivos do modelo OFC. Existe uma diferença clara entre os dois grafos: O modelo acima não inclui a repetição de seqüencias de vértices existentes no modelo OFC. Além dessa diferença, o modelo faz uso de variáveis escondidas, que representariam, somente de uma maneira estática e não detalhada, as correlações espaciais do modelo OFC. Naturalmente, para tempos grandes, quando a ergodicidade do modelo for aparente, uma distribuição estática de variáveis escondidas não é apropriada para reproduzir o mesmo grafo. Contudo, para reticulados suficientemente grandes, onde as correlações mudariam muito lentamente, uma distribuição estática de variáveis escondidas poderia reproduzir o mesmo comportamento do grafo de epicentros, de maneira qualitativa. Para isso, portanto, teria que ser escolhida uma forma de $\rho(h)$ e $G(h)$ que mais se aproximasse da dinâmica do modelo OFC. Como foi mostrado acima, existem diversas formas dessas funções que reproduzem qualitativamente o comportamento observado. Outras características topológicas da rede, como, por exemplo, aglomeração, reciprocidade [96], e as formas completas de $P(k)$ e $\bar{k}_{n n}(k)$ teriam que ser obtidas e comparadas, para se decidir qual se assemelha mais ao comportamento do modelo 
OFC. Uma correspondência completamente satisfatória, porém, é improvável, devido as diferenças inerentes já mencionadas. Contudo, a análise do modelo de redes markovianas mostra que as características da rede de epicentros podem ser atribuídas, em grande parte, à dinâmica de atração definida, que pode gerar, de maneira espontânea, grafos com distribuição de graus livre de escala e correlação linear. Adicionalmente, esse modelo é completamente independente da análise de epicentros, e pode ser útil para a análise de outros processos. 


\section{Capítulo 6}

\section{Conclusões}

Esse trabalho foi divido em duas partes. Na primeira parte, no capítulo 3, foi feito um estudo sistemático dos eventos do modelo OFC, onde foram identificadas e caracterizadas duas propriedades não-triviais dos eventos, de acordo com onde os epicentros ocorrem no reticulado e como as avalanches se distribuem espacialmente. Foi determinado que existe um "efeito de borda" no modelo, onde os epicentros ocorrem com mais freqüência próximos à borda do reticulado. A largura desse efeito no reticulado, e também a sua intensidade, dependem do valor de $\alpha$ e do tamanho dos eventos considerados. Essas características não dependem, porém, do tamanho do reticulado L, e, portanto, seriam desprezíveis no limite $\mathrm{L} \rightarrow \infty$. A camada mais externa do reticulado que é afetada por esse efeito tem uma largura, para alguns valores de $\alpha$, da ordem de $L_{B} \sim 100$, o que inviabiliza o estudo do modelo em reticulados dessa ordem de tamanho, sem que os eventos sejam propriamente isolados. Além disso, foi feito uma análise de como os eventos de diversos tamanhos, para diversos valores de $\alpha$, se distribuem espacialmente no reticulado, durante o processo de avalanche. As características espaciais dos eventos do modelo OFC foram comparadas com as de um modelo de avalanches aleatórias, definido como um andarilho aleatório sem retorno, com ramificação. Identificou-se uma separação de escalas: Eventos menores $\left(s<s_{t}\right)$ se distribuem no reticulado de maneira distinta dos maiores $\left(s>s_{t}\right)$, que possuem propriedades invariantes. O tamanho de transição $s_{t} \sim 100$ independe do valor de $\alpha$, e é maior do que o observado para avalanches aleatórias $\left(s_{t} \sim 10\right)$. A difusão e esparcidade dos eventos possuem expoentes que não dependem de $\alpha$ e são bem diferentes de avalanches aleatórias. Essa diferenciação de tamanhos representa um critério a mais que deve ser considerado na análise do modelo, de modo geral, quando se espera obter algum comportamento que não varie com o tamanho dos eventos. Usando esse critério, e o conhecimento obtido com o estudo do efeito de borda, fez-se uma avaliação da criticalidade do modelo, através da taxa de ramificação. Observou-se que, quando o efeito de borda e os eventos menores são desconsiderados, o sistema se aproxima mais do cenário de criticalidade. Porém, o número limitado de tamanhos de reticulado analisados impossibilitou uma afirmação mais precisa sobre a criticalidade do modelo. Apesar disso, ficou claro que os dois critérios adicionais são relevantes para essa análise.

Na segunda parte, no capítulo 5, foi analisado o grafo de epicentros consecutivos do modelo OFC. Esse grafo possui uma distribuição de graus larga, compatível com uma lei de potência, assim reproduzindo uma característica não óbvia de terremotos 
reais. O expoente dessa distribuição está relacionado com o grau médio do grafo, que é característico para cada valor de $\alpha$. Adicionalmente, a topologia desse grafo permitiu que fosse identificado um tipo característico de dinâmica. A correlação linear de graus revelou a existência de atratores temporários da dinâmica, que apresentam quase-periodicidade. Esses atratores estão vinculados com a ocorrência de eventos grandes, que os destroem, e são nesse sentido precursores dos mesmos. Foi feita também uma analise da rede de epicentros consecutivos de terremotos reais, onde se enfatizou a dependência das características da rede com a escala de observação. Foi mostrado que a inclinação da distribuição de graus depende unicamente do grau médio da rede, e depende, portanto da escala de observação e do número de eventos, e não possui uma inclinação universal. Foi identificada também uma dinâmica de atratores semelhante a do modelo OFC, porém diferente em vários aspectos. Primeiramente, os atratores não estão vinculados necessariamente com a ocorrência de eventos grandes, e sim com a aumento da taxa de eventos, como previsto pela lei de Omori. O atrator temporário seria, portanto, devido a uma seqüencia proeminente de foreshocks e aftershocks, e não explicitamente correlacionado com a ocorrência de eventos grandes. Além disso não foi observado nenhum tipo de quase-periodicidade, como no modelo OFC. Essas duas diferenças salientam limitações importante do modelo em sua capacidade de reproduzir a dinâmica de terremotos reais. Por último se estudou analiticamente uma classe de redes aleatórias baseadas em uma rede de Markov e variáveis escondidas. Determinou-se que uma dinâmica de atração apropriada é capaz de reproduzir algumas características observadas da rede de epicentros, como correlação linear de graus e distribuição de graus que decai como lei de potência, sem que algum tipo de invariância de escala seja suposto de maneira a priori.

Os estudos apresentados nessa tese poderiam ser continuados de algumas maneiras. A primeira seria a análise de outras propriedades do grafo de epicentros, como o perfil de aglomeração (ver seção 4.1.4, página 50) e estrutura de comunidades [97]. De fato, chegou a ser implementado um código de detecção de comunidades (ver apêndice $\mathrm{B}$ ), porém a análise de comunidades, nesse caso, não é tão fácil, pois a própria assortatividade do grafo geraria uma estrutura de comunidades, mesmo num grafo aleatório. Teria que ser feita uma análise comparativa, analítica ou numérica, com um modelo nulo correlacionado, para que fosse determinado o número e tamanho das comunidades esperadas. Outra abordagem seria a elaboração de redes diferentes, que capturariam as correlações espaço-temporais dos epicentros de outras maneiras. Em particular, seria útil uma construção de rede que não dependesse de uma escala de observação escolhida a priori, como é necessário com o grafo de epicentros consecutivos em um espaço contínuo. O estudo de uma rede com essa propriedade, a rede de recorrências, está ainda em andamento, e se encontra resumido no apêndice A.

Algumas das propriedades da rede de epicentros, tanto do modelo OFC quanto de terremotos reais, aparentam estar relacionadas com as leis empíricas de foreshocks e aftershocks. Uma maneira de entender melhor como essas leis empíricas, isoladamente, seriam responsáveis pelas propriedades observadas, como a dinâmica de atratores encontrada, seria considerar o comportamento do modelo ETAS (Epidemic Type Aftershock Sequence) [98]. Esse modelo não é nada mais do que as leis empíricas de Gutenberg-Richter e Omori, reunidas de maneira descorrelacionada: Em sua forma 
original, o modelo define somente temporalmente como os eventos de diferentes magnitudes são gerados, obedecendo as leis empíricas mencionadas, i.e., cada evento tem sua magnitude sorteada da lei de Gutenberg-Richter, e gera uma seqüência de aftershocks, de acordo com a lei de Omori, cujos eventos individuais também terão suas magnitudes sorteadas da mesma maneira, e darão origem a própria seqüência de aftershocks, e assim por diante. É possível adicionar um termo espacial ao modelo, que rege como os aftershocks se distribuiriam espacialmente, em relação ao seu evento gerador. Nesse caso, pode-se mostrar que a difusão de eventos pode ser mapeada no problema geral de caminhos aleatórios em tempo e espaço contínuos [99]. A rede de epicentros para o modelo ETAS poderia ser construída, e uma comparação com o que foi obtido, tanto para o modelo OFC quanto para terremotos reais, poderia ser feita. 


\section{Apêndice A}

\section{Rede de recorrências de epicentros}

Aqui será apresentado de forma bastante sucinta um trabalho, ainda em fase de andamento, que foi desenvolvido em colaboração com o Prof. Jörn Davidsen, da universidade de Calgary, Canadá. A colaboração foi iniciada em Fevereiro de 2006, em Dresden, Alemanha, durante o workshop intitulado " Dynamics on Complex Networks and Applications" ${ }^{1}$, realizado no Max-Planck-Institut für Physik komplexer Systeme. Posteriormente a colaboração foi intensificada com uma visita de 3 semanas à Calgary, em Fevereiro de 2007. Apesar da grande quantidade de resultados já obtidos, e de um manuscrito já em fase avançada de elaboração, esse último foi elaborado muito recentemente, e existem alguns pontos que ainda estão sendo discutidos e analisados, de modo que se optou pela não incorporação do estudo, de maneira detalhada, nessa tese. Porém, a versão preliminar do manuscrito pode ser vista na seção A.3, e o trabalho será resumido a seguir, junto com os principais resultados já obtidos.

\section{A.1 Definição da rede de recorrências}

Uma maneira geral de analisar a estrutura causal de processos pontuais foi proposta por Davidsen et al [100], e consiste em analisar a rede de recorrências, definida da seguinte maneira: Cada evento pontual, que ocorre num espaço $\mathrm{N}$-dimensional, é representado com um vértice em um grafo. É adicionado um arco direcionado de um vértice a outro se a distancia entre os dois eventos for menor do que todos os outros eventos que ocorreram temporalmente entre esses dois eventos. Deste modo, a rede representa um processo de quebra de recordes. Se espera, portanto, que a topologia desse grafo venha capturar a estrutura causal do processo pontual sendo estudado, que pode então ser comparada com um modelo nulo aleatório, sem estrutura causal, cujas características da rede de recorrências correspondente podem ser obtidas analiticamente [100]. A vantagem central desse método é a total falta de parâmetros, e as características da rede são unicamente definidas pelos dados.

Davidsen et al [100] aplicaram esse método na análise de epicentros de terremotos reais, e obtiveram uma série de resultados que apontam para uma estrutura causal de terremotos que é bastante robusta. Em particular, descobriu-se que a distancia de recorrências (a distância correspondente a cada arco da rede) possui uma forma

\footnotetext{
${ }^{1}$ http: //www.mpipks-dresden.mpg.de/ dyonet06/
} 
universal, que não varia com o tempo, e que depende somente da magnitude dos terremotos considerados. Essa variação, por sua vez, é compatível com a variação da distancia de ruptura de terremotos. Além disso, a distribuição de tempo de recorrências também não varia com o tempo. Ambos esses resultados são diferentes do caso aleatório, onde essas distribuições variam com o tempo. Outras propriedades topológicas do grafo, como distribuição de graus, também diferem do caso aleatório.

O trabalho original, feito em colaboração com Prof. Jörn Davidsen, consiste na aplicação dessa análise ao modelo OFC, para que esse possa ser comparado com terremotos reais.

\section{A.2 Principais resultados para o modelo OFC}

Várias das características principais da rede de recorrências do modelo OFC se assemelham às de terremotos reais, como, por exemplo, a distribuição de graus. Porém, muitas das características robustas de terremotos reais, como a invariância temporal da distribuição de distâncias e tempos de recorrências não foram encontradas no modelo OFC. Além disso, não foi possível encontrar uma forma universal da distribuição de distâncias de recorrências, que obedeça o mesmo ansatz da de terremotos reais. Por último, uma característica importante da dinâmica do modelo OFC, que é a repetição de epicentros no mesmo local (algo bem evidente no estudo da rede de epicentros consecutivos, apresentado no capítulo 5) se mostrou como uma diferença crucial entre o modelo e terremotos reais. Essas repetições tiveram que ser ignoradas explicitamente, para que muitas das características pudessem ser devidamente comparadas com a rede de terremotos reais. Essa análise, portanto, pôde identificar várias diferenças e semelhanças não-obvias entre o modelo OFC e terremotos reais, que reforça boa parte das conclusões apresentadas nessa tese. Essa comparação permite uma delineação mais clara do que pode ser atribuído, em terremotos reais, a uma dinâmica de SOC, representada pelo modelo OFC, e o que deve ser atribuído a uma dinâmica mais elaborada, que possivelmente deve levar em consideração outros detalhes da dinâmica de placas tectônicas, como a existência de um sistema composto de diversas falhas, com fronteiras não muito bem definidas, e que influem uma nas outras. 


\title{
A.3 Versão preliminar do manuscrito
}

\author{
Network of recurrent events for the Olami-Feder-Christensen model \\ Tiago P. Peixoto* \\ Instituto de Física, Universidade de São Paulo, Caixa Postal 66318, 05315-970 - São Paulo - Brazil \\ Jörn Davidsen ${ }^{\dagger}$ \\ Complexity Science Group, Department of Physics \& Astronomy, \\ University of Calgary, Calgary, Alberta T2N 1N4, Canada \\ (Dated: July 28, 2007)
}

\begin{abstract}
We numerically study the dynamics of a discrete spring-block model introduced by Olami, Feder and Christensen (OFC) to mimic earthquakes and investigate to which extent this simple model is able to reproduce the observed spatiotemporal clustering of seismicty. Following a recently proposed method to characterize such clustering by networks of recurrent events [Geophys. Res. Lett. 33, L1304, 2006], we find that for synthetic catalogs generated by the OFC model these networks have many non-trivial statistical properties. This includes characteristic degree distributions - very similar to what has been observed for real seismicity. There are, however, also significant differences between the OFC model and earthquake catalogs indicating that this simple model is insufficient to account for certain aspects of the spatiotemporal clustering of seismicity.
\end{abstract}

PACS numbers: 89.75.Da,05.65.+b,91.30.Dk,91.30.Px

\section{INTRODUCTION}

Describing and modelling the spatiotemporal organization of seismicity and understanding the underlying physical mechanisms of earthquake triggering have been proven challenging. Inspired by empirical regularities which include selfsimilar scaling laws like the Omori law and the GutenbergRichter law $[1,2]$, a wealth of mechanisms and models have been proposed including the concepts of a critical earthquake, of self-organized criticality, and more generally of the seismogenic crust as a self-organized complex system requiring a so-called system approach (see, for example, Refs. [3, 4] for a review). Yet, the origin of the observed non-trivial emergent features of earthquake occurrence is still one of the main unresolved problems in the field.

Resolving this issue may require measuring the microscopic state variables - the stress and strain at every point within the earth along active earthquake faults - and their exact dynamics. However, this is currently impossible. Yet, the associated earthquake patterns are readily observable making macroscopic approaches based on the concept of spatiotemporal point processes feasible, where the description of each earthquake is reduced to its size or magnitude, its epicenter and its time of occurrence. Describing the patterns of seismicity may shed light on the fundamental physics since these patterns are emergent processes of the underlying many-body nonlinear system.

Recently, such an approach has brought to light new properties of the clustering of seismicity in space and time [5-16]. In particular, the observed spatiotemporal clustering of seismicity suggests that the usual mainshock/aftershock scenario - where each event has at most one correlated predecessor of larger magnitude — is too simplistic and that the causal

*tpeixotoeif.usp.br

†davidsenephas.ucalgary.ca structure of seismicity could extend beyond immediately subsequent events. To quantify such correlations, a general procedure for inferring a plausible causal structure from clusters of localized events has been introduced in Refs. [17, 18]. The approach allows one to study the dynamical organization of spatiotemporal activity in terms of the topology of complex networks $[19,20]$ and has led to the detection of unexpected statistical features for earthquake catalogs from California. Most importantly, the approach provides a new and independent estimate of the rupture length and its scaling with magnitude.

In this article, we investigate to which extent the simple dynamics of the Olami-Feder Christensen (OFC) model [21] is sufficient to account for the observed spatiotemporal clustering of seismicity as characterized by the above network approach. The OFC model is maybe the simplest model in the class of (supposedly) self-organized critical (SOC) models which exhibit a phenomenology resembling seismicity. This includes the aforementioned Gutenberg-Richter law for the frequency-magnitude distribution $[21,22]$ and the Omori law for aftershocks [23, 24] as well as some statistical properties of epicenter locations [25]. In addition, the OFC model is of special relevance in the context of SOC. Systems are called self-organized critical if they reach a stationary state characterized by power laws without the need for fine-tuning an external parameter such as the temperature $[26,27]$. This is typically the case for slowly driven systems with fast avalanchelike dissipation events. Unlike the paradigmatic SOC sandpile model [28], where any amount of dissipation is enough to break criticality, the existence of criticality in the OFC model with dissipation is still debated [29-34].

We show that when the causal structure of the OFC model is studied with the method mentioned above, it does indeed reveal some similarities to seismicity, such as the degree distributions of the network, and some aspects of the recurrence time and distance statistics. However, there are several important differences that severely hinder its adoption as a plausible sole description of the fundamental mechanisms responsible for the spatiotemporal correlations of seismicity. Most 
of those discrepancies seems to be tightly related with the fact that the model is discrete and defined on a regular lattice, and exhibits quasi-periodic attractors [25, 35]. These features, which are totally absent in seismicity, manifest themselves quite clearly in several aspects of the recurrence network, such as in the "closing" of the cascade of recurrences when the event happens at exactly the same position, which alters the degree correlations and the growth of the network. Also, the recurrence time and distance statics show important differences. In the OFC model, the recurrence time statistics show a characteristic time due to the fact the system is driven and finite, and the dependence on the rate of events is different to what is observed in seismicity. The recurrence distance statistics bears only a superficial resemblance to real seismicity, but fails to reproduce the same scaling with event magnitude, which in seismicity is linked to the rupture length of the earthquake [18].

The outline of our paper is as follows. In Section II, we present the OFC model, and Section III summarizes the applied method to search for signs of causal structure in spatiotemporal data. Section IV presents the results obtained for the OFC model, which are compared with real seismicity. We conclude in Section V.

\section{OLAMI-FEDER-CHRISTENSEN MODEL}

The OFC model [21] is inspired by the Burridge-Knopoff spring-block model [36], and is defined on a square lattice of size $L^{2}$. To each site $(i, j)$, a "tension" $z_{i j}$ is assigned, initially chosen at random from the interval $\left[0, z_{c}[\right.$. The entire system is driven slowly, with every $z_{i j}$ increasing uniformly. Whenever a site reaches the threshold tension $z_{i j}=z_{c}$, a relaxation event - called avalanche or "earthquake" — starts. The originating site of the avalanche $(i, j)$ is called the epicenter. The dynamics of such an event is as follows: A fraction $\alpha$ of the tension at the epicenter is transferred to each of its four neighbors $z_{i \pm 1, j \pm 1}=z_{i \pm 1, j \pm 1}+\alpha z_{i j}$, and the tension at the site itself is reset $z_{i j}=0$. If the tension at any of the neighboring sites reaches the threshold, $z_{i \pm 1, j \pm 1} \geq z_{c}$, the same toppling rules are applied. This dynamics continues until there are no more sites in the system with $z_{i j} \geq z_{c}$. Then, the tension increases uniformly again until the next avalanche occurs. Without loss of generality, we set $z_{c}=1$. The total number of topplings during an avalanche is called the "size" of the avalanche $s$. In contrast, the total number of sites that toppled (ignoring multiple topplings of the same site) is called the "area" of the avalanche $a$. The parameter $\alpha$ defines the level of local conservation of the system. For $\alpha=0.25$ the system is locally conservative and for $\alpha<0.25$ it is dissipative. We consider here only the case of open boundary conditions, i.e., the sites at the border of the lattice transfer tension out of the system (or to an imaginary neighbor), so the system is always globally nonconservative.

After a transient regime, which is increasingly longer for smaller values of $\alpha$, the system reaches a stationary state which has a distribution of event sizes resembling a powerlaw in the tail for the largest, numerically accessible system sizes (see Ref. [33] for an extensive review and the most recent results). For the values of $\alpha \in\{0.18 ; 0.2 ; 0.22\}$ and $L=1000$ we consider here, the power law tail has an unique exponent around -1.8 [30]. Yet, the occurrence of events is not uniformly distributed within the lattice, and tend to happen closer to the boundaries $[25,31]$. This "border effect" prevents the event size statistics from obeying finite-size scaling (FSS) with the size of the lattice. Only when events close to the border are ignored and an internal subset of the system is considered, FSS is realized [31]. Interestingly, this border effect does not seem to scale with system size [25]. To accommodate for these observations, we generally restrict our analysis to synthetic catalogs generated by the OFC model which contain only those events involving sites which are all at a distance of at least 100 sites away from the boundary. The effective systems size is thus $L_{\text {bulk }}=800$.

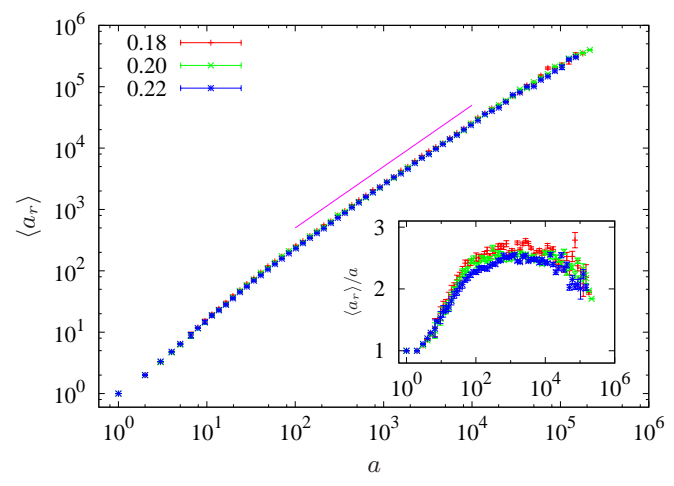

FIG. 1: (Color online) The average area $\left\langle a_{r}\right\rangle$ of the smallest rectangle on the lattice containing a given avalanche of spatial extent $a$ for different values of the dissipation parameter $\alpha$. Only avalanches originating within the bulk, $L_{\text {bulk }}=800$, are considered (see text for details). The solid line corresponds to a linear increase. Inset: Rescaled version indicating that the area scales linearly with $a$ independent of $\alpha$ for $300 \leq a \leq 30000$.

An important aspect in seismicity is the effect of the detection threshold: Earthquake catalogs are only complete above a certain magnitude value which depends on the network of seismometers deployed in a given area. Thus, it is crucial to understand how the statistical properties of seismicity vary with the magnitude of completeness. To address this issue in the OFC model, we consider catalogs for different lower threshold values of event sizes $s_{\mathrm{th}}$. Reasonable choices of these values are limited by the particular dynamics of the OFC model and lattice effects. For example, it is well known that events of size one have their own separate dynamics and obey a different statistics [33]. This is easy to justify, since events of size one will occur even if there is no self-organization, i.e., $\alpha=0$. The effects of this particular dynamics and of the discrete lattice can be clearly seen in the spatial shapes of the avalanches as summarized in Fig. 1: The ratio between the average area $\left\langle a_{r}\right\rangle$ of the smallest rectangle which contains an avalanche of area $a$ varies significantly with $a$ for all consid- 
TABLE I: Number of events $N$ in the catalogs generated by the OFC model for different values of $\alpha$ and lower size threshold $s_{\text {th }}$.

\begin{tabular}{c|c|c|c}
\hline \hline$s_{\text {th }}$ & $\alpha=0.18$ & $\alpha=0.20$ & $\alpha=0.22$ \\
\hline 300 & 1000000 & 1000000 & 1000000 \\
500 & 641933 & 676324 & 685237 \\
1000 & 327124 & 394235 & 400339 \\
3000 & 107550 & 148311 & 156189 \\
5000 & 60041 & 87102 & 94968 \\
10000 & 22205 & 40208 & 42991 \\
30000 & 2547 & 8432 & 8909 \\
\hline \hline
\end{tabular}

ered values of $\alpha$. Here the average is taken over all events of area $a$. Only for events above a certain size $a_{\text {th }} \sim 10^{2}$, does $a_{r}$ scale linearly with $a$ (see inset of Fig. 1) - independent of $\alpha$. Yet, this linear scaling is limited to values of $a<3 \times 10^{4}$ due to the finite system size. Since area and size of an avalanche are basically identical for the parameters of $\alpha$ considered here [39], we only consider catalogs with $s_{\text {th }} \in[300 ; 30000]$ in the following.

To be more specific, each synthetic catalog generated by the OFC model contains $N$ consecutive events or avalanches occurring after the statistically stationary regime has been reached for $L=1000$ and $L_{\text {bulk }}=800$. Each event $k$ is characterized by its size $s_{k}$, its epicenter location $(i, j)_{k}$ and its time of occurrence $t_{k}$ measured in terms of the avalanche number (or equivalently in the natural time scale of the OFC model [37]). For this choice, $t_{k}$ is an integer. The various catalogs for different values of $\alpha$ and $s_{\text {th }}$ are given in Table I.

\section{NETWORK OF RECURRENCES}

We analyze the catalogs generated by the OFC model according to a recently proposed method which has been proven helpful in characterizing the spatiotemporal clustering of seismicity and in detecting causal signatures between events $[17,18]$. The essential idea is to extend the notion of a recurrence to spatiotemporal point processes: An event is defined to be a recurrence of any previous event if it occurred closer in space than all intervening events. Recurrences are therefore record breaking events with respect to distance. By linking each event to its recurrences, a directed network [40] of recurrences is obtained: Each event $a_{k}$, with $k=1, \ldots, N$, is a vertex in the network and a directed edge from $a_{k}$ to $a_{m}$ exists for $k<m$ if $a_{m}$ is a recurrence of $a_{k}$, i.e., if the distance between $(i, j)_{m}$ and $(i, j)_{k}$ is smaller than the distance between $(i, j)_{k}$ and $(i, j)_{k}^{\prime}$ for all events $a_{k^{\prime}}$ with $k<k^{\prime}<m$. This definition assumes that the events are ordered according to their occurrence in time $t_{k}$. Obviously, each recurrence or edge can be characterized by the time interval $t=t_{m}-t_{k}$ between the two connected events $k$ and $m$ and by the spatial distance $l$ between the two. Note that the mapping of the dynamics to a network is entirely data-driven and does not impose any arbitrary space and time scales other than those associated with the given event or earthquake catalog — in contrast, for example, to methods typically used to define aftershocks. Comparing the statistical properties of the network of recurrences for a given catalog to the properties of a network obtained for a random point process without any causal relation between events highlights relevant parts of the underlying causal dynamical process(es) generating the pattern. For the OFC model, such a random process or null model can be obtained by shuffling the given catalog: Shuffle the sizes and the epicenter locations separately while keeping the times of occurrence. For a random spatiotemporal point process in continuous time and space, several statistical properties of the network of recurrences are even known analytically [18].

In the following, we do not only compare the network properties for the OFC model with those for its random or shuffled counterpart but also with the network properties found for earthquake catalogs from southern California [17, 18]. The particular focus is on the network topology and on distributions associated with the temporal and spatial distances between an event and its recurrences.

\section{RESULTS}

\section{A. Topological properties}

Networks can be generally characterized by their topology as, for example, summarized in Refs. [19, 20]. Here, we focus on four aspects, namely network growth with time, the degree distribution, degree-degree correlations and the clustering coefficient.

\section{Network growth}

An important aspect of the analysis of networks and their dynamics is the change in their topology with time. In the case of networks of recurrences, this corresponds to the situation when a given catalog is extended to cover a longer time period and, thus, contains more events. In general, some properties of the network of recurrences depend on its size $N$. For the case of random, uncorrelated events, one such property is the average degree $\langle k\rangle$. It grows with the size of the network as $\langle k\rangle \approx \ln (N)$ for $N \gg 1$ [18]. While this is roughly what we find for the shuffled catalogs generated by the OFC model, the original catalogs show quite a different growth as can be seen in Fig. 2. Independently of the value of $\alpha$, the average degree "saturates" quickly around a value close to 5 , and grows very little even after the catalog is a couple of orders of magnitude larger. When the catalog is shuffled, a portion of the growth can be well represented by $\ln (N)$ but only up to $\sim 10^{4}$ events, after which it grows more slowly.

These observations illustrate one of the main features of the OFC model, namely the repetitive occurrence of events originating at the same location. Obviously, there is a finite probability that the epicenters of two events are identical since the OFC model is defined on a discrete and finite lattice. If this happens, the cascade of recurrences of the first event ends or is "closed" and the number of recurrences of 


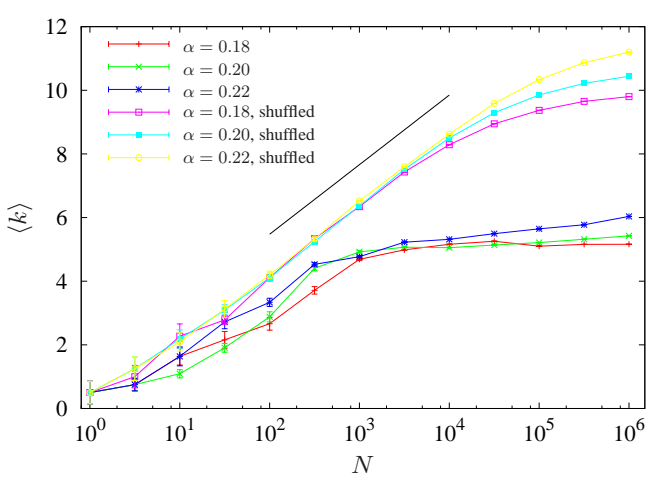

FIG. 2: (Color online) Mean degree $\langle k\rangle$ vs. catalog size $N$ for $s_{\text {th }}=300$ and different values of alpha, for the regular and shuffled catalogs generated by the OFC model. $N=10^{6}$ corresponds to the full catalogs - see Table I. The solid line is of the form $0.95 \ln (N)+$ const.

this event does not increase further. If this were exclusively due to the finiteness of the discrete lattice, one would expect this to happen according to a geometric distribution with average $L_{\text {bulk }}^{2}$. In particular, this effect would not be relevant in the thermodynamic limit $L_{\text {bulk }} \rightarrow \infty$. However, our simulations show that the repeated occurrence of the same epicenter happens much more frequently in the OFC model. This is due to marginal synchronization of neighboring sites [38] and the existence of quasi-periodic patterns in the dynamics of the OFC model $[25,35]$ causing the repeated triggering of epicenters and similar events. Consequently, the average out-degree of networks generated by the OFC model grows rather slowly. Moreover, the growth in $\langle k\rangle$ basically saturates after $\sim 10^{3}$ events as Fig. 2 shows. This is at least two orders of magnitude smaller than the rough estimate of $L_{\text {bulk }}^{2}=6.4 \times 10^{5}$ based on the lattice size.

When the catalog is shuffled it does not entirely remove the effect. This is because the average frequency of a given epicenter does not change and the distribution of these frequencies is quite broad, resembling a power law [25]. Yet, the shuffling destroys the relatively short periods of quasi-periodic dynamics and increases in most cases the time it takes for the activity to return to the same epicenter and to close a given cascade of recurrences. Thus, $\langle k\rangle$ is larger and its growth is very close to the predicted behavior for random, uncorrelated events until the effects of the broad distribution of the epicenters frequencies become important after $\sim 10^{4}$ events.

These high-frequency repetitions of epicenters can be characterized by the ratio of the number of events with "open" (i.e. not closed) cascades of recurrences $N_{o}$ to the total number of events $N$. These ratios are shown in Fig. 3 as a function of $N$. After a transient, this ratio stabilizes around a value which depends on $\alpha$, being larger for larger values of $\alpha$, for $\alpha>0$. This means that the quasi-periodic behavior is more dominant for stronger dissipation. For $\alpha=0$, the dynamics is even periodic leading to a discontinuity in the ratio and a value of one.

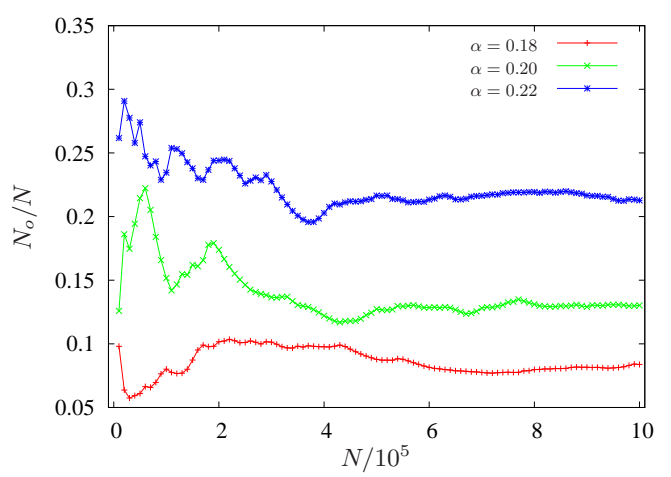

FIG. 3: (Color online) Ratio of number of "open" recurrences $N_{o}$, as described in the text, over the total number of events $N$, in function of the number events, for different alphas and $s_{\mathrm{th}}=300$.

Note that the apparent saturation for large $N$ is itself only a transient behavior for finite $L_{\text {bulk. Since }} N_{o}<L_{b u l k}^{2}$, the ratios will eventually go to zero.

The network growth described above differs significantly from what is obtained for seismicity, since real epicenters happen on continuous space and therefore never occur exactly in the same place (save, of course, for limitations of experimental precision). Since repetition is not possible, the network growth for seismicity does not exhibit the "saturation" of the average degree obtained for the OFC model, and grows instead continuously as $\langle k\rangle \approx 0.84 \ln (N)$ [18].

\section{Degree distributions}

A more detailed aspect of the network topology is the distribution of in- and out-degrees, as in Fig. 4. The out-degree distribution deviates significantly from the random case, where a Poisson distribution is expected both for the in- and outdegree distributions. The out-degree distribution seems instead to decay exponentially, with inclination slightly dependent on $\alpha$. The in-degree distribution is closer to a Poisson. The overall shape of the distributions also does not depend on the choice of lower size threshold for $300 \leq s_{\text {th }} \leq 30000$ (not shown). When the catalogs are shuffled, the obtained out-degree distribution is very close to a Poisson, while the in-degree distribution is narrower, as in Fig 5, like expected in the random case. The distributions, both of the shuffled and unshuffled catalogs, do not seem to be strongly affected by the "border effect" of model, and do not change significantly when all events in the lattice are considered (not shown).

The in- and out-degree distributions obtained for the OFC model are what resemble seismicity the most, where those distributions are basically the same as in Fig. 4 [18]. The only significant difference between seismicity and the OFC model is that the behavior for out-degree equal to 1 is not the same. For the OFC model the small out-degrees only overtake the 


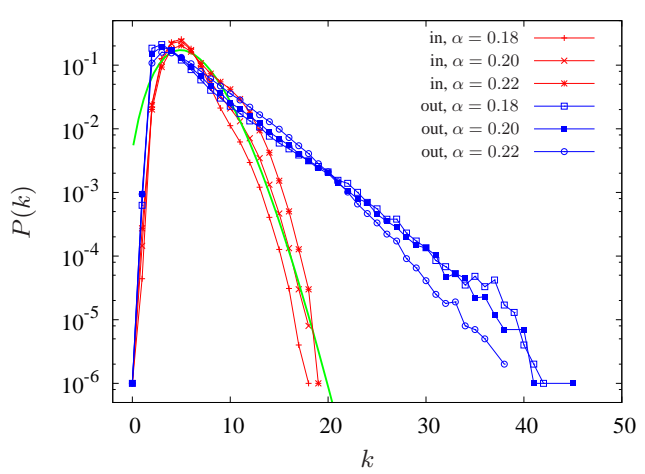

FIG. 4: (Color online) In-degree and out-degree distributions for networks generated by the OFC model for $s_{\text {th }}=300$ and different $\alpha$ 's (see Table I for details). The solid green line is a Poisson distribution with the same $\langle k\rangle$ as for $\alpha=0.20$.

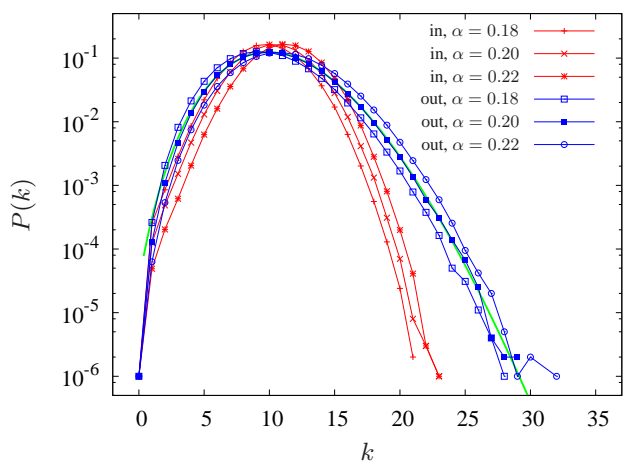

FIG. 5: (Color online) In-degree and out-degree distributions for networks generated from shuffled OFC catalogs with $s_{\text {th }}=300$ and different $\alpha$ 's. The solid green line is a Poisson distribution with the same $\langle k\rangle$ as for $\alpha=0.20$.

corresponding Poisson distribution for $k \geq 2$, but for seismicity it starts at $k \geq 1$. Other than that, the same causal information captured by the degree distribution for seismicity seem to be present in the obtained OFC catalogs.

\section{Degree-degree correlations}

The network topology can be further characterized by measuring the degree-degree correlations [20], i.e., how vertices of a given in- or out-degree ( $k_{\text {in }}$ or $k_{\text {out }}$ ) are connected to vertices with another $k_{\text {in }}$ or $k_{\text {out }}$. Here we consider also the combined degree-degree correlation, which describes how the $k_{\text {in }}$ and $k_{\text {out }}$ of individual vertices are correlated. To capture both these types of correlations, we measured the average $k_{\text {in }}$ or $k_{\text {out }}$ (either of the neighbors or of the same vertex), for all vertices, in function of the $k_{\text {in }}$ and $k_{\text {out }}$ of the originating vertex.

For the OFC model the causal structure does not result in any prominent degree-degree correlations in the recurrence network, as can be seen in Figs. 6 and 7, which also do not show any significant dependence on $\alpha$ or $s_{\text {th }}$ (not shown). For the neighbors degree correlations (Fig. 6), there are no qualitative differences between the shuffled and unshuffled catalogs. However, for the combined degree correlation (Fig. 7), both for the shuffled and unshuffled catalogs, we have that $\left\langle k_{\text {out }}\right\rangle\left(k_{\text {in }}\right)$ increases with $k_{\text {in }}$, which is different from what is expected for the random case [18]. The reason, however, to why it increases in both cases is related to the closing of the cascade of recurrences mentioned above. The dependence of $\left\langle k_{\text {out }}\right\rangle$ on $k_{\text {in }}$ is expected to be decreasing for a random process, since events early in the catalog will have a larger probability of having more recurrences (larger $k_{\text {out }}$ ), as they have the rest of the events in the catalog as possible candidates. However, these same events earlier in the catalog will be recurrences of fewer events (smaller $k_{\text {in }}$ ), as they have fewer events preceding them. But if it is possible for the cascade of recurrences to close, and no longer change with time, this decreasing correlation may not be present, since after a specific cascade is closed, the number of remaining events in the catalog is not important, as $k_{\text {out }}$ cannot change. The increasing dependence of $\left\langle k_{\text {out }}\right\rangle$ on $k_{\text {in }}$ can in turn be explained by considering the nodes with large $k_{\text {in }}$ as corresponding to sites with low activity which do not belong to the quasi-periodic attractors. These sites would not experience the aforementioned closing of the cascade of recurrences, and would thus have a larger out-degree. The shuffling of the catalog does not alter qualitatively this correlation, since it does not affect the closing of the cascade, but only the time it takes to close.

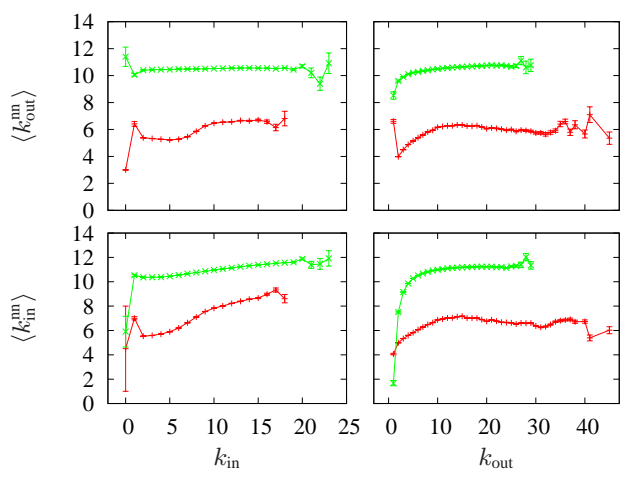

FIG. 6: (Color online) Degree-degree neighbor correlations for $\alpha=$ 0.2 and $s_{\text {th }}=300$. The curves on the bottom (red) are for the original catalog, and on top (green) for the shuffled catalog.

For seismicity, also no strong degree-degree correlation is found [18]. However some qualitative differences are detectable due to the absence of the closing of cascade of recurrences. The combined degree correlation $\left\langle k_{\text {out }}\right\rangle\left(k_{\text {in }}\right)$ increases with $k_{\text {in }}$ only for the unshuffled catalog and decreases for the 

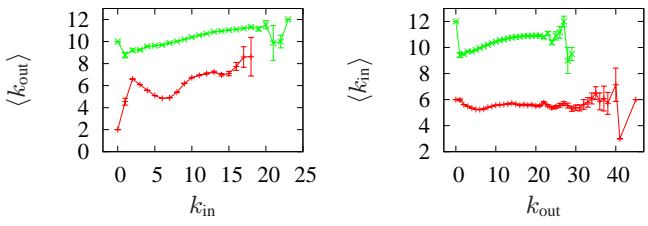

FIG. 7: Combined (same vertex) degree-degree correlations for $\alpha=$ 0.2 and $s_{\mathrm{th}}=300$. The curves on the bottom (red) are for the original catalog, and on top (green) for the shuffled catalog.

shuffled catalog, as expected for the random case. Thus the increasing dependence with the unmodified catalog is due to some causal structure different from the quasi-periodic attractors found in the OFC model.

\section{Clustering coefficient}

Another often measured network property is the clustering coefficient [20], which quantifies the density of triangles in the network, i.e. pairs of neighbors which are also neighbors of each other. In the present context, this refers to the probability that recurrences of the same event are also recurrences of each other. Here we use the definition based on the local clustering coefficient $C_{i}$ adapted to directed networks.

For all nodes $i$ with out-degree larger than one, the local clustering coefficient $C_{i}$ is given by the ratio of existing links $E_{i}$ between its $k_{i}^{\text {out }}$ recurrences to a maximum possible number of such links, $\frac{1}{2} k_{i}^{\text {out }}\left(k_{i}^{\text {out }}-1\right)$. Then the clustering coefficient $C$ of the network is defined as the average over all nodes $i$ with out-degree larger than one

$$
C=\left\langle C_{i}\right\rangle=\left\langle\frac{2 E_{i}}{k_{i}^{\text {out }}\left(k_{i}^{\text {out }}-1\right)}\right\rangle_{i} .
$$

For a completely random graph, such as the Erdős-Renyi graph, the above definition of the clustering coefficient is equal to the probability of any two vertices of the network being connected, $C_{\text {rand }}=\langle k\rangle /(N-1)$. Thus the clustering of uncorrelated networks will tend to zero for $N \rightarrow \infty$.

The values for the clustering coefficient of the recurrence network of the OFC model for different $\alpha$ 's are on table II. We compared the unmodified catalogs of Table I with the catalogs composed only of events for which the cascade of recurrences was not closed, i.e., the "open" events, and the shuffled catalogs. The unmodified catalogs generate networks which are significantly more clustered than with the shuffled catalogs. Moreover, the clustering seems to decrease slightly for larger values of $\alpha$. A significant amount of clustering seems to be related, however, to the quasi-periodic attractors of the dynamics, as the comparison with the "open" events shows. However, these "open" events, which don not belong to those attractors, still retain a higher clustering than the networks for the shuffled catalogs.
TABLE II: Clustering coefficient (Eq.(1)) for the recurrence network of the OFC model for different values of $\alpha$ and lower size threshold $s_{\text {th }}=300$, for the three types of catalogs: unmodified, with "open" recurrences only, and shuffled.

\begin{tabular}{c|r|r|r}
\hline \hline$\alpha$ & $C$ & $C$ (open) & $C$ (shuffled) \\
\hline 0.18 & $0.415260(8)$ & $0.23732(4)$ & $0.15633(2)$ \\
0.20 & $0.390983(8)$ & $0.21811(2)$ & $0.14467(2)$ \\
0.22 & $0.347044(6)$ & $0.201729(13)$ & $0.133249(12)$ \\
\hline \hline
\end{tabular}

The value of the clustering coefficient for seismicity, for the catalog of southern California studied in [18], is $C=0.2647$. However, the networks studied there have at most $\sim 10^{4}$ vertices, and different average degrees, and thus cannot be compared to the results of Table II, which are for networks with $10^{6}$ vertices. What can be compared instead is the fact that clusterization decreases when the catalog is shuffled, like it does for seismicity, and thus cannot correspond simply to a finite network size.

\section{B. Temporal distances of recurrences}

The probability density function (PDF) $p^{s_{\text {th }}}(t)$ for the time intervals $t$ associated with the recurrences and the edges of the network is another important characteristic. Fig. 8 shows this PDF for different catalogs generated by the OFC model, for $\alpha=0.2$. All PDFs decay approximately as $1 / t$ with a superposed peak at a characteristic time $t^{*}$ which does not depend on $s_{\text {th }}$. Such a characteristic time is expected since the activity shows quasi-periodic behavior as discussed above in Section IV A 1. Moreover, the characteristic time depends on the dissipation parameter $\alpha$, as Fig. 9 shows. This is due to the fact that the average tension added to the system between avalanches equals the amount dissipated, on average, by each avalanche, which is $\langle s\rangle(1-4 \alpha)$, where $\langle s\rangle$ is the average avalanche size. Therefore, after an average number $t^{*} \propto(\langle s\rangle(1-4 \alpha))^{-1}$ of topplings, an isolated, previouslytoppled site would be brought back close to the critical tension, without having to participate in an avalanche. From this argument, it also follows that $t^{*}$ is dependent on the size of the lattice and tends to infinity in the thermodynamic limit $L \rightarrow \infty$. The inset of Fig. 9 shows the rescaling of the $\mathrm{x}$-axis by $\langle s\rangle(1-4 \alpha)$, to test the above argument. The peaks do not line up perfectly, however, which is probably due both to border dissipation, which is not considered in the above argument, and the $\alpha$-dependent border effect already mentioned, which causes sites closer to the border to topple more often than in the bulk, making the return time non-homogeneous in space, which is also not considered above. Note, also, that the value of $\langle s\rangle$ is dependent of $\alpha$, despite the fact that the exponent of $P(s)$ seems to be universally $\approx-1.8$ for $\alpha<0.25$ [30]. This is because what changes in $P(s)$ between values of $\alpha$ is mostly the fraction of events of size $s=1$, with the tails of the distributions remaining the same. Sice events of size $s=1$ obey a different dynamics, and have quite different 
spatial distributions [25], this may also impact the argument above, and influence the dependence of $t^{*}$ on $\alpha$.

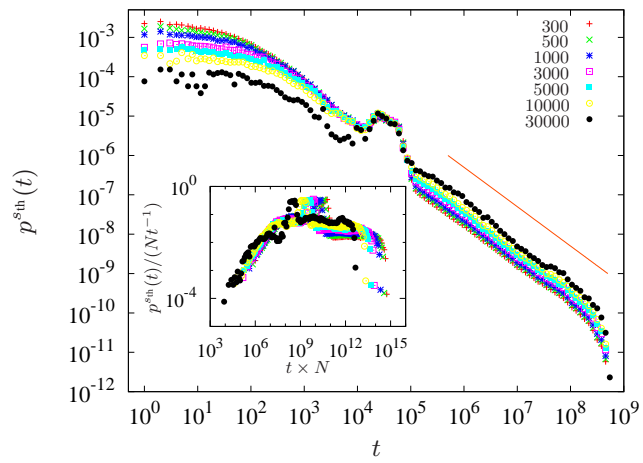

FIG. 8: (Color online) Distribution of time differences between events and their recurrences for different threshold sizes $s_{\mathrm{th}}$, for $\alpha=0.2$. The solid line is a power law with exponent -1 . Inset: Rescaled distribution of time differences.

As an attempt to isolate the effect of the closing of the cascade of recurrences present in the OFC model, the same statistics for $p^{s_{\text {th }}}(t)$ was obtained, but considering only recurrences where the originating event is still open (not shown). For those recurrences, the characteristic time scale is still present, but is not so prominent. Other than that, the overall shape is the same.

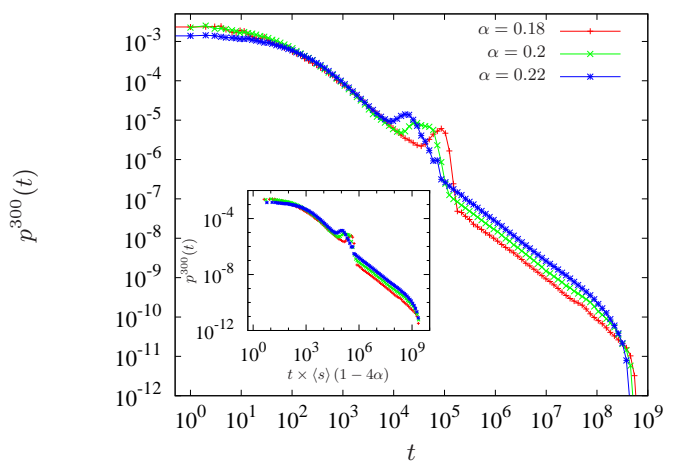

FIG. 9: (Color online) Distribution of time differences for $s_{\text {th }}=300$ and varying $\alpha$. Inset: $\mathrm{x}$-axis rescaled by $\langle s\rangle(1-4 \alpha)$, as shown in the legend.

For the shuffled catalog, $p^{s_{\text {th }}}(t)$ is shown in Fig. 10 for different values of $s_{\text {th }}$. As expected, the effect of the characteristic time scale is no longer present since the quasi-periodic behavior is absent in the shuffled catalog. Moreover, the inset of Fig. 10 clearly indicates that the curves can be collapsed by rescaling them with the respective number of events $N$ given in table I. This confirms that the shuffled catalog, at least for the recurrences times, behaves like the random case, where the characteristic time $t^{*}$ before the $1 / t$ decay scales with the inverse of the rate of events $t^{*} \sim T / N$ [18]. Note that the inset of Figure 8 also shows the same rescaling, and while the characteristic time peak spoils any chance of a complete collapse, it is possible at least to identify that the cut-off for small $t$ also scales like expected for the random case.

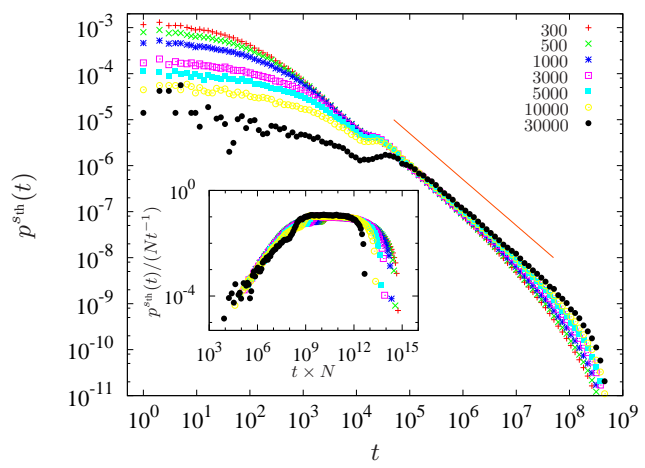

FIG. 10: (Color online) Distribution of time differences between events and their recurrences for the shuffled catalogs with different threshold sizes $s_{\text {th }}$, for $\alpha=0.2$. The solid line is a power law with exponent -1 . Inset: Rescaled distribution of time differences.

The properties of the recurrence times statistics described above show some important differences between the OFC model and seismicity. Besides the characteristic time due to the driving of the system in the OFC model, which is nonexistent in seismicity, the shapes for $p^{s_{\text {th }}}(t)$ change for different $s$ for the OFC model. For seismicity, all curves are independent of the magnitude threshold [18], which is a non-trivial characteristic. This dependence is however expected for the random case, where the transition point from constant to $1 / t$ decay is given by the rate of events, as described above (see inset of Fig. 10).

\section{Temporal hierarchy of subsequent recurrences}

Another important aspect of the network of recurrences is the possible existence of hierarchies of recurrences. This can be captured by the ratios $t_{i} / t_{i+1}$ for subsequent recurrences for the same event. Here, it is assumed that the recurrences for a given event are ordered according to their time of occurrence such that the $i$-th recurrence is followed by the $i+1$-th recurrence for all ranks $i$. The corresponding PDFs are shown in Fig. 11. For the catalogs generated by the OFC model, they exhibit generally two regimes, independent of $\alpha$ and $s_{\text {th }}$ (here shown only for $\alpha=0.2$ and $s_{\text {th }}=300$ ). For small arguments, $p\left(t_{i} / t_{i+1}\right)$ is roughly constant while for lager arguments it approximately decays according to a power law with exponent -0.85 . The transition point increases with increasing $i$ and is not detectable for $i=0$. In addition to these 
two regimes, there is also a peak around $t_{i} / t_{i+1}=1$. As Fig. 11 shows, there are no discernible differences between the original and the shuffled catalogs. Only the peak is more pronounced in the original catalog suggesting that it is due to the quasi-periodic dynamics and the characteristic time of the system (see Fig. 8). These observations directly imply that the particular form of $p\left(t_{i} / t_{i+1}\right)$ is not related to spatiotemporal correlations between events in the OFC model. Moreover, the constant regime can be attributed to the existence of closed cascades of recurrences described above. If only open recurrences are considered, the constant regime is absent (see Fig. 11). Another interesting difference is that when only open recurrences are considered for the shuffled catalog, things change significantly (see Fig 11 (d)), and the distributions of the ratios in this case seem to decay as power-laws with exponent dependent on $i$. Moreover, the inclination differences between the distributions for different $i$ 's seem to depend on $\alpha$, where the greater differences are for the larger values of $\alpha$ (not shown). For the unshuffled catalog, however, when only open recurrences are considered, the dependence on $\alpha$ is much weaker, and for the smallest value studied, $\alpha=0.18$, the inclinations all seem the same (not shown). Since, as explained previously, the shuffling of catalog does not remove the closing of the cascade of recurrences, the differences seen between the plots (b), (c) and (d) of Fig. 11, must be attributed to a special spatiotemporal dynamics of those events which do not belong to the quasi-periodic attractors responsible for the frequent repetition of epicenters.
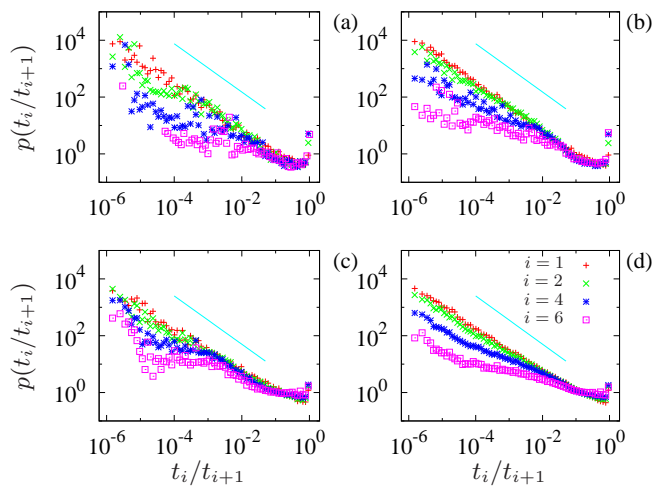

FIG. 11: Distribution of the ratio between the time differences of subsequent recurrences, for $\alpha=0.2$ and $s_{\text {th }}=300$, for (a) the regular catalog, (b) only the "open" recurrences, (c) the shuffled catalog and (d) only the "open" recurrences for the shuffled catalog. In all plots the solid line is a power-law with inclination -0.85 .

For seismicity, the ratios $t_{i} / t_{i+1}$ for subsequent recurrences revealed another non-trivial characteristic, where two powerlaw regimes could be noticed in the distribution of those ratios, which disappeared with the shuffled catalog [18]. The spatiotemporal correlations responsible for these results do not seem to be present for the OFC model, as the above analysis shows.

\section{Influence of the border}

The results above were obtained, as explained previously, by discarding events which occur within an outer layer of 100 sites in the lattice, in order to avoid the aforementioned border effect. As a further check of the validity of this measure, it is shown in Fig. $12 p^{s_{\text {th }}}(t)$ for $s=300$ and $\alpha=0.2$ for different lengths of the discarded border $L_{b}$. In this case, the influence of the border effect seem to be very weak. The number of events is the same for all curves $\left(10^{6}\right)$; what changes is only the time span and thus the rate of events. This is enough to account for some of the small differences seen, such as the different cut-offs. However, the differences seen after the characteristic time peak are smaller for $L_{b} \geq 50$ than for the other curves, indicating that the curves $L_{b}<50$ may indeed be influenced by the border effect. These differences are qualitatively the same for the other values of $\alpha$, only weaker (not shown).

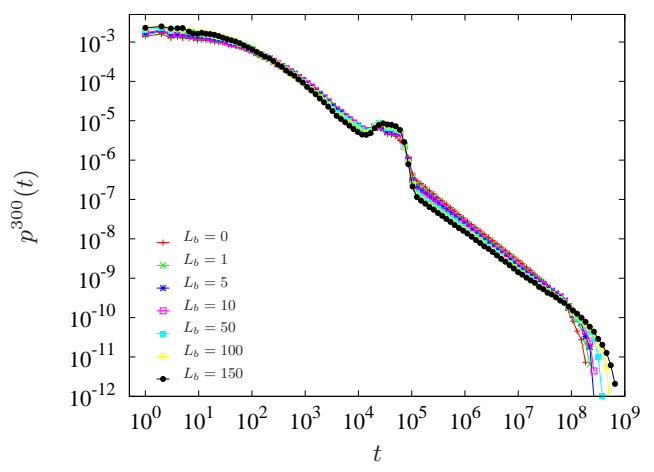

FIG. 12: (Color online) Distribution of time difference (measured in numbers of events) between the 0-Event and its recurrences for values of the discarded border length $L_{b}$, for $\alpha=0.2$

\section{Spatial distances of recurrences}

Exactly like the temporal distances of recurrences, the spatial distances and their PDF $p^{s_{\mathrm{th}}}(l)$ can be obtained for the OFC model for further characterization and comparison with seismicity. The distribution of recurrence distances $p^{s_{\text {th }}}(l)$ for $\alpha=0.2$ and different size thresholds are shown in Fig. 13. The results for other values of $\alpha$ are qualitatively similar, and thus are not shown. The overall shape of the distributions is rather broad and varies with $s_{\text {th }}$. The inset of Fig. 13 shows an attempted scaling collapse according to the ansatz

$$
p^{s_{\mathrm{th}}}(l) \sim \frac{\left(l / s^{0.3}\right)^{-1.5} F\left(l / s^{0.3}\right)}{s^{0.3}},
$$

which, if successful, would imply the existence of a characteristic distance dependent on $s_{\text {th }}$ with $l^{*} \sim s_{\text {th }}^{0.3}$. This would at least qualitatively reproduce the identification with the rupture 
length (see below), since $s_{\text {th }}$ should be proportional to $10^{b m}$, if the OFC model is to be compared with seismicity. However, as the inset of Fig. 13 clearly shows, the data does not collapse as intended and a collapse does not seem to be possible at all. When only the open recurrences are considered, as shown in Fig. 14, the collapse is significantly better, but still not convincing enough. This does, however, show that the dynamics of the events that eventually get its cascade of recurrences closed, which can be identified with the events belonging to quasi-periodic attractors, is significantly different from those that remain "open", with the latter approaching qualitatively more the behavior found in seismicity.

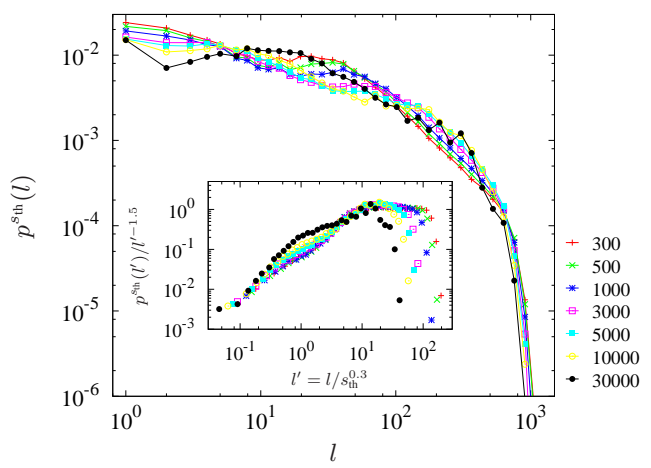

FIG. 13: (Color online) Distribution of recurrence distances for $\alpha=0.2$ and different threshold values. Inset: Distributions rescaled according to Eq.(2). Recurrences of distance $l=0$ are not shown, and were not used in the normalization.

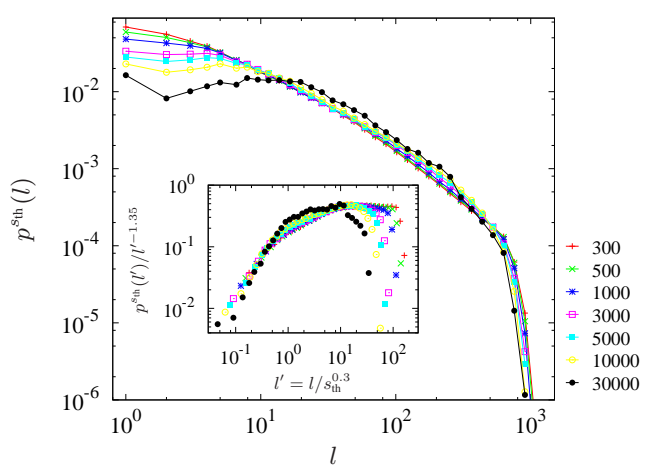

FIG. 14: (Color online) Distribution of recurrence distances for $\alpha=0.2$ and different threshold values, but only considering "open" recurrences. Inset: Distributions rescaled according to Eq.(2).

For the shuffled catalog the corresponding results for $p^{\text {st }}(l)$ are shown in Fig. 15. As the collapse in the inset shows, the different shapes seem to reproduce the random case, where it can be shown that $l^{*} \propto N^{-1 / D}$, where $N$ is the size of the cat- alog and $D$ is the underlying spatial dimension [18]. The collapse was done using the number of events $N$ obtained from Table I. However, the obtained exponent $1 / D \approx 0.2$ would imply that the dimension of the underlying space is $D \approx 5$, which clearly cannot be the case, since the OFC model is defined on a $2 \mathrm{D}$ lattice. This can be explained by the fact that the result for the random case was obtained for continuous space [18]. Therefore, in a discrete lattice, when the characteristic distance approaches the fundamental lattice distance, the identification of the exponent with $1 / D$ cannot be expected.

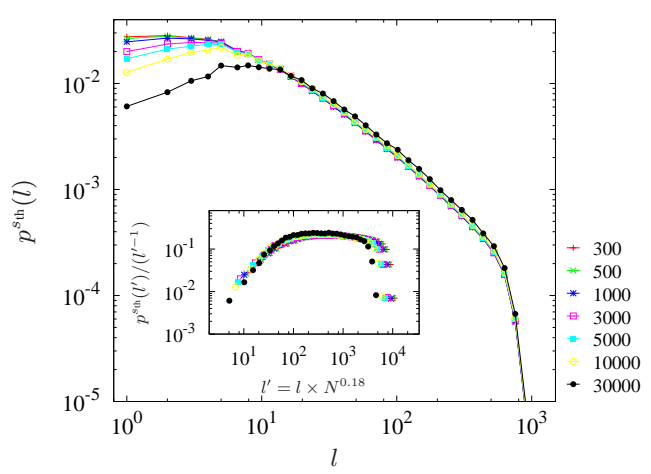

FIG. 15: (Color online) Distribution of recurrence distances for $\alpha=$ 0.2 and different threshold values, for the shuffled catalog. Inset: Distributions rescaled according to the number of events (see Table I) as indicated in the legend.

For seismicity [18], $p^{s_{\text {th }}}(l)$ shows a characteristic distance $l^{*}$, after which the distribution decays as a power-law with exponent $\sim 1.05$. The value of $l^{*}$ doesn't change with time, and depends only on the lower magnitude threshold. More specifically the scaling of this characteristic distance obeys the ansatz $l^{*} \propto 10^{0.45 m}$, where $m$ is the lower threshold magnitude, which makes an identification with the rupture length of an earthquake possible. As shown above, the OFC model does not successfully reproduce this. While the characteristic distance does depend on the lower threshold size, no simple scaling ansatz can be identified (Eq.(2)), even when only "open" recurrences are considered.

\section{Time dependence}

The other important aspect of the recurrence distance statistics is the time dependence. The recurrence distance distributions for the OFC model are shown in Fig 16, where it can be seen that the distributions vary with time for small distances for all cases: The unmodified catalog, open recurrences only and the shuffled catalog. The parts not shown in Fig. 16 were visually the same for all curves (except for small differences in the cut-off). Fig. 17 shows the same distributions as Fig. 16, but with the $\mathrm{x}$ and $\mathrm{y}$ axis scaled in function of $N^{\gamma}$, where $N$ is the number of events indicated in the legend. Only the 
shuffled catalog and open recurrences collapse well under this ansatz, while the time dependence of the unmodified catalog seems to be more elaborate. However, no catalog reproduces the expected behaviour for the random case, which would be $\gamma=1$ [18]. Again, like for the recurrence time statistics, this is probably because the result for the random case was obtained for continuous space, and the OFC model is defined on a 2D lattice. Note that, in absence of any special relation between the size of the event and its subsequent recurrences, the scaling in function of $N$ should be related to the scaling in function of $s_{\text {th }}$ simply by the distribution of event sizes $P(s) \sim s^{-1.8}$. Thus, we have that $N^{\gamma} \propto s_{\text {th }}^{-0.8 \gamma}$, and we can see that the exponent of the inset of Fig. 14 is in fact the same as in Fig 16 (b), i.e., $0.8 \times 0.37 \approx 0.3$. The inset of Fig. 15 and Fig. 16 (c) are already both rescaled in function of $N$, and also have same exponent. Therefore the different curves of Figs. 14 and 15 are due exclusively to the different number of events of different sizes. For the unmodified catalog, neither Fig. 13 nor 16 (a) shows a collapse under the proposed ansatz, and are thus difficult to compare.
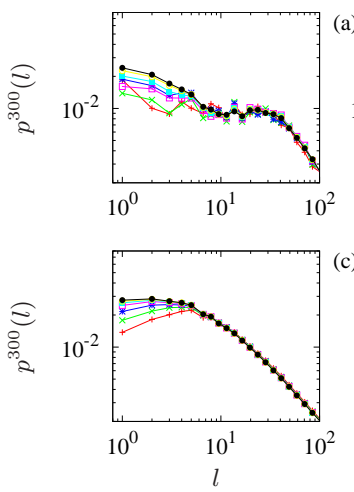

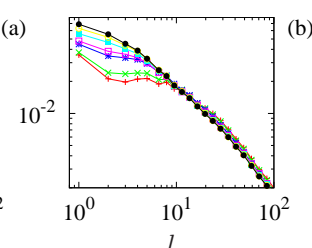

(c)

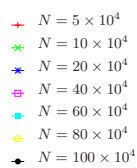

FIG. 16: (Color online) Distribution of recurrence distances for $\alpha=$ 0.2 and $s_{\mathrm{th}}=300$, for an increasingly larger potion of the catalog, for (a) the regular catalog, (b) only the "open" recurrences and (c) the shuffled catalog.

For seismicity [18], $p^{s_{\text {th }}}(l)$ shows a clear independence on time, which reveals a robust characteristic of seismicity, in sharp contrast to what is expected for the random model. This robustness is not reproduced by the OFC model, where $p^{s_{\text {th }}}(l)$ changes continuously with time, and seem to obey no simple scaling ansatz (see Fig. 17).

\section{Spatial hierarchy of subsequent recurrences}

The remaining feature to be looked at is the distribution of distance ratios $l_{i+1} / l_{i}$, where $l_{0}$ is the largest recurrence in the network, $l_{1}$ is the first recurrence of an event, $l_{2}$ is the second, etc. The distribution of those ratios can be seen in Fig. 18 and significant difference between the foure cases are visible, independent of $\alpha$ and $s_{\text {th }}$ (here shown only for $\alpha=0.2$ and
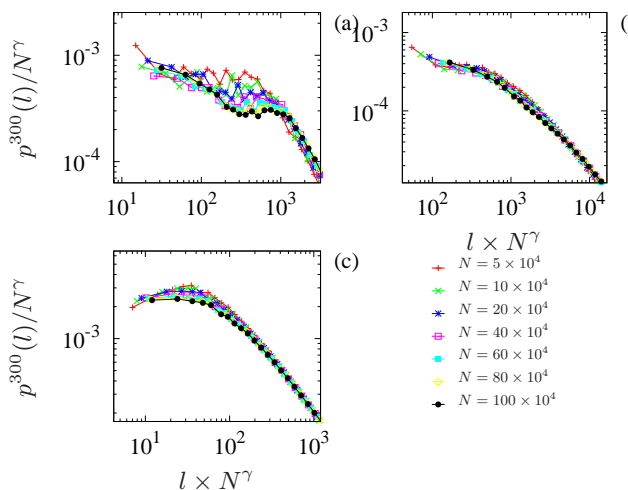

(c)

$l \times N^{\gamma}$

$+N=5 \times 10^{4}$

* $N=10 \times 10^{4}$

* $N=20 \times 10^{4}$

ㅁ. $N=40 \times 10^{4}$

$N=60 \times 10^{4}$
$N=80 \times 10^{4}$

- $N=100 \times 10^{4}$

FIG. 17: (Color online) Distribution of recurrence distances for $\alpha=0.2$ and $s_{\mathrm{th}}=300$, for an increasingly larger potion of the catalog, re-scaled as indicated in the legend, for (a) the regular cata$\log (\gamma=0.25)$, (b) only the "open" recurrences $(\gamma=0.37)$ and (c) the shuffled catalog $(\gamma=0.18)$.

$\left.s_{\text {th }}=300\right)$. In all cases the ratio $l_{1} / l_{0}$ is different than the rest, but nothing changes for the higher ranks. For the shuffled catalog the ratios increase as a power-law with exponent 0.67 , as expected for the random case with $D=1.67$, where it can be shown that $P(x)=D x^{D-1}$, independent of $i$, with $x=l_{i+1} / l_{i}$ [18]. However, when only "open" recurrences are considered, it is completely different from the random case, and the distributions depend strongly on $i$. The reason for this is not obvious, but indicate that the spatial distribution of events with "open" recurrences are by no means homogeneous in space. For the unmodified catalog the first ratio decays as a power-law, but all the others increase with apparently two regimes. For the open recurrences only, the higher rank ratios are almost uniformly distributed. All cases are however very different from seismicity, where the ratios all decay as a power-law with exponent $\sim 0.6$.

\section{Influence of the border}

Like for the recurrence time statistics, it is interesting to check how the border effect of the OFC model affects the recurrence distance statistics. Fig. 19 shows $p^{s_{\text {th }}}(l)$ for $s=300$ and $\alpha=0.2$ for different lengths of the discarded border $L_{b}$ (the results for other $\alpha$ 's were very similar, and thus are not shown). The different cut-offs for all the curves are simply due to the maximum possible distance being smaller for larger $L_{b}$. The differences, however, for small distances must be due to slightly different causal structure, since all catalogs have the same number of events $\left(10^{6}\right)$. Except for the cut-off, the distributions are virtually identical for $L_{b} \geq 50$. This further confirms the border effect, and the existence of the bulk dynamics which is invariant in respect to the distance from the border. 

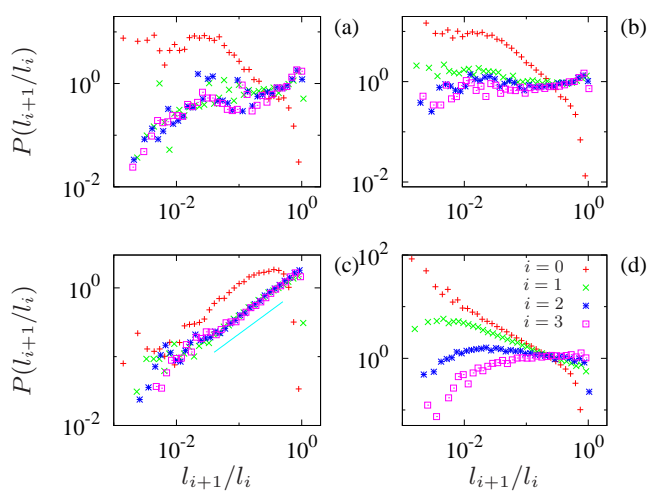

FIG. 18: Distribution of ratios between subsequent recurrences distances for $L_{B}=100$, for (a) the regular catalog, (b) only the "open" recurrences, (c) the shuffled catalog and (d) only the "open" recurrences for the shuffled catalog. The solid line is a power law with exponent 0.67 .

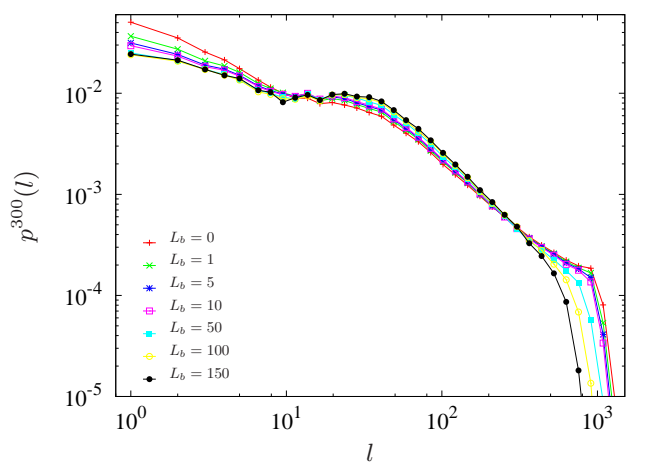

FIG. 19: Recurrence distance distribution, for $\alpha=0.2$ and $s_{\text {th }}=$ 300 , for different values of the discarded border length $L_{b}$.

\section{DISCUSSION \& CONCLUSION}

We have studied the network of recurrences of the OFC model, with the objective of characterizing its causal structure and comparing it to seismicity. We have found that, in agreement with previous results [23-25], the model does exhibit some non-trivial features observed in seismicity, but it comes short of a complete qualitative description of several robust features of spatiotemporal clustering captured by the used method. More specifically, the model reproduces a central topological feature of the recurrences network, which is the degree distributions, as well as the absence of non-trivial degree correlations, clustering coefficient, and some other partial aspects of the recurrence distance and time distributions. However, the two most important properties of the dynamics of seismicity identified by this recurrence approach are, firstly, that the time and distance distributions are time independent, and secondly, that the distance statistics provides an independent assessment of the rupture length of earthquakes. The OFC model fails to reproduce the first feature, as both the time and distance distributions vary with time. The second feature is also not reproduced. While there is a dependence of the distance distribution with the size of the events, it does not scale like the rupture length. One third, and more subtle, characteristic of the recurrences which is not reproduced by the OFC model is the hierarchy of recurrences, given by the distribution of ratios of time and distance between consecutive recurrences, which in the case of seismicity deviates significantly from the random case. Moreover, the whole analysis exposes another crucial aspect of the OFC model, which is the elevated occurrence of epicenters at distance zero from one another, tightly connected to quasi-periodicity and well distinct from seismicity.

Obviously, the OFC model was not intended to be a complete description of seismicity. It was mainly proposed as a conceptual model and a possible origin of the GutenbergRichter law from a SOC point of view. Also, like the Burridge-Knopoff spring-block model, it aims to model the dynamics of a single fault, and not the complex interplay of different fault structures as observed in reality. Despite these limitations, the OFC model is capable of showing a rich dynamics, reproducing even some more subtle features of the spatiotemporal clustering of earthquakes.

\section{ACKNOWLEDGMENTS}

Part of this work was supported by Fundação de Amparo à Pesquisa do Estado de São Paulo (FAPESP), process number 03/03429-6.
[1] D. L. Turcotte, Fractals and chaos in geology and geophysics (Cambridge University Press, Cambridge, UK, 1997), 2nd ed.

[2] S. Stein and M. Wysession, An introduction to seismology, earthquakes, and earth structure (Blackwell Publishing, Oxford, UK, 2002).

[3] F. Mulargia and R. J. Geller, eds., Earthquake science and seismic risk reduction, NATO Science Series (Kluwer Academic Publishers, Dordrecht, NL, 2003).
[4] J. B. Rundle, D. L. Turcotte, R. Shcherbakov, W. Klein, and C. Sammis, Review of Geophysics 41, 1019 (2003).

[5] P. Bak, K. Christensen, L. Danon, and T. Scanlon, Physical Review Letters 88, 178501 (2002).

[6] A. Helmstetter, G. Ouillon, and D. Sornette, Journal of Geophysical Research 108, 2483 (2003).

[7] A. Corral, Physical Review Letters 92, 108501 (2004).

[8] J. Davidsen and C. Goltz, Geophysical Research Letters 31, 
L21612 (2004).

[9] M. Baiesi and M. Paczuski, Physical Review E 69, 066106 (2004)

[10] R. Shcherbakov, D. L. Turcotte, and J. B. Rundle, Geophysical Research Letters 31, L11613 (2004).

[11] J. Davidsen and M. Paczuski, Physical Review Letters 94, $048501(2005)$

[12] A. Helmstetter, Y. Y. Kagan, and D. D. Jackson, Journal of Geophysical Research 110 (2005).

[13] V. N. Livina, S. Havlin, and A. Bunde, Physical Review Letters 95, 208501 (2005).

[14] G. Molchan and T. Kronrod, Geophysical Journal International 162, 899 (2005)

[15] R. Shcherbakov, D. L. Turcotte, and J. B. Rundle, Bulletin of the Seismological Society of America 96, 376 (2006).

[16] K. R. Felzer and E. E. Brodsky, Nature (London) 441, 735 (2006).

[17] J. Davidsen, P. Grassberger, and M. Paczuski, Geophysical Research Letters 33, L11304 (2006).

[18] J. Davidsen, P. Grassberger, and M. Paczuski, Physical Review E p. submitted (2006).

[19] R. Albert and A.-L. Barabasi, Review of Modern Physics 74, 47 (2002).

[20] M. E. J. Newman, SIAM Review 45, 167 (2003).

[21] Z. Olami, H. J. S. Feder, and K. Christensen, Physical Review Letters 68, 1244 (1992).

[22] K. Christensen and Z. Olami, Journal of Geophysical Research 97, 8729 (1992)

[23] S. Hergarten and H. J. Neugebauer, Physical Review Letters 88, 238501 (2002)

[24] A. Helmstetter, S. Hergarten, and D. Sornette, Physical Review E 70, 046120 (2004)

[25] T. P. Peixoto and C. P. C. Prado, Physical Review E 74 (2006).

[26] P. Bak, How nature works (Copernicus, New York, 1996)

[27] H. J. Jensen, Self-organized criticality (Cambridge University Press, Cambridge, UK, 1998)

[28] P. Bak, C. Tang, and K. Wiesenfeld, Physical Review Letters 59, 381 (1987).

[29] J. X. Carvalho and C. P. C. Prado, Physical Review Letters 84, 4006 (2000).

[30] S. Lise and M. Paczuski, Physical Review E 63, 036111 (2001).
[31] S. Lise and M. Paczuski, Physical Review E 64 (2001).

[32] G. Miller and C. J. Boulter, Physical Review E 66 (2002)

[33] F. Wissel and B. Drossel, Physical Review E 74, 066109 (2006).

[34] C. J. Boulter and G. Miller, Physical Review E 68, 056108 (2003).

[35] O. Ramos, E. Altshuler, and K. J. Måløy, Physical Review Letters 96 (2006).

[36] R. Burridge and L. Knopoff, Bulletin of the Seismological Society of America 57, 341 (1967).

[37] J. Davidsen and H. G. Schuster, Physical Review E 62, 6111 (2000).

[38] A. A. Middleton and C. Tang, Physical Review Letters 74, 742 (1995).

[39] The area $a$ of an avalanche can in principle be different from its size $s$, since sites can topple more than once. However, there is a transition value of $\alpha$, below which multiple topplings are impossible. This value can be obtained by considering the extremal situation where a site with tension 1 is about to topple, whose neighbors also have tension 1 . After the site topples, it will also cause the topplings of the neighbors, which will then return tension to original site. The amount of tension returned is $4 \alpha(1+\alpha)$. If this value is below 1 , then the original site will not topple a second time, which means that no site in any other situation will topple a second time. Thus, the transition value is $\alpha=(\sqrt{2}-1) / 2 \approx 0.207$. Below this value, $a=s$ for any event. Simulations show that even when the value of $\alpha$ is slightly above this transition, the occurrence of multiple topplings is negligible. For the range of $\alpha \in[0.22,0.18]$ studied here, multiple topplings play no detectable role.

[40] A network is composed of a set of discrete elements called vertices (or nodes) and a set of pairs of vertices (which can be ordered or not), called edges (or links), which may describe some relationship between two vertices. Two vertices are neighbors if there is a edge between them. The number of neighbors of a given vertex is called the degree of the vertex. If the edges of the network are directed, then the vertex can have in-neighbours and out-neighbours, depending on the direction of the corresponding edge, and therefore also an in-degree and an out-degree. See [20] for an extensive and detailed review of these concepts. 


\section{Apêndice B}

\section{O programa graph-tool de análise estatística de grafos}

Durante a realização do trabalho apresentado nessa tese foi detectado uma lacuna na disponibilidade de implementação de métodos numéricos de análise estatística de grafos, que motivou o desenvolvimento de um programa de análise de grafos, de caráter geral, que será descrito a seguir.

\section{B.1 Filosofia de implementação}

Apesar da existência de alguns pacotes e bibliotecas que proporcionam uma estrutura para se manipular grafos de maneira geral, como o LEDA $^{1}$ e a Boost Graph Library [101], a grande maioria das medidas estatísticas estudadas na área de redes complexas, como distribuição de graus, índice de aglomeração, correlação de graus, assortatividade, etc. (ver capítulo 4, página 47), são implementadas, muitas vezes, de maneira ad hoc, apesar de serem repetidamente usadas em quase todos os trabalhos da área. A relativa simplicidade de alguns algoritmos - como, por exemplo, obter a distribuição de graus de um grafo - justifica, inicialmente, essa abordagem. Contudo, conforme o número dessas medidas aumenta, e mais freqüentes se tornam o seus usos, mais útil se torna a coleção e organização desses algoritmos de maneira mais centralizada. Essa abordagem permite, além do fácil acesso para quem não pretendente desenvolver as próprias implementações, que os algoritmos sejam devidamente generalizados e montados de forma que a inter-operação entre eles possa ser feita de maneira conveniente. Essa conveniência, por sua vez, torna mais fácil análises mais elaboradas, que dependam de correlações entre as diversas medidas. Além disso, algoritmos mais elaborados — como detecção de comunidades e geração de grafos aleatórios - podem ser implementados, de maneira a usufruir dessa estrutura integrada.

Na tentativa de realizar tal implementação, foi desenvolvido o programa graph-tool, que pretende reunir os principais algoritmos de análise de redes complexas, e cujas principais características serão descritas a seguir.

\footnotetext{
${ }^{1}$ http: //www.algorithmic-solutions . info
} 


\section{B.2 Descrição geral do programa}

O programa graph-tool é dividido em duas partes. A parte central do programa, que corresponde a mais de $90 \%$ do seu tamanho, é escrita em $\mathrm{C}++$, em cima da Boost Graph Library ${ }^{2}$, e é a parte que implementa a grande maioria dos algoritmos. Essa parte do programa faz uso extenso de metaprogramação por templates [102], que resulta em código que é simultaneamente genérico [103] e otimizado. A parte restante do programa é escrita em Python ${ }^{3}$, e corresponde a interface de linha de comando com o usuário, e a extensão dinâmica do programa através dessa linguagem. Além disso, o programa faz uso, quando disponível, da interface de programação OpenMP4 ${ }^{4}$, que proporciona, de maneira quase trivial, versões de muitos dos algoritmos que rodam em paralelo, e podem assim fazer uso de vários processadores.

O programa, em sua versão atual, possui as seguintes funções:

1. Suporte para multigrafos direcionados e não direcionados.

2. Suporte para propriedades arbitrárias, vinculadas aos vértices e/ou arestas.

3. Suporte para modificação ou criação de propriedades, de maneira genérica, usando Python, que permite a elaboração de algoritmos arbitrários, de maneira fácil, pelo usuário.

4. Suporte para "filtragem" de vértices e/ou arcos, baseando-se em suas propriedades.

5. Histograma de graus ou propriedades escalares.

6. Histograma combinado (bidimensional) de graus ou propriedades escalares.

7. Histograma de correlação de graus ou propriedades escalares de vértices.
8. Correlação média de graus ou propriedades escalares de vizinhos mais próximos.

9. Coeficiente de aglomeração (usual e estendido).

10. Coeficiente de Assortatividade.

11. Betweenness Centrality.

12. Distância média e histograma de distâncias (tanto completo quanto baseado em sorteios aleatórios).

13. Estatística de componentes.

14. Reciprocidade [96].

15. Detecção de comunidades, baseada no método descrito em [97], que permite a detecção de comunidades em grafos correlacionados.

16. Geração de grafos aleatórios, direcionados e não direcionados, com distribuição de graus e correlações arbitrárias, definidas pelo usuário.

17. Suporte para análise de evolução temporal de grafos.

\footnotetext{
${ }^{2}$ http://www . boost.org/libs/graph/doc/index.html

${ }^{3}$ http: //www.python.org

${ }^{4}$ http: //www . openmp.org
} 


\section{B.3 Disponibilidade}

O programa é software livre ${ }^{5}$, licenciado sob a GNU General Public License ${ }^{6}$, versão 3 ou superior, e se encontra disponível online, no endereço http://graph-tool . forked. de. Na página, se encontra disponível, além do código fonte, uma documentação extensa sobre o uso do programa, com exemplos. Existe também uma lista de email, onde podem ser feitas perguntas e discussões gerais sobre o programa. Problemas encontrados, e também requisições, podem ser relatados pela própria página, que inclui uma base de dados de bugs, com discussão integrada. O código fonte pode também ser obtido do repositório git ${ }^{7}$, pelo endereço git://git.forked.de/ graph-tool (acessível também por http://git.forked.de/?p=graph-tool, com um navegador) que inclui o histórico de modificação do programa, e também a versão de desenvolvimento mais atual. Esse repositório permite também, de maneira fácil, o desenvolvimento colaborativo e descentralizado do programa.

Desde sua disponibilização inicial no segundo semestre de 2006, o programa recebeu uma atenção razoável, e foram registrados, desde então, mais de dois mil downloads. A página é visitada regularmente, por indivíduos espalhados no mundo inteiro, como pode ser visto na figura B.3.1, que mostra o número de visitas de acordo com a sua localização, obtida pelo endereço IP e informações do navegador, no período de Julho de 2007 a Outubro de 2007. A mesma figura para outros períodos, desde o segundo semestre de 2006, é bastante semelhante. Isso mostra uma razoável aceitação do programa pela comunidade científica, considerando o seu pouco tempo de existência. Uma parte do programa, o leitor de arquivos graphml ${ }^{8}$, foi inclusive aceita para inclusão na Boost Graph Library ${ }^{9}$, que pretende ser eventualmente incorporada na biblioteca padrão de templates do $\mathrm{C}++$.

\footnotetext{
${ }^{5}$ http://www.fsf.org/licensing/essays/free-sw.html

${ }^{6} \mathrm{http}: / /$ www.gnu .org/licenses/gpl-3.0.html

${ }^{7}$ http://git.or.cz

${ }^{8}$ http://graphml.graphdrawing.org/

${ }^{9} \mathrm{http}$ ://www. boost-consulting.com/boost/libs/graph/doc/read_graphml.html write_graphml.html)
} 


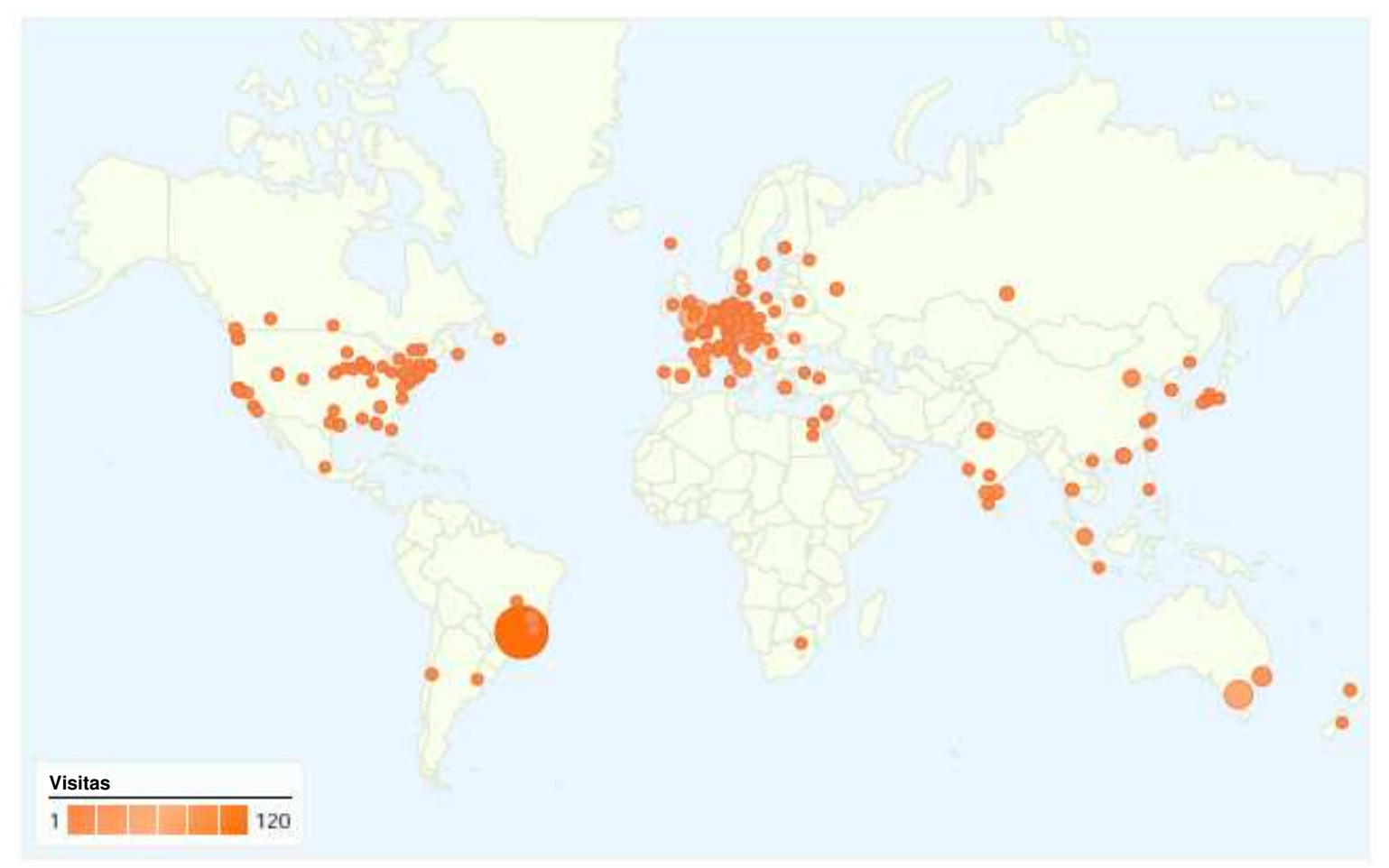

Figura B.3.1: Número de visitas à pagina http://graph-tool.forked.de, de acordo com a sua localização, no período de Julho de 2007 a Outubro de 2007. 


\section{Apêndice C}

\section{Artigos publicados}

Segue neste apêndice as referências [1-3], que correspondem a alguns resultados apresentados nos capítulos 3 e 5. 


\title{
C.1 Artigo "Distribution of epicenters in the Olami-Feder- Christensen model" [1]
}

PHYSICAL REVIEW E 69, 025101(R) (2004)

\section{Distribution of epicenters in the Olami-Feder-Christensen model}

Tiago P. Peixoto* and Carmen P. C. Prado ${ }^{\dagger}$

Instituto de Física, Universidade de São Paulo, Caixa Postal 66318, 05315-970 São Paulo, São Paulo, Brazil

(Received 14 October 2003; published 25 February 2004)

\begin{abstract}
We show that the well established Olami-Feder-Christensen (OFC) model for the dynamics of earthquakes is able to reproduce a striking property of real earthquake data. Recently, it has been pointed out by Abe and Suzuki that the epicenters of earthquakes could be connected in order to generate a graph, with properties of a scale-free network of the Barabási-Albert type. However, only the nonconservative version of the Olami-FederChristensen model is able to reproduce this behavior. The conservative version, instead, behaves like a random graph. Besides indicating the robustness of the model to describe earthquake dynamics, those findings reinforce that conservative and nonconservative versions of the OFC model are qualitatively different. Also, we propose a completely different dynamical mechanism that, even without an explicit rule of preferential attachment, generates a scale-free network. The preferential attachment is in this case a "byproduct" of the long term correlations associated with the self-organized critical state.
\end{abstract}

DOI: 10.1103/PhysRevE.69.025101

PACS number(s): 05.65.+b, 89.75.Da, 89.75.Kd, 45.70.Ht

The concept of self-organized criticality (SOC) was introduced by Bak, Tang, and Wiesenfeld [1] as a possible explanation of scale invariance in nature. Since this seminal work, a great number of cellular automata and coupled map models have been investigated in an attempt to elucidate the essential mechanisms hidden in a wide class of different nonlinear phenomena whose statistics of events (or avalanches) are governed by power laws. However, up to now, although there are successful analytical investigations of several models, one still lacks a general theoretical framework for selforganized criticality. For many models, most of the results are still pure numerical. For a review see, for instance, recent works of Jensen and Turcotte [2,3].

In this context, a model that has been widely studied in the literature is the Olami-Feder-Christensen (OFC) model for the dynamics of earthquakes. The original OFC model, introduced in 1992 [4], is a two-dimensional coupled map model defined on a square lattice, whose dynamical rules were inspired in a spring-block model proposed to describe the dynamics of earthquakes [5]. Earthquakes, in the real world, are associated with many power laws, the best known of them being the Gutenberg-Ritcher law for the distribution of avalanche energies. The OFC model assigns-to each site of a square lattice-a real variable $z_{i, j}$ (energy or tension), initially chosen at random in the interval $\left[0, z_{c}\right)$, where $z_{c}$ is a threshold value; $z_{i, j}$ increases slowly throughout the lattice and each time that, for a given site, $z_{i, j}$ exceeds $z_{c}$, the system relaxes. A fraction $\alpha z_{i, j}$ of the tension of site $(i, j)$ is then distributed to each of its nearest neighbors. As a consequence, the tension of some of its neighbors may also exceed $z_{c}$, generating an "avalanche" that will only stop when $z_{i, j}$ $<z_{c}$ again for all sites of the lattice. We have assumed, as usual, open boundary conditions in our simulations.

Within the OFC model, there is a dissipation parameter $\alpha$. If $\alpha=0.25$, the total tension in the lattice, $\Sigma z_{i, j}$, is conserved during the avalanching process, in the bulk of the

*Electronic address: tpeixoto@if.usp.br

${ }^{\dagger}$ Electronic address: prado@if.usp.br lattice (there is always dissipation in the boundaries). But if $\alpha<0.25$, there is some dissipation also in the bulk of the system. This model has been widely studied in literature. At the same time, it is a prototype of self-organization in systems with nonconservative relaxation rules (the existence of SOC in the nonconservative models is, up to now, not well understood [6-9]) and a paradigm of the success of SOC ideas, since it is able to reproduce important aspects of the dynamics of earthquakes.

Recently, Abe and Suzuki [10] observed a new power law in the statistics of earthquakes. They analyzed earthquake data from both the district of southern California and Japan, connecting their epicenters in order to generate a graph. Each area analyzed was divided into small cubic cells; they associated with each of these cells a node every time an earthquake started inside it. The epicenters of two successive earthquakes were linked, defining an edge. In this way, the data have been mapped into a complex growing graph that behaves like a scale-free network of the Barabási-Albert type [11]. The degree distribution of the graph decays as a power law. The clustering coefficient and the diameter of a cluster were also calculated, showing small-world network properties [12]. These features have revealed another aspect of earthquakes as a complex critical phenomenon.

We then decided to check whether the Olami-FederChristensen model could also predict this striking behavior. We found that the nonconserving version of the model reproduces the behavior of experimental data, even for a very small degree of nonconservation. The degree distribution of the evolving network formed by its epicenters is scale-free. However, the conservative version of the model has a qualitatively different behavior, more similar to a random graph, whose degree distribution is Poisson, indicating that most of the nodes have the same degree and, although random, the corresponding network is much more homogeneous. These results are in agreement with some recent observations that support the claims that conservative and nonconservative versions of the OFC model are quite different. Hergarten and Neugebauer [13] studying the efficiency of the OFC model to predict foreshocks and aftershocks, de Carvalho and Prado 
T. P. PEIXOTO AND C. P. C. PRADO
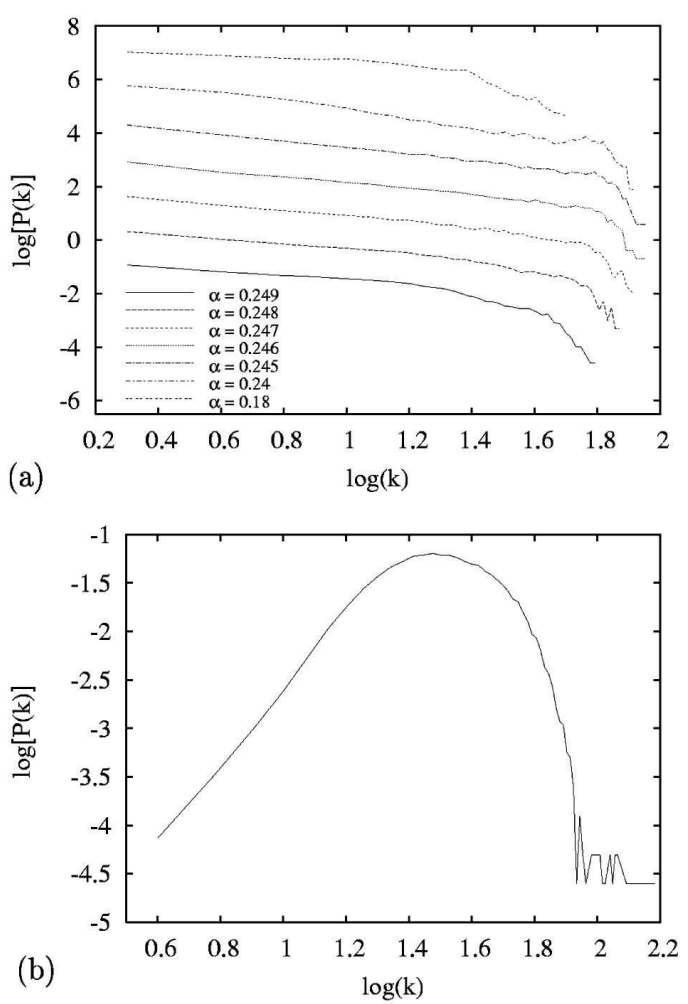

FIG. 1. Degree distribution $P(k)$ for different values of $\alpha$. (a) Nonconservative regime: the results show a scale-free network behavior in all cases. The curves for $\alpha<0.249$ have been shifted upwards along the $y$ axis for clarity, otherwise they would all coincide. In all cases, $L=200$ and the number of registered epicenters is $10^{5}$. (b) Conservative regime: the degree distribution is similar to a random graph. In this case we have $L=200$ and $10^{6}$ events. Lowering the statistics does not change this behavior. All log scales are base 10 .

[14], studying the transient behavior of the OFC model, and Miller and Boulter [15], studying the distribution of values at which supercritical sites topple, have also reported qualitatively different behaviors for conservative and nonconservative OFC models.

In a complex graph, the edges are not distributed in a regular way, and not all nodes have the same number of edges. One possible way to characterize complex networks is through its distribution function $P(k)$, which gives the probability that a random selected node has exactly $k$ edges ( $k$ is called the degree of the node). In a random graph, since the edges are placed randomly among the nodes, the majority of nodes have approximately the same degree, close to the average connectivity $\langle k\rangle$, and the distribution $P(k)$ is a Poisson distribution with a peak at $P(\langle k\rangle)$. Most complex networks, however, have a distribution function $P(k)$ that deviates significantly from a Poisson distribution. In particular, for a large number of networks, associated with a wide class of systems, ranging from the World Wide Web to meta-
PHYSICAL REVIEW E 69, 025101(R) (2004)

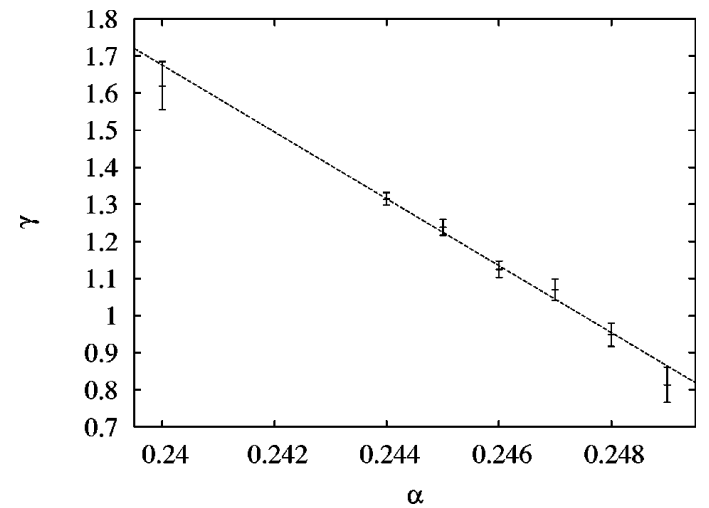

FIG. 2. Exponent $\gamma$ that characterizes the power-law behavior of $P(k)$. The slope $\gamma$ seems to increase linearly with $\alpha$, at least for values of $\alpha$ close to the conservative regime. In all cases, $L=200$ and the number of epicenters is $10^{5}$.

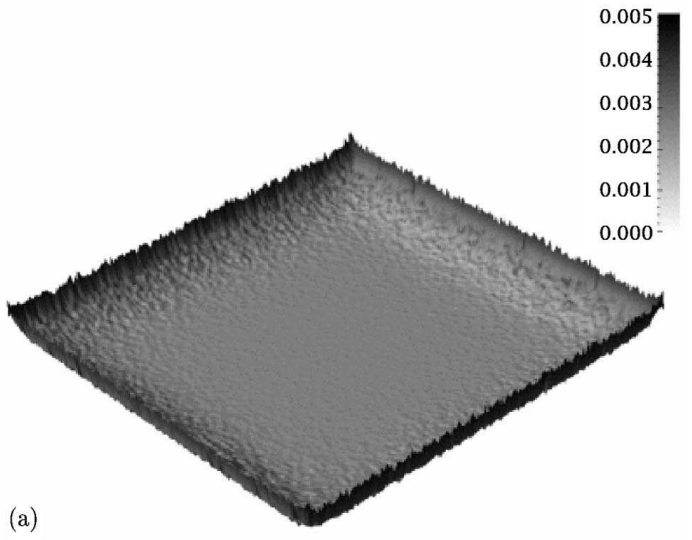

(b)

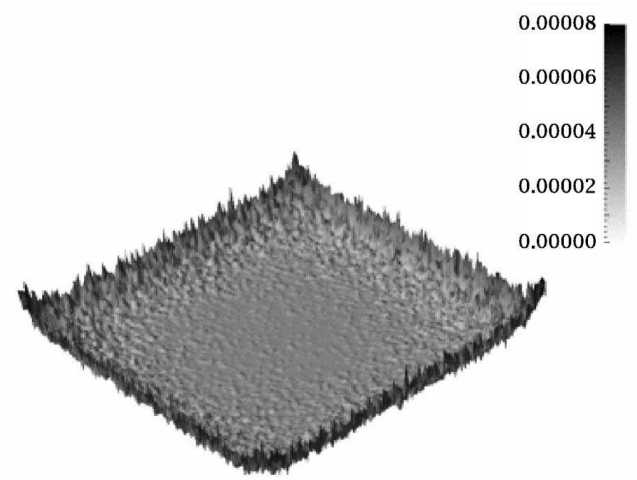

FIG. 3. Spatial distribution of node degrees in the nonconservative case, for $\alpha=0.249, L=200$, and $10^{5}$ events. Sites associated with nodes of higher degree are darker and, as one can see, are closer to the boundaries. Panel (b) is a blow up of (a). The 20 sites closer to the boundaries do not appear in the picture, and the scale has been changed in order to show the details of the bulk of the lattice. We can see that the structure of the network observed in (a) is reproduced (and it is not an effect due to the boundaries). 


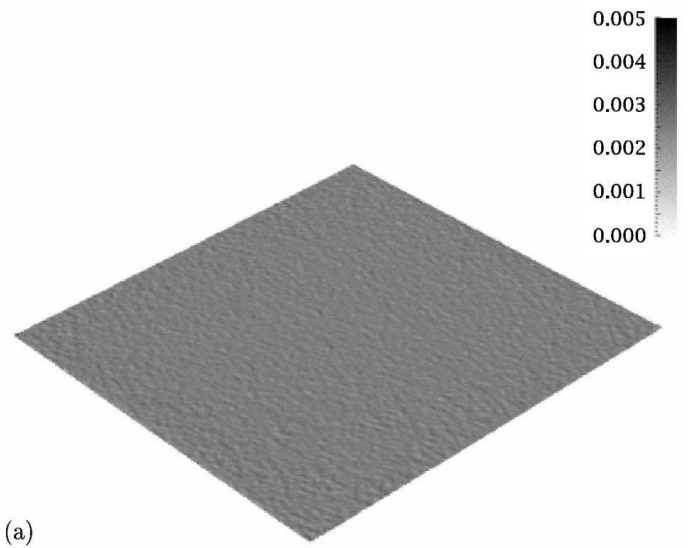

(a)

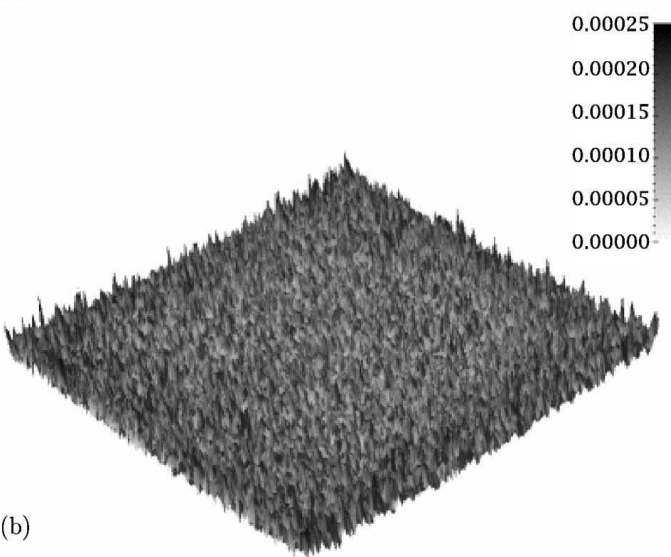

FIG. 4. Spatial distribution of node degrees for the conservative case. Sites associated with nodes of higher degree are darker, $L$ $=200$, and the number of epicenters is $10^{6}$. (a) The same scale of Fig. 3(a) has been used. (b) The scale has been changed to reveal details of the structure of the network that, in this case, is much more homogeneous and quite different from that observed in the nonconservative regime.

bolic networks, $P(k)$ has a power-law tail, $P(k) \sim k^{-\gamma}$. Such networks are called scale-free [11], and have called the attention of many researchers in the last years.

We simulated the OFC model in a square lattice, building graphs with a procedure very similar to what has been employed by Abe and Suzuki. Each site that gives birth to a new avalanche, of any size, is an epicenter; each epicenter defines a node, and every node is then connected to the node where the next epicenter occurs, establishing a link or edge between them. If two subsequent earthquakes start in the same cell (which does not happen if each site is a cell, but do happen with larger cells), we have a loop. After many avalanches this procedure generates a complex network (or graph), and we have studied some of its statistical properties.

After eliminating a transient of at least $10^{6}$ events, we calculated numerically the distribution function $P(k)$ for the graph constructed from the time sequence of epicenters in the OFC model for different values of $\alpha$ and different lattice

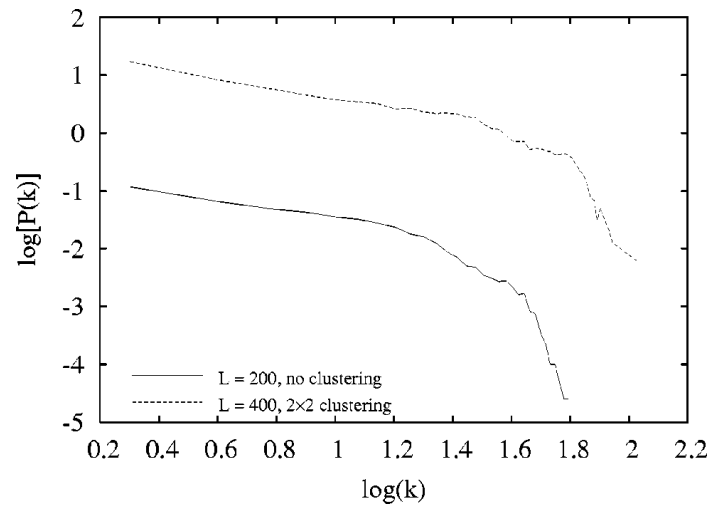

FIG. 5. Degree distribution $P(k)$, for $\alpha=0.249, L=200$, and $10^{5}$ events, for different cell sizes. All log scales are base 10.(a) Continuous line: $L=200$ and each site of the lattice defines a cell. (b) Dashed line: $L=400$ and each four adjacent sites are in the same cell. The curve has been shifted upwards in the $y$ axis for clarity.

sizes. As the first and last sites are the only ones with an odd number of edges (if they do not coincide), they are eliminated. Our results for the distribution $P(k)$ can be seen in Fig. 1. It is clear that, if $\alpha<0.25$ [Fig. 1(a)], the distribution is scale-free for some decades, with an exponent $\gamma$ that varies linearly with $\alpha$ (see Fig. 2), at least for values of $\alpha$ not too far from the conservative regime. In Fig. 1 some curves have been shifted upwards for the sake of clarity. They would coincide, except for a small change in the slope, otherwise. We have also observed that the network grows toward the inside of the lattice, with the most connected sites in the borders and the most inner sites being the last ones being added to it [see Fig. 3(a)]. The complex structure, however, is not a boundary effect. If we take out the border sites and adjust the scale, we see that the same spatial structure is reproduced [Fig. 3(b)]. Because one needs a growing network to observe the scale-free behavior [11], after a certain number of events, as a consequence of the finite size of the lattice, most of the sites of the lattice have already become part of the network. At this point the scale-free behavior starts to break.

If the system is conservative, however, the distribution function $P(k)$ has a well-defined peak, indicating a higher degree of homogeneity among the nodes [Fig. 1(b)]. Figures 4(a) and 4(b), which should be compared with Fig. 3, show the spatial distribution of connectivities (degree of the nodes) in the lattice. As expected, it is much more homogeneous. This homogeneous behavior is not destroyed if we change the statistic of events.

Finally, our findings also seem to be robust with respect to the cell size and the size of the lattice. If we increase the size of the cell, defining, for instance, four adjacent sites of the lattice as a unique cell, there is no change in the results, not even in the exponent $\gamma$ that characterizes the degree distribution $P(k)$, as shown in Fig. 5. Also, there is no change if we increase the size of the lattice.

In conclusion, we have shown that the nonconservative version of the Olami-Feder-Christensen model is able to 


\section{T. P. PEIXOTO AND C. P. C. PRADO}

reproduce the scale-free network associated with the dynamics of epicenters observed on real earthquake data. The conservative version of the model displays a qualitatively different behavior, being closer to a random graph. The smallest degree of nonconservation seems to be enough to change the behavior of the model, since for $\alpha=0.249$ we see that $P(k)$ has already a well-defined power-law behavior for some decades. Those findings, besides giving an indication of the robustness of this model to reproduce the dynamics of earth-
PHYSICAL REVIEW E 69, 025101(R) (2004)

quakes, reproducing the experimental findings of Abe and Suzuki, present a completely different dynamical mechanism to generate a scale-free network. There is no explicit rule of preferential attachment, and the preferential attachment observed in the network is a signature of the model dynamics. Maybe the complete study of the properties of this network can help solve some still controversial aspects of the OlamiFeder-Christensen model and of self-organized critical behavior.
[1] P. Bak, C. Tang, and K. Wiesenfeld, Phys. Rev. Lett. 59, 381 (1987); Phys. Rev. A 38, 364 (1988).

[2] H. Jensen, Self-Organized Criticality (Cambridge University Press, New York, 1998).

[3] D.L. Turcotte, Rep. Prog. Phys. 62, 1377 (1999).

[4] Z. Olami, H.J.S. Feder, and K. Christensen, Phys. Rev. Lett. 68, 1244 (1992).

[5] R. Burridge and L. Knopoff, Bull. Seismol. Soc. Am. 57, 341 (1967)

[6] J.X. de Carvalho and C.P.C. Prado, Phys. Rev. Lett. 84, 4006 (2000)

[7] K. Christensen, D. Hamon, H.J. Jensen, and S. Lise, Phys. Rev. Lett. 87, 039801 (2001); J.X. de Carvalho and C.P.C.
Prado, ibid. 87, 039802 (2001)

[8] S. Lise and M. Paczuski, Phys. Rev. E 63, 036111 (2001).

[9] G. Miller and C.J. Boulter, Phys. Rev. E 66, 016123 (2002).

[10] S. Abe and N. Suzuki, Europhys. Lett. (to be published); e-print cond-mat/0308208.

[11] A.-L. Barabási and R. Albert, Science 286, 506 (1999); R. Albert and A.-L. Barabási, Rev. Mod. Phys. 74, 47 (2002).

[12] D.J. Watts and S.H. Strogatz, Nature (London) 393, 440 (1998).

[13] S. Hergarten and H.J. Neugebauer, Phys. Rev. Lett. 88, 238501 (2002).

[14] J.X. de Carvalho and C.P.C. Prado, Physica A 321, 519 (2003).

[15] G. Miller and C.J. Boulter, Phys. Rev. E 67, 046114 (2003). 


\title{
C.2 Artigo "Statistics of epicenters in the Olami-Feder- Christensen model in two and three dimensions " [2]
}

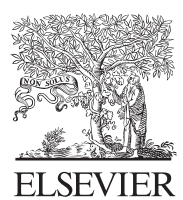

Available online at www.sciencedirect.com

SCIENCE d) DiREct.

PHYSICA

Physica A 342 (2004) 171-177

www.elsevier.com/locate/physa

\section{Statistics of epicenters in the Olami-Feder- Christensen model in two and three dimensions}

\author{
Tiago P. Peixoto*,1, Carmen P.C. Prado \\ Instituto de Física, Universidade de São Paulo, Caixa Postal 66318, 05315-970, São Paulo, SP, Brazil
}

Received 25 November 2003; received in revised form 19 December 2003

Available online 17 May 2004

\begin{abstract}
Recently, Abe and Suzuki pointed out that epicenters of earthquakes could be connected in order to generate a graph, with properties of a scale-free network. We have shown that the Olami-Feder-Christensen (OFC) model for the dynamics of earthquakes, defined both in square and cubic lattices, is able to reproduce this new behavior. The distribution of distances between successive earthquakes is also presented. Our results indicate the robustness of the OFC model to describe earthquake dynamics. Surprisingly, we found that only the non-conservative version of the OFC model generates a network with scale-free properties. The conservative version, instead, behaves like a random graph. The distribution of distances in 3-D and the distribution of connectivities in a 2-D lattice confirm the differences observed between the conservative and non-conservative regime.
\end{abstract}

(c) 2004 Elsevier B.V. All rights reserved.

PACS: 05.65.+b; 89.75.Da; 89.75.Kd; 47.70.Ht; 91.30.Dk

Keywords: Self-organized criticality; Earthquake; Complex networks; Complex systems

The concept of self-organized criticality was introduced by Bak et al. [1], as a possible explanation of scale invariance in nature. To illustrate their basic ideas, they presented a cellular automaton model, the sandpile model, so-called because of a possible analogy between its dynamical rules and the movement of sand or snow in avalanches. Since this work, a great number of cellular automata and coupled map models have been investigated in an attempt to elucidate the essential mechanisms hidden a wide

\footnotetext{
* Corresponding author.

E-mail addresses: tpeixoto@if.usp.br (T.P. Peixoto), prado@if.usp.br (C.P.C. Prado).

${ }^{1}$ Thiago Peixoto thanks the support of the Brazilian agency FAPESP.
} 
class of different non-linear phenomena whose statistics of events (or avalanches) are governed by power-laws. However, up to now, one still lacks from a general theoretical framework for self-organized criticality. Most of the results are purely numerical. Success in analytical investigations have been achieved mainly in the study of a special class of models that became known as Abelian models [2,3], in mean-field-type calculations (see for instance Refs. [4-8]) or through a renormalization group approach [9].

In this context, a model that has raised a lot of controversy and, as a consequence, has been widely studied, is the Olami-Feder-Christensen (OFC) model for the dynamics of earthquakes [10]. They proposed a non-conserving model that, up to now, seems very robust to predict many different features of real earthquake statistics, and has become known as OFC model.

Recently, Abe and Suzuki [11] observed a new power-law in the statistics of earthquakes. They analyzed earthquake data from both the district of southern California and Japan, connecting their epicenters in order to generate a graph. Each area analyzed was divided into small cubic cells; they associated each of these cells to a node, every time an earthquake started inside it. The epicenters of two successive earthquakes were linked, defining an edge. In this way the data could be mapped into a complex growing network that showed a scale-free behavior of the Barabási-Albert type (for a review, see Ref. [12]). These features have revealed a novel aspect of earthquakes as a complex critical phenomenon.

In this paper we studied the OFC model both in two and three dimensions, to see if it could also predict this new behavior of real earthquakes. Both two and three dimension versions of the model generated a scale-free network, as observed in the real earthquake data, but only when we assume non-conserving relaxation rules. The scale-free behavior was observed even for a very small degree of non-conservation $(\alpha=0.249)$. However, the conservative version of the model $(\alpha=0.25)$ showed a qualitatively different behavior, more similar to a random graph, whose degree distribution is Poisson, indicating that most of the nodes have about the same connectivity and that the corresponding network is much more homogeneous. These results are in agreement with some recent observations, reinforcing that conservative and non-conservative versions of the OFC model are quite different. Hergarten and Neugebauer [13] studying the efficiency of the OFC model to predict foreshocks and aftershocks, de Carvalho and Prado [14], studying the transient behavior of the OFC model and Miller and Boulter [15] studying the distribution of values at which supercritical sites topple have also reported qualitatively different behaviors between the conservative and non-conservative OFC model.

The original OFC model is a two-dimensional coupled-map model whose dynamical rules were inspired in a spring-block model proposed by Burridge and Knoppov in 1967 [16]. Earthquakes, in the real world, are associated with many power-laws, the most known of them being the Gutenberg-Ritcher law for the distribution of energies of the earthquakes. The OFC model assigns - to each site of a square lattice-a real variable $z_{i, j}$ (energy or tension), initially chosen at random in the interval $\left[0, z_{c}\right)$, where $z_{c}$ is a threshold value. $z_{i, j}$ increases slowly throughout the lattice, reproducing the slow relative movement of two tectonic plates in a fault. Each time that, for a given site, $z_{i, j}$ exceeds the threshold value $z_{c}$, the system relaxes. The tension of site $z_{i, j}$ becomes 
zero and a fraction $\alpha z_{i, j}$ of its tension is then distributed among its nearest-neighbors. As a consequence, the tension of some of its neighbors may also exceed $z_{c}$, generating an 'avalanche' that will only stop when $z_{i, j}<z_{c}$ for all sites of the lattice. In this work, we assume open boundaries.

Within the OFC model there is a dissipation parameter $\alpha$. In a square lattice, if $\alpha=0.25$, the total tension in the lattice, $\sum z_{i, j}$, is conserved during the avalanching process, in the bulk of the lattice (there is always dissipation in the boundaries). But if $\alpha<0.25$ there is some dissipation also in the bulk of the system. The model is said to be 'conservative' in the first case, and 'non-conservative' in the second, and it has been widely studied in literature. It is a prototype of self-organization in systems with non-conservative relaxation rules (the existence of SOC in the non-conservative models is, up to now, not well understood [17]) and also a paradigm of the success of SOC ideas, since it is able to reproduce important aspects of the dynamics of earthquakes.

The complexity of numerous social, biological or communication systems is related to the rather interwoven web defined by the system's components and their interactions. In this approach, the society can be seen as a huge social network whose nodes are individuals or organizations, connected by social interactions, or cell functioning by a complex metabolic network, whose nodes are substrates and enzymes, and the edges represent chemical interactions. Equally complex networks appear in many other situations, and the study of their properties have mobilized many researchers in the recent years [12]. The study of more complex networks began with the study of random graphs, following a model proposed by Erdös and Rényi [18] that views the network as a set of nodes which are connected pairwise with equal probability. In a complex graph, the edges are not distributed in an regular way and not all nodes have the same number of edges. One possible way to characterize complex networks is through its distribution function $P(k)$, which gives the probability that a random selected node has exactly $k$ edges. $k$ is called the degree or connectivity of the node. In a random graph, since the edges are placed randomly among the nodes, the majority of nodes have approximately the same degree, close to the average connectivity $\langle k\rangle$, and the distribution $P(k)$ is a Poisson distribution with a peak at $P(\langle k\rangle)$. Most complex networks, however, have a distribution function $P(k)$ that deviates significantly from a Poisson distribution. In particular, for a large number of networks, associated with a wide class of systems, $P(k)$ has a power-law tail, $P(k) \sim k^{-\gamma}$.

We simulated the OFC model in both square and cubic lattices, building graphs with a procedure very similar to what has been employed by Abe and Suzuki. Each site that produces a new avalanche is an epicenter; each epicenter defines a node, and every node is then connected to the node where the next epicenter occurs, establishing a link or edge between them. After many avalanches this procedure generates a complex network (or graph), and we have studied the connectivity distribution of it. Here we make a distinction between degree and connectivity: degree is defined as the number of other nodes to which a given node $i$ is connected; connectivity is defined as the number of edges of a node. In the procedure described above, employed to obtain the network from the distribution of epicenters, site $i$ can be connected to site $j$ that can be connected to site $i$ again, what makes the degree distribution different from the connectivity distribution. 

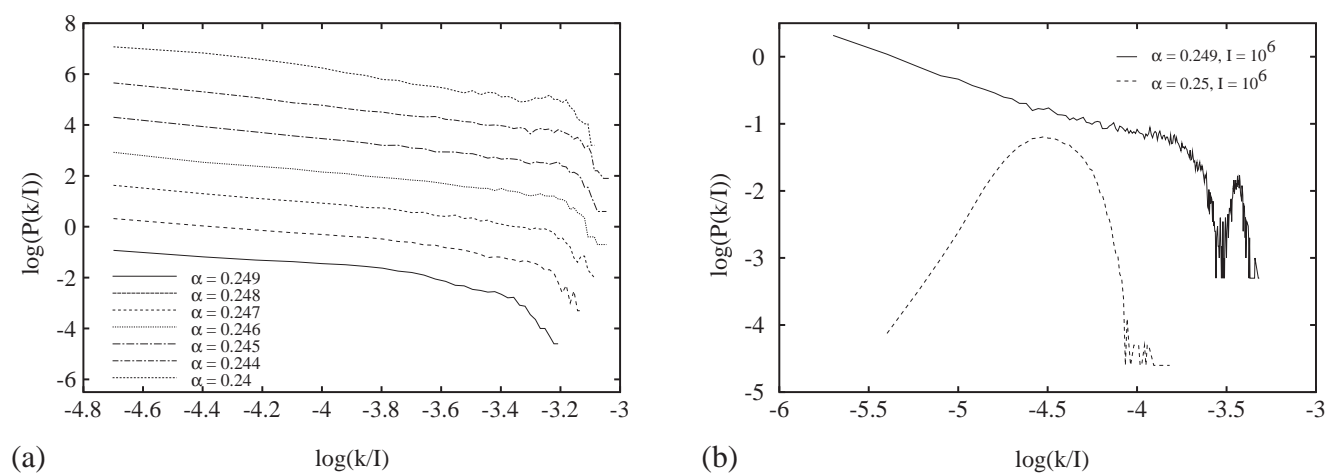

Fig. 1. Degree distribution $P(k)$ for different values of $\alpha$. (a) Non-conservative regime: the results show a free-scale network behavior for $\alpha$ ranging from 0.249 to 0.240 . The curves for $\alpha<0.249$ have been shifted upward along the $y$ axis for clarity, otherwise, they would coincide. In all cases $L=200$ and the number of epicenters is $10^{5}$. (b) Degree distribution $P(k)$ for the conservative regime, in comparison with a slightly non-conservative case $(\alpha=0.249)$ : the results are similar to a random graph; in this case we have $L=200$ and $10^{6}$ events, and there is no shift of the curves. The curves were normalized by the total number of connections $I$ for the sake of comparison.

We have already shown [19] that the OFC model, defined on a square lattice, could reproduce quite well this behavior, in the non-conservative regime. After eliminating a transient of at least $10^{6}$ events, we calculate numerically the distribution function of connectivities $P(k)$ for different values of $\alpha$ and lattice sizes in a square lattice. Our results for the distribution $P(k)$ can be seen in Fig. 1, both for the conservative and non-conservative regimes. It is clear that, if $\alpha<0.25$ (Fig. 1a), the distribution is scale-free for many decades, with an exponent $\gamma$ that varies linearly with $\alpha$. We now reproduce this study for the OFC model in a cubic lattice (see Fig. 2). As Abe and Suzuki have built a three-dimensional network, we have thought it was important to check the robustness of those results with respect to the dimension of the model. Note that, in this case, the conservative regime corresponds to $\alpha=1 / 6=0.166 \ldots$.. Fig. 2 shows that there is no significative difference in the behavior of the model when one increases the dimension of the lattice, showing that our result is robust also with respect to the dimension of the model. Also in this case, the conservative regime behaves more like a random graph then like a scale-free network.

In the non-conservative regime, where we observe the scale-free behavior, the most connected sites are in the borders and the most inner sites are the last ones to be added to the network. The complex structure, however, is not a boundary effect. If we take out the most outer sites and adjusts the scale, we see that the same spatial structure is reproduced towards the inside of the lattice. In opposition, the distribution of connectivities in the lattice, in the conservative case, is much more homogeneous (see Fig. 3).

Finally, in Fig. 4, we can see the distribution of distances among two connected epicenters, in the three-dimensional case, for different values of the conservation parameter $\alpha$. The statistics of distances between successive earthquakes is a new concept introduced by Abe and Suzuki [20]. Notice the difference between conservative 

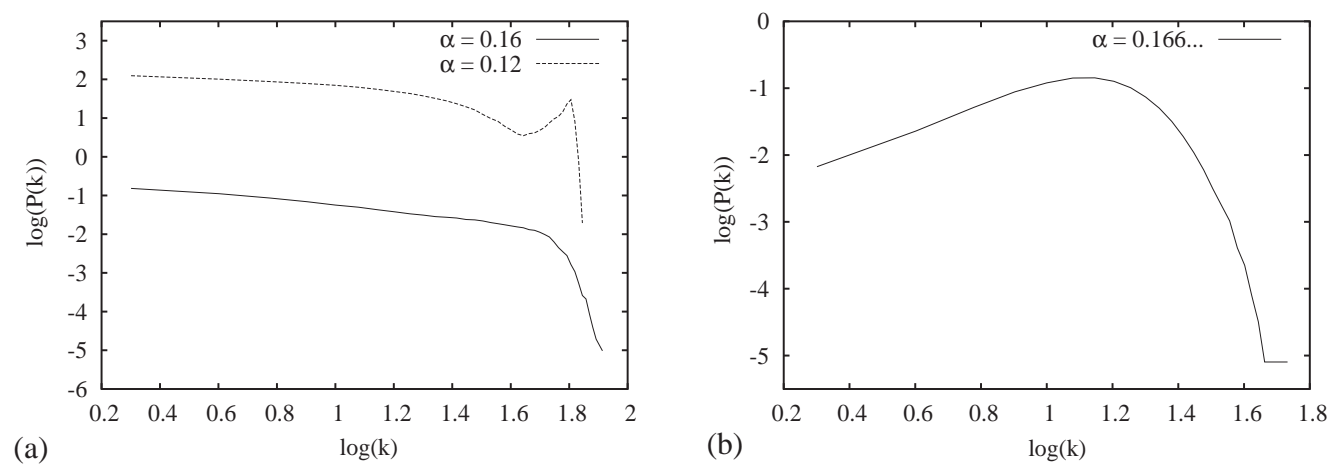

Fig. 2. Degree distribution $P(k)$ for a three-dimensional lattice of size $50 \times 50 \times 50$. (a) Non-conservative regime: the results show a scale-free network behavior for $\alpha=0.16$ and 0.12 . The curve for $\alpha=0.12$ have been shifted upward along the $y$ axis for clarity. The peak observed for higher connectivities is an indication that the lattice started to saturate. (b) Degree distribution $P(k)$ for the conservative regime $(\alpha=1 / 6 \sim 0.166 \ldots)$. The results are similar to a random graph.

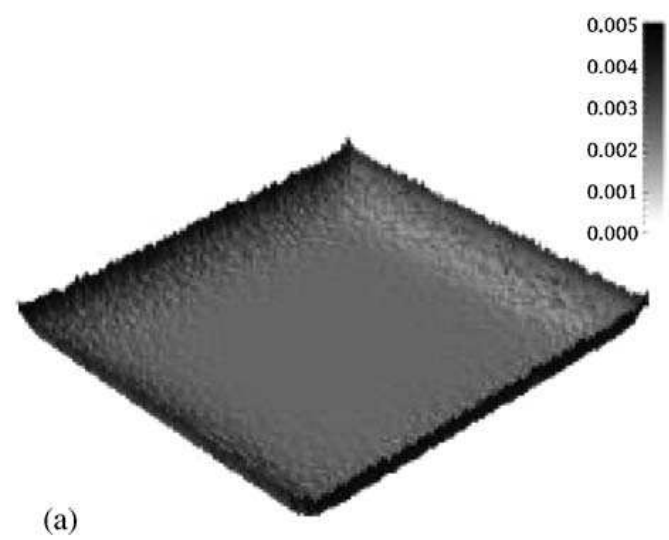

(a)

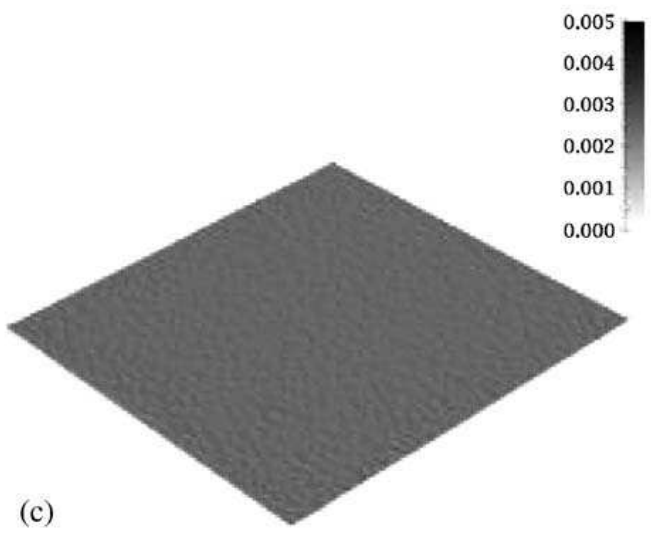

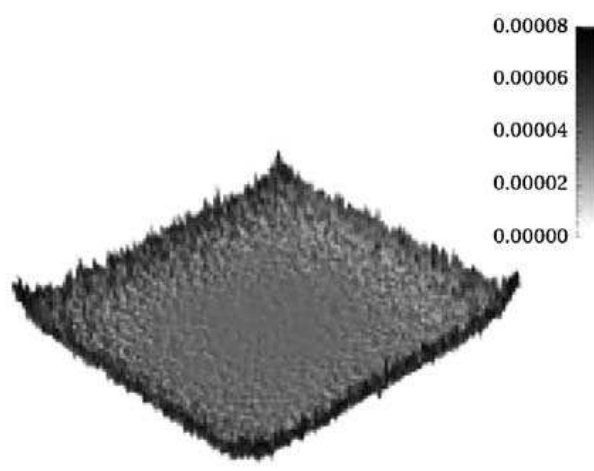

(b)

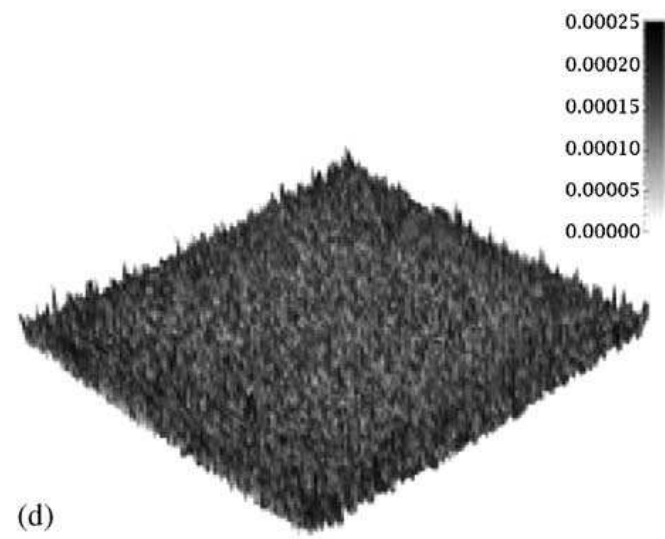

Fig. 3. (a) Spacial distribution of connectivities in the non-conservative case, for $\alpha=0.249, L=200$ and $10^{5}$ events. Sites associated with nodes of higher degree are darker and as one can see, closer to the boundaries. (b) A blow up of (a). The 20 sites closer to the boundaries were not plotted and the scale has been changed in order to show the details of the bulk. They show that the structure of the network found in (a) is reproduced toward the inside of the lattice, so it is not a boundary effect. (c) Spacial distribution of connectivities for the conservative case. Sites associated with nodes of higher degree are darker. The same parameters and scale of (a) was employed. (d) Same as (c), but the scale has been changed to reveal the structure of the network that, in this case, is much more homogeneous. 


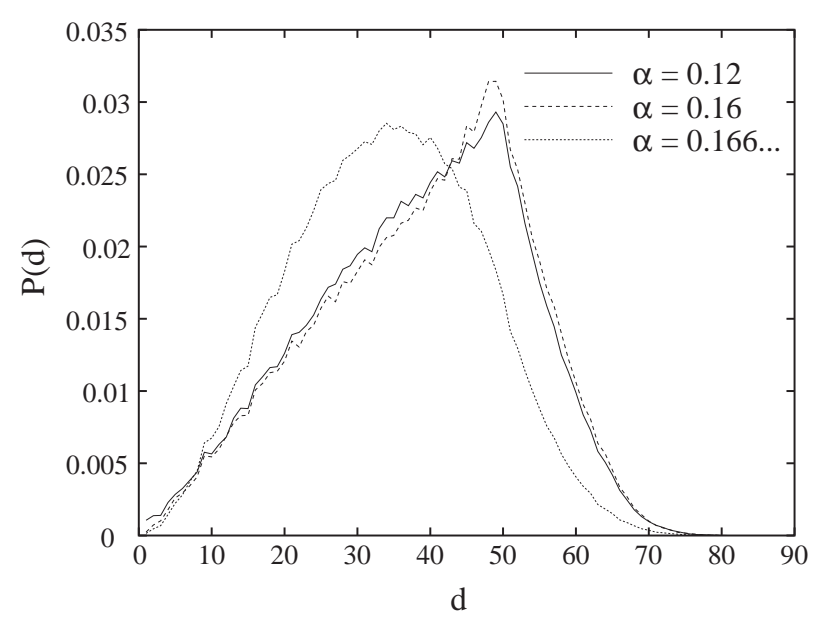

Fig. 4. Distribution of distances between two successive epicenters in the conservative and non-conservative cases, for a three-dimensional lattice of size $L=50$. Notice the difference between conservative and non-conservative regimes.

and non-conservative regimes. While in the conservative case there is a distribution around an average value of $d \sim 35$, in the non-conservative case the distribution is not symmetric, and most of the distances are about the linear size $L=50$ of the lattice.

In conclusion, we have shown that the non-conservative version of the OFC model, both in two and three dimensions is able to reproduce the scale-free network associated to the dynamics of the epicenters observed on real earthquake data. The conservative version of the model displays a different behavior, being more close to a random graph. The smallest degree of non-conservation seems to be enough to change the behavior of the model, since for $\alpha=0.249$ we see that $P(k)$ has already a well-defined power law behavior. Those findings, besides giving an indication of the robustness of this model to reproduce the dynamics of earthquakes, present a completely new dynamical mechanism to generate a scale-free network. Now there is no explicit rule of preferential attachment, and the preferential attachment observed in the network is a signature of the system dynamics. We hope that a complete study of the properties of the network can help to solve some still controversial aspects of the OFC model.

\section{References}

[1] P. Bak, C. Tang, K. Wiesenfeld, Phys. Rev. Lett. 59 (1987) 381-384.

[2] D. Dhar, R. Ramaswamy, Phys. Rev. Lett. 63 (1989) 1659-1662.

[3] D. Dhar, Phys. Rev. Lett. 64 (1990) 1613-1616.

[4] A. Vespignani, S. Zapperi, Phys. Rev. Lett. 78 (1997) 4793-4796.

[5] H.-M. Bröker, P. Grassberger, Phys. Rev. E 56 (1997) 3944-3952.

[6] M.-L. Chabanol, V. Hakim, Phys. Rev. E 56 (1997) R2343-R2346.

[7] O. Kinouchi, C.P.C. Prado, Phys. Rev. E 59 (1999) 4964.

[8] S.T.R. Pinho, C.P.C. Prado, Braz. J. Phys. 33 (2003) 476.

[9] L. Pietronero, A. Vespignani, S. Zapperi, Phys. Rev. Lett. 72 (1994) 1690-1693.

[10] Z. Olami, H.J.S. Feder, K. Christensen, Phys. Rev. Lett. 68 (1992) 1244-1247. 
[11] S. Abe, N. Suzuki, Europhys. Lett. 65 (2004) 581.

[12] R. Albert, A.-L. Barabási, Rev. Mod. Phys. 74 (2002) 47.

[13] S. Hergarten, H.J. Neugebauer, Phys. Rev. Lett. 88 (2002) 8501.

[14] J.X. de Carvalho, C.P.C. Prado, Physica A 321 (2003) 519.

[15] G. Miller, C.J. Boulter, Phys. Rev. E 67 (2003) 046114.

[16] R. Burridge, L. Knopoff, Bull. Seismol. Soc. Am. 57 (1967) 341.

[17] J.X. de Carvalho, C.P.C. Prado, Phys. Rev. Lett. 84 (2000) 4006.

[18] P. Erdös, A. Rényi, Publ. Math. Debrecen 6 (1959) 290.

[19] T. Peixoto, C.P.C. Prado, Phys. Rev. E 69 (2004) 025101 (R).

[20] S. Abe, N. Suzuki, J. Geophys. Res. 108 (2003) 2113. 


\title{
C.3 Artigo "Network of epicenters of the Olami-Feder- Christensen model of earthquakes" [3]
}

PHYSICAL REVIEW E 74, 016126 (2006)

\author{
Network of epicenters of the Olami-Feder-Christensen model of earthquakes \\ Tiago P. Peixoto* and Carmen P. C. Prado ${ }^{\dagger}$ \\ Instituto de Física, Universidade de São Paulo, Caixa Postal 66318, 05315-970 São Paulo, São Paulo, Brazil \\ (Received 25 February 2006; published 31 July 2006)
}

We study the dynamics of the Olami-Feder-Christensen (OFC) model of earthquakes, focusing on the behavior of sequences of epicenters regarded as a growing complex network. Besides making a detailed and quantitative study of the effects of the borders (the occurrence of epicenters is dominated by a strong border effect which does not scale with system size), we examine the degree distribution and the degree correlation of the graph. We detect sharp differences between the conservative and nonconservative regimes of the model. Removing border effects, the conservative regime exhibits a Poisson-like degree statistics and is uncorrelated, while the nonconservative has a broad power-law-like distribution of degrees (if the smallest events are ignored), which reproduces the observed behavior of real earthquakes. In this regime the graph has also an unusually strong degree correlation among the vertices with higher degree, which is the result of the existence of temporary attractors for the dynamics: as the system evolves, the epicenters concentrate increasingly on fewer sites, exhibiting strong synchronization, but eventually spread again over the lattice after a series of sufficiently large earthquakes. We propose an analytical description of the dynamics of this growing network, considering a Markov process network with hidden variables, which is able to account for the mentioned properties.

\section{INTRODUCTION}

Several different phenomena in nature spontaneously exhibit scale-invariant statistics. An attempt to identify a supposed basic mechanism behind this behavior was made by Bak et al. [1], who introduced the concept of self-organized criticality (SOC). SOC is characterized by slowly driven systems, with fast avalanchelike bursts of dissipation. Despite probably not being the sole explanation for scale invariance in nature, a wide range of systems do appear to exhibit SOC, such as sandpiles [1], forest fires [2], and earthquakes [3]. However, no general framework for SOC systems exists, and the mechanism behind it is not very well understood. In particular, the existence of SOC in nonconservative systems is still debated [4-6]. This discussion is frequently focused on one of the most studied and archetypal nonconservative SOC models, the Olami-Feder-Christensen (OFC) model for earthquakes. Despite being defined by very simple rules (see Sec. II), this model possesses very rich dynamics, and is able to reproduce a wide range of statistics of real earthquakes, such as the Gutenberg-Richter law for the distribution of event sizes [3,7] and the Omori law for fore- and aftershocks $[8,9]$.

In this work we concentrate on the behavior of the epicenters in the OFC model, in both the conservative and nonconservative regimes, studied as a growing complex network with scale-free behavior $[10,11]$.

As known previously [4,12], we confirm that in both regimes epicenters are more frequent closer to the border, and we study this effect in detail. We show, however, that this border effect does not scale with system size, and should not therefore be considered representative of the dynamics of the

\footnotetext{
*Electronic address: tpeixoto@if.usp.br

†Electronic address: prado@if.usp.br
}

model in the thermodynamic limit. The length of the effect is dependent on the level of dissipation, and is relatively large for the range of parameters normally studied, especially when close to the conservative limit, where an exponentially decaying layer dominates, and it is hard to observe anything else other than this border effect. The existence of this nonscaling border is in accordance with what was found in [4], that only earthquakes from a smaller internal subset of the lattice exhibit finite-size scaling in the event size statistics.

We turn then to the dynamics of epicenters. Recently there has been an increasing interest in complex networks [13] as a tool for describing very diverse systems, many of which exhibit a type of scale invariance that seems to be due to a general mechanism of preferential attachment $[14,15]$. In order to study the epicenter dynamics in the OFC model, we construct a network of consecutive epicenters in the bulk, and examine its properties in more detail. ${ }^{1}$

The network of epicenters, in the nonconservative regime, shows scale invariance in the degree statistics, if the epicenters of the smaller events are discarded. This network has also an unusual correlation among vertices of high degree, which makes it very distinct from networks created with a preferential attachment rule. These results reproduce what has been found by Abe and Suzuki $[16,17]$ for real earthquakes, further contributing to the success of this simple model in capturing the essential earthquake dynamics. We show that this degree correlation seems to be due to the existence of temporary attractors for the dynamics, which shows periods of strong synchronization. We also noticed that a drop in the average in-degree of the network seems to precede big earthquakes, which could in principle be used to predict at least an increase in the probability of big events in a given fault.

\footnotetext{
${ }^{1}$ In a previous study [10], we also analyzed some aspects of the same network, but did not take into account the border effect, and looked only at smaller lattices.
} 
We also show that is possible to reproduce some of the characteristics of the complex epicenter network found in the nonconservative version of the OFC model by defining a growing procedure based on a Markov chain with hidden variables. To each possible epicenter (vertex) is attached a hidden variable, and the probability of connections among epicenters (related to the time sequence of events) is now given as a function of the hidden variable of both vertices (instead of a simple preferential attachment rule, as in a Barabási-Albert-type network [15]).

This paper is organized as follows. In Sec. II we briefly present the Olami-Feder-Christensen model for earthquakes; in Sec. III we discuss in detail the way the spatial distribution of epicenters depends on the distance to the borders, in the conservative, nonconservative, and "almost conservative" regimes; in Sec. IV we review the way we can build a scale-free network from the time series of epicenters, and present the main properties of this network when the border effect is discarded. This network, although showing a scalefree behavior, is quite different from Barabási-Albert-type networks, with a strong correlation among vertices with high degree. In Sec. V we show how we can grow a network with similar properties based on a Markov chain process with hidden variables and, finally, in Sec. VI, we summarize our results.

\section{THE OFC MODEL}

The OFC model [3] was inspired by the BurridgeKnopoff spring-block model [18], and is defined as a twodimensional (2D) coupled map on a square lattice. To each site $(i, j)$ in the lattice is assigned a "tension" $z_{i j}$, initially chosen at random from the interval $\left[0, z_{c}[\right.$. The entire system is driven slowly, with every $z_{i j}$ increasing uniformly. Whenever a site reaches the threshold tension $\left(z_{i j}=z_{c}\right)$, an avalanche starts (the "earthquake"). The first site to reach $z_{c}$ and start an avalanche is called the epicenter. A fraction $\alpha$ of the tension of the toppling site is transferred to each of its four neighbors $\left(z_{i \pm 1, j \pm 1}=z_{i \pm 1, j \pm 1}+\alpha z_{i j}\right)$, and its tension is set to zero $\left(z_{i j}=0\right)$. If any of the neighbors acquires a tension $z_{i \pm 1, j \pm 1} \geqslant z_{c}$, the same toppling rules are applied, until there are no more sites in the system with $z_{i j} \geqslant z_{c}$. Without loss of generality, we set $z_{c}=1$. The total number of sites that topple until the avalanche is over is called the "size" of the avalanche. The parameter $\alpha$ defines the level of local conservation of the system. For $\alpha=0.25$ the system is locally conservative and for $\alpha<0.25$ it is dissipative. We consider here only the case with open boundary conditions, i.e., the sites at the border of the lattice transfer tension to nonexisting neighbors, so the system is always globally nonconservative, but tends to conservative in the thermodynamic limit if $\alpha=0.25$.

\section{INFLUENCE OF THE BORDERS ON THE FREQUENCY OF EPICENTERS}

We find that, in the stationary regime of the OFC model, the number of times a site is an epicenter varies according to how close that site is to the border, with epicenters closer to the border occurring much more often. We will refer to this

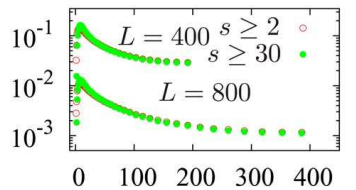

(a) $\alpha=0.25$
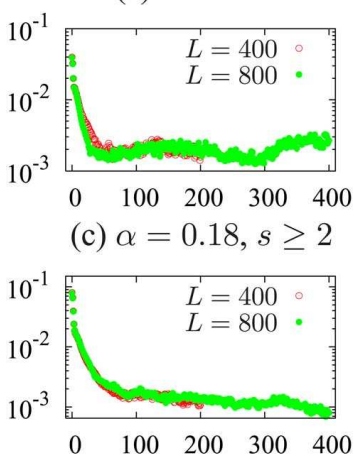

(e) $\alpha=0.22, s \geq 2$ (c) $\alpha=0.18, s \geq 2$ (b) $\alpha=0.249, s \geq 2$

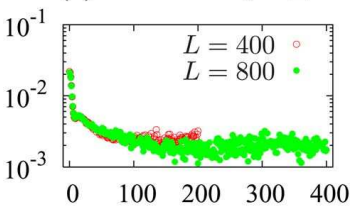

(d) $\alpha=0.18, s \geq 30$

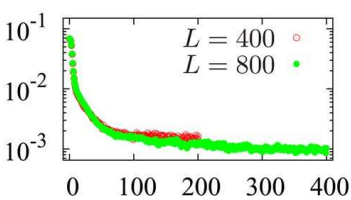

(f) $\alpha=0.22, s \geq 30$

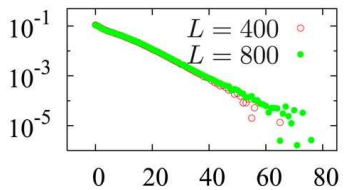

FIG. 1. (Color online) Frequency of epicenters ( $y$ axis) as a function of the distance from the border ( $x$ axis), for different values of $\alpha, L$, and earthquakes size $s$. The data for $L=400$ in (a) were shifted upward for clarity. From (c) to (f) the data for different values of $L$ were collapsed on top of each other by hand. All quantities are dimensionless.

excess of epicenters in the borders as the border effect. Figure 1 shows the average frequency with which a site was an epicenter, given its distance from the border, for $\alpha=0.25$, $0.249,0.22$, and 0.18 . We have gathered statistics from two lattice sizes $L=400$ and 800 , and considered at least 6 $\times 10^{6}$ events (after the transient). We have considered epicenters only of earthquakes larger than $1(s \geqslant 2)$, since size-1 earthquakes seem to obey their own statistics [19]. We have also considered epicenters that gave rise to larger earthquakes $(s \geqslant 30)$, to observe the dependence of the border effect on earthquake size. ${ }^{2}$

For the conservative regime, as can be seen in Fig. 1(a), the border effect is clearly weaker than in the nonconservative regime, and the decay proceeds slowly toward the bulk. It does not seem to scale with system size. Moreover, the dependence on earthquake size appears to be weak for most of the border effect, except for the very first few layers of sites close to the border.

Figures 1(c)-1(f) also show the same results for the nonconservative case, for $\alpha=0.18$ and 0.22 . We notice that the border effect is composed roughly of three parts. First there is a thin region, comprised of the first few sites closest to the border, where the effect is strong and seems to decay exponentially. This region is followed by a thicker layer of sites,

\footnotetext{
${ }^{2}$ We realize, however, that this is rather coarse, since, due to the power-law distribution of event sizes, there is no characteristic event size to compare to. We wanted only to detect eventual differences in the statistics from the "very small" events. It would also take a much longer time to consider only larger earthquakes.
} 
NETWORK OF EPICENTERS OF THE OLAMI-FEDER-...

with a slower but also exponentially decaying effect; and finally there is a third region in which the decay is not exponential and proceeds still more slowly toward the bulk of the system. None of those regions seem to scale with system size, with the possible exception of the third, longer layer. The overall border effect seems, however, to depend on the earthquake size (in the contrast with what was observed in the conservative case), as can be seen in Figs. 1(d) and 1(f), which shows clearly that the border effect decays more slowly toward the bulk of the system if only larger events are considered. In Figs. 1(c)-1(f), the data for lattices of different size $L$ were collapsed by hand, that is, curves were shifted up and down in order to coincide, since statistics are different in each case. The slope and the size of the layers, however, were not changed.

The border effect also depends on $\alpha$. The closer the system is to the conservative regime, the stronger and thicker is the layer of sites affected by it. Note that for $\alpha=0.249$, the almost conservative case [see Fig. 1(b)], the border effect is so strong that almost no epicenters happen in the bulk of the system, and only the fast exponentially decaying border effect is seen. This indicates that the lattice size $L=800$ is still too small to study the system in this regime. If we compare this figure with Fig. 1(a), we note that there is also evidence of a sharp transition from the nonconservative to the conservative regime of the model, for which the border dependence of epicenters is radically different.

The crucial role of the border in this model was already pointed out by Middleton and Tang [4], who argued that the inhomogeneity introduced by the open boundary inhibits the synchronization of the bulk, which would otherwise reach a periodic state, as happens with a system with periodic boundaries. The resulting "self-organization" would begin at the border and then proceed toward the bulk, following a power law in time. Also, it has been shown in [4] that, while the statistics of event sizes in the OFC model does not seem to obey finite-size scaling (FSS), this behavior is recovered only when events inside a smaller internal subset of the tension lattice are considered. Thus, the existence of nonscaling border effects is to be expected.

We proceed to examine the dynamics of the epicenters in the model, but only those unrelated to the nonscaling border effect. Therefore, unless otherwise noted, we ignored all the epicenters belonging to an outer layer of 100 sites in the lattice, for all the systems studied.

\section{SEQUENCES OF EPICENTERS AS A COMPLEX NETWORK}

A graph (or network) is a set of discrete items, called vertices or nodes, with connections between them, called edges or links. An edge connecting vertices $i$ and $j$ is $d i$ rected if it is defined in only one direction (connects vertex $i$ with vertex $j$, for instance, but not site $j$ with site $i$ ) and a graph is said to be directed if its edges are directed. There may be more than one edge between a pair of vertices, and the graph is called in this case a multigraph. The number of edges connected to a vertex is called the degree of the vertex; since there may be more than one edge between two vertices,
PHYSICAL REVIEW E 74, 016126 (2006)

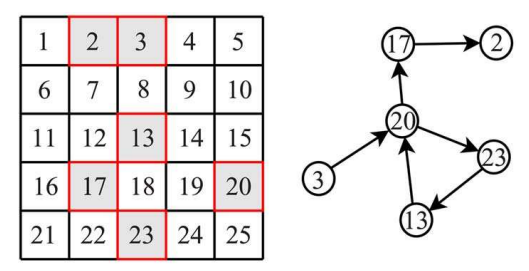

FIG. 2. (Color online) An example of an epicenter graph (right), generated from a sequence of epicenters [marked in red (gray)] from a $5 \times 5$ tension lattice (left). The graph corresponds to the following sequence of epicenters: 3, 20, 23, 13, 20, 17, 2.

the degree of a vertex is not necessarily equal to the number of its neighbors. If the graph is directed, it is then possible to talk about out-degree (number of edges leaving a vertex) and in-degree (number of edges incident to a vertex). The degree distribution of a graph, $P(k)$, gives the probability that a randomly sampled vertex has degree $k$. Graphs have been the subject of systematic study by mathematicians for some time, but recent years witnessed a growth in the interest in this subject among physicists, with emphasis on large-scale statistical properties of graphs. Many statistical mechanics concepts and techniques have been widely used, and a good review on recent developments in this subject can be found in [13]. We will show that some tools of network theory can help to get a deeper understanding of the dynamics of the OFC model and maybe of the dynamics of real earthquakes.

The sequence of epicenters in the OFC model can be used to construct a directed multigraph in the following manner. Each site that is an epicenter represents a vertex. Two consecutive epicenters are connected by a directed edge, from the first to occur to the second (see Fig. 2). Since, in principle, the same site can become an epicenter two times consecutively, loops are allowed (but do not occur often). It is also possible for the same sequence of epicenters to happen more than once, so parallel edges are also allowed. This graph has certain regularities. The out-degree of every vertex is always equal to the in-degree, except for the very first and last epicenters of the sequence, and therefore the total degree is always an even number. Also, if the direction of the edges is ignored, the graph is always composed of only one component.

We have constructed graphs for the epicenters of the OFC model with $L=400$ and 800 , and for $\alpha=0.25,0.22$, and 0.18 . We also considered the graphs for epicenters of different earthquake sizes. We then observed the degree distribution and the degree correlation of the graph. The results for the nonconservative regime are averages over 5-11 graphs, depending on the size of earthquakes considered, each graph with $6 \times 10^{6}$ edges.

\section{A. Degree distribution}

Since the in-degree of the network is equal to the outdegree, it is sufficient to describe only one of the two, and here we choose arbitrarily the in-degree.

For the conservative regime [Fig. 3(a)], the in-degree distribution seems to be Poissonian (which gets stretched if 

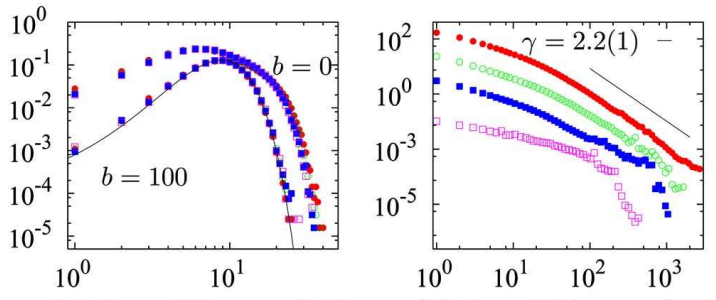

(a) $L=400, \alpha=0.25$

(b) $L=800, \alpha=0.18$

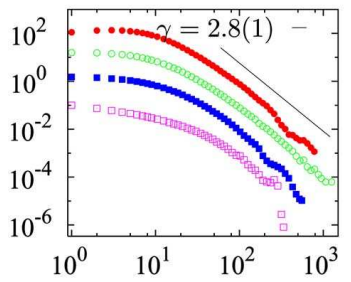

(c) $L=800, \alpha=0.22$

FIG. 3. (Color online) In-degree distribution $P(k)$ ( $y$ axis) as a function of the in-degree $k$ ( $x$ axis), for different values of $L, \alpha$, and earthquake size $s$. In (a) are shown the distributions for two different sizes of the discarded border $b$, and the solid line is the corresponding Poisson distribution. The data for $b=0$ were shifted upward for clarity. In (b) and (c) the solid line is the result of fitting a power law $k^{-\gamma}$ to the data when $s \geqslant 30$. The data for different earthquake sizes were shifted upward for clarity. All quantities are dimensionless.

more sites from the border are considered), indicating that, in this regime, epicenters in the bulk of the lattice occur randomly. Moreover, the degree distribution does not depend on the minimum size of the earthquakes considered.

For the nonconservative regime the situation changes. As can be seen in Figs. 3(b) and 3(c), if only larger earthquakes are considered, the in-degree distribution resembles more a power law. The exponent of the power law seem to be dependent on $\alpha$, with smaller $\alpha$ leading to steeper lines. For $\alpha=0.22$ and $s \geqslant 30$, in Fig. 3(c), the high fluctuations at the tail of the in-degree distribution represent a lack of statistics, due to an average over only five realizations of the graph, while for $s \geqslant 5$, for instance, the average was over ten different graphs. For both $\alpha=0.22$ and 0.18 , the difference of inclination of the power-law region of the distributions is very small between the data for $s \geqslant 5$ and $s \geqslant 30$, indicating that it is not strongly dependent on the lower bound of the considered earthquake sizes, provided it is large enough for the power law to emerge.

\section{B. Correlations between degree distribution and tension distribution in the lattice}

It is interesting to observe where the epicenters happen in the tension lattice. As has already been shown in [20], the stationary state of the OFC model, for $\alpha<0.25$ (nonconservative), exhibits patchy synchronized regions within the bulk of the system with sites that have similar tension, and behaves similarly to the OFC model with periodic boundary

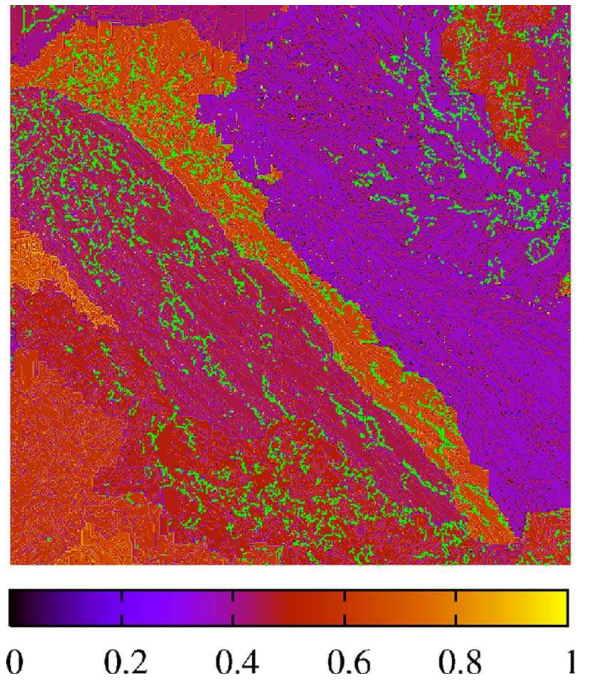

FIG. 4. (Color online) Snapshot of the tension lattice at the stationary state, for $L=800$ and $\alpha=0.18$. The next $10^{4}$ epicenters, for earthquake sizes $s \geqslant 2$, after this configuration, are marked in green (light gray). All quantities are dimensionless.

conditions, exhibiting heavy synchronization. As can be seen in Fig. 4, for $\alpha=0.18$, the epicenters seem to happen mostly in the frontiers among those synchronized regions, and in valleylike structures inside the plateaus. As only larger earthquakes are considered, the epicenters happen increasingly in smaller and less structured regions (not shown). The same behavior was also observed for $\alpha=0.22$.

In Fig. 5 can be seen the in-degree of a vertex placed in the tension lattice, i.e., the number of times a site was an epicenter, for $\alpha=0.18$ and $s \geqslant 2$. The epicenters seem to be

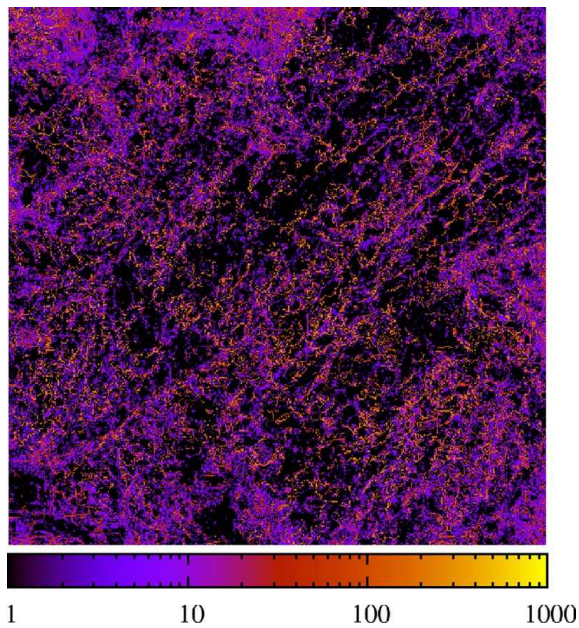

FIG. 5. (Color online) In-degree of vertices placed in the bulk of tension lattice, i.e., the number of times a site was an epicenter, for $L=800$ and $\alpha=0.18$. Only earthquakes with sizes $s \geqslant 2$ were considered. All quantities are dimensionless. 

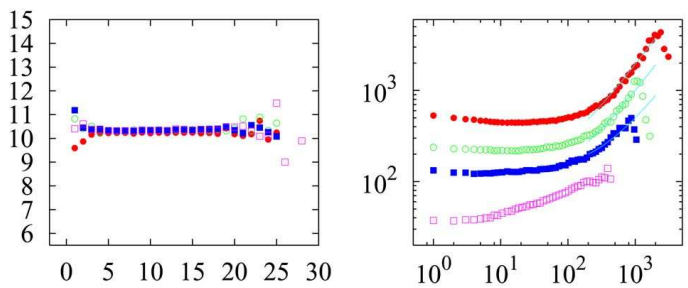

(a) $\alpha=0.25$

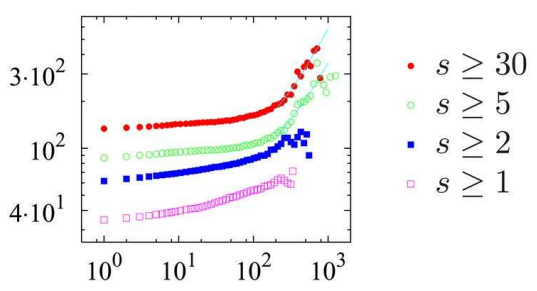

(c) $\alpha=0.22$

FIG. 6. (Color online) Average in-degree of nearest outneighbors $k_{N N}(k)$ ( $y$ axis) as a function of the in-degree $k$ ( $x$ axis), for different values of $L, \alpha$, and earthquake size $s$. The solid lines are fitted straight lines. All quantities are dimensionless.

well distributed inside the bulk, but aggregated in stripelike structures. For $s \geqslant 30$ the epicenters seem considerably less aggregated (not shown). For $\alpha=0.22$ the results were observed to be very similar.

\section{Degree correlation}

One further basic aspect of the epicenter network which we analyzed was the degree correlation, i.e., how vertices are connected to each other based on their degrees. We look at the average in-degree of the nearest "out-neighbors" of a vertex (vertices that receive an edge coming from it), as a function of the degree of the vertex.

We found that for the conservative regime [Fig. 6(a)], the graph seems to be uncorrelated, with the in-degree of the nearest neighbors being independent on the in-degree of the originating vertex. Together with the in-degree distribution (Poissononian), this puts this graph closer to the class of totally random graphs such as the Erdős-Rényi graph [21].

The situation is again very different for the nonconservative regime [Figs. 6(b) and 6(c)]. In that case, the degrees seem highly correlated, with vertices with high in-degree connecting predominantly to other vertices of high in-degree, which makes the network assortative. The correlation seems to be linear for higher degrees, when only larger earthquakes are considered. ${ }^{3}$ Citation networks $[14,15]$ and other networks that are grown with a preferential attachment rule have a quite different behavior, with an in-degree distribution following a power law, but in those cases the degree corre-

\footnotetext{
${ }^{3}$ The in-degree correlation of the graph for $s \geqslant 1$ is also an increasing function, and perhaps also linear. But the lack of vertices of high degree makes it difficult to be certain.
}

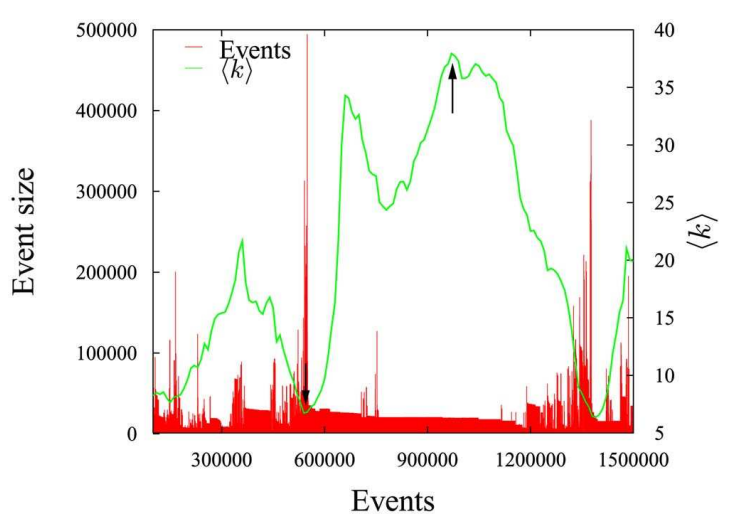

FIG. 7. (Color online) Average in-degree of the subgraph composed only of the last $10^{5}$ events, and the amplitudes of the events that generated the graph. The regions indicated by the arrows correspond to the subgraphs in Figs. 8 and 9. All quantities are dimensionless.

lation also decays with a power law [22], converging to a constant value for large in-degrees. Thus, the dynamics responsible for generating this network must be fundamentally different from the dynamics generated by a preferential attachment rule. Recently it has also been found that a very similar network, when constructed with real earthquake data, is also assortative and exhibits similar degree correlations [17].

What indeed is unveiled by this high correlation among high in-degree vertices is an attracting dynamics: Connections from vertices of one type are much more probable to vertices of the same type, eventually trapping the sequence of epicenters in a smaller region of the lattice, stretching the in-degree distribution, and generating the observed in-degree correlation. This trapping seems to be strongly correlated to the occurrence of very large earthquakes, and the large-scale redistribution of tensions that is caused by them. This can be seen in Fig. 7, where is shown the average in-degree of the subgraph composed only of the last $10^{5}$ events, together with the amplitude of the corresponding events. Whenever a large earthquake occurs, the average in-degree drops, meaning that the last epicenters happened in a larger number of sites. In fact the decay of the average in-degree starts before the main big earthquake, and seems to occur together with the smaller events that lead up to it, the so-called foreshocks [8,9,23]. Thus, the large events, together with their foreshocks, are responsible for breaking the attractor, and spreading the epicenters to a larger region. After the sequence of large events, the trapping of epicenters starts again, until the next sequence of large events sweeps it again. Although we did not make an extensive analysis to define the degree of certitude of this observation, monitoring the in-degree of this network may represent a promising way of predicting an increase in the probability of observing large earthquakes in a given fault, and to identify, among the small events, the signature 


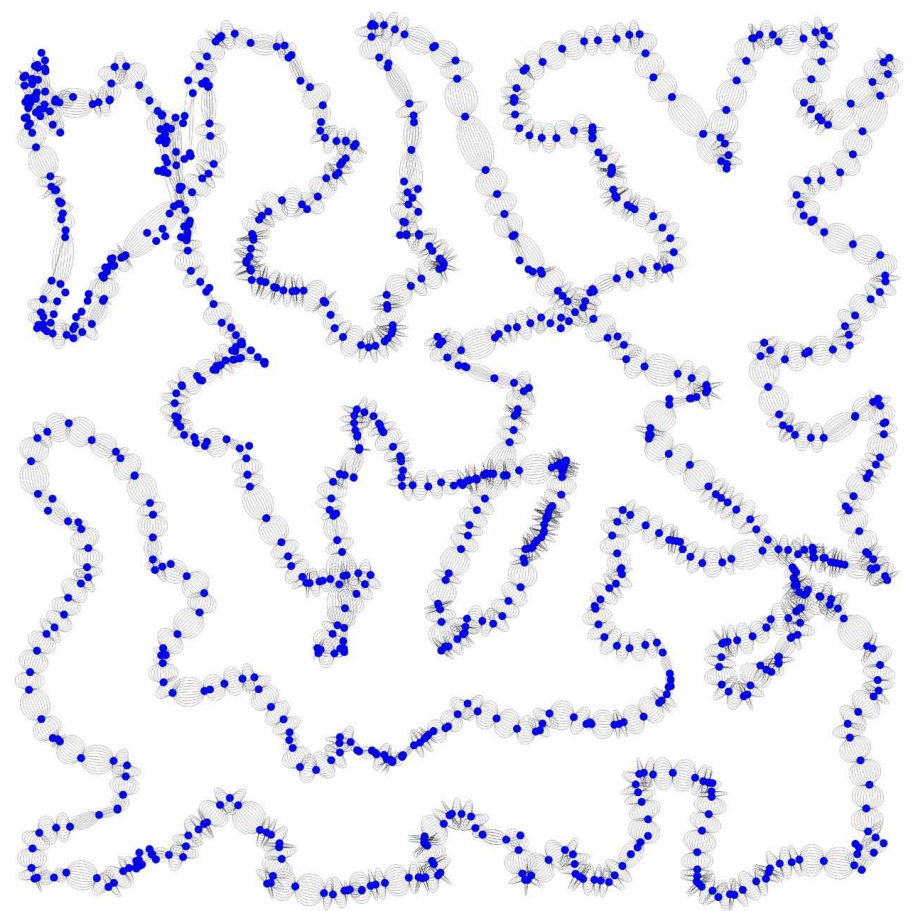

FIG. 8. (Color online) Subgraph composed of $10^{4}$ consecutive epicenters, corresponding to the marked region at the right in Fig. 7. of the foreshocks that precede a main shock. ${ }^{4}$ Since the network of epicenters generated by the OFC model seems to reproduce many aspects of the network of epicenters built from real data $[16,17]$, including the degree correlation mentioned above, it would be interesting to see in more detail if both graphs are actually generated by the same overall dynamics. This, however, would require a more systematic and thorough analysis of real earthquake data, and therefore would be better suited for a separate work.

To illustrate the topology of the graph during both situations, we show a subgraph of the whole network, corresponding to a region of $10^{4}$ events collected during the period that the dynamics is trapped in an attractor (Fig. 8), and just after a large earthquake (Fig. 9), as indicated in Fig. 7. As can be seen in Fig. 8, the attractor region is dominated by synchronization, where the same sequence of $\sim 10^{3}$ epicenters occurs repeatedly. During the occurrence of the large events, the same subgraph looks like Fig. 9, where synchronization is still present, but in a much smaller degree.

\section{MARKOV NETWORKS WITH HIDDEN VARIABLES}

In this section we describe a general random graph model, based on hidden variables and a Markov chain. It is based on

\footnotetext{
${ }^{4}$ It is important to note that the data in Fig. 7 show only earthquakes that did not initiate inside the discarded outer layer and whose magnitudes tend to be large, and thus are potentially related to the anticipated decay of the average in-degree before a main large event.
}

a similar class of networks developed by Boguñá et al. [24], but modified in order to account for the topology of the epicenter graph observed in the OFC model. Our goal is to better understand the type of dynamics that is able to generate graphs with properties examined in the previous section.

Consider a set of $N$ vertices, where $N \gg 1$. To each vertex $\nu$ is assigned a hidden variable $h_{\nu}$, sampled from a distribution $\rho(h)$. A directed multigraph can be constructed via a Markov chain, in the following manner. Starting from a random vertex $\mu$, a directed edge is added from $\mu$ to $\nu$ with probability $P(\mu \rightarrow \nu) \equiv r\left(h_{\mu}, h_{\nu}\right)$, and likewise from $\nu$ to any other vertex $\omega$ with probability given by $r\left(h_{\nu}, h_{\omega}\right)$, and so forth. After a transient stage, the graph will have properties that are entirely defined by $\rho(h)$ and $r\left(h, h^{\prime}\right)$. This graph is rather general, and, in fact, every Markov process generates such a graph if the discrete states of the chain are thought of as vertices and the transition as directed edges. With this basic procedure in mind we can proceed to calculate the statistical properties of the graph.

\section{In-degree distribution}

As in the network of epicenters, every vertex of the network generated in the way described above has the in-degree equal to the out-degree. Thus, it is sufficient to describe only one of the two. To find the in-degree distribution of this graph, one must consider an ensemble of graphs and the probability in the ensemble of one vertex $\nu$ receiving one connection after a time $T, w_{\nu}(T)$, which is given by 


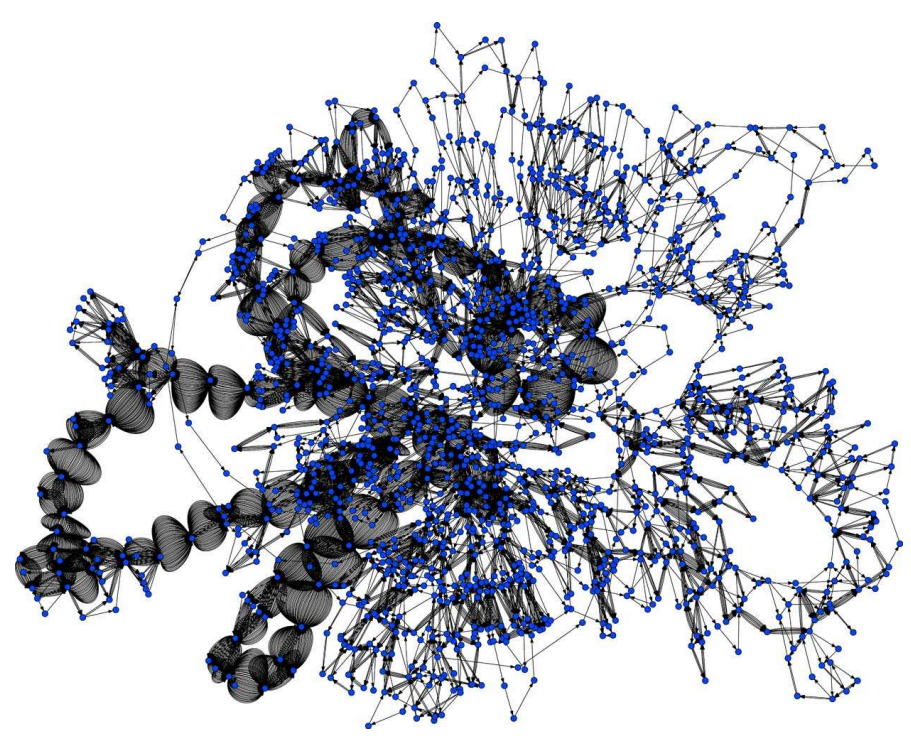

$$
w_{\nu}(T+1)=\sum_{\mu} P(\mu \rightarrow \nu) w_{\mu}(T) .
$$

After a long time $T$, the system reaches the stationary state $w(\infty)$ given by

$$
w(\infty)=\mathbf{P}^{n} w(\infty),
$$

where $\mathbf{P}$ is the transition matrix defined by $P(\mu \rightarrow \nu), w(T)$ is the state vector at time $T$, and $n$ is the period of the solution (we will consider only $n=1$ from now on).

The probability that a vertex $\mu$ has in-degree $k$ after a time $T \gg 1, P(k \mid \mu, T)$, is given simply by the binomial distribution,

$$
P(k \mid \mu, T)=\left(\begin{array}{l}
T \\
k
\end{array}\right) w_{\mu}^{k}\left(1-w_{\mu}\right)^{T-k} \approx \frac{\left(T w_{\mu}\right)^{k} e^{-T w_{\mu}}}{k !},
$$

where $w_{k} \equiv w_{k}(\infty)$, which can be approximated by the Poisson distribution, as in the rightmost term.

The total in-degree distribution after a time $T, P(k \mid T)$, is then given by

$$
P(k \mid T)=\frac{1}{N} \sum_{\mu} P(k \mid \mu, T) .
$$

Now since a vertex $\mu$ is labeled uniquely by its hidden variable $h_{\mu}$, we must have then that $w_{\mu} \equiv w\left(h_{\mu}\right)$. Thus, $w(h)$ can be obtained by rewriting Eq. (1),

$$
w(h)=N \int_{h} r\left(h_{\mu}, h\right) w\left(h_{\mu}\right) \rho\left(h_{\mu}\right) d h_{\mu}
$$

assuming that $h$ is a continuous variable (the last expression would just be a sum if it were discrete). Solving this integral equation for $w(h)$, it is possible then to obtain the degree distribution through Eq. (4),
FIG. 9. (Color online) Subgraph composed of $10^{4}$ consecutive epicenters, corresponding to the marked region at the left in Fig. 7.
$P(k, T)=\int_{h} \frac{(T w(h))^{k} e^{-T w(h)}}{k !} \rho(h) d h$.

\section{In-degree correlation}

It is also possible to calculate the degree correlation of this graph. The probability of one vertex $\mu$, with in-degree $k$, connecting to another vertex of degree $k^{\prime}$ is given by

$$
P\left(k^{\prime} \mid k, \mu, T\right)=\frac{P(k \mid \mu, T)}{N P(k, T)} \sum_{\nu} P(\mu \rightarrow \nu) P\left(k^{\prime}-1 \mid \nu, T\right) .
$$

The total probability of one vertex with degree $k$ connecting to one of degree $k^{\prime}$ is then simply

$$
P\left(k^{\prime} \mid k, T\right)=\sum_{\mu} P\left(k^{\prime} \mid k, \mu, T\right),
$$

and the average in-degree of the nearest out-neighbors is then just

$$
\bar{k}_{N N}(k, T)=\sum_{k^{\prime}} k^{\prime} P\left(k^{\prime} \mid k, T\right)
$$

In terms of the hidden variables, substituting Eqs. (6) and (3) in (8) and calculating the sum in Eq. (9), we have then

$$
\begin{aligned}
\bar{k}_{N N}(k, T)= & 1+\frac{N}{P(k, T)} \iint_{h} \frac{\left[T w\left(h_{\mu}\right)\right]^{k} e^{-T w\left(h_{\mu}\right)}}{k !} \\
& \times r\left(h_{\mu}, h_{\nu}\right) T w\left(h_{\nu}\right) \rho\left(h_{\mu}\right) \rho\left(h_{\nu}\right) d h_{\mu} d h_{\nu} .
\end{aligned}
$$

\section{Attractor dynamics}

We want to understand how correlations such as those seen in Figs. 6(b) and 6(c) and power-law distributions can arise from this type of network. For that we must define a 

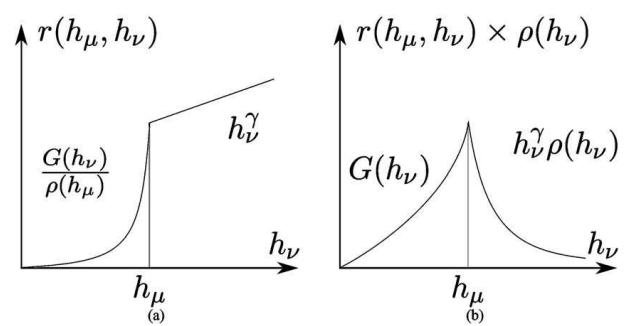

FIG. 10. (a) Connection probability [Eq. (11)] from a vertex $\mu$ to a vertex $\nu$, and (b) connection probability from a vertex $\mu$ to any vertex with hidden variable $h_{\nu}$.

suitable $r\left(h, h^{\prime}\right)$ and $\rho(h)$. It is clear that what uniquely defines the in-degree of some vertex is its hidden variable. Thus, for the in-degree correlation to be of the form $\bar{k}_{N N}(k)$ $\sim k$ for large $k$, we must have that $\bar{h}^{\prime}(h) \sim h$ for large $h$, where $\bar{h}^{\prime}(h)$ is the average hidden variable of the outneighbors of a vertex with hidden variable $h$. With this in mind, we define then the following general expression for the connection probability:

$$
r\left(h_{\mu}, h_{\nu}\right)=F\left(h_{\mu}\right)\left(\frac{G\left(h_{\nu}\right) h_{\mu}^{\gamma}}{\rho\left(h_{\nu}\right)}\left[h_{\nu}<h_{\mu}\right]+\frac{G\left(h_{\mu}\right) h_{\nu}^{\gamma}}{\rho\left(h_{\mu}\right)}\left[h_{\nu}>h_{\mu}\right]\right)
$$

where $G(h)$ is a function that dictates how fast the connection probability decays for $h_{\nu}<h_{\mu}$ (see Fig. 10), and the exponent $\gamma$ defines the preference with which vertices with higher $h$ are chosen. The function $F\left(h_{\mu}\right)$ is simply given by the normalization condition $\Sigma_{\nu} r\left(h_{\mu}, h_{\nu}\right)=1$.

We considered a few shapes for $G(h)$ and $\rho(h)$ and calculated the degree distribution and degree correlation through Eqs. (6) and (10), always for $k \gg 1$. The results are summarized in Table I.

What we find is that the effect of adopting a connection probability like the one described by Eq. (11) is to generate an in-degree distribution corresponding to a stretched form of $\rho(h)$. If $G(h)$ is independent of $h$, and the trapping in the region of similar $h$ is the weakest, we have the following possibilities. If $\rho(h)$ is a power law with exponent $\beta$, then $P(k)$ will also be a power law with exponent in the region [1, $\beta]$, approaching 1 if $\gamma$ is large. When $\rho(h)$ is an exponential distribution, the resulting in-degree distribution will be a stretched exponential as indicated in Table I, which will also

TABLE I. Different asymptotic shapes for $\bar{k}_{N N}(k)$ and $P(k)$ for different shapes of $G(h)$ and $\rho(h)$, for $k \gg 1$.

\begin{tabular}{lccc}
\hline \hline$\rho(h)$ & $G(h)$ & $\bar{k}_{N N}(k)$ & $P(k)$ \\
\hline$\frac{h^{-\beta}}{\beta-1}$ & 1 & $\sim k$ & $\sim k^{-(\beta+\gamma) /(\gamma+1)}$ \\
$\beta e^{-\beta h}$ & 1 & $\sim k$ & $\sim k^{-\gamma /(\gamma+1)} e^{-C k^{1 /(\gamma+1)}}$ \\
$\beta e^{-\beta h}$ & $e^{\xi h}$ & $\sim k$ & $\sim k^{-(\beta+\xi) / \xi}$ \\
\hline \hline
\end{tabular}

resemble a power law if $\gamma$ is relatively large. Now, considering a stronger trapping effect with $G(h)$ increasing exponentially, we have that an exponential $\rho(h)$, with decay parameter $\beta$, is enough to create a power-law distribution of in-degrees, with exponents in the interval $[1, \beta]$, approaching 1 with faster $G(h)$. This means that it is not necessary to assume an intrinsic scale invariance, represented by a power law in $\rho(h)$, for the existence of a power law in $P(k)$. Furthermore, the asymptotic in-degree distribution in this case does not depend on $\gamma$, being totally dominated by the trapping behavior, and not by the preference of connection.

The process described above shows a variety of ways in which graphs with in-degree distributions resembling power laws and linear in-degree correlation can be created. Looking at only these properties, it is not possible to know which one of the possibilities (if any) is more likely to describe the epicenter network. Moreover, the process above would not account for the strong synchronization observed in Figs. 8 and 9. After all, the sequences of epicenters are probably not simple Markovian processes. However, the above model, as a first approximation, serves the purpose of illustrating how such correlations and in-degree distribution can occur, and presents a general analytical framework for further modeling.

\section{CONCLUSIONS}

We have shown that the epicenters in the OFC model occur predominantly near the boundary of the lattice, but this preference does not seem to scale with system size. This border affinity depends on the dissipation parameter $\alpha$, being less for smaller values of $\alpha$. It is also dependent on the earthquake size, with epicenters of larger earthquakes having a border effect which decays more slowly toward the bulk. We have also studied the network of consecutive epicenters, and found that it is sharply different in the two regimes of the model. In the conservative regime it is rather featureless, with uncorrelated in-degree statistics and Poisson in-degree distribution. However, in the nonconservative regime, it has an unusual linear degree correlation among vertices of high degree, and a broad distribution of in-degrees resembling a power law, but only when the smaller earthquakes are not considered. The in-degree distribution and correlation in this regime are similar to what was found very recently for real earthquakes $[16,17]$. Furthermore, we noticed that the high correlation of in-degrees is due to an attractor dynamics where the occurrence of epicenters tends to synchronize, with the same sequence of epicenters occurring continuously. This synchronization is broken by large earthquakes, which spread the epicenters over a larger portion of the lattice, thus populating the graph with vertices of smaller in-degree. Interestingly, the effects of the large events on the topology of the epicenter network are noticeable before the actual main event, and seem to be related to the series of increasingly larger foreshocks that precede it. Since the prediction of the OFC model that there would be an in-degree correlation in the epicenter graph corresponds to what has been recently found for real earthquakes [17], further detailed analysis of this behavior may prove useful for the prediction of large 
earthquakes. Lastly, we described a general analytical network model based on a Markovian process and hidden variables, which is able to reproduce the most general aspects of the epicenter network, when a suitable attractor dynamics is specified. There are several aspects of the dynamics of epicenters that remain uncovered. It would be of special interest to look at other topological properties of the epicenter graph, such as the dependence of the clustering coefficient on indegree, and the existence of community structure $[25,26]$. Furthermore, it would also be useful to compare in detail some of the results here obtained, such as the dynamics responsible for the in-degree correlation and the epicenter synchronization, with the epicenter network of real earthquakes.

\section{ACKNOWLEDGMENT}

This work was supported by Fundação de Amparo à Pesquisa do Estado de São Paulo (FAPESP), Process No. 03/ 03429-6.
[1] P. Bak, C. Tang, and K. Wiesenfeld, Phys. Rev. Lett. 59, 381 (1987).

[2] B. Drossel and F. Schwabl, Phys. Rev. Lett. 69, 1629 (1992).

[3] Z. Olami, Hans Jacob S. Feder, and K. Christensen, Phys. Rev. Lett. 68, 1244 (1992).

[4] S. Lise and M. Paczuski, Phys. Rev. E 64, 046111 (2001).

[5] S. Lise and M. Paczuski, Phys. Rev. E 63, 036111 (2001).

[6] J. X. de Carvalho and C. P. C. Prado, Phys. Rev. Lett. 84, 4006 (2000).

[7] B. Gutenberg and C. F. Richter, Ann. Geofis. 9, 1 (1956).

[8] F. Omori, J. Coll. Sci., Imp. Univ. Tokyo 7, 111 (1894).

[9] S. Hergarten and H. J. Neugebauer, Phys. Rev. Lett. 88, 238501 (2002)

[10] T. P. Peixoto and C. P. C. Prado, Phys. Rev. E 69, 025101(R) (2004).

[11] T. P. Peixoto and C. P. C. Prado, Physica A 342, 171 (2004).

[12] A. A. Middleton and C. Tang, Phys. Rev. Lett. 74, 742 (1995).

[13] M. E. J. Newman, SIAM Rev. 45, 167 (2002).

[14] D. J. de S. Price, J. Am. Soc. Inf. Sci. 27, 292 (1976).
[15] A.-L. Barabási and R. Albert, Science 286, 506 (1999).

[16] S. Abe and N. Suzuki, Europhys. Lett. 65, 581 (2004).

[17] S. Abe and N. Suzuki, e-print cond-mat/0602076.

[18] R. Burridge and L. Knopoff, Bull. Seismol. Soc. Am. 57, 341 (1967).

[19] P. Grassberger, Phys. Rev. E 49, 2436 (1994).

[20] B. Drossel, Phys. Rev. Lett. 89, 238701 (2002).

[21] P. Erdös and A. Rényi, Publ. Math. (Debrecen) 6, 290 (1959).

[22] R. Pastor-Satorras, A. Vázquez, and A. Vespignani, Phys. Rev. Lett. 87, 258701 (2001).

[23] A. Helmstetter, S. Hergarten, and D. Sornette, Phys. Rev. E 70, 046120 (2004).

[24] M. Boguñá and R. Pastor-Satorras, Phys. Rev. E 68, 036112 (2003).

[25] M. E. J. Newman and M. Girvan, Phys. Rev. E 69, 026113 (2004).

[26] S. Muff, F. Rao, and A. Caflisch, Phys. Rev. E 72, 056107 (2005). 


\section{Referências Bibliográficas}

[1] T. Peixoto e C. Prado, Distribution of epicenters in the olami-feder-christensen model, Physical Review E 69, 25101 (2004).

[2] T. P. Peixoto e C. P. C. Prado, Statistics of epicenters in the olami-feder-christensen model in two and three dimensions, Physica A 342, 171 (2004).

[3] T. P. Peixoto e C. P. C. Prado, Network of epicenters of the olami-feder-christensen model of earthquakes, Physical Review E 74, 016126 (2006).

[4] N. Fiedler-Ferrara e C. P. C. Prado, Caos: Uma Introdução (Edgard Blucher LTDA, 1994), $2^{\mathrm{a}}$ ed.

[5] K. T. Alligood, Chaos: an introduction to dynamical systems (Springer-Verlag New York, LLC, 1997).

[6] A. Pikovsky, M. Rosemblum e J. Kurths, Synchronization: A Universal Concept in Nonlinear Sciences (Cambridge University Press, 2001).

[7] J. A. Anderson, An Introduction to Neural Networks (The MIT Press, Cambridge, 1995).

[8] H. J. Jensen, Self-Organized Criticality (Cambridge University Press, Cambridge, 1998).

[9] D. L. Turcotte, Self-organized criticality, Reports on Progress in Physics 62, 1377 (1999).

[10] R. Dickman, Paths to self-organized criticality, Brazilian Journal of Physics 30, 27 (2000).

[11] P. Bak, C. Tang e K. Wiesenfeld, Self-organized criticality: An explanation of the 1/f noise, Physical Review Letters 59, 381 (1987).

[12] P. Bak, C. Tang e K. Wiesenfeld, Self-organized criticality, Physical Review A 38, 364 (1988).

[13] M. Newman, Power laws, pareto distributions and zipf's law, Contemporary Physics 46, 323 (2005).

[14] B. Barriere e D. L. Turcotte, Seismicity and self-organized criticality, Physical Review E 49, 1151 (1994). 
[15] Z. Olami, H. J. S. Feder e K. Christensen, Self-organized criticality in a continuous, nonconservative cellular automaton modeling earthquakes, Physical Review Letters 68, 1244 (1992).

[16] B. Drossel e F. Schwabl, Self-organized critical forest-fire model, Physical Review Letters 69, 1629 (1992).

[17] P. Bak e K. Sneppen, Punctuated equilibrium and criticality in a simple model of evolution, Physical Review Letters 71, 4083 (1993).

[18] M. Paczuski e D. Hughes, A heavenly example of scale-free networks and selforganized criticality, Physica A: Statistical Mechanics and its Applications 342, 158 (2004).

[19] Manna, Kiss e Kertész, Cascades and self-organized criticality, Journal of Statistical Physics 61, 923 (1990).

[20] R. Frigg, Self-organised criticality - what it is and what it isn't, Studies In History and Philosophy of Science Part A 34, 613 (2003).

[21] T. Tsuchiya e M. Katori, Proof of breaking of self-organized criticality in a nonconservative abelian sandpile model, Physical Review E 61, 1183 (2000).

[22] S. Hergarten e H. J. Neugebauer, Foreshocks and aftershocks in the olami-federchristensen model, Physical Review Letters 88, 238501 (2002).

[23] A. Helmstetter, S. Hergarten e D. Sornette, Properties of foreshocks and aftershocks of the nonconservative self-organized critical olami-feder-christensen model, Physical Review E 70, 046120 (2004).

[24] M. Newman, The structure and function of complex networks, SIAM Review 45, 167 (2003).

[25] R. Albert e A.-L. Barabási, Statistical mechanics of complex networks, Reviews of Modern Physics 74, 47 (2002).

[26] B. Wellman e S. Berkowitz, Social Structures: A Network Approach (Cambridge University Press, Cambridge, 1988).

[27] D. J. de Solla Price, Networks of scientific papers, Science 149, 510 (1965).

[28] A.-L. Barabási e R. Albert, Emergence of scaling in random networks, Science 286, 509 (1999).

[29] D. Watts e S. Strogatz, Collective dynamics of 'small-world' networks, Nature 393, 409 (1998).

[30] R. Burridge e L. Knopoff, Model and theoretical seismicity, Bulletin of the Seismological Society of America 57, 341 (1967).

[31] S. Wolfram, A New Kind of Science (Wolfram Media, 2002). 
[32] P. Grassberger, Efficient large-scale simulations of a uniformly driven system, Physical Review E 49, 2436 (1994).

[33] B. Drossel, Complex scaling behavior of nonconserved self-organized critical systems, Physical Review Letters 89, 238701 (2002).

[34] A. A. Middleton e C. Tang, Self-organized criticality in nonconserved systems, Physical Review Letters 74, 742 (1995).

[35] S. Lise, Self-organization to criticality in a system without conservation law, Journal of Physics A 35, 4641 (2002).

[36] J. X. de Carvalho e C. P. C. Prado, Dealing with transients in models with selforganized criticality, Physica A: Statistical Mechanics and its Applications 321, 519 (2003).

[37] F. Wissel e B. Drossel, Transient and stationary behavior of the olami-federchristensen model, Physical Review E 74, 066109 (2006).

[38] B. Gutenberg e C. F. Richter, Magnitude and energy of earthquakes, Nature 176, 795 (1955).

[39] L. P. Kadanoff, S. R. Nagel, L. Wu e S. min Zhou, Scaling and universality in avalanches, Physical Review A 39, 6524 (1989).

[40] S. Lise e M. Paczuski, Self-organized criticality and universality in a nonconservative earthquake model, Physical Review E 63, 036111 (2001).

[41] S. Lise e M. Paczuski, Scaling in a nonconservative earthquake model of selforganized criticality, Physical Review E 64, 046111 (2001).

[42] C. J. Boulter e G. Miller, Nonuniversality and scaling breakdown in a nonconservative earthquake model, Physical Review E 68, 056108 (2003).

[43] S. Zapperi, K. B. Lauritsen e H. E. Stanley, Self-organized branching processes: Mean-field theory for avalanches, Physical Review Letters 75, 4071 (1995).

[44] T. E. Harris, The Theory of Branching Processes (Dover Publications, 2002).

[45] J. X. de Carvalho e C. P. C. Prado, Self-organized criticality in the olami-federchristensen model, Physical Review Letters 84, 4006 (2000).

[46] K. Christensen, D. Hamon, H. J. Jensen e S. Lise, Comment on "self-organized criticality in the olami-feder-christensen model", Physical Review Letters 87, 039801 (2001).

[47] J. X. de Carvalho e C. P. C. Prado, de carvalho and prado reply:, Physical Review Letters 87, 039802 (2001).

[48] G. Miller e C. J. Boulter, Measurements of criticality in the olami-feder-christensen model, Physical Review E 66, 016123 (2002). 
[49] G. Miller e C. J. Boulter, Crossover behavior in the event size distribution of the olami-feder-christensen model, Physical Review E 67, 046114 (2003).

[50] H.-M. Bröker e P. Grassberger, Random neighbor theory of the olami-federchristensen earthquake model, Physical Review E 56, 3944 (1997).

[51] F. Omori, On the aftershocks of earthquakes, J. Coll. Sci. Imp. Univ. Tokyo 7, 111 (1894).

[52] Y. Kagan e L. Knopoff, Statistical study of occurrence of shallow earthquakes, Geophysical Journal of the Royal Astronomical Society 55, 67 (1978).

[53] B. C. Papazach, Time distribution of reservoir-associated foreshocks and its importance to prediction of principal shock, Bulletin of the Seismological Society of America 63, 1973 (1973).

[54] L. Jones e P. Molnar, Some characteristics of foreshocks and their possible relationship to earthquake prediction and premonitory slip on faults, Journal of Geophysical Research 84, 3596 (1979).

[55] A. Helmstetter, Is earthquake triggering driven by small earthquakes?, Physical Review Letters 91, 058501 (2003).

[56] F. Tajima e H. Kanamori, Global survey of aftershock area expansion patterns, Physics of The Earth and Planetary Interiors 40, 77 (1985).

[57] D. Marsan, C. J. Bean, S. Steacy e J. McCloskey, Observation of diffusion processes in earthquake populations and implications for the predictability of seismicity systems, Journal of Geophysical Research 105, 28,081?28,094 (2000).

[58] A. Helmstetter e D. Sornette, Foreshocks explained by cascades of triggered seismicity, Journal of Geophysical Research 108, 2457 (2003).

[59] D. von Seggern, S. S. Alexander e C.-E. Baag, Seismicity parameters preceding moderate to major earthquakes, Journal of Geophysical Research 86, 9325 (1981).

[60] J. L. Hardebeck, J. J. Nazareth e E. Hauksson, The static stress change triggering model: Constraints from two southern california aftershock sequences, Journal of Geophysical Research 103, 24427 (1998).

[61] S. Toda, R. S. Stein, P. A. Reasenberg, J. H. Dieterich e A. Yoshida, Stress transferred by the 1995 mw=6.9 kobe, japan, shock: Effect on aftershocks and future earthquake probabilities, Journal of Geophysical Research 103, 24,543?24,566 (1998).

[62] A. Nur e J. R. Booker, Aftershocks caused by pore fluid flow?, Science 175, 885 (1972).

[63] O. L. Anderson e P. C. Grew, Stress corrosion theory of crack propagation with applications to geophysics, Reviews of Geophysics and Space Physics 15, 77 (1977).

[64] B. D. Hughes, Random Walks and Random Environments: Volume 1: Random Walks (Oxford University Press, USA, 1995). 
[65] B. D. Hughes, Random Walks and Random Environments: Volume 2: Random Environments (Oxford University Press, USA, 1996).

[66] N. Biggs, E. Lloyd e R. Wilson, Graph Theory, 1736-1936 (Oxford University Press, 1986).

[67] L. Euler, Solutio problematis ad geometriam situs pertinentis, Commentarii academiae scientiarum Petropolitanae 8, 128 (1741).

[68] A. Rapoport e W. Horvath, A study of a large sociogram., Behav Sci 6, 279 (1961).

[69] J. Cohen, F. Briand e C. Newman, Community food webs (Springer-Verlag New York, 1990).

[70] S. Pimm, Food Webs (University of Chicago Press, 2002).

[71] C. Zhou, L. Zemanova, G. Zamora, C. C. Hilgetag e J. Kurths, Hierarchical organization unveiled by functional connectivity in complex brain networks, Physical Review Letters 97, 238103 (2006).

[72] I. Farkas, H. Jeong, T. Vicsek, A. Barabási e Z. Oltvai, The topology of the transcription regulatory network in the yeast, saccharomyces cerevisiae, Physica A: Statistical Mechanics and its Applications 318, 601 (2003).

[73] N. Guelzim, S. Bottani, P. Bourgine e F. Kepes, Topological and causal structure of the yeast transcriptional regulatory network, Nat Genet 31, 60 (2002).

[74] M. Faloutsos, P. Faloutsos e C. Faloutsos, On power-law relationships of the internet topology, Proceedings of the conference on Applications, technologies, architectures, and protocols for computer communication p 251-262 (1999).

[75] A. Broido, Internet topology: connectivity of ip graphs, Proceedings of SPIE 4526, 172 (2003).

[76] R. Albert, H. Jeong e A. Barabási, Internet: Diameter of the world-wide web, Nature 401, 130 (1999).

[77] B. Huberman, The Laws of the Web: patterns in the ecology of information (MIT Press, 2001).

[78] S. Boccaletti, V. Latora, Y. Moreno, M. Chavez e D. Hwang, Complex networks: Structure and dynamics, Physics Reports 424, 175 (2006).

[79] P. Erdős e A. Rényi, On random graphs, Publ. Math. Debrecen 6 (1959).

[80] M. E. J. Newman, Mixing patterns in networks, Physical Review E 67, 026126 (2003).

[81] A. H. Abdo e A. P. S. de Moura, Clustering as a measure of the local topology of networks, physics/0605235 (2006). 
[82] S. N. Dorogovtsev, J. F. F. Mendes e A. N. Samukhin, Structure of growing networks with preferential linking, Physical Review Letters 85, 4633 (2000).

[83] P. L. Krapivsky, S. Redner e F. Leyvraz, Connectivity of growing random networks, Physical Review Letters 85, 4629 (2000).

[84] P. L. Krapivsky e S. Redner, Organization of growing random networks, Physical Review E 63, 066123 (2001).

[85] L. A. Adamic, B. A. Huberman;, A.-L. Barabási, R. Albert, H. Jeong e G. Bianconi;, Power-law distribution of the world wide web, Science 287, 2115a (2000).

[86] S. Milgram, The small world problem, Psychology Today 2, 60 (1967).

[87] J. Travers e S. Milgram, An experimental study of the small world problem, Sociometry 32, 425 (1969).

[88] Barrat e Weigt, On the properties of small-world network models, The European Physical Journal B - Condensed Matter and Complex Systems 13, 547 (2000).

[89] M. Baiesi e M. Paczuski, Scale-free networks of earthquakes and aftershocks, Physical Review E (Statistical, Nonlinear, and Soft Matter Physics) 69, 066106 (2004).

[90] M. Baiesi e M. Paczuski, Complex networks of earthquakes and aftershocks, physics/0408018 (2004), nonlinear Processes in Geophysics (2005) 12: 1 - 11.

[91] S. Abe e N. Suzuki, Scale-free network of earthquakes, Europhysics Letters (EPL) 65, 581 (2004).

[92] O. Ramos, E. Altshuler e K. J. MålØy, Quasiperiodic events in an earthquake model, Physical Review Letters 96, 098501 (2006).

[93] S. Abe e N. Suzuki, Complex earthquake network, arXiv:0708.2203 (2007).

[94] P. Shearer, E. Hauksson e G. Lin, Southern california hypocenter relocation with waveform cross-correlation, part 2: Results using source-specific station terms and cluster analysis, Bulletin of the Seismological Society of America 95, 904 (2005).

[95] M. Boguñá e R. Pastor-Satorras, Class of correlated random networks with hidden variables, Physical Review E 68, 036112 (2003).

[96] G. Zamora-López, V. Zlatić, C. Zhou, H. Štefančić e J. Kurths, Reciprocity of networks with degree correlations and arbitrary degree sequences, arxiv:0706.3372 (2007).

[97] J. Reichardt e S. Bornholdt, Statistical mechanics of community detection, Physical Review E 74, 016110 (2006).

[98] Y. Ogata, Statistical model for standard seismicity and detection of anomalies by residual analysis, Tectonophysics 169, 159 (1989). 
[99] A. Helmstetter e D. Sornette, Diffusion of epicenters of earthquake aftershocks, omori's law, and generalized continuous-time random walk models, Physical Review E 66, 061104 (2002).

[100] J. Davidsen, P. Grassberger e M. Paczuski, Networks of recurrent events, a theory of records, and an application to finding causal signatures in seismicity, physics/0701190 (2007).

[101] J. G. Siek, L.-Q. Lee e A. Lumsdaine, The Boost Graph Library User Guide and Reference Manual (Addison-Wesley Professional, 2001).

[102] D. Abrahams e A. Gurtovoy, C++ Template Metaprogramming: Concepts, Tools, and Techniques from Boost and Beyond (Addison-Wesley Professional, 2004).

[103] D. Vandevoorde e N. M. Josuttis, C++ Templates: The Complete Guide (AddisonWesley Professional, 2002), $1^{\text {a }}$ ed. 